\title{
Site C0009'
}

\author{
Expedition 319 Scientists $^{2}$
}

\section{Chapter contents}

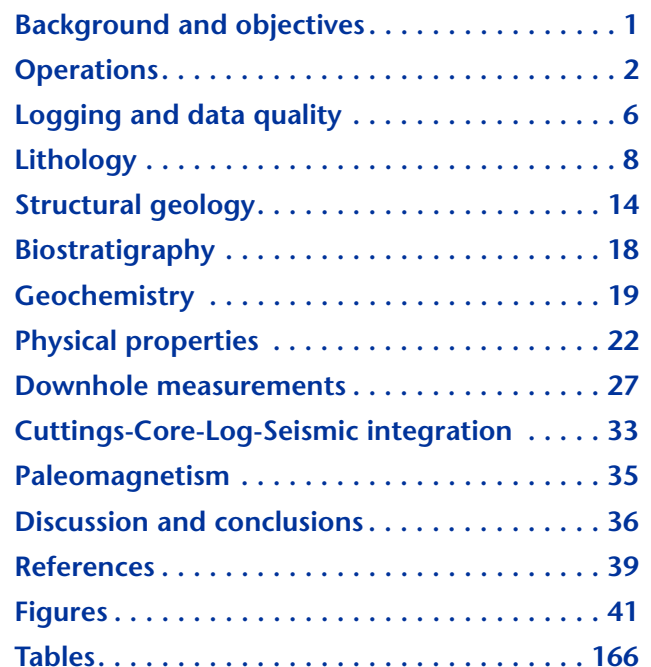

1'Expedition 319 Scientists, 2010. Site C0009. In Saffer, D., McNeill, L., Byrne, T., Araki, E., Toczko, S., Eguchi, N., Takahashi, K., and the Expedition 319 Scientists, Proc. IODP, 319: Tokyo (Integrated Ocean Drilling Program Management International, Inc.).

doi:10.2204/iodp.proc.319.103.2010

'Expedition 319 Scientists' addresses.

\section{Background and objectives}

Integrated Ocean Drilling Program (IODP) Site C0009 (proposed Site NT2-11B) is located in the Kumano forearc basin $\sim 20 \mathrm{~km}$ northwest of IODP Site C0002, drilled during IODP Expeditions 314 and 315 (Kinoshita, Tobin, Ashi, Kimura, Lallemant, Screaton, Curewitz, Masago, Moe, and the Expedition 314/315/ 316 Scientists, 2009) (see Figs. F1, F2, F3 in the "Expedition 319 summary" chapter). The purpose of this site was to secure a location for a long-term monitoring system in the hanging wall directly above the plate boundary where it is hypothesized to be interseismically locked, conduct downhole measurements and wireline logging, and collect core and cuttings within the forearc basin and underlying units. One key motivation for collecting core in the lower part of the borehole was to obtain samples for shore-based geotechnical and mechanical analyses near the depth of the potential observatory installation.

Based on seismic intepretation and the results of drilling at Site C0002, the anticipated geology from the top of the section to the planned total depth (TD) was a thick sequence of flat-lying to gently dipping turbidites, hemipelagic muds, and volcanic ash layers to $\sim 825 \mathrm{~m}$ seismic depth below seafloor (SSF), deposited in the forearc basin. Below this, a slope deposit of fine-grained mudstone analogous to lithologic Unit III at Site C0002 (Kinoshita, Tobin, Ashi, Kimura, Lallemant, Screaton, Curewitz, Masago, Moe, and the Expedition 314/315/316 Scientists, 2009) was anticipated to overlie a section composed of slope basin deposits and/ or older accreted trench wedge sediments comprising the accretionary wedge down to the intended TD of $\sim 1600$ meters below seafloor (mbsf). Several prominent seismic reflection surfaces can be identified near Site C0009 and traced regionally in the threedimensional (3-D) seismic reflection data (see Fig. F4A in the "Expedition 319 summary" chapter). Seismic Surface S1 within the basin fill separates continuous, high-amplitude reflectors above and lower amplitude, less continuous reflectors below and can be traced to Site C0002 just below the seafloor. Seismic Surface S2 represents a downlap surface at the base of the well-stratified basin deposits. Unconformity UC1 is a local angular unconformity at Site C0009. Unconformity UC2 is an unconformable boundary marking a change from clear seismic reflectors to discontinuous low-amplitude reflectors near the base of the proposed borehole. Seismic reflectors in the upper section at Site C0009 (including 
surfaces such as seismic Surface S1 mentioned above) can be traced to Site C0002, and they suggest widely divergent sediment deposition rates between the two sites during basin history (cf. Fig. F6B in the "Expedition 319 summary" chapter).

The scientific and operational objectives for Site C0009 were to drill, sample, log, and case the formation to 1600 mbsf. Specifically, our scientific goals at this site were to

- Characterize the lithology, depositional history, physical properties, chemistry and composition, and deformation of the Kumano Basin sediments and underlying units through analysis and integration of cuttings, core, mud gas, measurement while drilling (MWD), and wireline logging data;

- Directly measure stress and pore pressure conditions throughout the section from wireline logging Modular Formation Dynamics Tester (MDT) measurements;

- Characterize the velocity structure in the rock volume around and below the borehole by conducting zero-offset, circular, and "walkaway" vertical seismic profile (VSP) experiments; and

- Case the hole to 1500 mbsf in preparation for later placement of an observatory, which will monitor deformation, seismicity, pore pressure and temperature.

\section{Operations}

\section{Shingu, Japan, port call}

Loading for IODP Expedition 319 began on 8 May 2009 at Shingu, Japan. A "prespud" meeting was held aboard the D/V Chikyu on 9 May 2009. The Chikyu departed Shingu at $0930 \mathrm{~h}$ (all times given are local) on 10 May 2009 for Site C0009 a few days later than originally planned because of bad weather.

\section{Transit to Site C0009}

Upon arrival at Site C0009, the ship was set in dynamic positioning mode, the Big Head transducers were lowered, and a detailed seabed survey began at $1700 \mathrm{~h}$ on 12 May, finishing on 15 May. Official water depth at the site is $2082.3 \mathrm{~m}$ drilling depth below rig floor (DRF) (2054 m mud depth below sea level [MSL]). Two arrays of 10 transponders were deployed during 16 and 17 May and were immediately calibrated. The 36 inch conductor pipe, gamma ray attenuation (GRA)/Mudmat, and drilling ahead tool (DAT) were rigged up and the vessel moved $5 \mathrm{nmi}$ upstream to lower the 36 inch conductor through the GRA and Mudmat on 17 May.

\section{Hole C0009A}

Operations at Site C0009 consisted of several drilling phases (summarized in Table T1), as well as casing and hole completion. Initial operations began with a run in the hole and jet-in after the remotely operated vehicle (ROV) seafloor survey.

Hole C0009A $\left(33^{\circ} 27.4704^{\prime} \mathrm{N}, 136^{\circ} 32.1489^{\prime} \mathrm{E}\right)$ was spudded at $0930 \mathrm{~h}$ on 19 May, followed by jetting-in the 36 inch conductor. The 36 inch conductor was successfully installed to $2136.8 \mathrm{~m}$ DRF (54.5 m drilling depth below seafloor [DSF]) by $1730 \mathrm{~h}$ on 19 May. However, the top connection of the 36 inch DAT sheared because of excessive slackoff and bending of the pipe above the DAT. A successful fishing run was completed on 23 May and the 26 inch drilling bottom-hole assembly (BHA) reentered the 36 inch wellhead at $0700 \mathrm{~h}$ on 24 May. Drilling with the 26 inch BHA, including MWD tools (Table T2), continued to $2795 \mathrm{~m}$ DRF (712.7 m DSF) and successfully reached the target depth on 25 May. A dynamic positioning system (DPS) malfunction occurred on 26 May, the investigation of which continued until 30 May, when the DPS was fixed and carefully observed in order to evaluate repairs. During this time, the 20 inch casing was prepared for installation. A final decision regarding the DPS failure was made on 31 May and operations resumed.

Preparations for running the 20 inch casing began on 1 June and the casing was installed to $2786.2 \mathrm{~m}$ DRF (703.9 m DSF) on 2 June, with cement operations concluding on 3 June. Rigup for running riser pipe and blowout preventer (BOP) installation continued until 7 June. Meanwhile, a thruster failure occurred on 4 June and investigations into the cause continued until 8 June. Running down the BOP with riser pipe began on 8 June, including attachment of fairings to the uppermost 11 sections of the riser pipe. Problems with the riser tensioner Riser Antirecoil System (RARS) valves were discovered on 13 June and troubleshooting continued until 17 June. The rotating telescopic joint load ring became stuck on 19 June; however, the BOP was successfully connected to the wellhead on 21 June.

Following a BOP pressure test, the 17 inch drill-out cement assembly was run into the hole on 24 June and the $3 \mathrm{~m}$ cement plug was drilled out to $2798 \mathrm{~m}$ DRF (715.7 m DSF) by 25 June. After this, two leakoff tests (LOTs) were conducted below the casing shoe on 26 June (see "Leak-off test"). Following the LOTs, the hole was drilled with a $12 \frac{1}{4}$ inch drilling BHA with MWD tools, including Power-V and MWD (Table T2), beginning on 28 June. Cuttings and drilling mud gas were continuously collected during drilling. The $12 \frac{1}{4}$ inch drilling reached TD at $3686 \mathrm{~m}$ 
DRF (1603.7 m DSF) on 2 July, including several short trips and circulation from bottoms up.

After reaming, circulation, and cleaning the hole, coring with the $105 / 8$ inch rotary core barrel (RCB) bit started on 5 July (Table T3). A total of nine cores were collected (Table T4) with RCB coring operations finishing on 8 July after reaching a TD of $3676.2 \mathrm{~m}$ DRF (1593.9 m DSF). The first two cores had very poor recovery because of problems with equipment. After coring, the cored section was reamed with the $12^{1 / 4}$ inch drilling assembly to open the hole and collect additional cuttings. Opening the hole with the $12^{1 / 4}$ inch drilling assembly continued to a TD of $3686 \mathrm{~m}$ DRF (1603.7 m DSF). During this time, lost circulation material was added to drilling mud to remediate minor lost circulation in the hole (see "Mud program").

On 12 July, two wireline logging runs were conducted: a first run with Environmental Measurement Sonde (EMS)-High-Resolution Laterolog Array (HRLA)-Platform Express (PEX)-gamma ray and a second run with Formation MicroImager (FMI)-Hostile Natural Gamma Ray Spectrometry Cartridge (HNGC)-Sonic Scanner-EMS-Power Positioning Device and Caliper Tool (PPC) (see "Logging" in the "Methods" chapter for details). Prior to a third wireline logging run with the MDT, a 121/4 inch wiper trip assembly was run to clean the hole. After the wiper trip, MDT logging was conducted on 14 and 15 July (see "Logging" in the "Methods" chapter).

Soon after MDT operations finished and the tools were pulled out of the hole, the hole was opened to 17 inches (on 16 July). Drilling mud gas was collected during this hole opening phase. Hole opening operations continued until the hole was reamed down to 3650 m DRF (1567.7 m DSF) on 19 July. Several wiper trips and circulation bottoms ups were conducted to clean the hole prior to installing $133 / 8$ inch casing. Preparations for running casing began on 21 July, and the casing was successfully installed on 22 July. The $13 \% / 8$ inch casing shoe was set at $3624.3 \mathrm{~m}$ DRF (1542 m DSF) (Fig. F1). Cementing the $13 \% 3$ inch casing took place on 23 July. During cementing operations, landing of the second cement plug could not be confirmed, and cement loss was observed (84\% efficiency for the cement job). Upon pulling the cementing assembly to the surface, cement was found on the ports of the tool, indicating the possibility of a cement leak from the tool at the casing hanger. A junk basket with a $12 \frac{1 / 16}{1}$ inch gauge ring was run into the hole to determine if any cement was left inside the $13 \frac{3}{8}$ inch casing. The junk basket run encountered resistance at 2075-2080 m DRF (near the wellhead). After several attempts, the junk basket was rerun with an $81 / 4$ inch gauge ring, and the hole was found to be sufficiently clear to run the Versatile Seismic Imager (VSI) tool string. These modifications to the operations plan (running the junk basket rather than a cement scraper, as well as the cancellation of the cement-bond log) were made in part to adjust the VSP operation time to match the availability of the shooting vessel, the R/V Kairei.

Five VSI sensor arrays were rigged up on 24 July, and a check shot test was performed. There was a problem found in the VSP cables, so the sensor arrays were retrieved and checked. Four arrays of VSP tools (a total of 16 shuttles) were put back into the hole after finding a communication problem between the Number 4 and Number 5 arrays. The walkaway VSP experiment with the Kairei was started at $2000 \mathrm{~h}$ on 24 July. One line and one circle shooting transect for the walkaway VSP experiment were completed on 25 July, followed by a zero-offset VSP on the same day (see "VSP operations"). Preparations to retrieve the BOP started on 26 July, and all riser pipes and the BOP were safely retrieved on 30 July. Retrieving transponders via ROV was completed early on 31 July, and the ROV set the corrosion cap into the wellhead on the same day. All operations for Hole C0009A were completed at $2359 \mathrm{~h}$ on 31 July. The Chikyu started moving to IODP Site C0010 (proposed Site NT2-01J) at $0001 \mathrm{~h}$ on 1 August.

\section{Leak-off test}

After 20 inch casing was run to $703.9 \mathrm{~m}$ DSF and cemented to $708.6 \mathrm{~m}$ DSF, the hole was deepened to $715.7 \mathrm{~m}$ DSF. The hole was circulated and cleaned. Preparations for the LOT started at $2315 \mathrm{~h}$ on 25 June. From $\sim 0001$ to $0200 \mathrm{~h}$ on 26 June, there were various problems with a valve (the upper inline blowout preventer [IBOP]). The lower IBOP kill line was flushed and tested at 1000 pounds per square inch (psi).

The first LOT began at $0215 \mathrm{~h}$, with $1.08 \mathrm{~g} / \mathrm{cm}^{3}$ of KNPP mud, at a pump rate of $0.25 \mathrm{bbl} / \mathrm{m}$. Pumping stopped when the pump pressure reached $116 \mathrm{psi}$, with a total volume pumped of $2.2 \mathrm{bbl}$. The leak-off pressure was $105 \mathrm{psi}$, or an equivalent mud weight (EMW) of $1.106 \mathrm{~g} / \mathrm{cm}^{3}$ at the casing shoe. The maximum pressure was recorded as 116 psi $(\mathrm{EMW}=1.109$ $\mathrm{g} / \mathrm{cm}^{3}$ ). After pumping stopped there was a flowback volume of $0.5 \mathrm{bbl}$. Preparation for the second LOT started at $0306 \mathrm{~h}$. Both mud tanks were filled for a line pressure test. Pressure was held at 272 psi. At $0322 \mathrm{~h}$, the LOT proceeded with $1.08 \mathrm{~g} / \mathrm{cm}^{3} \mathrm{KNPP}$ mud at a pump rate of $0.25 \mathrm{bbl} / \mathrm{m}$. The pump was stopped when pressure reached $135 \mathrm{psi}$, for a total pumped volume of $3.6 \mathrm{bbl}$. The leak-off pressure was 
$105 \mathrm{psi}\left(\mathrm{EMW}=1.106 \mathrm{~g} / \mathrm{cm}^{3}\right)$. The maximum pump pressure was 133 psi $\left(\mathrm{EMW}=1.113 \mathrm{~g} / \mathrm{cm}^{3}\right)$. After pumping stopped there was a flowback volume of $0.5 \mathrm{bbl}$.

\section{VSP operations}

The VSP experiment was divided into two parts: a walkaway VSP in conjunction with the research vessel Kairei, and a zero-offset VSP conducted solely by the Chikyu (Table T5). Details regarding VSP operations can be found in "Downhole measurements" in the "Methods" chapter. Operations for the walkaway VSP were adjusted from the precruise plans because of scheduling uncertainties and delays with expedition operations. One line of air gun shooting, combined with one circuit around the Chikyu, was achievable in the time available. Before ocean-bottom seismometer (OBS) deployment, synchronization of radio signals between the Kairei and the Chikyu was checked and confirmed. The Kairei began operations by dropping eight OBSs to augment an array of four broadband ocean-bottom seismometers (BBOBSs) that had been deployed in 2008. After cementing operations were completed, a $12 \frac{1}{16}$ inch gauge junk basket was run through the casing; however, after three failed attempts at trying to pass 2080 $\mathrm{m}$ DRF, the gauge ring was changed to $8 \frac{1}{4}$ inch, which was able to reach $3300 \mathrm{~m}$ DRF. After pulling out of the hole following the junk basket run, the VSI tool string, consisting of 20 seismometers, was lowered into the hole to $2085.5 \mathrm{~m} \mathrm{DRF}$ at $0730 \mathrm{~h}$ on 24 July. Checks of the calipers on each seismometer, which are used to couple the tools to the formation, indicated a short circuit somewhere in the string. Therefore, the VSI string was pulled from the hole at $1030 \mathrm{~h}$ and 4 seismometers were removed to reduce risks of further cable problems, leaving 16 seismometers remaining on the VSI tool for the walkaway VSP. The VSI tool was again lowered into the hole at 1600 $\mathrm{h}$ and locked in the casing from 2999.2 to $3227.8 \mathrm{~m}$ DRF. The Kairei deployed four air gun strings (see "Vertical seismic profile"), and after a check shot at $1951 \mathrm{~h}$, it was determined that the formation coupling was poor at this interval, so the VSI tool was raised to 2963.7-3222.3 $\mathrm{m} \mathrm{DRF}$ and anchored in preparation for a shaker test, which tests the connection of the seismometers to the casing and, in turn, the casing to the formation. The Kairei began moving along the linear transect, shooting at $2018 \mathrm{~h}$, and recorded the first position at $\sim 24.1 \mathrm{~km}$. The line was shot with a $60 \mathrm{~m}$ shot interval. When the Kairei reached a point $500 \mathrm{~m}$ from the Chikyu at $0311 \mathrm{~h}$ on 25 July, she made a slight deviation from course and then at $0327 \mathrm{~h}$ suspended shooting until the circle (clockwise around the Chikyu) transect began at
$0405 \mathrm{~h}$. The shooting interval for the circle track line was $30 \mathrm{~s}$ at $3.5 \mathrm{~km}$ from the Chikyu; shooting finished at $0632 \mathrm{~h}$. The Kairei then returned to the line transect and resumed shooting at $0713 \mathrm{~h}$. At $10.7 \mathrm{~km}$ from Hole C0010A, the Number 3 gun array on the Kairei unexpectedly stopped firing; however, firing continued with the three remaining arrays. Shooting on the line transect was completed at $0847 \mathrm{~h}$ on 25 July, when the Kairei reached a point $29.3 \mathrm{~km}$ from Hole C0009A.

Preparations for the zero-offset VSP experiment began immediately following the walkaway VSP; the Chikyu deployed a set of air guns suspended from a crane off the port side of the ship. These were shifted to a point farther from the Chikyu to avoid damage to the azimuth thrusters. A delay of $\sim 4 \mathrm{~h}$ occurred because of repeated failures of the shear pin on the compensation line. An additional delay was caused by the use of faulty shackles on the air gun assembly-the crane operator noticed that condemned shackles had been used and called for their replacement before deploying the air gun at $1145 \mathrm{~h}$. The zero-offset VSP began with the VSI array in the same position as the walkaway VSP, but between shootings the array was moved upward in the casing at $122 \mathrm{~m}$ intervals to provide data throughout the borehole. Shooting and recording began at $1620 \mathrm{~h}$. It was soon discovered that Seismometers 9 and 10 were malfunctioning, so the zero-offset VSP was run using only eight seismometers. At $1916 \mathrm{~h}$, pulling out of the hole for the VSI tool string began, finishing rigdown at $0100 \mathrm{~h}$ on 26 July.

\section{Mud program}

One of the major differences in riser drilling compared with riserless drilling is the use of weighted mud to control or balance formation pressures and sweep cuttings from the hole. Riser drilling is commonplace in the petroleum industry, and weighted mud has been used for some riserless drilling projects in IODP (e.g., Flemings et al., 2005). However, riser drilling with weighted mud is a new element in IODP drilling that carries important considerations for merging scientific and operational objectives. Continuous monitoring of mud weight, annular pressure, mud losses, and other circulation data during riser drilling provides important scientific data to constrain formation pore fluid pressure and state of stress (e.g., Zoback, 2007). On the other hand, problems related to mud weight during drilling or cementing may jeopardize successful drilling of the borehole itself, as well as the ability to achieve postdrilling scientific objectives including observatory installations and active source seismic experiments (e.g., VSP studies) that require hydraulic sealing or 
coupling of casing to the formation. Unsuccessful hole completion (cementing operations) can also impair deepening of the borehole by later drilling. For these reasons, we describe some key observations and operations related to the mud program and hole conditions during drilling of Hole C0009A.

In general, mud weight is selected such that the pressure of the mud column in the borehole is sufficient to balance formation fluid pressure but remains below the fracture pressure (approximately equal to the least principal stress plus the tensile strength of the formation at a given depth). If mud weight is too low (underbalanced condition), fluid may enter the borehole, leading to partial or complete borehole collapse or, in the case of significant gas, possible blowout. If mud weight is too high (overbalanced condition), the pressure of the mud in the borehole can cause fracturing of the formation and/or mud losses can occur with varying degrees of severity. Fracturing and loss of circulation because of overbalancing can impact the ability to circulate cuttings and to control pressure in the borehole, potentially leading to packoffs or hole collapse. In addition to the risks of borehole failure, if the downhole pressure during cementing leads to overbalance (i.e., exceeds the fracture pressure) such that the cement column cannot be supported by the formation, this can lead to insufficient cement fill outside the casing and/or a final cement level lower than planned because of cement loss under the column weight (e.g., Abbas et al., 2004; Nelson and Guillot, 1990).

In shallow riser holes drilled in deep water, hole balance is especially challenging because (1) small differences in mud weight are integrated down the entire length of the riser and thus translate to large differences in absolute pressure in the borehole, and (2) at shallow depths below seafloor the difference between formation pore pressure and the least principal stress (effective stress) is generally small in magnitude (Fig. F2). For example, in $2000 \mathrm{~m}$ water depth, the pressure in a column of $1.03 \mathrm{~g} / \mathrm{cm}^{3}$ mud weight (assumed seawater density) and that of a 1.07 $\mathrm{g} / \mathrm{cm}^{3}$ mud weight is $\sim 0.8 \mathrm{MPa}(20.2 \mathrm{MPa}$ versus 21 $\mathrm{MPa}$ ) (Fig. F2). For typical marine sediments, this excess pressure generated by the mud column in the riser itself would exceed the lithostatic stress to $\sim 160$ mbsf. In contrast, for riserless drilling the pressure generated by the mud column would be integrated only from the seafloor downward because during drilling the borehole annulus is subject to a seawater hydrostatic boundary condition at the wellhead. Borehole pressures are typically reported as both absolute pressures and an equivalent circulating density (ECD) (units of $\mathrm{g} / \mathrm{cm}^{3}$ ), which is computed as the total pressure divided by the product of depth below a reference datum and gravitational acceleration.

\section{Mud program in Hole C0009A}

We conducted drilling and casing of the upper $\sim 704$ $\mathrm{m}$ DSF in riserless mode but used a light mud (1.04 $\mathrm{g} / \mathrm{cm}^{3}$; for comparison, the average seawater density between mean sea level and the wellhead is $\sim 1.03 \mathrm{~g} /$ $\mathrm{cm}^{3}$ ) to sweep the hole at intervals (Table T3). During these operations, we collected MWD data, including annular pressure while drilling (APWD), which provided a direct measurement of mud pressure at the bit. This pressure may differ from that computed from mud weight measured on the drillship because of the additional pressure that must be applied to overcome frictional resistance as the mud flows up the annulus or because of cuttings from the formation suspended in the mud that can increase its density. Mud was sampled and tested twice daily by a service company (see C0009MUD.PDF in OPERATIONS in "Supplementary material") to confirm the mud weight and chemical composition, so we believe that a significant difference between actual and intended mud weight is unlikely.

For riserless operations in the upper $700 \mathrm{~m} \mathrm{DSF}$, the ECD computed from APWD measurements generally ranged from 1.13 to $1.16 \mathrm{~g} / \mathrm{cm}^{3}$ (Fig. F3; Table T3). The pumping rate during drilling was 1000 gallons per minute (gpm). The measured borehole pressures are smaller than the lithostatic stress (i.e., the overburden) below the $54.5 \mathrm{~m}$ DSF surface casing (Fig. F3B). However, if the minimum horizontal stress is smaller than the vertical stress, as is likely to be the case in a basinal setting, the fracture gradient could be smaller than the lithostatic gradient.

For riser drilling, the planned mud weight was $1.08-1.10 \mathrm{~g} / \mathrm{cm}^{3}$, or greater if deemed necessary (Kobayashi et al., 2009). Drilling proceeded from 27 June to 6 July using a nominal mud weight of $1.08 \mathrm{~g} /$ $\mathrm{cm}^{3}$. After some difficulty with coring operations (see C0009MUD.PDF and DAILYRPT.PDF in OPERATIONS in "Supplementary material"), mud weight was increased to $1.09 \mathrm{~g} / \mathrm{cm}^{3}$ on 6 and 7 July, and again to $1.10 \mathrm{~g} / \mathrm{cm}^{3}$ from 8 July until the end of riser drilling operations (Table T3; see also C0009MUD.PDF and DAILYRPT.PDF in OPERATIONS in "Supplementary material"). During drilling, a pumping rate of $\sim 700 \mathrm{gpm}$ was used. In the first period of riser drilling from 27 June to 8 July, mud losses of $\sim 10-20 \mathrm{~m}^{3} /$ day were observed (Fig. F4; see also DAILYRPT.PDF in OPERATIONS in "Supplementary material"). After the mud weight was increased to $1.10 \mathrm{~g} / \mathrm{cm}^{3}$ on 8 July, mud losses increased 
to $\sim 40-50 \mathrm{~m}^{3} /$ day and were sustained at this rate for the remainder of riser drilling operations. The mud losses prior to 8 July are characterized as "seepage" (losses $<1.5 \mathrm{~m}^{3} / \mathrm{h}$ ), whereas those after 8 July qualify as "partial lost returns" but remain at the lower range of values for this categorization (Abbas et al., 2004).

The APWD tool was not run during any phase of riser drilling. However, MDT measurement provided a direct measurement of the static mud column pressure during the wireline logging operation (Fig. F5A). The measured pressure gradient corresponds to an ECD of $1.13 \mathrm{~g} / \mathrm{cm}^{3}$ (Fig. F5B, F5C), which exceeds the shipboard mud weight measurements of $1.10 \mathrm{~g} / \mathrm{cm}^{3}$ (see "Downhole measurements" and C0009MUD.PDF in OPERATIONS in "Supplementary material"). This difference could be caused by cuttings load in the annulus. Because the MDT measurements were obtained in a static column, the circulating ECD is likely to have been higher still (cf. Fig. F3).

The measured mud column pressure also slightly exceeds the fracture pressure equivalent to $1.10-1.11 \mathrm{~g} /$ $\mathrm{cm}^{3}$ measured by an LOT at the 20 inch casing shoe (703.9 m DSF) (Fig. F5) but is lower than the fracture pressure determined from an MDT test at $874.3 \mathrm{~m}$ wireline log matched depth below seafloor (WMSF), which yielded a value of the least principal stress equivalent to an ECD of $\sim 1.20 \mathrm{~g} / \mathrm{cm}^{3}$. These values are similar to the predrilling estimate of fracture gradient of $1.15 \mathrm{~g} / \mathrm{cm}^{3}$ at $700 \mathrm{mbsf}$ but lower than the predrilling estimate of $1.34 \mathrm{~g} / \mathrm{cm}^{3}$ at $1500 \mathrm{mbsf}$ (Kobayashi et al., 2009).

\section{Discussion}

In the riserless borehole drilled to $700 \mathrm{~m}$ DSF, measured borehole pressures are $\sim 10 \%$ greater than those computed for a static column of the planned mud weight $\left(\sim 1.15\right.$ versus $\left.1.04 \mathrm{~g} / \mathrm{cm}^{3}\right)$. This difference may be due to circulation pressures during drilling. Alternatively, it could be related to cuttings load in the annulus or to a difference between actual and intended mud weight. During riser drilling, the measured pressure in the borehole exceeded the pressure expected for a static column of $1.10 \mathrm{~g} / \mathrm{cm}^{3}$ mud. This discrepancy illustrates the importance of APWD data to enable real-time monitoring of downhole pressure and ECD, especially to account for the additional downhole pressure generated by circulation. APWD can also be used as an indirect indicator of overbalanced or underbalanced hole conditions.

The observed static mud weight in the riser hole during the MDT wireline run exceeded the fracture pressure determined by the LOT but lies below that measured by MDT hydraulic fracture testing. A mud pressure at or near the fracture gradient could partly explain the observed mud losses from seepage into the formation or hydraulic fracturing. Additional pressure generated during mud circulation would further increase any overbalance present. The offset between planned and actual static mud weight was only a few percent, but because of the large water depth (and thus riser length), the difference in pressure at $700 \mathrm{~m}$ DSF between a column of 1.10 and $1.13 \mathrm{~g} / \mathrm{cm}^{3}$ is $\sim 1 \mathrm{MPa}$, equivalent to $\sim 20 \%-25 \%$ of the vertical effective stress at this depth. Although this is highly speculative, possible damage or fracturing of the formation may also provide a partial explanation of difficulty encountered during cementing operations for the $13 \% / 8$ inch casing, including lack of resistance, low efficiency, and apparently incomplete filling of the annulus (based on zero-offset VSP results; see "Downhole measurements") (see DAILYRPT.PDF in OPERATIONS in "Supplementary material") and could also be related to the apparent washout of the borehole below the casing shoe at $703.9 \mathrm{~m}$ DRF as observed in caliper and other logs (see "Logging results").

\section{Logging and data quality Logging results}

Logging data collected during MWD (gamma ray logs) and wireline logging Runs 1 and 2 are presented in Figures F6 and F7 (see also C0009_F1.AI in LOGGING in "Supplementary material"). Detailed discussion and interpretation of individual logs are incorporated into the subsequent disciplinary sections (i.e., lithology, structural geology, and physical properties). MDT data collected during wireline logging Run 3 and VSP data (zero-offset, circular, and walkaway) from Run 5 are presented in "Downhole measurements." Logging Run 4 consisted of a junk basket run before the VSP, which was conducted inside the casing (Fig. F8).

\section{Depth correction of wireline log data}

In order to correlate observations from wireline logs with core and cuttings, depth-shifting of the data to a common reference datum was required (see "Introduction" in the "Methods" chapter for general information on depth reference terminology). We chose to register the depths for the logs to the bottom of the 20 inch casing (703.9 m DSF or $2786 \mathrm{~m} \mathrm{DRF),} \mathrm{be-}$ cause it is clearly identifiable in all three wireline logging runs (Fig. F9). The 20 inch casing, bottom of the 26 inch hole, and bottom of the 17 inch hole are all clearly detected by caliper and resistivity data in wireline logging Run 1 and by caliper data in Run 2 (Figs. F9, F10). The natural gamma ray (NGR) data 
collected by wireline logging Runs 1 and 2 show a clear increase corresponding to the bottoms of the 26 and 17 inch holes, although this response may also be the result of hole shape. The NGR data collected during VSP operations also show an increase corresponding to the bottom of the 17 inch hole.

Depth references for each logging run are listed in Table T6 and shown graphically in Figure F11. The height of the rig floor (rotary table) is $28.3 \mathrm{~m}$ above sea level (presuming minimal variation in this parameter during drilling operations), and water depth is reported as $2054.0 \mathrm{~m}$. Wireline log depths are all tied to the drillers depth at the 20 inch casing shoe, located at $2786.2 \mathrm{~m}$ DRF (703.9 m DSF, $2785.0 \mathrm{~m}$ wireline depth below rig floor [WRF]). Therefore $2081.1 \mathrm{~m} \mathrm{(2785.0-703.9)}$ is subtracted from the logging depth (WRF) to give the depth below seafloor of the wireline logging data, corrected relative to the drillers depth. This value is given in meters WMSF (referring to the matching of the individual wireline logging runs to each other). After registering the depths in this way, WMSF depth as reported here is equivalent in depth to DSF.

FMI images have been corrected for tool acceleration during the logging run (see "Logging" in the "Methods" chapter) as well as relative to the other wireline logs. Depths of these corrected data are also reported in meters WMSF (relative to the seafloor).

\section{Operations}

MWD measurements were taken during three different drilling phases, and five wireline logging runs were conducted in Hole C0009A (Fig. F12). MWD measurements were taken during drilling, the first three wireline logging runs were conducted after riser drilling and coring, and the last two runs were conducted after the hole was cased and cemented (Fig. F8).

On completion of drilling with a $12 \frac{1}{4}$ inch bit to $3686 \mathrm{~m} \mathrm{DRF}$ and a wiper trip, the first wireline logging tools were rigged at $2230 \mathrm{~h}$ on 7 July 2009. The passive heave compensator (see Fig. F4B in the "Methods" chapter) was set up at $0100 \mathrm{~h}$ on 8 July. This was the first time the passive heave compensator was used instead of the active heave compensator, which is typically used for riserless logging operations. Setup and use of this system throughout wireline logging operations was smooth.

Logging Run 1 began at $0145 \mathrm{~h}$ with the EMS-HRLAPEX-gamma ray tool string (23.6 m long) (Fig. F12). Density, porosity, gamma radiation, caliper, laterolog resistivities, and mud properties were measured during this run. The tool string could not pass beyond $1585.9 \mathrm{~m}$ WMSF after several attempts, and hence the hole was logged from that depth to the 20 inch casing shoe (703.9 m WMSF), and the lowermost 8 $\mathrm{m}$ of the cored zone at the bottom of hole was not logged. A repeat section of $92 \mathrm{~m}$ was logged from the bottom to $1493.9 \mathrm{~m}$ WMSF. The main log covers an interval between 703.9 and 1585.9 m WMSF.

Logging Run 2 consisted of FMI, Sonic Scanner, and HNGC (spectral gamma) (31.77 m long tool string). The tool string could not be lowered below $1581.1 \mathrm{~m}$ WMSF. Run 2 was logged from that depth to the 20 inch casing shoe and included a repeat section for the interval from 763.9 to $849.5 \mathrm{~m}$ WMSF.

Logging Run 3 consisted of a $23.44 \mathrm{~m}$ long tool string with the MDT to conduct measurements of stress magnitude, pore pressure, and permeability. Data collected from the first two logging runs were used to select the MDT test locations, and gamma ray was included on the MDT tool to refine targeting of the measurement intervals. Because this tool was being deployed for the first time in scientific ocean drilling, there were multiple discussions among the science party, Center for Deep Earth Exploration (CDEX) science support and operations, the Schlumberger engineer, and specialists to develop a final deployment plan.

Logging Run 4 consisted of a junk basket run with an $8 \frac{1}{4}$ inch gauge ring run inside the casing. Logging Run 5 consisted of the walkaway, circular, and zerooffset VSP experiments and used 16 VSI shuttles.

\section{Log data quality}

Wireline log data quality is assessed primarily by cross-correlating available logs and hole shape. Density, neutron porosity, and resistivity images are affected the most by borehole conditions. Resistivity and gamma ray data may be degraded where borehole diameter greatly increases or is washed out. Deep investigation measurements such as resistivity and sonic velocity are the least sensitive to borehole conditions. Environmental corrections are applied to the original data immediately after data acquisition at the well site by the field engineer. If necessary, additional correction and data processing are conducted at the well site and/or consulting centers by specialists to reduce these effects. Data quality indicators are divided into three log types: sonic velocity, resistivity images, and other logs (except neutron porosity); they are shown together with composite logs and the lithologic units (Fig. F7).

\section{Available data}

Hole C0009A was drilled with MWD APWD for the 26 inch hole, MWD Power-V for the $12^{1 / 4} 4$ inch hole, and a conventional drilling assembly for hole open- 
ing to 17 inches. Three separate wireline logging runs were conducted after opening the cored interval to $12^{1 / 4}$ inch diameter. Wireline data were processed and depth-shifted on board the Chikyu by the Logging Staff Scientist and logging specialists (see details in the "Methods" chapter). Lists of available data from both logging while drilling (LWD)/MWD and wireline logging are provided in Tables T2 and T4 in the "Methods" chapter.

\section{Repeatability}

To ensure data quality, repeat runs were conducted over $92 \mathrm{~m}$ for logging Run 1 and $85.6 \mathrm{~m}$ for logging Run 2, and comparisons were made between several logs to confirm reproducibility during and between the runs. The comparison between the main and repeat sections of Runs 1 and 2 indicates good correlation between the two except for the neutron porosity. The large scatter and large absolute values of neutron porosity raised some doubt about the data quality. Neutron porosity is affected by standoff and is generally not reliable in zones of washout, breakouts, and significant borehole rugosity. By restricting the data to a zone of small standoff for High-Resolution Density Device (HRDD) (standard resolution density standoff $<0.02 \mathrm{inch}$ ), we may recover a better correlation between the main log and the repeated section (see "Physical properties").

\section{Data quality}

Three different calipers were run for hole diameter measurement. Among them, the six arm caliper from EMS provides the best indication of hole shape. Because of hole shape effects, resistivity data below $1283 \mathrm{~m}$ WMSF are of poor/medium quality. Resistivity images from FMI are also degraded by borehole shape and fracturing at depths below $1283 \mathrm{~m}$ WMSF. Because of their high sensitivity to hole shape, density and porosity were also affected significantly below 3365 m DRF (1282.7 m WMSF). Anomalous density values were recorded at several depths, and porosity data exhibit wide variation throughout the measured range. Gamma ray data exhibit a steady trend and do not exhibit any indication of poor data quality. In Figure F7, the caliper logs indicate that the borehole is in-gauge from the top to $1284.9 \mathrm{~m}$ WMSF; however, the borehole below $1284.9 \mathrm{~m}$ WMSF is highly rugose and possibly washed out.

\section{Sonic velocity data processing and quality}

Immediately after data acquisition from the Sonic Scanner, the data were sent to Schlumberger's Tokyo Data and Consulting Service for further processing available only with in-house software. The processing procedure included extracting compressional, shear, and Stoneley velocities using BestDT, a sonic processing module on Schlumberger's GeoFrame software. The waveforms are of very high quality, except for a few intervals with very large borehole size. The monopole waveforms consist of very good formation arrivals, and the compressional velocity results are also clear. The dipole waveforms contain decent formation arrivals. After detailed analysis on dispersion plots, the best processing results were obtained using multishot shear parametric inversion (MSPI) processing rather than slowness time coherence. MSPI processing is based on dispersion analysis by a curve-fitting technique to compute the correct shear velocity. In some intervals, the shear slowness processed from cross-dipoles indicates the presence of anisotropy (intrinsic or stress induced) as well as borehole alteration. Stoneley wave results are more sensitive to borehole conditions, and hence more affected by washout than other velocity data, especially for the interval below $1284.9 \mathrm{~m}$ WMSF.

\section{Lithology}

Based on a range of data available from cuttings and core and wireline logging, we defined four lithologic units at Site C0009 that were differentiated using geological, geophysical, and geochemical characteristics (Fig. F13). Unit boundaries and lithologies are constrained by

- Macroscopic observations;

- Microscopic observations including smear slides and thin sections;

- Mineralogical observations by X-ray diffraction (XRD) and X-ray fluorescence (XRF);

- MWD, including gamma ray data; and

- Wireline logging data (NGR, caliper, density, photoelectric effect [PEF], spontaneous potential [SP], resistivity, and sonic velocity).

We also compared cuttings and cores in the cored interval from $\sim 1510$ to $\sim 1594 \mathrm{~m}$ core depth below seafloor (CSF) to quantify possible artifacts and uncertainties related to the use of cuttings as stratigraphic indicators.

At Site C0009, the cuttings show a progressive change in the degree of cohesion with depth (see LITHOLOGY in "Supplementary material"). Between 707.7 (where the first cuttings were retrieved) and $812.7 \mathrm{~m}$ mud depth below seafloor (MSF), the cuttings were noncohesive, and individual grains were dispersed in the drilling mud. At $812.7 \mathrm{~m} \mathrm{MSF}$, the first relatively coherent chips of sediment were identified, and we interpret this to approximately mark the change from silty mud to silty mudstone in the stratigraphic section, although the chips were still 
relatively soft and might normally be classified as mud rather than mudstone. At 1037.7 m MSF, the sediment chips were noticeably harder and more lithified and appeared more like silty mudstones. We therefore consider the fine-grained material in the wall rock below $812.7 \mathrm{~m}$ MSF to be silty mudstone, although locally partially disaggregated by drilling.

\section{Limitations using cuttings}

Drilling and drilling mud circulation, including the retrieval of cuttings, significantly disturbs and mixes the formation in the vicinity of the drill bit; thus lithologic variations that are normally observed and documented in cores cannot be recognized. For example, drilling typically disaggregates partially lithified sediments, generally making it impossible to differentiate muds from mudstones or sands from sandstones. Spalling or collapse of wall rock into the drilling mud, producing "cavings," also results in vertical mixing of lithologies that makes it difficult to accurately reconstruct stratigraphic relations. Finally, infiltration of drilling fluid into high-porosity cuttings and precipitation of spurious solid phases significantly modifies the physical properties of the cutting chips.

The unit boundaries described below are defined primarily from log data, which were determined to be more accurate than depths of cuttings intervals. However, consistency between the two data sets (i.e., boundaries from cuttings and log data) is good in terms of depth, with typical mismatches of less than $\sim 10 \mathrm{~m}$.

\section{Lithologic Unit I}

Depth: 0-467 m LWD depth below seafloor (LSF)

Age: Holocene-Pleistocene ( 0 to $<0.9 \mathrm{Ma}$ )

Lithology: silty mud with cyclical sand-rich layers

The initial $54.5 \mathrm{~m}$ DSF was drilled and cased to set the conductor pipe. Below this, a 26 inch hole was drilled to $707.7 \mathrm{~m}$ LSF in riserless mode. No cuttings were recovered in this interval and no wireline logging data are available from this interval. Recorded parameters included weight on bit, rate of penetration (ROP), and gamma ray data, the latter from MWD. Lithologic interpretation was based on the gamma ray logs in this interval.

Unit I is composed of silty mud with abundant sandrich beds ranging up to $40 \mathrm{~m}$ in thickness. In the upper part of the unit (above $\sim 360 \mathrm{~m} \mathrm{LSF}$ ), gamma ray values gradually decrease upsection and are capped by an abrupt increase, suggesting seven to eight sequences with increasing sand fractions uphole. High gamma ray values >150 gAPI (American Petroleum
Institute units) at 233 and $244 \mathrm{~m}$ LSF suggest the presence of ash layers or very clay rich layers.

Between 360 and $467 \mathrm{~m} \mathrm{LSF}$, some low gamma ray zones record the presence of sand, but these are either less abundant or thinner relative to the overlying section. In addition, the cycles in this interval appear to show upward increases in the proportion of mud (i.e., the gamma ray values gradually increase upward and then are capped by an abrupt decrease). Gamma ray values range between 50 and 110 gAPI, with some cycles of decreasing sand fractions uphole and fewer cycles of increasing sand fractions uphole, though these cycles are shorter and more muted than those in the upper part of the hole. The most prominent feature is a substantial excursion to low gamma ray values from 454 to $467 \mathrm{~m} \mathrm{LSF}$; here, the lowest values in the logged interval were recorded (30 gAPI). This excursion is consistent with a sandy interval: sharp at the base and fining upward, which marks the Unit I/II boundary.

\section{Lithologic Unit II}

Interval: cuttings Samples 319-C0009A-1-SMW through 24-SMW

Depth: 467-791 m LSF (cuttings from 707.7 to $812.7 \mathrm{~m} \mathrm{MSF})$

Age: Pleistocene ( $<0.9$ to $\sim 0.9 \mathrm{Ma})$

Lithology: silty mud with silt and sand interbeds

Unit II is composed dominantly of silty clay, with silt and sand interbeds and minor interbeds of volcanic ash. It is distinguished from Unit I by a distinct drop in gamma ray values. Below $467 \mathrm{~m} \mathrm{LSF}$, there is a variable but generally low gamma ray interval, suggesting continuing occurrence of sand layers. The log has little character and is interpreted to be similar to the upper unit.

Cuttings, which start at $707.7 \mathrm{~m}$ MSF, comprise coarse to fine sand grains dispersed in the drilling mud, with a few weakly consolidated clayey agglomerates (Figs. F14, F15, F16). Drilling contamination is high in this area. The typical grain-size distribution in the cuttings based on the Atterberg method is given by representative Sample 319-C0009A-23SMW with $\sim 81 \%$ sand, $9 \%$ silt, and $10 \%$ clay fractions. However, the sand fraction may be overestimated by this method and/or by effects from the riser drilling process. Sand- and silt-sized grains (45 $\mu \mathrm{m}-1 \mathrm{~mm}$ ) are angular to rounded and moderately well sorted. Quartz is the dominant mineral, followed by lithic fragments (mostly metamorphic, some sedimentary), partly reworked volcanic glass and pumice, feldspar, partly broken shallow-water and planktonic fossils, rare wood/lignite fragments, mica, and heavy minerals (e.g., pyrite, amphibole, 
apatite, and zircon). In the interval from 712.7 to $715.7 \mathrm{~m}$ MSF (Sample 319-C0009A-3-SMW), the amount of volcanic glass markedly increases and likely corresponds to local ash-rich beds. Detailed observations on cuttings from all units are summarized in C0009_T1.XLS and C0009_T2.XLS in LITHOLOGY in "Supplementary material" (see also Figs. F17, F18).

Unit II is characterized by high density (up to $2.2 \mathrm{~kg} /$ $\mathrm{cm}^{3}$ ) and $P$-wave velocity (up to $2300 \mathrm{~m} / \mathrm{s}$ ) compared to Unit III below (Fig. F19). SP increases slightly through the unit up to $-110 \mathrm{mV}$, and resistivity values range from 1.2 to slightly over $1.4 \Omega \mathrm{m}$. Gamma ray values increase slightly with depth from 75 to $>80$ gAPI, whereas PEF decreases steadily from 3.2 to $<2.6 \mathrm{~b} / \mathrm{e}^{-}$. The change in character of the gamma ray $\log$ at $>100 \mathrm{~m}$ LSF coincides with the change from riserless drilling above to riser drilling with mud below. We do not know whether the change in log character reflects a change in lithology or drilling parameters and/or log processing.

\section{Lithologic Unit III}

Interval: cuttings Samples 319-C0009A-25-SMW through $\sim 128$-SMW

Depth: 791-1285 m WMSF (cuttings from 812.7 to $1287.7 \mathrm{~m} \mathrm{MSF}$ )

Age: Pleistocene-late Pliocene ( 0.9 to $\sim 3.8 \mathrm{Ma}$ )

Lithology: silty mudstone with rare silty-sand interbeds

Unit III is composed of abundant silty clay and poorly lithified silty claystone, with interbeds of silt and fine sand layers. It is distinguished from Unit II by generally having (Figs. F17, F19)

- Finer mineral grains,

- Higher wood/lignite content,

- Higher glauconite content,

- Slightly increased consolidation state,

- Higher total organic carbon (TOC) content (see "Geochemistry"),

- Lower P-wave velocity, and

- Higher resistivity values.

The Unit II/III boundary is defined by localized occurrence of silt-rich samples at $\sim 802.7$ to $\sim 812.7 \mathrm{~m}$ MSF (Samples 319-C0009A-25-SMW and 26-SMW), change in cohesion of the cuttings, reduced sorting of the sand fraction (poorly sorted) in the upper part of Unit III, which then progressively increases again downhole, and sharp peaks and shifts in logging data values (see below). Cuttings recovered from Unit III consist mainly of fine sand, silt, clay, and soft chips of silty clay. These chips are progressively more lithified downhole (Fig. F17). Differences in mineral and organic composition (see below) allow further subdivision into two lithologic subunits.

Log data in Unit III also display differences from Unit II (Fig. F19). The Unit II/III boundary is sharp and marked by distinct decreases in $P$-wave velocity, density, and PEF and an increase in SP. PEF values are particularly high $\left(>3 \mathrm{~b} / \mathrm{e}^{-}\right)$in contrast to $2.5 \mathrm{~b} / \mathrm{e}^{-}$in Unit II. This difference suggests a lithologic change, such as increasing silt content, and is consistent with cuttings characteristics (see below). Additionally, an increasing proportion of mud is suggested by a gradual increase of gamma ray values through most of Unit III. The largest variation in $P$-wave velocity is observed between 1010 and $1285 \mathrm{~m}$ WMSF and corresponds approximately to Subunit IIIB (see below). This region, which also correlates with slightly higher density and resistivity, is coincident with the highest mud gas concentrations and the largest and most abundant wood/lignite fragments in cuttings samples (see below and "Geochemistry").

\section{Subunit IIIA}

Interval: cuttings Samples 319-C0009A-25-SMW through 74-SMW

Depth: 802.7-1037.7 m MSF

Age: Pleistocene-late Pliocene ( $\sim 0.9$ to $\sim 2.8 \mathrm{Ma})$

Lithology: silty mudstone with rare silty-sand interbeds

Subunit IIIA extends from $\sim 802.7$ to $\sim 1037.7 \mathrm{~m} \mathrm{MSF}$, with a typical grain size distribution given by representative Sample 319-C0009A-46-SMW with 17\% sand, $76 \%$ silt, and $7 \%$ clay fractions. It is composed dominantly of silty clay, with rare interbeds of silt and fine sand and minor interbeds of fine ash. The silt/sand fraction contains subangular-to-rounded grains that are moderately well sorted (Figs. F14, F17). The composition of these grains is broadly similar to Unit II (i.e., quartz is the dominant component, followed by lithic fragments, partly reworked volcanic glass and pumice, feldspar, partly broken fossils, wood/lignite fragments, and heavy minerals; Fig. F15). Rounded glauconite grains complement the grain assemblage from $\sim 887.7$ to $892.7 \mathrm{~m} \mathrm{MSF}$ (Sample 319-C0009A-43-SMW) and are an additional distinctive feature of Subunit IIIA. A similar increase in glauconite was detected at Site C0002 in Unit III. Partly reworked fossils are common and most are replaced by pyrite (Figs. F14, F15, F16).

\section{Subunit IIIB}

Interval: cuttings Samples 319-C0009A-75-SMW through $~ 128-S M W$

Depth: 1037.7-1287.7 m MSF

Age: Pliocene ( 2.8 to $\sim 3.8 \mathrm{Ma})$ 
Lithology: silty mudstone with rare silty-sand interbeds and abundant wood/lignite fragments

The Subunit IIIA/IIIB boundary at $1037.7-1042.7 \mathrm{~m}$ MSF (Sample 319-C0009A-75-SMW is marked by an abrupt increase in wood/lignite fragments and rounded glauconite (Figs. F14, F15, F16, F17, F18). The wood/lignite fragment abundance remains relatively high throughout Subunit IIIB, with typical sizes of $\sim 2 \mathrm{~mm}$ and some fragments as large as $\sim 15$ $\mathrm{mm}$. This component defines Subunit IIIB relative to Subunit IIIA. The increased wood/lignite abundance correlates with high TOC and $\mathrm{CH}_{4}$ observed in cuttings and mud gas, respectively (see "Geochemistry"). Other detrital grains do not differ significantly in geometry, size, or composition from those of Subunit IIIA, pointing toward broadly similar lithologic assemblages in these two units (Figs. F14, F15, F16, F17, F18). The typical grain-size composition of the bulk cuttings from Subunit IIIB is given by the representative Sample 319-C0009A-85-SMW with $~ 35 \%$ sand, $41 \%$ silt, and $24 \%$ clay fractions.

At the Subunit IIIA/IIIB boundary, the silty clay chips (cuttings) are sufficiently indurated to allow separation from drilling mud by washing, and the chips can be prepared for XRD, XRF, and other analyses (see the "Methods" chapter). Relative abundance of total clay minerals, quartz, feldspars, and calcite were obtained by XRD measurements (Fig. F20). Pyrite, glauconite, halite, and organic matter were also detected in XRD patterns, but their abundances were not determined. Quartz and feldspar content remains fairly constant throughout Subunit IIIB, with values of $22-28 \mathrm{wt} \%$ and $11-18 \mathrm{wt} \%$, respectively (average values $=25 \mathrm{wt} \%$ and $14 \mathrm{wt} \%$, respectively). Calcite shows modest variations (11-20 wt\%) that may be related to variable calcite contamination by drilling mud. However, similar values have been detected at Site C0002 in Unit III. Total clay minerals are $41-50 \mathrm{wt} \%$ and show an inverse correlation to calcite abundance.

Major and minor element contents $\left(\mathrm{SiO}_{2}, \mathrm{Al}_{2} \mathrm{O}_{3}\right.$, $\mathrm{TiO}_{2}, \mathrm{Na}_{2} \mathrm{O}, \mathrm{MgO}, \mathrm{CaO}, \mathrm{K}_{2} \mathrm{O}, \mathrm{Fe}_{2} \mathrm{O}_{3}, \mathrm{MnO}$, and $\mathrm{P}_{2} \mathrm{O}_{5}$ ) were analyzed by XRF and complemented by loss on ignition (LOI) measurements. In many samples, chemical composition was relatively low, and LOI was particularly high; thus, XRF values were recalculated without the LOI component (LOI-free) to remove any bias linked to high abundance of organic matter and water content (Fig. F21). The cuttings may have been contaminated by calcite precipitation because of a high $\mathrm{pH}(\mathrm{pH}=\sim 10)$ in the drilling mud, as suggested by higher calcite values. However, as $\mathrm{pH}$ stayed mostly constantly high throughout drilling, $\mathrm{pH}$ does not appear to explain the fluctuations in calcite content (see "Geochemistry"). LOI- free $\mathrm{CaO}$ content downsection is poorly correlated to log data (Figs. F19, F20, F21), divergence of XRD and XRF values between core and cuttings samples in the cored interval (see discussion in "Lithologic Unit IV"), and comparison with potentially equivalent units at Site C0002 (Expedition 315 Scientists, 2009). The LOI content in Subunit IIIB is high (up to 24 $\mathrm{wt} \%$ ) and correlates with increased wood/lignite abundance and gas content in the drilling mud (see "Geochemistry"). $\mathrm{Fe}_{2} \mathrm{O}_{3}$ and $\mathrm{MnO}$ contents display a trend similar to LOI content, which may be related to increased abundance of glauconite and some heavy mineral grains. Both XRD and XRF (LOI-free) analyses indicate relatively constant quartz/SiO content in Subunit IIIB.

Compositional variation is also observed in log data between $\sim 1168$ and $1297.7 \mathrm{~m} \mathrm{MSF}$ (e.g., gamma ray, SP, and PEF) (Figs. F19, F20).

\section{Lithologic Unit IV}

Interval: cuttings Samples 319-C0009A-127-SMW through 215-SMW

Depth: $1285 \mathrm{~m}$ WMSF to TD (cuttings from 1287.7 to $1603.7 \mathrm{~m} \mathrm{MSF}$ )

Age: late Miocene ( $\sim 5.6$ to $\sim 7.9 \mathrm{Ma})$

Lithology: silty mudstone with minor silt interbeds and rare interbeds of fine vitric tuff

Unit IV is composed dominantly of silty claystone, with common silt interbeds, few poorly consolidated sand layers, and rare interbeds of fine vitric tuff. It is distinguished from Unit III by

- Finer-grained sediments with markedly higher consolidation,

- Decrease in wood content,

- Decrease in glauconite content, and

- Changes in logging data sets including higher $P$ wave velocity and lower SP values, as shown in Figures F14, F15, F16, F17, F18, and F19.

In addition, there are structural features preserved in the cuttings of Unit IV that are not observed in Unit III (see "Structural geology"). At the Unit III/IV boundary, we also observed changes in the composition of cuttings measured by XRD and XRF; an increase in $P$-wave velocity; and a decrease in bulk density, resistivity, and SP values from wireline logs (Figs. F19, F20, F21). The Unit III/IV boundary is marked by an $\sim 1.8 \mathrm{Ma}$ hiatus (3.8-5.6 Ma).

\section{Observations from cores}

In Unit IV, nine cores were recovered from 1509.7 to $1593.9 \mathrm{~m}$ CSF. Lithologies include brown-gray silty claystone, minor interbeds of brown-gray siltstonesandstone, and minor interbeds of light gray fine vit- 
ric tuff. Different combinations of these lithologies in the cores define four lithofacies (Fig. F22) that are representative of Unit IV based on comparison with cuttings and log data. Lithification of the sediments decreases with increasing grain size (i.e., sandstones are less consolidated than silty claystones).

The clayey and silty sediments of Unit IV are generally moderately to highly bioturbated (Fig. F23). Ichnospecies include widespread Chondrites and rare Zoophycos, indicating deepwater environments. Siltstone-sandstone beds are grain supported and show common normal grading and rare inverse grading. Parallel laminae and basal erosional contacts are common in sandy siltstone beds (Figs. F16, F23). Average thicknesses of siltstone-sandstone beds are $\sim 5$ $\mathrm{cm}$ in Cores 319-C0009A-3R through 8R and $\sim 20 \mathrm{~cm}$ in Core 319-C0009A-9R, correlating with a slight grain size change downhole (i.e., finer grained sediments in Cores 319-C0009A-3R through 8R relative to Core 319-C0009A-9R). Cross-laminae are common in the coarsest sediments (i.e., silty sandstonesandstone) and are mostly encountered in Core 319C0009A-9R (Fig. F23). Interbeds of fine vitric ash are typically $<2 \mathrm{~cm}$ thick and contain $\sim 100 \%$ subangular-to-angular volcanic glass fragments with minor amounts of planktonic fauna (e.g., radiolarians). Increases in tuff content occur between $\sim 1579.5$ and $\sim 1582.0 \mathrm{~m}$ CSF (Core 319-C0009A-8R) and possibly between $\sim 1509.7$ and $\sim 1520.0 \mathrm{~m}$ CSF (Core 319C0009A-1R). Some of the tuff beds display spectacular convolute bedding (Fig. F23). In comparison to Unit IV of Site C0002, which shows highly fractured mudstone, the rocks from Site C0009 are only moderately fractured. Bioturbation and mineralogy on the other hand, are similar between the two sites.

Microscopic observations and XRD and XRF analyses provide constraints on the composition of cored sediments (Figs. F20, F21) (see below). Silty claystones are predominantly composed of a clay-sized, mostly carbonate-bearing argillaceous matrix incorporating minor amounts of quartz, feldspar, volcanic glass, planktonic fossils, coal, and accessory minerals (e.g., iron hydroxides, iron sulfides, and zircon). Some silty claystones also include a significant component of volcanic ash and can be described as tuffite. Siltstones-sandstones have a matrix composition similar to the silty claystones, with higher contents of quartz and feldspar. XRD values show in general typical differences in sand, silt, and clay-rich sections; however, the values are in general lower than in cuttings. XRD values from Site C0002 show an abrupt compositional shift in calcium between Unit III and Unit IV toward very low values. These low values in calcite content could not be observed in the core samples at Site C0009.

\section{Observations from cuttings}

Cuttings from Unit IV comprise fine sandy-to-silty grains and abundant lithified silty claystone fragments (up to $\sim 2 \mathrm{~cm}$ in size) (Figs. F14, F15, F16). Increased lithification occurs between 1322.7 and 1372.7 m MSF (Samples 319-C0009A-135-SMW through 144-SMW). The typical distribution in terms of grain size from representative Samples 319C0009A-123-SMW and 129-SMW is $29 \%-38 \%$ sand, $38 \%-52 \%$ silt, and $20 \%$ clay fraction. Grains of the silty/sandy fraction are angular to subrounded and moderately well sorted (Figs. F14, F15, F16). Cuttings indicate no major lithologic variation within Unit IV. Quartz is dominant, followed by feldspar, partly reworked volcanic glass fragments, heavy minerals (similar in composition to Units II and III), glauconite, and coal. Wood/lignite fragments are rare, whereas partly reworked planktonic fossils and shell fragments are common. The occurrence of wood/lignite fragments in samples from the upper part of Unit IV points toward mixing with cavings from units above or material plucked from the formation by drilling mud as it traveled up the annulus above the bit (Figs. F14, F15, F16, F17). Hence, other grains such as lithoclasts observed in Unit IV samples may also be the result of contamination from units above. We note that comparisons of cuttings and core samples in this unit is difficult, as washing cuttings with fresh deionized water (see "Introduction" and "Lithology" in the "Methods" chapter) may have affected the chemical composition of the cuttings.

\section{Mineralogical and geochemical analyses (XRD and XRF)}

Mineral abundances and bulk compositions determined by XRD and XRF in core samples show distinct variations between different lithologies (Figs. F20, F21). For example, quartz content is low in tuff layers (14 wt\%), higher in silty claystones (18-36 $\mathrm{wt} \%)$, and highest in sandstones and siltstones (23-54 wt\%). XRD and XRF analyses from cuttings are more homogeneous than from core samples probably because of preferential preservation of finegrained (better-consolidated) sediments in the drilling mud with respect to coarse-grained (less-consolidated) sediments. This interpretation is further supported by similarities between samples of silty sandstone in cores and cuttings samples in terms of quartz, feldspar, and clay minerals abundances, as well as $\mathrm{SiO}_{2}, \mathrm{Al}_{2} \mathrm{O}_{3}, \mathrm{TiO}_{2}, \mathrm{MgO}, \mathrm{K}_{2} \mathrm{O}, \mathrm{Fe}_{2} \mathrm{O}_{3}, \mathrm{MnO}$, and $\mathrm{P}_{2} \mathrm{O}_{5}$ (LOI-free) contents (Figs. F20, F21). Calcite contamination of cuttings samples by drilling mud is supported by 
- Higher calcite and $\mathrm{CaO}$ (LOI-free) contents in silty sandstones from cuttings samples than those from cores;

- An abrupt increase in calcite and $\mathrm{CaO}$ content in cuttings ( 4 and $\sim 3 \mathrm{wt} \%$, respectively) at 1507.7-1512.7 m MSF (Sample 319-C0009-176SMW), which correlates to a change of drilling mode (i.e., noncoring to coring); and

- Similar trends of $\mathrm{CaO}$ (LOI-free) and LOI contents in cuttings samples, which are dissimilar to log data trends (Figs. F19, F20, F21).

Clay mineral abundance determined by XRD of cuttings is higher in Unit IV than in Unit III, and quartz and feldspar abundances are reduced relative to Unit III. These values remain relatively constant throughout Unit IV. Other measures of bulk composition (XRD and XRF) of Unit IV and Subunit IIIB are also distinct (Figs. F20, F21).

\section{Observations from log data}

Unit IV is characterized by a sharp increase in $P$-wave velocity; increased variability in caliper; and sharp decreases in SP, resistivity, and bulk density relative to Unit III (Fig. F19). Other logging data exhibit more gradual changes across the Unit III/IV boundary. Density decreases from 2.1 to $1.9 \mathrm{~kg} / \mathrm{cm}^{3}$ and PEF increases from 2.8 to $>3.2 \mathrm{~b} / \mathrm{e}^{-}$at the boundary. Gamma ray values also increase slightly from 75 to $>80$ gAPI. Increased gamma ray values through this zone are consistent with the higher clay content. The increased $P$-wave velocity may also be related to decreased gas content below the Unit III/IV boundary.

\section{Preliminary analyses of clay mineralogy}

Five samples were selected from washed rock cuttings for more detailed preliminary investigation of the clay minerals illite, illite-smectite, and smectite (792.7, 902.7, 1087.7, 1267.7, and 1297.7 m MSF; Fig. F24). We separated two grain-size fractions: $<2$ $\mu \mathrm{m}$ and 2-64 $\mu \mathrm{m}$. The samples contain abundant smectite, illite, and chlorite \pm kaolinite. High d-spacings ( 16-18 $\AA$ ) were detected in all (air-dried) samples, which may be due to rehydration of smectite in drilling mud and surface exposure effects. Higher dspacing ( 17.6-18 $\AA$ ) in the clay-size fraction than those in the coarser fraction $(\sim 16.7 \AA)$ may reflect different interlayer cations in expandable clay minerals and/or different abundances of detrital and authigenic minerals. The smectite (001) peak area and peak intensity increase with depth, reflecting an increase in smectite abundance relative to other clay minerals. Illite (001) peaks slightly broaden at $\sim 10 \AA$ (full widths half maximum $0.2-0.3$ ), possibly indi- cating reduced crystallinity with increasing depth. The different intensity of the different grain sizes is probably a crystal size effect. These changes indicate that detrital clay minerals have not yet undergone diagenetic transformation, although authigenic reactions are possible (e.g., smectite replacing dispersed volcanic glass). A more detailed investigation of the relative amount and types of illite and smectite minerals is necessary to determine the actual changes with depth.

\section{Interpretation of drilled sequences}

Overall, the stratigraphic succession is interpreted as a series of mudstones, with varying sand and silt turbidite abundance filling the forearc basin and potentially prism slope basins and/or the trench. We interpret Unit I as a turbidite-rich unit deposited in the Kumano Basin that is significantly sandier than units drilled at Site $\mathrm{C0002}$ (Expedition 315 Scientists, 2009) (Fig. F13). Unit II is also interpreted as a basinfill unit deposited in the Kumano forearc basin. It is characterized by turbidites that are coarser than those in underlying Units III and IV and the units drilled at Site C0002 but markedly thinner and finer grained than those in Unit I above. Composition of detrital grains points toward sediment supply from erosion of exposed sedimentary and metasedimentary rock units within the Outer Zone of Japan, including the Shimanto Belt (e.g., Taira et al., 1988; Isozaki and Itaya, 1990).

Unit III includes two subunits containing thinly bedded fine-grained turbidites (Subunits IIIA and IIIB) that were deposited above the carbonate compensation depth (CCD) and interpreted as basal Kumano forearc basin deposits. The lower subunit (IIIB) apparently had an increased supply of terrigenous organic matter (i.e., wood fragments), possibly because of a change in climate and/or topographic relief. As for Units I and II above, the detrital sediment composition of Unit III at Site C0009 indicates that the sediments were partly sourced from exposed sediments and metasediments of the Outer Zone of Japan. We interpret the fine-grained $(\sim 3.8-3.3 \mathrm{Ma})$ sediments at Subunit IIIB at Site C0009 (1168-1285 m MSF interval) as a lateral equivalent of $(\sim 3.8-3.3 \mathrm{Ma})$ Unit III at Site C0002 with a similar increase of glauconite and the occurrence of pyritized fossils. However, occurrence of wood/lignite fragments and the increased gas content (see "Geochemistry") is very different.

Unit IV is a mudstone also containing thin-bedded fine-grained turbidites and was deposited above the CCD. It resembles Unit IV at Site C0002 (Expedition 315 Scientists, 2009) in terms of sedimentary facies. However, sedimentary, geochemical, or structural ev- 
idence is lacking to clearly suggest that this unit was accreted in a trench setting. Thus, Unit IV could be interpreted as a weakly deformed package of accreted trench sediments, trench-slope deposits, or sediments deposited in the distal reaches of the early Kumano Basin. The long hiatus between deposition of Units IV and III at Site C0009 (from 5.6 to $3.8 \mathrm{Ma}$ ) is similar to the hiatus between Units III and IV at Site C0002 (from $\sim 5.1$ to $3.7 \mathrm{Ma}$ ) (Expedition 315 Scientists, 2009), suggesting a tectonic event of regional significance in this interval.

\section{Structural geology}

The structural geology of Hole C0009A included the study of cuttings from 1097.7 to $1512.7 \mathrm{~m} \mathrm{MSF}$ (Samples 319-C0009A-87-SMW through 173-SMW) and cores from 1510.5 to $1593.9 \mathrm{~m}$ CSF (Cores 319C0009A-1R through 9R). Analysis of FMI resistivity image data from 710 to $1580 \mathrm{~m}$ WMSF was also performed.

\section{Types and distribution of structures in cuttings, 1097.7-1512.7 m MSF}

Cuttings were studied with a binocular microscope. Approximately 20 grains were selected from the $>4$ $\mathrm{mm}$ size fraction at each $5 \mathrm{~m}$ depth interval; smaller grains were not large enough to systematically recognize structures. Structures recognized include slickensides, vein structures, and web structures. Slickensides are grooved, polished, and striated (or slickenlined) surfaces (Fig. F25). Vein structures are subparallel dark bands visible on the surfaces of the cuttings. There are no apparent offsets across vein structures at the millimeter scale, and in places they have anastamosing geometries and splays (Fig. F26A-F26E). Web structures are similar to vein structures in their appearance but form a wider array of crosscutting geometries and some accommodate small $(<1 \mathrm{~cm})$ displacement (e.g., Fig. F26F).

Thin sections of representative vein structures illustrate their microstructural characteristics (Fig. F27). The well-defined vein structures do not contain obviously fractured grains and did not fracture grains in the surrounding matrix. Cross-polarized views do not show a particular crystallographic difference between vein structures and the surrounding rock (Fig. F27A), but some do appear to be finer grained than the surrounding rock. Displacements across vein structures are not apparent though, locally, shearstrain indicators are present, such as inclined granular foliation (Fig. F27B, F27C). Lenses of opaque minerals are locally preserved adjacent to vein structures (Fig. F27D).

\section{Discussion}

The fact that grains were not fractured by the vein structures suggests that the sediments were incohesive at the time of deformation (see "Microstructures"). This interpretation is also consistent with previous studies. For example, similar structures have been observed on the Boso-Miura Peninsula in forearc basin sedimentary rocks where they are usually oriented perpendicular to bedding. Vein structures were also found in slope apron and slope basin deposits of the Middle America Trench off Guatemala (Cowan, 1982) and Peru (Lindsley-Griffin et al., 1990). Brothers et al. (1996) and Ohsumi and Ogawa (2008) have shown that vein structures have a relationship between height and spacing and are interpreted as forming by oscillatory deformation such as shaking of incohesive sediments (e.g., resulting from an earthquake or a debris flow).

The most important structural observation in the cuttings is that the vein structures are more numerous in an $200 \mathrm{~m}$ depth interval between $\sim 1300$ and $\sim 1500 \mathrm{~m}$ MSF (Unit IV) than in any other interval. Slickensided surfaces and web structures, although less common than the vein structures, are also concentrated in this interval. Vein structures are rare in the cuttings above 1332.7 m MSF (cuttings Sample 319-C0009A-136-SMW) and below 1482.7 m MSF (cuttings Sample 319-C0009A-167-SMW) (Fig. F28; see C0009_T2.XLS in STRUCGEOL in "Supplementary material"). Web structures were only identified in cuttings from Samples 319-C0009A-162-SMW and 165-SMW (1452.7 and 1467.7 m MSF, respectively). Slickensides have variable appearances (Fig. F25) and in most cases coincide with vein structures. Although some of the slickensides may have formed during drilling, their restricted depth range and the correlation of this depth to other primary structures suggests that they are original structures and have tectonic significance.

The depth interval of abundant vein structures in Hole C0009A is below Unconformity UC2 and in lithologic Unit IV, which is below the comparable depth range of vein structures recognized at Site C0002 (Expedition 315 Scientists, 2009). Based on previous research on vein structures, structures at Site C0009 may have formed during seismic shaking of then partially consolidated materials (Ogawa, 1980; Brothers et al., 1996).

\section{Types and distribution of structures in cores, 1510-1593 m CSF}

We identified a number of structural features in the cores, including bedding and planar fabrics, shear zones, faults, slickenlined faults, and vein structures 
(see Fig. F29). These terms are only descriptive and do not imply a specific deformation mechanism.

\section{Bedding}

Bedding was measured systematically in the core. Bedding is best defined where sand or silt layers are in contact with adjacent finer layers or sedimentary structures are present. Bedding can also be recognized where trace fossils and zones of bioturbation are aligned parallel to bedding and are preserved in their undeformed state.

\section{Planar fabrics}

Planar fabrics are defined by discontinuous sand or silt layers, zones of bioturbation, or parting planes (folia) within muddy lithologies. Increasing fabric intensity toward shear zones and deformed trace fossils or sedimentary structures can be used to distinguish planar fabric from bedding.

\section{Shear zones}

Shear zones are planar bands that are dark relative to the surrounding rock and sediment (Fig. F29A). They range in width from $<1 \mathrm{~mm}$ to $\sim 1 \mathrm{~cm}$. They are composed of fine sediment particles and transmit light in thin sections, even though they are dark or even black in the cores. They locally show evidence of shear, crosscut primary sedimentary features, and are crosscut by other structures; many do not show evidence of shear displacement (Fig. F29A). Locally, shear zones occur at the center or top of thicker $(\sim 10$ $\mathrm{cm}$ ) deformed intervals. Elsewhere, shear zones cut across apparently undeformed sediment and rock. Where offset markers or sense-of-shear indicators are present, the sense is clear reverse (thrust) displacement. On the cut face of the core, many shear zones are apparently oriented parallel to subparallel to bedding. However, 3-D examination generally indicates that these shear zones are oblique to bedding. Commonly, shear zones form networks of thinner anastomosing zones.

\section{Faults}

Faults are thin $(<1 \mathrm{~mm})$, planar, or listric structures that are dark relative to surrounding rock. Faults are generally discrete surfaces, whereas shear zones are thicker zones of deformation. Faults typically show clear evidence of displacement at core scale, including offset markers (e.g., bedding, burrows, or small pumice fragments) and fault drag. Faults are distinguishable from shear zones because they are thin and commonly show displacements. Locally, faults cut shear zones, although in many places they "sole" into shear zones or are part of fault networks adjacent to shear zones (Fig. F29B, F29D).

\section{Slickenlined faults}

Slickenlined faults have slickenlines and rough or polished surfaces. Slickenlined faults cut all other structures, and in most instances have striated surfaces. Some slickenlined faults clearly displace primary sedimentary or preexisting structural features. There are generally few recognizable markers, and shear sense has to be interpreted from the slickenlines' texture (Fig. F29C). Slickenlines are widely associated with steps or, less commonly, spoon-shaped indentations on the faulted or sheared surface, producing an asymmetry that reflects the slip sense during deformation (e.g., Petit, 1987; Angelier, 1994). Steps were interpreted as extension cracks (or " $\mathrm{R}$ " shears activated as extension cracks) that connect en echelon " $\mathrm{P}$ " shears within the fault or shear zone. In some cases, the combined set of $P$ shears and extension cracks provides an indication of shear sense; in other cases, extension cracks or P shears alone were used as evidence for slip sense. Spoon-shaped indentations were interpreted as $\mathrm{R}$ shears within the fault or shear zone and indicated a sense-of-slip synthetic to the main fault or shear zone.

\section{Vein structures}

Vein structures are relatively rare. Vein structures in cores are dominantly of the sigmoidal thin mudfilled extensional crack or vein type (Ogawa, 1980; Cowan, 1982; Brothers et al., 1996). Although only six examples of vein structures were recognized in cores, numerous examples occur in cuttings from $\sim 1325$ to $1475 \mathrm{~m} \mathrm{MSF}$ (see above). Figure F30 shows that they are filled with clay-sized particles.

\section{Microstructures}

Thin sections from parts of the core were made to investigate three structures: vein structures, shear zones, and faults. Figure F30 shows that vein structures are filled with clay particles and microcrystalline residue or precipitate. Shear zones occur both parallel to and crosscutting sedimentary layering (Fig. F31). Locally, shear zones show demonstrable sense of shear. Shear zones are typically darker and finer grained than the adjacent bedding. A shear zone associated with bedding is shown in Figure F32. The shear zone has several finer grained discrete shear zones separated by more coarse grained regions (Fig. F32A, F32B). The orientation of possible Riedel shears (Fig. F32A, F32C) suggests a sinistral slip sense. Stratigraphic up is the top of the photograph, so overlying units verge in the updip direction. 
Faults are observed in thin sections as bedding truncations (Fig. F31D, F31E).

\section{Mineralogy of shear zones}

We used XRD analysis to document the mineralogy of a bedding-parallel shear zone and compare it to the sediments above and below. The results are shown in Figure F33 for material above the shear zone (Fig. F33A), within the shear zone (Fig. F33B), and below it (Fig. F33C). The bulk mineralogy of the three zones is nearly identical, showing basically quartz, feldspar, and minor illite, suggesting that the material within the shear zone formed from the same sediment surrounding it, with no mineralogical differentiation.

\section{Structural orientations}

Structures in cores show distinct statistical groupings in orientation. Bedding has modal dips of $30^{\circ}-50^{\circ}$. Shear zones have modal dips of $30^{\circ}-40^{\circ}$, reflecting that a number of the shear zones are parallel to bedding planes. Faults have two dip modes of $10^{\circ}-30^{\circ}$ and $50^{\circ}-70^{\circ}$, possibly reflecting both thrust and normal faults. But because most faults do not have a clear sense of offset, the relationship of steepness of dips to slip sense is unclear. Slickenlined faults have modal dips of $20^{\circ}-40^{\circ}$ and $50^{\circ}-60^{\circ}$, with the latter, steeper inclination more common. Further analysis of the kinematics and geographic orientations of the structures could further elucidate if they belong to separate geometric populations (Fig. F34).

The magnitude of bedding dips based on observations from the cores and FMI image data (see "FMI borehole image interpretation") show a change with depth from a range of $\sim 10^{\circ}-35^{\circ}$ at $1510-1520 \mathrm{~m}$ CSF to $\sim 40^{\circ}-70^{\circ}$ at $1570-1580 \mathrm{~m} \mathrm{CSF}$ (Fig. F35).

\section{Crosscutting relationships and kinematics}

We interpret the relative age of structures as follows: the early shear zones are dominantly thrusts, intermediate generations of faults are mixed normal and thrust faults (potentially accommodating a spatially and temporally complex strain history), and the youngest faults accommodate dominantly oblique slip. Crosscutting relationships in support of this interpretation include the following:

- Slickenlined faults crosscut all other structures, and are therefore youngest;

- Faults are intermediate in age, in places crosscutting shear zones, but in other places soling into them or forming adjacent networks; and

- Shear zones appear to have formed when the sediments were relatively incohesive as they are locally associated with folds and fabrics that coin- cide with thinning and thickening of silt-sand horizons.

In detail, structures show diverse kinematic relationships. The shear zones are mostly thrusts (Fig. F31E), more rarely normal faults (Fig. F31D), or exhibit ambiguous kinematics associated with distributed strain at low angles to bedding (e.g., oblique strain fabrics when viewed in the strike plane). Faults exhibit either normal or reverse shear sense; however, markers clearly offset by strike-slip displacements are difficult to recognize in cores. Normal faults can be cut by thrust faults, which subsequently can be cut by normal faults. The normal faults, where documented, are minor in frequency and in displacement, and they appear to be the result of minor deformation that was concurrent with thrusting.

Markers offset by slickenlined faults and associated slickenlines are consistent with oblique or strike-slip deformation, though normal and reverse faults also occur. A number of these faults could be drilling induced.

\section{Anisotropy of magnetic susceptibility}

The measurement technique and theory of magnetic susceptibility (MS) is introduced in "Physical properties" in the "Methods" chapter and MS results are presented in "Physical properties." Anisotropy of magnetic susceptibility (AMS) terminology is described in "Structural geology" in the "Methods" chapter. Because AMS units are nondimensional and normalized to unit vectors, only the degree of anisotropy is included in AMS units (unlike MS, which is a scalar property). The AMS ellipsoid is a useful tool for quantifying deformation fabrics because it can approximate the finite strain ellipsoid (Borradaile, 1988).

Samples from cores exhibit degrees of anisotropy (in terms of the ratio of maximum to minimum principal axes of the AMS ellipsoid $(P)$ between 1.014 and 1.059 (Fig. F36A). These values are similar to those found in the Barbados accretionary prism (Housen et al., 1996). There is no obvious statistical pattern of distribution in anisotropy values (Fig. F36A), nor does the anisotropy change over the limited range of core sample depths.

The shapes of the AMS ellipsoids are given by the comparison of the ratio of the maximum to the intermediate principal axes of the AMS ellipsoid $(L)$ and the ratio of the intermediate to minimum principal axes $(F)$ (Fig. F36B). Similar to a Flinn diagram for finite strain, $L$ versus $F$ values that plot below a line with a slope of unity are oblate, whereas those that plot above the line are prolate. Nearly all data plot in the oblate field, though a few are near or 
above the $L=F$ line. In at least one case, we attribute the latter to analytical error (for a sample with an AMS $L$ value of $>1.04$ ) and in the other cases to essentially isotropic samples (with respect to the AMS ellipsoid).

Orientation of the principal axes of the AMS ellipsoid in geographic space is not known without paleomagnetic reorientation of the cores. From $\sim 1530$ to $\sim 1590 \mathrm{~m} \mathrm{CSF}$, the inclination of the minimum axis (also equal to the oblate ellipsoid inclination because the intermediate and maximum axes are similar) decreases from $\sim 80^{\circ}$ to $\sim 10^{\circ}$ (Fig. F36C), with a few outlier data points that may be due to analytical error. The change in the AMS ellipsoid orientation with depth is similar to the change in bedding orientation within the cored interval, consistent with the minimum axis of the AMS data being approximately perpendicular to bedding.

\section{Using caliper logs to document breakouts}

Failure and enlargement of a borehole on opposite walls forms a breakout that is commonly interpreted as a compressive failure. Breakouts provide specific information about stress orientation and, in some cases, stress magnitude (Zoback, 2007) and are commonly detected with borehole imaging tools, including resistivity tools (Zoback, 2007). Calipers can also measure borehole enlargement associated with breakouts. The four arms of the FMI tool act as a caliper (Fig. F7 in the "Methods" chapter) with pairs of opposing arms (Caliper 1 and Caliper 2).

The FMI caliper shows an in-gauge borehole $(\sim 12$ inch diameter) at depths shallower than $1285 \mathrm{~m}$ WMSF. Below this depth to the base of the borehole, the hole is significantly enlarged, with one caliper commonly indicating $\geq 16-18$ inches diameter and the other typically close to 12 inches diameter. The greater enlargement is recorded by Caliper 1 and 2 alternately because of tool rotation as the tool is drawn up the hole. These shifts in largest caliper measurement lead to division of the borehole into Interval A (1300-1455 m WMSF), Interval B (1465-1530 m WMSF), and Interval C (1545-1578 m WMSF) (Fig. F37). These intervals are not contiguous but represent the depths of orientation stability between the shorter sections where the caliper drifts.

Caliper 1 orientation is defined magnetically and recorded as Pad 1 azimuth (P1AZ) in logging data files (Fig. F37). Caliper 2 is located 90 from Caliper 1. Caliper 1 orientation above $1285 \mathrm{~m}$ WMSF rotated smoothly and spiraled clockwise (viewed downhole) as the tool was drawn uphole (Fig. F37). Below this depth, caliper orientation was stable over Intervals A, B, and C but jumped clockwise at discrete depths as the tool was pulled uphole. We believe two of the opposing arms of the caliper were confined to the bilaterally enlarged portion of the borehole within each of these intervals.

The orientation of the enlarged portion of the borehole is determined from the largest caliper value and from the orientation of Caliper 1 (Table T7). The orientation of the largest caliper (i.e., borehole enlargement) is remarkably stable even as the entire tool rotated in discrete clockwise increments. The mean value of that orientation, weighted for the depth of borehole sampled in each interval, defines an alignment $46^{\circ}-226^{\circ}$ (northeast-southwest). We interpret this orientation as a series of breakouts. Accordingly, this would represent the direction of minimum stress in the horizontal plane $\left(S_{\mathrm{hmin}}\right)$ with the maximum stress in the horizontal plane $\left(S_{\text {Hmax }}\right)$ at $136^{\circ}-316^{\circ}$ (southeast-northwest), $90^{\circ}$ to $S_{\text {hmin }}$. This direction of $S_{\text {Hmax }}$, plotted with the previous results of Expedition 314 (Fig. F38), is similar to $S_{\mathrm{H} \max }$ at sites drilled on the prism slope seaward of the Kumano Basin and is nearly perpendicular to $S_{\mathrm{Hmax}}$ at Site C0002 near the seaward edge of the Kumano Basin (Tobin et al., 2009a).

\section{Breakouts and drilling-induced tensile fractures from FMI images}

We also examined FMI data for breakouts and drilling-induced tensile fractures (DITFs), both of which can provide information on stress orientations. Breakout geometry is obvious from the deviations of caliper measurements (see "Using caliper logs to document breakouts"). A breakout should appear as an area of low resistivity, representing the enlargement formed by failure and spallation of the borehole wall. Although a lowered resistivity value may occur in a breakout interval, this low-resistivity signal is not typically bilateral at Site C0009. For example, in Figure F39, low resistivity values are recorded on all four pads in the breakout area, making picking the opposing areas of low resistivity problematic. The inability to recognize breakouts in FMI data may result from the extension of the four tool arms into the local borehole diameter. If all of the arms remain in contact with the borehole wall, any lowered resistivity signal of the elongated borehole axis will be minimized. The $\sim 50 \%$ coverage of the borehole by the FMI also may have limited our ability to clearly identify breakouts. Overall, investigation of the breakout interval below $1285 \mathrm{~m}$ WMSF showed inconsistent definition of breakouts using resistivity image data.

We studied FMI data for evidence of fractures, specifically DITFs (Fig. F39). DITFs should be vertical and 
normal to the borehole wall and occur in matched pairs on opposite sides of the borehole. We did observe some fractures from $~ 800$ to $1000 \mathrm{~m}$ WMSF. Of these fractures, we only picked those that were vertical and apparently normal to the borehole. Only one example shows another paired fracture on the opposite side of the borehole. Because of the $\sim 50 \%$ coverage of the borehole by the FMI, the matching pairs may have been missed. The individual fractures appear to have a dominant orientation trending west-northwest-east-southeast (Fig. F40; see C0009_T4.XLS in STRUCGEOL in "Supplementary material"). This orientation deviates somewhat westerly from the orientation of $S_{\mathrm{Hmax}}$ from caliper data.

\section{FMI borehole image interpretation}

Bedding dips and faults were gathered from FMI data. Bedding dips $(N=189)$ were shallow to the north-northwest Fig. F41; see C0009_T5.XLS in STRUCGEOL in "Supplementary material"). Faults $(N=39)$ dip moderately to shallowly to the northwest, including one documented example of a normal fault (Fig. F42; see C0009_T6.XLS in STRUCGEOL in "Supplementary material"). The mean inclination of the faults is $\sim 45^{\circ}$ with a modal dip between $60^{\circ}$ and $70^{\circ}$. The faults are all resistive in character with the exception of one of undetermined nature. We examined the changes in bedding attitude of the different units. Unit I and upper Unit II were not sampled by FMI data. Subunit IIIA had mostly shallow bedding dips to the north-northwest-northeast (Fig. F43). The contact between Subunits IIIA and IIIB appears to be a $3 \mathrm{~m}$ thick deformed zone of three faults dipping $3^{\circ}-10^{\circ}$ to the northeast. In between these three faults, bedding dips steeply (up to $78^{\circ}$ ) (see Fig. F5 in the "Expedition 319 summary" chapter). This deformed zone is interpreted as a thrust fault system. Subunit IIIB has shallow bedding dips mostly to the northwest (Fig. F44). Unit IV has shallow to moderate dips consistently to $340^{\circ}-350^{\circ}$ (Fig. F45).

\section{Summary}

Most faults identified in FMI images dip to the northwest and strike northeast-southwest. $S_{\mathrm{Hmax}}$, however, is also oriented to the northwest. Thus, if the northwest-dipping faults are active, it precludes $S_{\mathrm{Hmax}}$ from being $\sigma_{2}$ because $\sigma_{2}$ should be parallel to the strike of the associated faults. In this case, $\sigma_{1}$ must be horizontal and oriented northwest-southeast, suggesting that the northwest-dipping faults are thrust faults and $\sigma_{3}$ is vertical.

\section{Biostratigraphy \\ Calcareous nannofossils}

The biostratigraphic framework of the sequence in Hole C0009A was established exclusively based on calcareous nannofossils in cuttings and cores from 715.7 to $1603.7 \mathrm{~m}$ MSF. Cuttings were collected at $5 \mathrm{~m}$ intervals for the entire riser drilled sequence (715.7-1603.7 m MSF), whereas only the lowermost section was cored from 1509.7 to $1593.9 \mathrm{~m} \mathrm{CSF}$. The uppermost part of the hole had been cemented prior to drilling the sampled sequence, stratigraphically isolating the upper $715.7 \mathrm{~m}$ interval and therefore preventing downhole contamination from within this interval. A total of 75 samples were examined at 5-30 m spacing, with closer spacing at important lithologic boundaries (see "Lithology") or where the presence of nannofossil datums and/or zonal boundaries was anticipated. Calcareous nannofossils are generally moderately preserved throughout the sequence, although there is a trend toward poorer preservation in the lower section, especially below 1292.7 m MSF (Sample 319-C0009A-127-SMW). Except for a few samples from the top sand-rich interval in lithologic Unit II (see "Lithology"), most samples yielded abundant nannofossils and the major age-diagnostic taxa appear reasonably continuous throughout their ranges. Therefore, most of the important Neogene and Quaternary datums summarized by Raffi et al. (2006) (see "Biostratigraphy" in the "Methods" chapter) were recognized and, consequently, the drilled sequence was zoned using Martini's (1971) nannofossil scheme (Tables T8, T9; Fig. F46). However, frequent downhole contamination prevented the use of some important nannofossil datums based on first (or first consistent) occurrence.

\section{Pleistocene}

The first cuttings Sample 319-C0009A-2-SMW (712.7 $\mathrm{m}$ MSF) is composed of cement with muddy water and yielded a few nannofossils including the agediagnostic large- and medium-sized Gephyrocapsa specimens (Table T8). The presence of this genus and cooccurrence of Pseudoemiliania lacunosa indicate that this sample lies between the last occurrence (LO) of $P$. lacunosa (0.436 Ma) and the first occurrence (FO) of Gephyrocapsa. The latter datum is considered most probably equivalent to the reentrance (RE) of medium Gephyrocapsa ( $\geq 4 \mu \mathrm{m})(1.04 \mathrm{Ma}$; see "Biostratigraphy" in the "Methods" chapter), considering its stratigraphic position relative to the underlying, more reliable datum. The first reliable datum is the last consistent occurrence (LCO) of Reticulofenestra asanoi $(0.90 \mathrm{Ma})$, which was observed between 777.7 
and 787.7 m MSF (between Samples 319-C0009A-19SMW and 21-SMW) (Tables T8, T9; Fig. F46).

We observed the LCO of large Gephyrocapsa ( $>5.5$ $\mu \mathrm{m})(1.24 \mathrm{Ma}$ ) between 842.7 and $852.7 \mathrm{~m}$ MSF (between Samples 319-C0009A-33-SMW and 35-SMW). The LO of Helicosphaera sellii $(1.34 \mathrm{Ma})$ is recorded between 897.7 and 902.7 m MSF (between Samples 319-C0009A-44-SMW and 45-SMW). Directly below the latter sample, the LO of Calcidiscus macintyrei (1.60 Ma) was observed between 902.7 and $912.7 \mathrm{~m}$ MSF (between Samples 319-C0009A-45-SMW and 47-SMW). The single fragmented specimen of $\mathrm{C}$. Macintyrei in Sample 319-C0009A-45-SMW is considered reworked. The close stratigraphic positioning of the LOs of $H$. sellii and C. macintyrei could be attributed to the reworking of $C$. macintyrei into younger sediments, a common phenomenon in a tectonically active region, or the possible existence of a hiatus or a condensed interval. Further study is needed to help address this problem.

Other important Pleistocene datums based on first occurrence are not applicable, considering the stratigraphic context of more reliable LOs in cuttings, likely because of caving and mixing during mud circulation (Table T8). Examples include the first consistent occurrences (FCOs) of large Gephyrocapsa $(>5.5 \mu \mathrm{m})$ and R. asanoi, RE of medium Gephyrocapsa $(\geq 4 \mu \mathrm{m})$, and FOs of Gephyrocapsa size groups (see "Biostratigraphy" in the "Methods" chapter). Therefore, the Pliocene/Pleistocene boundary, defined by the FO of medium Gephyrocapsa $(>3.5 \mu \mathrm{m})$ $(1.67 \mathrm{Ma})$, is not identified in the hole.

\section{Pliocene}

As an alternative datum to the normally used FO of medium Gephyrocapsa, the Pliocene/Pleistocene boundary is approximated by the LO of Discoaster brouweri (2.06 Ma), which defines the base of Zone NN19 and is recorded between 927.7 and $932.7 \mathrm{~m}$ MSF (between Samples 319-C0009A-51-SMW and 52-SMW) with an increase in the number of discoasters (Tables T8, T9). The base of Zone NN18 is placed between 952.7 and $957.7 \mathrm{~m}$ MSF (between Samples 319-C0009A-56-SMW and 57-SMW), which is defined by the LO of Discoaster pentaradiatus (2.393 $\mathrm{Ma})$. The rare occurrence of this species in the overlying Samples 319-C0009A-51-SMW and 47-SMW is considered as a result of reworking (Table T8).

The Zone NN17/NN16 boundary, defined by the LO of Discoaster surculus (2.52 Ma), is observed between 977.7 and $987.7 \mathrm{~m}$ MSF (between Samples 319C0009A-61-SMW and 63-SMW). Slow sedimentation rates are indicated for the upper part of the Pliocene based on the closely spaced four datums (1.6-2.52 Ma) below 842.7 m MSF (Figs. F46, F47).
In Zone NN16, the LOs of Discoaster tamalis (2.87 Ma) and Sphenolithus spp. (3.65 Ma) are also recognized, and both taxa were continuously observed below 1062.7 and 1242.7 m MSF (Samples 319C0009A-79-SMW and 117-SMW), respectively (Table T9). The LO of Reticulofenestra pseudoumbilicus ( $>7$ $\mu \mathrm{m})(3.79 \mathrm{Ma})$ recorded between 1272.7 and 1282.7 m MSF (between Samples 319-C0009A-123-SMW and 125-SMW) corresponds to the base of Zone NN16.

\section{Miocene}

Directly below the Zone NN16/NN15 boundary, Discoaster quinqueramus (an important index species in the upper Miocene) was identified at $1292.7 \mathrm{~m} \mathrm{MSF}$ (Sample 319-C0009A-127-SMW) and consistently occurs downhole to TD (Table T8). The LO of D. quinqueramus $(5.59 \mathrm{Ma})$ is placed between 1282.7 and 1292.7 m MSF (between Samples 319-C0009A-125SMW and 127-SMW). Sample 319-C0009A-127-SMW is assigned to the upper part of Zone NN11 because of the abundant occurrence of $R$. pseudoumbilicus ( $>7$ $\mu \mathrm{m})$ and the presence of Amaurolithus specimens. Therefore, most of Zone NN15, Zones NN14-NN12, and very possibly part of Zone NN11 are missing, indicating the presence of a major unconformity (Figs. F46, F47). The missing interval is $\sim 1.8 \mathrm{~m}$.y. but needs to be refined in further study.

The presence of $D$. quinqueramus and the co-occurrence of Discoaster berggrenii down to the base of the hole indicate that the interval below Sample 319C0009A-127-SMW falls within Zone NN11. The paracme end (end of temporarily absent and/or present with scattered specimens; Raffi et al., 2006) of R. pseudoumbilicus (>7 $\mu \mathrm{m})(7.077 \mathrm{Ma})$ is tentatively placed between 1482.7 and $1492.7 \mathrm{~m}$ MSF (between Samples 319-C0009A-167-SMW and 169-SMW). Moreover, $D$. surculus continuously occurs below the upper part of the Pliocene down to the base of the drilled sequence, and thus its FCO $(7.88 \mathrm{Ma})$ must be below TD. The base of the hole is therefore $<7.88 \mathrm{Ma}$.

\section{Geochemistry}

\section{Gas geochemistry results}

Scientific online mud gas monitoring was performed during several phases of drilling at Site C0009: during drilling of a $12^{1 / 4}$ inch hole from 703 to $1510 \mathrm{~m}$ MSF (drilling Phase 2 operations, see C0009_T1.XLS in GEOCHEM in "Supplementary material"), core drilling of a $105 \%$ inch hole from 1510 to $1594 \mathrm{~m}$ MSF (drilling Phase 3), and enlargement of the hole to 17 inches from 703 to 1569 m MSF (drilling Phase 8, see C0009_T2.XLS in GEOCHEM in "Supplemen- 
tary material"). Core drilling (Phase 3) was conducted with low ROP in combination with the same mud pumping rate used during Phase 2, which resulted in low gas concentrations in the drilling mud. Low mud gas concentrations are a common feature during core drilling. Because of similar compositions and distributions of gas with depth, the discussion of results from both the initial drilling (Phase 2) and hole opening (Phase 8) phases are integrated here.

\section{Gas composition}

The principal formation gases extracted from the returning drilling mud were hydrocarbons, mainly methane $\left(\mathrm{CH}_{4}\right)$. As much as $14 \mathrm{vol} \% \mathrm{CH}_{4}$ was detected during Phase 2 and as much as 3 vol\% was detected during Phase 8 . During Phase 2, the gas chromatograph (GC) was not in operation; however, diagnostic ion currents measured by the mass spectrometer did not indicate the presence of higher hydrocarbons $\left(\mathrm{C}_{2+}\right)$. During Phase 8 , the GC detected traces of ethane $\left(\mathrm{C}_{2} \mathrm{H}_{6}\right.$; up to 16 parts per million by volume [ppmv] ) and propane $\left(\mathrm{C}_{3} \mathrm{H}_{8}\right.$; up to $\left.3 \mathrm{ppmv}\right)$. The $\mathrm{CH}_{4} / \mathrm{C}_{2} \mathrm{H}_{6}$ ratio was consistently $>500$ and generally $\sim 1000$.

Because of the constant high $\mathrm{pH}$ of the drilling mud $(>10), \mathrm{CO}_{2}$ concentration was always low (i.e., significantly lower than air concentrations [ $370 \mathrm{ppmv}])$. Any $\mathrm{CO}_{2}$ entering the hole would have immediately reacted with drilling mud to form hydrogen carbonate according to the following reaction:

$$
\mathrm{CO}_{2}+\mathrm{H}_{2} \mathrm{O} \leftrightarrow \mathrm{H}_{3} \mathrm{O}^{+}+\mathrm{HCO}_{3}^{-}(\mathrm{pka}=6.5) .
$$

The consistently low $\mathrm{H}_{2}$ content $(<100$ ppmv) positively correlates with the occurrence of $\mathrm{CH}_{4}$. However, $\mathrm{H}_{2}$ could also be produced by $\mathrm{CH}_{4}$ fragmentation on the ion source of the mass spectrometer. The $\mathrm{CH}_{4} / \mathrm{H}_{2}$ ratio from postexpedition measurements on pure methane samples will confirm whether the $\mathrm{H}_{2}$ was produced artificially. Helium concentration never exceeded 6 ppmv and was always derived from air, as shown by constant $\mathrm{He} / \mathrm{Ar}$ ratios.

\section{Gas distribution with depth}

The depth distribution of gas from online measurements from 716 to $1454 \mathrm{~m}$ MSF during Phase 2 is discussed and compared with results from Phase 8 drilling from 716 to $1270 \mathrm{~m}$ MSF (Fig. F48). Mud gas measurements from below $1270 \mathrm{~m}$ MSF in Phase 8 were affected by very high methane background concentrations because the gas-loaded drilling mud was not circulated out after passing a gas-rich interval at $1270 \mathrm{~m} \mathrm{MSF}$; therefore, these data are not discussed here.
Down to $\sim 800 \mathrm{~m} \mathrm{MSF}$, methane concentration was relatively low during Phase 2. From 800 to $930 \mathrm{~m}$ MSF, methane concentration increased, reaching a local maximum at $\sim 880 \mathrm{~m} \mathrm{MSF}$, and decreased sharply below this depth. Methane concentration was also high between 930 and $1000 \mathrm{~m}$ MSF, peaking at $\sim 970 \mathrm{~m}$ MSF. The highest methane concentration in the entire well (maximum value $=14 \mathrm{vol} \%$ at $1130 \mathrm{~m}$ MSF) was observed between 1050 and 1220 m MSF. A sharp peak was observed between 1250 and $1280 \mathrm{~m}$ MSF, with maximum values of $\sim 12 \mathrm{vol} \%$ at $\sim 1270$ m MSF. Below 1280 m MSF, methane concentration decreased abruptly to $\sim 4-5$ vol\%.

During Phase 8 , better depth resolution was achieved by modifying the gas extraction setup (see "Geochemistry" in the "Methods" chapter) and in general lower gas concentrations were observed. Reduced gas concentration is due to higher mud weight that slowed gas liberation from cuttings into the drilling mud. The interval from $\sim 800$ to $930 \mathrm{~m}$ MSF, characterized by enhanced methane concentration during drilling Phase 2, did not exhibit high methane. This might be due to heterogeneous methane distribution at depth (i.e., locally enriched methane was liberated during Phase 2 only). Apart from this, both data sets exhibit similar downhole trends; however, most features in the gas profiles identified during Phase 2 are shifted $\sim 10-20$ m deeper in Phase 8. A possible explanation could be an error in conversion from lag time to lag depth during Phase 8 .

The distribution of methane correlates with the presence of organic fragments (wood and lignite) in drill cuttings (Fig. F48). This observation implies that wood and coal are the primary source of hydrocarbons in the mud gas. Two degradation processes of organic material can account for hydrocarbon genesis: thermal degradation of organic matter (thermogenic gas) and microbial degradation of organics (biogenic gas). The $\mathrm{CH}_{4} /\left(\mathrm{C}_{2} \mathrm{H}_{6}+\mathrm{C}_{3} \mathrm{H}_{8}\right)$ ratio provides an indication of hydrocarbon origin. Thermal degradation of organic matter generates hydrocarbons with a $\mathrm{CH}_{4} /\left(\mathrm{C}_{2} \mathrm{H}_{6}+\mathrm{C}_{3} \mathrm{H}_{8}\right)$ ratio $<50$, whereas microbial gas has a ratio $>100$. During Phase 8 , the $\mathrm{CH}_{4} /$ $\left(\mathrm{C}_{2} \mathrm{H}_{6}+\mathrm{C}_{3} \mathrm{H}_{8}\right)$ ratio was uniformly $>500$, and generally 1000 (Fig. F49). The molecular composition of hydrocarbons measured during hole opening clearly suggests a microbial source of natural gas, although this ratio might be somewhat biased by the different solubility of hydrocarbons in drilling mud (ethane and propane have higher solubility in water-based liquids than methane). Moreover, estimated in situ temperatures of $<50^{\circ} \mathrm{C}$ at the bottom of the hole are too low for significant hydrocarbon generation via thermal degradation of organics (see "Physical properties"). 
Postexpedition studies on the thermal maturity of organic matter in cuttings will illuminate whether or not thermal degradation can account for the hydrocarbon generation. Isotopic studies of methane $\left(\delta^{13} \mathrm{C}\right.$ and H/D) and, if possible, ethane, from drilling mud gas and cuttings gas samples will provide conclusive evidence to distinguish between a biogenic or thermogenic origin. At this stage, the correlation between wood and coal fragments and peak methane concentration is interpreted to result from in situ microbial decomposition of organic matter.

Under the assumption of an isotropic linear elastic media, measured $V_{\mathrm{p}} / V_{\mathrm{S}}$ ratio is related to Poisson's ratio. Figure F50 shows Poisson's ratio calculated from $V_{\mathrm{P}} / V_{\mathrm{S}}$ logs and the measured methane concentration during Phase 2 . The two data sets are clearly anticorrelated, implying that hydrocarbons are located in the pore space of the formation and these cause the lower Poisson's ratio. The $V_{\mathrm{p}}$ and $V_{\mathrm{S}}$ logs have a depth of investigation of a few meters. On the basis of the correlation between stratigraphic observations and mud gas data (Fig. F48), gas migration through permeable strata or fractures seems unlikely to play a significant role in the observed gas distribution. This interpretation is also consistent with the absence of gases migrating from greater depths (i.e., helium, heavy hydrocarbons) and with indications that hydrocarbons were produced from in situ microbial degradation of organic material.

\section{Organic geochemistry}

\section{Inorganic carbon, total carbon, and total nitrogen}

TOC, total nitrogen (TN), and $\mathrm{CaCO}_{3}$ were determined from inorganic carbon, total carbon, and $\mathrm{TN}$ measurements in 111 cuttings samples from 1038 to 1588 m MSF (see "Geochemistry" in the "Methods" chapter for analytical procedures) and in 34 core samples from 1509.8 to $1591.5 \mathrm{~m}$ CSF. TOC and TN concentrations and the TOC to TN (TOC/TN) ratio are shown in Tables T10 and T11 and plotted together in Figure F51.

The calcium carbonate content in cuttings samples calculated from the inorganic carbon content ranges from 7.56 to $16.31 \mathrm{wt} \%$, with an average of 13.28 $\mathrm{wt} \%$. $\mathrm{CaCO}_{3}$ concentration and its distribution with depth are in good agreement with calcite data from XRD measurements (see "Lithology"). The meaning of the $\mathrm{CaCO}_{3}$ data, however, is unclear, as they are apparently affected by interaction of the cuttings with the drilling mud. From 1038 to 1460 m MSF, the $\mathrm{CaCO}_{3}$ profile exhibits values scattered between 11 and $16 \mathrm{wt} \%$, with minimum values at 1103,1292 , 1333, and 1388 m MSF. Below 1460 m MSF, carbon- ate decreases from $\sim 16 \mathrm{wt} \%$ at $1460 \mathrm{~m}$ MSF to 7.6 $\mathrm{wt} \%$ at $1588 \mathrm{~m}$ MSF. In core samples, $\mathrm{CaCO}_{3}$ concentration is noticeably lower than for cuttings in the same depth interval, with a range between $\sim 1$ and 9 $\mathrm{wt} \%$, and shows considerable scatter.

TOC content of cuttings samples ranges from 0.93 to $8.7 \mathrm{wt} \%$, with an average of $2.51 \mathrm{wt} \%$. The relatively high TOC values, particularly in the interval between 1080 and $1240 \mathrm{~m} \mathrm{MSF}$, with maximum values $>8 \mathrm{wt} \%$ at 1088 and $1183 \mathrm{~m} \mathrm{MSF}$, probably derive from wood and coal, which are common in Subunit IIIB (see "Lithology") and also correlate with the occurrence of methane gas (see "Mud gas monitoring" in the "Methods" chapter). TOC content decreases to $\sim 1 \mathrm{wt} \%$ at $1250 \mathrm{~m} \mathrm{MSF}$. At $1510 \mathrm{~m} \mathrm{MSF}$, TOC increases sharply and remains at $\sim 2 \mathrm{wt} \%$ until the deepest sample (1592 m MSF). This increase, however, is probably artificial and may be caused by a different drilling mud used during core drilling. A similar feature is observed in $\mathrm{CaCO}_{3}$ data at this depth. TOC concentration in core samples between $\sim 1510$ and $1600 \mathrm{~m}$ MSF is significantly reduced relative to cuttings samples, with a range of 0.25 to 0.9 wt $\%$, and exhibits minimal scatter.

TOC and TN show a very similar distribution with depth, suggesting that both derive from the same source. TN content ranges from 0.051 to $0.128 \mathrm{wt} \%$, with an average of $0.077 \mathrm{wt} \%$. Core samples have similar but slightly higher average values relative to cuttings samples, but exhibit much greater scatter. The TOC/TN ratio ranges from 13.8 to 74.5 , with an average of 29.8. Core sample ratios are reduced relative to cuttings samples, driven by the lower TOC values, and range from $\sim 3$ to 18 . TOC/TN of marine organic matter typically ranges from $\sim 4$ to $\sim 10$, whereas terrestrial organic matter shows higher values. This distinction arises from the absence of cellulose in algae, its abundance in terrestrial plants, and the protein richness of algae (Meyers, 1997). Therefore, these results suggest that the source of organic matter in much of the borehole is terrestrial, which is in agreement with the wood and coal fragments observed in drill cuttings, particularly from Subunit IIIB. Deviations between core and cuttings samples in the 1510-1595 m MSF depth interval, specifically in $\mathrm{CaCO}_{3}$ and TOC concentrations, suggest that cuttings are subject to contamination by drilling mud; however, trends in the cuttings data may reflect changes in the formation.

\section{Interstitial water geochemistry}

A total of seven whole-round sections from Cores 319-C0009A-3R to 9R were collected for interstitial water analyses. The sediments from the cored interval were highly lithified; it therefore took a special 
effort to extract a minimum volume of pore water for analysis. No pore water could be obtained from Core 319-C0009A-3R, which was squeezed using the conventional IODP procedure. From Cores 319C0009A-4R to 9R (1537-1584 m CSF), pore water could be liberated only by squeezing for up to $54 \mathrm{~h}$ (see "Geochemistry" in the "Methods" chapter for the modified squeezing technique and Table T12 for squeezing times and composition of each sample). Water extraction from drilling mud for reference was unsuccessful, although several different filtering and extraction techniques (including centrifuging) were attempted. Coring during riser drilling and with continuous circulation of drilling mud during Expedition 319 was different than in most previous IODP coring operations; therefore, comparison between data sets from this and other expeditions should be treated with caution. The following interpretation is based on the assumption that any core material contaminated by drilling mud was removed prior to interstitial water extraction.

Squeezing was completed after obtaining $4 \mathrm{~cm}^{3}$ of pore water. The long extraction period may have caused degradation of species involved in microbial activities. $\mathrm{NH}_{4}{ }^{+}$and $\mathrm{PO}_{4}{ }^{3-}$ concentrations were below detection limits for all samples, and sulfate concentration was very low $(<0.4 \mathrm{mM})$. Assuming that no sulfate reduction took place during the sample treatment, the low sulfate concentration suggests that pore fluids were not diluted with seawater during sample recovery. The high chloride concentration (Fig. F52) probably indicates evaporation during the many hours of sample extraction. This conclusion is based on the large difference in these data (up to $1053 \mathrm{mM}$ chloride, almost twice the seawater value) and those collected during IODP Expeditions 315 and 316 (Ashi et al., 2008; Kimura et al., 2008). During Expeditions 315 and 316, the general trend is toward chloride concentrations lower than seawater with depth (with the exception of IODP Site C0004). Given the probable evaporation of water before and/ or during processing, we can only provide an estimate of the in situ chloride concentration $(500 \mathrm{mM})$. If we correct the other data for this assumed evaporation, then much of the data are consistent with the deepest data from Site C0002, where pore waters were recovered from as deep as $1043 \mathrm{~m}$ CSF (Expedition 315 Scientists, 2009).

The six pore water samples cover a depth range of 47 $\mathrm{m}$; formation pore waters from this narrow depth range should exhibit highly similar compositions (Figs. F52, F53, F54). Standard deviation of the six samples for the major ions in seawater is greatly reduced after taking into account the likelihood of evaporation during processing. With the evapora- tion correction (assuming $500 \mathrm{mM}$ chloride), $\mathrm{Na}^{+}$ and sulfate values are consistent with deep pore water from Site C0002; $\mathrm{Mg}^{2+}$ values are lower and $\mathrm{Ca}^{2+}$ values are higher, probably reflecting continued in situ alteration of ash at the base of the drilled section; and $\mathrm{Mn}, \mathrm{Fe}, \mathrm{V}, \mathrm{Zn}, \mathrm{Mo}$, and $\mathrm{U}$ values are generally similar. In contrast, these six pore water samples, corrected for evaporation, have much higher $\mathrm{K}^{+}, \mathrm{Li}^{+}$, $\mathrm{Sr}^{2+}, \mathrm{Ba}^{2+}, \mathrm{Rb}^{+}$, and $\mathrm{Cs}^{+}$than at Site $\mathrm{C} 0002$ and slightly higher $\mathrm{Br}^{-}$concentrations (Ashi et al., 2008). The higher $\mathrm{Br}^{-}$values are likely linked to the presence of wood and microbial processes that degrade organic matter. The alkali metals are reactive during clay diagenesis and are affected by the temperature of reaction, generally being removed from solution at low temperatures and added to solution at high temperatures. Given greater concentrations for all of these elements relative to results from Expeditions 315 and 316 , specifically $\mathrm{K}^{+}$, the deep samples from Site C0009 are generally consistent with warmer in situ temperatures. The high alkaline earth elements ( $\mathrm{Sr}$ and $\mathrm{Ba}$ ) are likely linked to carbonate remobilization ( $\mathrm{Sr}$ ) and low sulfate concentration (Ba). Overall, the deep samples from Site C0009 are consistent with warmer in situ temperatures or a more reactive sediment matrix than at Site C0002. Given a maximum temperature of $50^{\circ}-60^{\circ} \mathrm{C}$, these high alkaline and alkali values are likely diagenetic. Two elements, $\mathrm{B}$ and $\mathrm{Si}$, have lower concentrations than those from Expeditions 315 and 316 . The Si data are likely an artifact of sampling and precipitation of quartz during extraction. The solubility of quartz is $\sim 120 \mathrm{mM}$, the observed concentration of several of the samples, at $30^{\circ} \mathrm{C}$.

\section{Physical properties \\ Cuttings and cores}

\section{Whole-round multisensor core logger (cores)}

The results of whole-round multisensor core logger (MSCL-W) measurements on cores are summarized in Figure F55. MSCL-W GRA density, MSCL-W MS, and NGR all increase slightly with depth, with values ranging from 1.8 to $2.2 \mathrm{~g} / \mathrm{cm}^{3}, 7 \times 10^{-3}$ to $12 \times 10^{-3}$ SI, and 44 to 47 counts per second (cps), respectively (Fig. F55). The excursion from $\sim 1579$ to $\sim 1582 \mathrm{~m}$ CSF in all three data sets corresponds to ash-rich layers (see "Lithology"). The zone of decreased density from 1546 to 1556 m CSF in the MSCL-W GRA density data corresponds to measurements made on Core 319-C0009A-5R and is possibly a result of poor calibration. $P$-wave velocity exhibits significant scatter (values between 1200 and $1800 \mathrm{~m} / \mathrm{s}$ ) (Fig. F55D) and is lower than the velocity measured 
on discrete samples (see "Discrete $\boldsymbol{P}$-wave velocity [cores]"). The discrepancy may be related to the gap between the core and core liner, which is commonly filled with air and/or water. Only a few reliable MSCL-W resistivity measurements are available, and the values exhibit no trends (Fig. F55E).

\section{Porosity and density (cuttings and cores)}

As described in the "Methods" chapter, porosity is computed from the total water content in the sample and includes interstitial pore water as well as water bound in hydrous minerals, including opal and hydrous clays.

\section{Cuttings}

A total of 96 discrete samples from the 1-4 mm size fraction cuttings were analyzed for MAD. Measurements start at $1037 \mathrm{~m} \mathrm{MSF}$, where recovered cuttings were sufficiently lithified to differentiate them from the drilling mud and to extract usable chips (Fig. F56). Measured porosity in Subunit IIIB remains nearly constant with depth (average value of 56\%) above the Subunit IIIB/Unit IV boundary (1285 m WMSF). Within Unit IV, porosity decreases rapidly (from values $>50 \%$ to $45 \%$ ) from 1285 to $1450 \mathrm{~m}$ MSF, below which the trend reverses and porosity increases to values of $\sim 56 \%$ but exhibits significant scatter. Bulk density derived from MAD measurements increases downhole and mirrors the porosity trend (Fig. F56B). Above the Subunit IIIB/Unit IV boundary (from 1037 to 1285 m MSF) bulk density averages $1.7 \mathrm{~g} / \mathrm{cm}^{3}$, and it increases with depth to higher values below the Subunit IIIB/Unit IV boundary. Bulk density values below this boundary exhibit some scatter, with an average value of $1.85 \mathrm{~g} / \mathrm{cm}^{3}$. Average grain density within Unit III is $2.54 \mathrm{~g} / \mathrm{cm}^{3}$ and exhibits significant scatter (from 2.3 to $2.7 \mathrm{~g} /$ $\mathrm{cm}^{3}$ ) (Fig. F56C). Average grain density in Unit IV is $2.66 \mathrm{~g} / \mathrm{cm}^{3}$. Values remain relatively constant throughout Unit IV above $\sim 1500 \mathrm{~m} \mathrm{MSF}$, where they decrease to an average value of $2.6 \mathrm{~g} / \mathrm{cm}^{3}$ and exhibit a slight trend of decreasing grain density with depth to the base of the hole. The low grain densities in Unit III are correlated with increased TOC (Fig. F57). A preliminary calculation taking into account a dry sample containing $90 \%$ mineral grains with an assumed density of $2.65 \mathrm{~g} / \mathrm{cm}^{3}$ and $10 \%$ wood with a density of $0.9 \mathrm{~g} / \mathrm{cm}^{3}$ yields an average grain density of $2.48 \mathrm{~g} / \mathrm{cm}^{3}$. Thus, a wood abundance on the order of $5 \%-10 \%$ can potentially explain the anomalously low overall grain densities throughout much of Unit III.

The MAD cuttings data indicate a consistent consolidation trend above the Subunit IIIB/Unit IV boundary, with a sharp decrease in porosity below that depth. However, porosity values are anomalously high throughout the depth range of cuttings analyses when compared with porosities reported for Site C0002, $20 \mathrm{~km}$ to the southeast in the Kumano Basin (Ashi et al., 2008). Considering their depth of burial, these samples exhibit high porosity, low bulk density (and low grain density in Unit III), and relatively large variations in porosity. These could be the result of methodological or geological processes. There are at least four methodological effects that could lead to overestimates of porosity in the recovered cuttings:

- Incomplete removal of water prior to determination of wet mass, resulting in films of water from the soaking and washing process remaining on the 1-4 mm sized cuttings;

- Fracturing or mechanical volume change of the cuttings, possibly related to gas expansion or drilling disturbance;

- Interaction with drilling mud and with water during washing and soaking (Fig. F58), resulting in swelling of clay minerals; and

- Residue from drilling mud and additives remaining on the surface of cuttings even after washing.

Hole C0009A is the first IODP hole in which cuttings were recovered and processed for MAD. The techniques and data described here are preliminary and should be a helpful guide for future riser holes. In particular, a number of the potential issues noted here could be related to the size of the analyzed cuttings fraction. The small size makes the cuttings vulnerable to chemical interactions with the drilling mud. Even a small amount of swelling in these small pieces of material will cause large differences in observed porosity. The size also makes it difficult to remove all of the water and drilling mud, especially in cases where the cuttings were very soft.

Several geological processes could also affect porosity, including

- Sediment composition (mineralogy, grain size distribution, and degree and type of cementation) affecting sediment consolidation behavior, which could result in differences in porosity (and bulk density) trends, and

- Presence of overpressured fluid in sediments of the lower Kumano Basin because of high sedimentation rates and genesis of $\mathrm{CH}_{4}$ from microbially driven wood decomposition.

However, no evidence of underconsolidation or significant overpressure is observed in the logs or MDT measurements (Fig. F59; see "Downhole measurements"). 


\section{Cores}

Porosity measured on core samples ranges from $28 \%$ to $44 \%$, with an average value of $34 \%$ (Fig. F60). Porosity exhibits a slight trend to lower values downsection, but with some variability. Observed ash layers at $\sim 1510$ and $1580 \mathrm{~m}$ CSF exhibit low porosity. Bulk density in the cored interval ranges from 1.84 to $2.2 \mathrm{~g} / \mathrm{cm}^{3}$, with an average value of $2.1 \mathrm{~g} / \mathrm{cm}^{3}$. Although there is some scatter, a downward trend of increasing bulk density is observed. Grain density ranges from 2.3 to $3.0 \mathrm{~g} / \mathrm{cm}^{3}$, with most values $>2.6$ $\mathrm{g} / \mathrm{cm}^{3}$ and an average value of $2.7 \mathrm{~g} / \mathrm{cm}^{3}$. Other than a few anomalous values in the $2.3 \mathrm{~g} / \mathrm{cm}^{3}$ range, the values are constant with depth. It is also important to note that technical problems led to poor recovery in the upper part of the cored section, and it is difficult to determine if the samples collected are fully representative of the formation.

Core samples exhibit significantly lower porosities (30\%-35\%) than cuttings samples (40\%-55\%) (Fig. F61). Porosity values from core samples are consistent with those expected at this depth $(>1500 \mathrm{~m}$ CSF), whereas values from cuttings are significantly higher (e.g., porosity values at Expedition 315 Site C0002; Ashi et al., 2008). The overestimate of porosity from cuttings compared with core measurements is consistent with the anomalously high values observed in cuttings throughout the hole, as described above. Because cuttings appear to overestimate porosity and underestimate bulk density, we compared core and cuttings MAD data in detail in the cored interval (Fig. F62). The trend between the two data sets is approximately linear and indicates that cuttings porosity values may be useful in identifying trends in formation porosity but that the absolute values are subject to large errors.

\section{Discrete $\boldsymbol{P}$-wave velocity (cores)}

Over the cored interval, $P$-wave velocity $\left(V_{\mathrm{P}}\right)$ is nearly constant (Fig. F63A). The average $V_{\mathrm{P}}$ in the $x$ and $y$-directions is $\sim 2050 \mathrm{~m} / \mathrm{s} . V_{\mathrm{p}}$ in the $z$-direction is consistently lower than the other directions, with an average of $1800 \mathrm{~m} / \mathrm{s}$. The ash-rich layers $(\sim 1580 \mathrm{~m}$ CSF) exhibit lower velocity values than other lithologies $(\sim 1700 \mathrm{~m} / \mathrm{s})$. $P$-wave velocity exhibits an inverse relationship with porosity, although there is considerable scatter (Fig. F64); values from the ashrich samples do not fit this trend (low porosity, low $\left.V_{\mathrm{P}}\right)$. In some cases, minor faults and/or fractures are present and may give rise to the anisotropy.

$P$-wave velocity exhibits anisotropy ranging from $\sim 0 \%$ to values as high as $15 \%-20 \%$ (Fig. F63B). Horizontal velocity is higher than vertical velocity in most samples, but the ash-rich samples show the opposite relationship.

\section{Thermal conductivity (cores)}

Bulk thermal conductivity measurements were conducted on the working half of cores from 1529 to $1594 \mathrm{~m}$ CSF (Cores 319-C0009A-3R to 9R, 1 measurement per core) with a half-space probe but could not be conducted on Cores 319-C0009A-1R and $2 \mathrm{R}$ because of their low recovery (3\% and $22 \%$, respectively). Values remain in a narrow range of $1.57-1.76 \mathrm{~W} /(\mathrm{m} \cdot \mathrm{K})$, except at $1581 \mathrm{~m} \mathrm{CSF}$ (interval 319-C0009A-8R-7, 18-32 cm), where thermal conductivity drops to $\sim 1.1 \mathrm{~W} /(\mathrm{m} \cdot \mathrm{K}$ ) (Fig. F65). This section coincides with an ash-rich layer. No clear correlation between thermal conductivity and porosity is observed for these samples.

\section{Natural gamma ray (cuttings)}

Natural radioactivity was measured with the multisensor core logger (MSCL) on unwashed cuttings. The natural radioactivity background is $35 \mathrm{cps}$, which is subtracted from the data shown in Figure F66. The MSCL gamma ray data follow the downhole gamma ray trend from the wireline logging data to first order (see "Lithology") but are offset to slightly higher values. NGR increases sharply at $\sim 700$ $m$ MSF, consistent with MWD gamma ray measurements (see "Logging and data quality"), and remains high below this depth.

\section{Magnetic susceptibility (cuttings)}

MS measurements were conducted on the cuttings used for MAD measurements. To remove effects of measured sample weight, we calculated mass magnetic susceptibility (MMS) from measured raw data MS (bulk susceptibility) by:

$$
\begin{gathered}
\text { MMS }\left(\mathrm{m}^{3} / \mathrm{kg}\right)=\left[\mathrm{MS} \times \text { sample volume }\left(\mathrm{m}^{3}\right)\right] / \\
{\left[\text { sample weight }(\mathrm{g}) \times 10^{-3}\right] .}
\end{gathered}
$$

The depth range of MS measurements corresponds to Subunit IIIB and Unit IV; results are presented in Figure F67. MMS is high in Subunit IIIB (above $1292.7 \mathrm{~m}$ MSF) and decreases abruptly across the boundary. Average MMS values are $1.14 \times 10^{-7} \mathrm{~m}^{3} / \mathrm{kg}$ in Subunit IIIB (48 values, from 1037 to $1292.7 \mathrm{~m}$ MSF) and $8.93 \times 10^{-8} \mathrm{~m}^{3} / \mathrm{kg}$ in Unit IV (48 values, from $1292.7 \mathrm{~m}$ MSF to TD).

\section{Logging}

Physical properties from logging data include thermal neutron porosity, density, resistivity, and sonic velocity. Porosity is also computed from density and 
estimated from resistivity. This porosity is based on the total water content of the formation. In mud and mudstone, this includes both pore water and water bound in hydrous minerals (e.g., clays and opal).

\section{Lithodensity and porosity}

Density and neutron porosity values are sensitive to borehole conditions and in particular to borehole diameter. Neutron porosity values exhibit significant scatter (Fig. F68). The lower bound of these data is generally consistent with bulk densities and porosities determined from density logs (Figs. F69, F70) but shifted to slightly higher values.

\section{Neutron porosity}

Thermal neutron porosity exhibits substantial scatter, with values ranging from $\sim 0.4$ to $>0.6$ in Units II and III. Scatter increases in Unit IV, with values ranging from $\sim 0.4$ to 1.0 (Fig. F68). Where the borehole wall is rugose, the thermal neutron porosity measurement tends to incorporate a contribution from the drilling fluid. Therefore, the lower bound of the neutron porosity log should be considered to best reflect formation porosity and should be used for comparison with other porosity measurements. Despite the scatter, neutron porosity variations between units can be identified. Throughout Unit II, the lower bound of porosity remains approximately constant at $\sim 38 \%$. It increases to $50 \%$ in Subunit IIIA, decreases to $40 \%$ in Subunit IIIB, and increases to $\sim 50 \%$ in Unit IV. The degree of scatter decreases significantly at the Subunit IIIA/IIIB boundary and increases at the Unit IV boundary, where hole conditions change dramatically.

\section{Lithodensity}

Throughout Unit II, log density is nearly constant at $\sim 2.2 \mathrm{~g} / \mathrm{cm}^{3}$ (Fig. F69). Decreased density at the very top of this unit ( 715-725 m WMSF) is linked to bad hole conditions as documented by caliper measurement. At the Unit II/Subunit IIIA boundary, the log density drops to $\sim 2.0 \mathrm{~g} / \mathrm{cm}^{3}$ and increases slightly downsection within Unit III to $2.2 \mathrm{~g} / \mathrm{cm}^{3}$ at its base. In Unit IV, density drops to $1.95 \mathrm{~g} / \mathrm{cm}^{3}$ and fluctuates between 1.7 and $2.0 \mathrm{~g} / \mathrm{cm}^{3}$ between $\sim 1300$ and $\sim 1430 \mathrm{~m}$ WMSF. Below this depth, the log exhibits a trend of increasing density downhole with fluctuations at $\sim 1492$ and $\sim 1560 \mathrm{~m}$ WMSF. When a filter is applied to eliminate data from borehole sections with caliper values $>12.5$ inches, the density log exhibits an increasing trend throughout Unit IV, but the scatter in the upper $1300 \mathrm{~m}$ remains unchanged.

\section{Density-derived porosity}

A porosity profile was computed from the lithodensity $\log$ assuming a constant grain density $\left(\rho_{g}=\right.$ $\left.2.65 \mathrm{~g} / \mathrm{cm}^{3}\right)$ and fluid density $\left(\rho_{\mathrm{w}}=1.024 \mathrm{~g} / \mathrm{cm}^{3}\right)$ (see "Physical properties" in the "Methods" chapter) (Fig. F70). This calculation of porosity does not take into account the possible effects of free gas; it also overestimates the interstitial porosity because bulk density includes water contained in hydrous minerals. Because porosity data from MAD measurements made on core and cuttings samples also incorporate the total water included in the sample (interstitial and bound in hydrous minerals), the log-derived and MAD porosity values can be directly compared. Porosity in the lowermost section of Unit II hovers around $30 \%$, sharply increasing to $40 \%$ at the Unit II/Subunit IIIA boundary, and gradually decreases to $35 \%$ at the base of Subunit IIIB, with several small fluctuations (Fig. F70). At the Unit III/IV boundary, porosity exhibits a sharp increase from $38 \%$ to $42 \%$ and decreases gradually downhole below this depth. The increase is coincident with an increase in clay content at the boundary (see "Lithology"). In general, density-derived porosity is $\sim 5 \%$ lower than the lowest bound of the neutron porosity. The discrepancy between the two estimations of porosity tends to decrease in zones containing gas in Subunit IIIB (1043-1047, 1060-1199, and 1258-1280 m WMSF; see "Geochemistry"). MAD porosity measurements on core samples and those derived from the density log are comparable in the cored interval (Fig. F71), whereas cuttings porosity values are considerably higher, as discussed above.

\section{Electrical resistivity Resistivity logs}

Several resistivity measurements were acquired at different depths of penetration. The HRLA provides deep resistivity (see Table T5 in the "Methods" chapter) samples every $0.15 \mathrm{~m}$. The Mirco-Cylindrically Focused Log (MCFL) documents the microresistivity of the formation, and the EMS tool is a direct measurement of mud resistivity. Typically, the greater the depth of investigation, the higher the resistivity measurement, because an invasion of the formation by the very conductive mud $(\sim 0.7 \Omega \mathrm{m})$ filtrate affects the shallow penetration measurements the most. Resistivity obtained from the High Resolution Laterolog Array Tool (HRLT) is corrected for this effect and provides an estimate of true formation resistivity ("true resistivity"). True resistivity ranges between 0.9 and $2.65 \Omega \mathrm{m}$ (Fig. F72) and generally increases with depth but exhibits large fluctuations. Because 
the true resistivity log integrates the resistivity value over a large volume, it is generally less sensitive to borehole conditions; however, it still exhibits considerable scatter in Unit IV, which is characterized by the largest caliper and highest borehole rugosity.

Within Unit II, true resistivity increases slightly (from 1.4 to $1.8 \Omega \mathrm{m}$ ) from $\sim 710$ to $\sim 780 \mathrm{~m}$ WMSF and decreases below this to $\sim 1.4 \Omega \mathrm{m}$ at the Unit II/III boundary. In Subunit IIIA, the resistivity value gradually increases from 1.4 to $1.7 \Omega \mathrm{m}$ at $\sim 910 \mathrm{~m}$ WMSF, where it abruptly decreases to $1.4 \Omega \mathrm{m}$ at $\sim 919 \mathrm{~m}$ WMSF. This drop is coincident with decreases in $P$ wave velocity and gamma ray (Fig. F7) and may correspond to a minor change in lithology. Below this depth, resistivity increases to $\sim 2.4 \Omega \mathrm{m}$ at $\sim 1020 \mathrm{~m}$ WMSF and then decreases sharply to $1.6 \Omega \mathrm{m}$ at $\sim 1027 \mathrm{~m}$ WMSF, just above the Subunit IIIA/IIIB boundary. Resistivity decreases just above the Unit III/IV boundary at $1285 \mathrm{~m}$ WMSF. Below this boundary, resistivity decreases with depth to $\sim 1316 \mathrm{~m}$ WMSF, below which it increases to $1459 \mathrm{~m}$ WMSF and then fluctuates around $2.1 \Omega \mathrm{m}$ to $1572 \mathrm{~m}$ WMSF.

\section{Temperature log and estimation of downhole temperature}

Two temperature records were obtained by the EMS tool during wireline logging Runs 1 and 2 (drilling Phases 5 and 6; Table T1) from above the 20 inch casing shoe ( 690 m WMSF) to $1590 \mathrm{~m}$ WMSF (Fig. F73; see "Downhole temperature"). Because these logging data are strongly affected by drilling disturbance and are far from thermal equilibrium, we compute a synthetic temperature profile in the formation using estimated thermal conductivity values and assuming a heat flow of $39 \mathrm{~mW} / \mathrm{m}^{2}$ (determined at Site C0002) (Ashi et al., 2008). We assumed a $2^{\circ} \mathrm{C}$ bottom water temperature and a thermal conductivity profile obtained by combining (1) Site C0002 thermal conductivity data for the upper $800 \mathrm{~m}$ (where no reliable porosity are available at Site C0009) and (2) thermal conductivity computed from density-derived porosity (see "Physical properties" in the "Methods" chapter) at Site C0009 from 800 to 1572 m WMSF. Below 1572 m WMSF, we assume a constant thermal conductivity of $1.7 \mathrm{~W} /(\mathrm{m} \cdot \mathrm{K})$ because the density measurements were not reliable. This synthetic temperature profile exhibits slight changes in gradient near the major unit boundaries, and the estimated temperature at the bottom of the hole is $48^{\circ} \mathrm{C}$ (Fig. F73).

\section{Estimation of porosity from resistivity}

We calculated seawater electrical resistivity using the temperature profile estimated above and used it to evaluate the formation factor from true resistivity ("Physical properties" in the "Methods" chapter). Formation factor, in turn, is related to porosity by Archie's law. The Archie's law parameters that best fit to the caliper-filtered density-derived porosity and MAD core porosity are $a=1$ and $m=2.4$. The resulting estimates of porosity (resistivity-derived porosity) (Fig. F74) are in good agreement with densityderived porosity except in Unit II, where densityderived porosity is lower, and in Unit III at 910 and $\sim 1017$ m WMSF, where resistivity-derived porosity sharply increases and density-derived porosity decreases. Neither the conductivity of clay minerals nor gas saturation are taken into account in this calculation; both will affect the resulting porosity as well as the choice of the Archie's law parameters.

The resistivity-derived porosity generally decreases with depth (Fig. F74). In Unit II, it decreases to $40 \%$ at $774 \mathrm{~m}$ WMSF, then increases to $43 \%$ at the Unit III boundary. From this boundary, it decreases to $37 \%$ at 910 m WMSF, where it abruptly increases to $42 \%$ and then decreases gradually to $33 \%$ at $\sim 1285 \mathrm{~m}$ WMSF. The estimated porosity increases from $32 \%$ to $37 \%$ at the Unit III/IV boundary. Within Unit IV, it generally decreases with depth.

\section{Sonic log}

\section{P-wave velocity}

$P$-wave velocity increases continuously from 2000 $\mathrm{m} / \mathrm{s}$ at the top of Unit II to $2300 \mathrm{~m} / \mathrm{s}$ at its base (Fig. F75), decreases sharply to $2000 \mathrm{~m} / \mathrm{s}$ just above the Unit II/III boundary, and varies (from 2000 to 2200 $\mathrm{m} / \mathrm{s}$ ) from $\sim 790$ to $\sim 1010 \mathrm{~m}$ WMSF. From that depth to $\sim 1285 \mathrm{~m}$ WMSF, we identify four zones of low $P$ wave velocity $(\sim 1700 \mathrm{~m} / \mathrm{s}): \sim 1012$ to $1025 \mathrm{~m}$ WMSF, $\sim 1043$ to $\sim 1047 \mathrm{~m} \mathrm{WMSF}, 1060$ to $1199 \mathrm{~m}$ WMSF, and $\sim 1258$ to $\sim 1280 \mathrm{~m}$ WMSF. These zones broadly coincide with the increased abundance of wood fragments and gas content in Subunit IIIB (see "Geochemistry" and "Lithology"). We interpret the low $V_{\mathrm{P}}$ to indicate zones with increased gas saturation (Fig. F75). $P$-wave velocity increases sharply from 1940 to $2400 \mathrm{~m} / \mathrm{s}$ at the Unit III/IV boundary (1285 $\mathrm{m}$ WMSF). Although $P$-wave velocity in Unit IV is somewhat scattered because of degraded borehole conditions, a gradual trend $(\sim 1350$ to $\sim 1450 \mathrm{~m}$ WMSF) of increasing $V_{\mathrm{p}}$ with depth is evident.

\section{S-wave velocity}

In Unit II, shear-wave velocity $\left(V_{\mathrm{S}}\right)$ increases gradually from $800 \mathrm{~m} / \mathrm{s}$ at $715 \mathrm{~m}$ WMSF to $1070 \mathrm{~m} / \mathrm{s}$ at $790 \mathrm{~m}$ WMSF. $S$-wave velocity decreases slightly at the Unit II/III boundary and increases gradually with depth within Units III and IV. $S$-wave velocity is less 
variable than $P$-wave velocity in Subunit IIIB (Fig. F75).

\section{$V_{P} / V_{S}$ and Poisson's ratio}

$V_{\mathrm{p}} / V_{\mathrm{S}}$ and Poisson's ratio were calculated from $P$ wave and $S$-wave velocities (Fig. F76). Both are indicators of gas content because they decrease with increased gas saturation. In Units II and IV, $V_{\mathrm{P}} / V_{\mathrm{S}}$ and Poisson's ratios are nearly constant with depth. $V_{\mathrm{P}} / V_{\mathrm{S}}$ ratio in Units II and IV is 2.7 and 2.3, respectively, and Poisson's ratio is 0.41 and 0.38 , respectively. In contrast, these indicators exhibit larger variation in Unit III, especially in the zone from 1037 to $1285 \mathrm{~m}$ WMSF (Subunit IIIB), where $V_{\mathrm{P}} / V_{\mathrm{S}}$ ratio decreases from 2.5 to 2.0 and Poisson's ratio decreases from 0.39 to 0.32 .

Gas-rich intervals can also be identified from the relationship between resistivity and $P$-wave velocity (Figs. F75, F77). This is based on the fact that $P$-wave velocity and resistivity both increase with decreasing porosity, but resistivity increases with gas content whereas $P$-wave velocity decreases. Subunit IIIB is characterized by a significant decrease in $P$-wave velocity and increase in resistivity, which differs from the trends in Units II and IV. Comparison of the two downhole profiles confirms the presence of four gasrich intervals.

\section{Stoneley wave velocity}

Stoneley wave velocity was measured by the Sonic Scanner and shows similar patterns to the $S$-wave velocity (Fig. F78). A Stoneley wave is a type of surface wave that propagates along the wall of the borehole. If fractures exist in the borehole or the borehole wall is highly irregular in shape, the Stoneley wave velocity will decrease. Stoneley wave velocity increases gradually from $\sim 700$ to $\sim 1000 \mathrm{~m} / \mathrm{s}$ at $1565 \mathrm{~m}$ WMSF and exhibits significant scatter in Unit IV, possibly related to borehole conditions.

\section{Comparison of $\boldsymbol{P}$-wave velocity with porosity}

Cross-plots between $P$-wave velocity and caliper filtered density-derived porosity and resistivity-derived porosity are presented in Figure F79. Both cross-plots document an increase in velocity with decreased porosity, except in Subunit IIIB. In this unit, velocity is generally lower than in other units, probably due to the presence of gas. In addition, porosity values in this unit may need to be corrected to higher values because the porosities were computed assuming that all pore fluid is seawater, and gas saturation was not taken into account.

\section{Estimation of gas saturation}

Cross-plotting $V_{\mathrm{P}} / V_{\mathrm{S}}$ versus the $P$-wave slowness (1/ $\left.V_{\mathrm{P}}\right)$ is useful to assess the effect of gas saturation on these quantities (see "Physical properties" in the "Methods" chapter) (Fig. F80). Units II and IV plot similarly, whereas part of Unit III follows a trend to lower $V_{\mathrm{P}} / V_{\mathrm{S}}$ values and higher slowness, as expected from the Reuss average for pore fluid bulk modulus $K_{\mathrm{f}}$ (Brie et al., 1995) (see "Physical properties" in the "Methods" chapter). Results of the calculation (parameters of calculation showed in Table T13) indicate a gas saturation of $\sim 10 \%$ and true porosity (when accounting for gas) of $\sim 25 \%$ in Subunit IIIB.

\section{Downhole measurements}

\section{Modular Formation Dynamics Tester results}

The MDT wireline logging tool assembly was run to measure in situ pressure and stress (Tables T14, T15, T16; Fig. F59). The tool was operated in two modes: single probe and dual packer. The single probe test (SPT) pushes a probe against the borehole wall, extracts fluid to reduce pore pressure, and records the subsequent pressure recovery. The results are used to estimate in situ pore pressure and permeability. The dual packer test isolates an interval of the formation ( $1 \mathrm{~m}$ at Site C0009) to either draw down the pressure (to determine in situ pressure and permeability over a larger volume than in SPTs) or increase the borehole pressure to create a hydraulic fracture and measure the in situ least principal stress (See "Modular Formation Dynamics Tester" in "Downhole measurements" in the "Methods" chapter). The results are presented below in three sections: SPT results, dual packer drawdown results, and dual packer hydraulic fracture test results (see also C0009MDT.PDF and C0009_T1.XLS in DOWNHOLE in "Supplementary material").

\section{Single probe test results}

For each SPT, we plotted the measured pore pressure and fluid withdrawal rate (Figs. F81, F82, F83, F84, F85, F86, F87, F88, F89). A summary of events for each deployment is included in Table T16. The SPTs can be divided into two types: rapid pressure recovery and slow pressure recovery. Test MDT_059 illustrates a rapid recovery (Fig. F81). Initially, the pore pressure recorded mud pressure in the borehole; after this, the probe was set, resulting in a small pressure increase (45-114 s; Table T16; Fig. F81). Three drawdown tests were then performed (drawdown in Fig. F81). In each drawdown, between 4.8 and $9.9 \mathrm{~cm}^{3}$ of formation fluid was extracted at $60 \mathrm{~cm}^{3} / \mathrm{min}$ (Table 
T16) and pore pressure declined by $\sim 0.2$ to $0.5 \mathrm{MPa}$. After drawdown, pore pressure rapidly recovered (within $10 \mathrm{~s}$ ) to a constant value of $28.23 \mathrm{MPa}$. This final value is lower than borehole pressure (31.20 $\mathrm{MPa}$ ) (mud pressure in Fig. F81) and is $\sim 0.5 \mathrm{MPa}$ higher than hydrostatic pressure (blue dashed line in Fig. F81). Test MDT_078 exhibits similar recovery behavior (Fig. F88).

In contrast, Test MDT_60 illustrates slow recovery behavior (Fig. F82). In two drawdowns, $\sim 5 \mathrm{~cm}^{3}$ was extracted at 30 and $50 \mathrm{~cm}^{3} / \mathrm{min}$, resulting in a total pressure drop of $\sim 10-11 \mathrm{MPa}$. Pore pressure then gradually rose during the recovery phase. Even after 120 s, pore pressure was still rising (Table T16; Fig. F82).

We used the final build-up pressure at the end of the drawdown cycles as an estimate of in situ (formation) pore pressure (Table T15; Fig. F90A). In the case of slow recovery, the last pressure value is unlikely to reflect the true in situ pore pressure and is probably most appropriately considered a minimum. In a pressure-depth plot, the final build-up pressures generally plot on a straight line that is very slightly above estimated hydrostatic pressure (compare red triangles to solid blue line in Fig. F90A) (Table T15). The deepest SPT measurement has an estimated in situ pore pressure that is less than the hydrostatic pressure. However, pore pressure was still rapidly rising at the end of the test (Fig. F86) and we infer that pore pressure did not reach the in situ pore pressure during the recovery. Hydrostatic pressure is calculated by assuming a pore fluid density of $1023 \mathrm{~kg} /$ $\mathrm{m}^{3}$. The slight apparent overpressure could be due to (1) the influence of drilling mud on the surrounding formation pressure, (2) an underestimate of hydrostatic pressure, or (3) the presence of actual slight overpressure.

Fluid mobility is calculated according to Equation 36 in "Downhole measurements" in the "Methods" chapter. It is important to note that Schlumberger suggests that fluid mobility values $<10^{-15} \mathrm{~m}^{2} / \mathrm{cp}$ may be unreliable. The drawdown mobilities are presented in Table T15 and Figure F90, where mobility is defined as the ratio of permeability to viscosity. Mobility ranges from $<10^{-16}$ to $10^{-14} \mathrm{~m}^{2} / \mathrm{cp}$ (Table T15; Fig. F90). Generally, mobility is lower where gamma ray values are higher (Fig. F59A). For example, five SPT measurements were made in Unit III (Fig. F59A). Three of these were made at approximately the same depth ( $\sim 875 \mathrm{~m}$ WMSF), have low mobility, and are in a zone of relatively high gamma ray values (Fig. F59A). Near the base of Unit III, one SPT measurement records a relatively high mobility and is in a relatively low gamma ray interval (Test MDT_065). Test MDT_065, which has high mobility, was conducted at a depth (1175 m WMSF) where there was an anomalously low sonic velocity (Fig. F59A). The underlying measurement (Test MDT_078) at $1217 \mathrm{~m}$ WMSF records low mobility and is in a zone of high gamma ray values. The three SPTs in Unit IV all record low mobility and have generally high gamma ray values (Fig. F59A).

\section{Dual packer drawdown test results}

Test MDT_073 was a dual packer drawdown test (Tables T14, T16; Figs. F91, F92). At 1539.69 m WMSF (tool zero depth), the MDT's dual packers were inflated to isolate a $1 \mathrm{~m}$ section where the borehole was relatively smooth. The test location was selected based on criteria summarized in the "Methods" chapter. The packers were first inflated (1630-2000 s; Fig. F91). Then pressure generated by the packer inflation was bled off (2000-2800 s) and a drawdown test was performed ( $\sim 3200-3450$ s). It was planned to draw the pressure down by $5 \mathrm{MPa}$. However, because of initial concern over borehole stability conditions, the drawdown was stopped after pressure had declined by $3.52 \mathrm{MPa}$ (Figs. F91, F92). Then pressure was allowed to recover for $180 \mathrm{~s}$ (Figs. F91, F92).

Pressure recovery from the MDT dual packer drawdown test is analyzed using the curve-matching approach of Papadopulos et al. (1973), which uses an analytical solution in dimensionless coordinates wherein fractional pressure dissipation $\left(\left[P-P_{\mathrm{d}}\right] /\left[P_{\mathrm{i}}-\right.\right.$ $\left.P_{\mathrm{d}}\right]$ ) is plotted against the log of dimensionless time $(\beta)$ for different dimensionless storage parameters $(\alpha)$ (Fig. F93). $P$ is pore pressure during the recovery, $P_{\mathrm{d}}$ is pore pressure at the start of the recovery, and $P_{\mathrm{i}}$ is in situ pore pressure. The dimensionless time $(\beta)$ is:

$$
\beta=\pi k L t / \mu C
$$

where

$$
\begin{aligned}
& k=\text { permeability, } \\
& L=\text { length of the open section, } \\
& t=\text { time since the onset of the buildup, } \\
& \mu=\text { fluid viscosity, and } \\
& C=\text { system compressibility. }
\end{aligned}
$$

The dimensionless storage parameter $(\alpha)$ is:

$$
\alpha=\pi r_{\mathrm{w}}{ }^{2} L S_{\mathrm{s}} / C,
$$

where

$$
\begin{aligned}
& r_{\mathrm{w}}=\text { well bore radius, and } \\
& S_{\mathrm{S}}=\text { specific storage. }
\end{aligned}
$$

The data from the recovery part of the drawdown test are matched with type curves (plotted in log time) from the Papadopulos et al. (1973) solution. We assume $P_{\mathrm{i}}=39.321 \mathrm{MPa}, P_{\mathrm{d}}=35.621 \mathrm{MPa}$, and 
other parameters are as presented in Table T17. Our data most closely match when $\alpha=10^{-1}$ and $\beta=t /$ 1000 , which define a storage coefficient $\left(S_{s}\right)$ of $5.2 \times$ $10^{-11} \mathrm{~Pa}^{-1}$ (Equation 4) and a permeability $(k)$ of $1.3 \times$ $10^{-17} \mathrm{~m}^{2}$ (Equation 3). These calculations should be viewed with caution because system compressibility (C) was calculated only from the water stiffness $\left(K_{\mathrm{f}}=\right.$ $2 \mathrm{GPa}$ ): the water volume $(V)$ in the $1 \mathrm{~m}$ long $12^{1 / 4}$ inch borehole is $0.0760 \mathrm{~m}^{3}$; thus, $C=V / K_{\mathrm{f}}=3.8 \times$ $10^{-11} \mathrm{~m}^{3} / \mathrm{Pa}$. If the tool itself had significant compressibility, the true storativity would be lower and the resulting permeability would be higher. In addition, in situ pressure $\left(P_{\mathrm{i}}\right)$ was assumed to equal pressure in the borehole $(39.21 \mathrm{MPa})$. This pressure is most likely too high (Fig. F92), and if a lower pressure were used, it would also result in a higher calculated permeability.

\section{Dual packer hydraulic fracture test results}

Hydraulic fracture tests using the MDT dual packer were carried out near the top (Test MDT_080) and bottom of the $12^{1 / 4}$ inch open hole section (Test MDT_074) (Fig. F59). As for the dual packer drawdown test, test locations were selected on the basis of other logging data (see the "Methods" chapter). Test MDT_074 is located within the cored section (Core 319-C0009A-3R) of Unit IV at $1532.7 \mathrm{~m} \mathrm{WMSF}$ (Tables T14, T16). Test MDT_080 at $873.7 \mathrm{~m}$ WMSF was the last test in wireline logging Run 3.

Figure F94 illustrates the pressure and injection rate during hydraulic fracture Test MDT_074. From 1400 to $3200 \mathrm{~s}$, fluid was injected in a series of pulses. After each injection, the pumps were stopped and pore fluid pressure fell. At $\sim 3200 \mathrm{~s}$, pressure reached $41.9 \mathrm{MPa}$ and then the pumps were stopped for $600 \mathrm{~s}$ to change the setting of pumping because the pressure continued to increase without breakdown and the rate of pressure increase was too slow. After changing the pumping parameter to use dual pump, we resumed pumping with an interruption at $3960 \mathrm{~s}$ before the final injection from 4017 to $4207 \mathrm{~s}$. Pressure immediately after this final injection was 41.6 $\mathrm{MPa}$. We take this pressure to be an instantaneous shut in pressure (ISIP) and thus tentatively represents the least principal stress magnitude (Fig. F94). However, it should be emphasized that the ISIP is not reproducible, and therefore we do not have confidence in this estimate of least principal stress.

The MDT tool was moved to $878.7 \mathrm{~m}$ WMSF for Test MDT_080. In this test, the pressure cycle was repeated five times maintaining the same flow rate (Fig. F95). The pressure-time curve for the last four cycles did not change significantly. For each of these cycles, we report the ISIP in Table T18. Figure F95B illustrates an example of these values for one of the cycles. ISIP was determined by finding the break in slope on a pressure-time plot after injection ceased. Based on these four values, we estimate ISIP to be $34.8 \mathrm{MPa}$. ISIP is commonly interpreted to record the least principal stress $\left(\sigma_{3}\right)$.

Least principal stress magnitudes for Tests MDT_074 and MDT_080 are shown in Figure F90A. We place much more confidence in the measurement from Test MDT_080 (873.7 m WMSF) than the measurement from Test MDT_074. For each measurement, we calculate the effective stress ratio $(K)$ by

$$
K=\left(\sigma_{3}-P_{\mathrm{h}}\right) /\left(\sigma_{\mathrm{v}}-P_{\mathrm{h}}\right),
$$

where

$$
\begin{aligned}
\sigma_{3}= & \text { least principal stress, } \\
P_{\mathrm{h}}= & \text { hydrostatic pressure (calculated assuming a } \\
& \text { pore fluid density of } 1023 \mathrm{~kg} / \mathrm{m}^{3} \text { ), and } \\
\sigma_{\mathrm{v}}= & \text { overburden stress (see Fig. F90A caption for } \\
& \text { explanation of overburden calculation). }
\end{aligned}
$$

For Tests MDT_080 and MDT_074, $K=0.82$ and 0.44 , respectively. We do not know the orientation of fractures induced or activated by hydraulic fracturing because no borehole images were taken after the hydraulic fracture tests. However, we can verify that $\sigma_{3}<\sigma_{v}$ at both test depths (Figs. F94, F95).

\section{Leak-Off test}

As a standard part of drilling operations, two LOTs were performed at the base of the 20 inch casing (2786.2 m DRF, $703.9 \mathrm{~m} \mathrm{DSF}$ ). As defined in "Logging and data quality" (Fig. F82), the base of cement lies at $2790.9 \mathrm{~m} \mathrm{DRF} \mathrm{(708.6} \mathrm{m} \mathrm{DSF).} \mathrm{The} \mathrm{bot-}$ tom of the 17 inch hole at this time (after drilling out the cement plug) was at $2798 \mathrm{~m}$ DRF $(715.7 \mathrm{~m}$ DSF). The mud density in the hole was $1080 \mathrm{~kg} / \mathrm{m}^{3}$. The LOT was performed with the outer annulus closed by the BOP, and pressure was measured at the cement pumps. A summary of operations is included in Table T19, and the pressure-time data are included in a supplementary data table (see C0009_T2.XLS in DOWNHOLE in "Supplementary material").

Figure F96 illustrates volume injected versus pressure during the LOTs. We interpret leak-off pressure to be at the break in slope on the pressure-time plot (Zoback, 2007). Leak-off pressures were found to be 100 psi $(0.689 \mathrm{MPa})$ and $105 \mathrm{psi}(0.724 \mathrm{MPa})$ for LOT 1 (Fig. F96A) and LOT 2 (Fig. F96B), respectively. The pressure of the mud column to the leak-off depth (2790 m DRF, $712.9 \mathrm{~m} \mathrm{DSF}$ ) is $29.53 \mathrm{MPa}$. Thus, downhole leak-off pressures are 30.22 and 30.25 $\mathrm{MPa}$, respectively, for LOTs 1 and 2 . These values are interpreted to equal least principal stress (Fig. F90). 
We note that there is considerable uncertainty in picking the slopes of the lines to determine least principal stress $\left(\sigma_{3}\right)$ (e.g., Fig. F96B). The stress ratio $(K)$ is 0.44 for both LOT measurements of $\sigma_{3}$.

\section{Downhole temperature}

Borehole temperature logs were acquired during each wireline logging run (drilling Phases 5, 6, and 7) (Fig. F97; see also C0009_T3.XLS in DOWNHOLE in "Supplementary material"). The EMS tool (see "Logging" in the "Methods" chapter) recorded borehole temperature during wireline logging Runs 1 and 2 from the 20 inch casing shoe (703.9 m WMSF) to $\sim 1585 \mathrm{~m}$ WMSF (Fig. F97). Borehole temperatures are higher in Run 2 than in Run 1 throughout the borehole. Wireline logging Run 2 was initiated $\sim 14.5$ $\mathrm{h}$ after Run 1 . There was no circulation between the two logging runs. After wireline logging Run 2 and before Run 3, there was circulation for a wiper trip to clean the hole. The MDT tool was run during wireline logging Run 3 (see "Operations," Table T1), and temperature was recorded for each MDT test (circles and squares in Fig. F97). Temperatures recorded as the MDT was run into the hole are lower than temperatures recorded when the tool was being pulled out of the hole (compare circles to squares in Fig. F97).

Prior to wireline logging, circulation during drilling cooled the borehole and the near-borehole region. We interpret that the three wireline logging runs record the borehole temperature gradually equilibrating with the surrounding formation. The low values recorded by the MDT during tool lowering are due to either circulation during the wiper trip between Runs 2 and 3 or to the thermal inertia of the tool. Measured temperature increases with depth in all three runs, and there are two changes in temperature gradient at $\sim 720$ and $1300 \mathrm{~m}$ WMSF (Fig. F97). These depths are very close to the boundaries of logging and lithologic units (see "Lithology"), and the changes in gradient may be related to thermal conductivity contrasts at unit boundaries.

\section{Vertical seismic profile}

\section{Walkaway VSP experiment at Site C0009}

The two-ship, or walkaway, VSP experiment differed from most studies in industry and from preceding walkaway experiments in scientific ocean drilling in that it was the first walkaway experiment in IODP riser drilling and it employed an array of seismometers. In IODP, a wireline downhole seismic receiving system with up to 20 geophones is available, more geophones than commonly used during industry applications. The scientific objective during Expedition
319 was to illuminate deep reflectors with long offsets using wide-angle (refraction) information to measure bulk physical properties below the borehole. Improved constraints on physical properties of the lower plate are desired to better constrain earthquake seismographs. In industry, reflection seismic imaging in a volume around a well is the common objective.

Because the use of new techniques involved unanticipated problems during riser drilling, flexibility and multiple changes in the scheduling of the shooting ship Kairei were required and impacted the Kairei's other scheduled cruises. These changes were necessary because the Kairei was the preferred shooting ship for the walkaway VSP experiment with its powerful tuned array of air guns. The scheduling delays were linked to unanticipated operational problems and delays due to weather (see "Operations"). Therefore, the time window for the walkaway VSP shifted up until the final cementing of the $13 \% 3$ inch casing. After tools for the walkaway VSP were in the hole, cable failures between seismometers caused an additional $7 \mathrm{~h}$ delay while the cable was pulled out of the hole to make repairs. The Kairei also experienced problems with the strong Kuroshio Current that slowed its operations so as to stay within the required array tow speed. During operations, the plan for the walkaway VSP experiment was continually revised. Ultimately, we obtained 880 shot records in Line 1 and 275 shots in circular line Circle 1 (Fig. F98).

\section{Seismometer orientation}

For the walkaway VSP, the VSI seismometers were clamped to the casing (Fig. F99). The horizontal first motion records from circle-shooting data (Fig. F100) clearly show a dependency of polarity and amplitude on the direction of the air gun shot (Fig. F101). The orientation of each VSI seismometer was not controlled because the seismometers were connected by wireline. However, using first-motion polarity and amplitude, the orientation of each seismometer can be estimated by finding the direction of maximum negative amplitude of the first motion in the $x$ - and $y$-components. Preliminary results of this estimation are shown in Table T20. The results suggest that the upper 11 seismometers were rotated relative to one another and that below this the seismometers (12-20) were consistently oriented. All seismometers showed similar response except for one at $3126 \mathrm{~m}$ WRF (1044.9 m WMSF) (Seismometer 10). This seismometer had a much smaller response to the air gun signals for all components, and irregular responses to signals were observed, suggesting poor coupling of the seismometer to the casing (or of the casing to the 
formation). The seismometers exhibited relatively stable responses over a wide range of shot directions, so first-motion amplitude followed a cosine relationship very closely (Fig. F101) and the differences in estimated azimuth of seismometer axes ( $x$ - and $y$-) were in most cases close to $90^{\circ}$ (Table T20). It is not clear why the $x$-azimuth is estimated to be $90^{\circ}$ clockwise from $y$, whereas Schlumberger claims the opposite (i.e., that the $y$-azimuth is $90^{\circ}$ clockwise from $x$ ).

\section{Walkaway VSP records}

Seismic records from walkaway VSP Line 1 exhibit various types of seismic waves. The range of horizontal offset between sensors and air gun shooting spans from $400 \mathrm{~m}$ to $29.3 \mathrm{~km}$. In these ranges, we are able to identify direct wave arrivals, seismic phases associated with multiples in the ocean, refractions from accretionary prism layers, and reflections from interfaces below the seismometers within the accretionary prism as well as from the splay fault and presumably from the deeper décollement (Figs. F102, F103). Apparent velocities of major refracted waves (which correspond to regions immediately below velocity discontinuities) are 1.75-1.8, 1.89-1.9, $2.45-2.6,3.05$, and $4.0 \mathrm{~km} / \mathrm{s}$. Seismic phases from deeper boundaries are not clear from records for single seismometers because of noise, but reflections of apparent velocity of $6.6-6.8 \mathrm{~km} / \mathrm{s}$ are present. We may be able to identify seismic phases from the deeper décollement by stacking the borehole seismic array records because arrivals of upgoing refracted and reflected waves from the shallower boundaries in the array record (indicated by Areas A and B in Figs. F104, F105) show good coherence over the length of the array. We can identify deep seismic phases better in shot records from the southern part of the linear transect than the northern part. This is probably due to (1) increased background noise level and reduced source strength in the northern shots and (2) the possible effect of boundaries dipping to the northwest. Background noise appeared to increase in northern shots of offset $>10 \mathrm{~km}$, but it is not known why. The amplitude of the air gun signal was reduced for shots north of $10.7 \mathrm{~km}$ offset because Kairei experienced air gun problems in one of the four subarrays and continued shooting with the remaining three subarrays.

Deeper and weaker seismic phases appear clearer in horizontal component records than the vertical records because of the effects from seismic waves traveling vertically along the casing, as explained in detail below. Horizontal records from each seismometer were rotated to decompose the radial and transverse directions from the air gun shot. Figure F103 shows rotated horizontal records from the borehole seismometer at $3004 \mathrm{~m}$ WRF (922.9 $\mathrm{m}$ WMSF). The amplitude of signals in the transverse component is much smaller than in the radial component for most arrivals. In radial horizontal component records, some phases are clearly observed $\sim 1 \mathrm{~s}$ after refracted $P$-wave arrivals, which have similar apparent velocities to the preceding $P$ phases. We interpret these later arrivals as $P$ to $S$ converted waves from boundaries below the borehole.

Records from the seismic array provide a distinct advantage over single seismometer records, in that phase identification of different seismic waves is possible by differentiating their propagation direction and speed. In the walkaway VSP data set from 16 seismometers spaced at $\sim 15 \mathrm{~m}$ intervals, upgoing and downgoing waves are clearly distinguishable (Figs. F104, F105). In these figures, upgoing refracted waves dominate in Area A, whereas in Area B upgoing reflected waves and downgoing direct waves are mixed. Velocity filtering on the data set would help illuminate seismic phases of primary interest, including upgoing reflections and refractions from deep boundaries. These seismic phases are apparent at frequencies $<20 \mathrm{~Hz}$ for vertical, and $<30 \mathrm{~Hz}$ for horizontal records (e.g., index A and B in Figs. F104, F105).

In addition to these phases, there are other types of waves observed in the walkaway VSP records, which are generally treated as noise in data processing. In near-offset recordings, we can identify an irregular phase dominated in high frequencies $(>20 \mathrm{~Hz})$ preceding the direct wave arrivals through the formation (C in Fig. F104). This phase has high apparent velocity in the array $(\sim 6 \mathrm{~km} / \mathrm{s})$ and is coherent in amplitude over the array for each shot but changes irregularly in amplitude for different shots. It probably corresponds to subordinate seismic waves generated by direct waves hitting the structure of the borehole in some places, but it is not clear why these waves behave so differently for air gun shots separated by only $60 \mathrm{~m}$. We also observe later phases abundant in high-frequency energy prior to the direct wave arrival (D in Fig. F104). These phases have similar amplitude between adjacent shots and also a similar apparent velocity of $\sim 6 \mathrm{~km} / \mathrm{s}$. The same type of seismic phase was also observed in the zero-offset VSP experiment. From the observations in zerooffset VSP data, it seems likely that this signal is generated at several boundaries in the borehole from direct waves in the formation. Some of these boundaries correspond to mechanical elements of the borehole construction, such as the wellhead and the bottom of the 36 inch casing, but others are not correlated to casing shoes or other borehole boundaries and might be related to formation boundaries. The phase (D in Fig. F104) also has horizontal energy as 
indicated by D in Figure F105. On the other hand, we observe an earlier phase (E in Fig. F105), which is prominent only in the horizontal component. We also observed a later phase ( $F$ in Fig. F105) in the horizontal component, which has an apparent velocity similar to that for water. The later phase may be a sound wave traveling down to the bottom of the casing, and we see a similar phase in zero-offset VSP records. In the zero-offset VSP records we also identified seismic phases that reflected back from a depth close to the bottom of the $133 / 8$ inch casing, with an apparent velocity near that of water. We also observed that seismic waves are sometimes generated within the interval of the seismic array and propagate both upward and downward with an apparent velocity near that of water; we interpret this as a wave in the mud within the hole (G in Fig. F105).

\section{Zero-offset VSP experiment at Site C0009}

A zero-offset VSP (check shot) was carried out following the walkaway VSP. Zero-offset seismic data were obtained by moving the seismic array upward from the depth of the walkaway VSP experiment, at 121 $\mathrm{m}$ intervals, until the bottom of the array reached a depth near the seafloor. Eight shuttles were used to acquire the waveforms. A three gun (each 250 in $^{3}$ ) air gun array deployed from the Chikyu was used as the seismic source. A total of 94 shots were fired. Generally, 10 shots were fired for each seismic array position.

\section{Zero-offset VSP records}

The zero-offset VSP data contain many seismic phases related to the structure of the borehole. The earliest phases observed in the vertical component are vertically oriented waves propagating downward from the wellhead at an apparent velocity of $6 \mathrm{~km} / \mathrm{s}$ (A in Fig. F106A). These probably correspond to subordinate seismic waves generated at the wellhead and propagating along the casing. The seismic wave may be reflected upward at the bottom of the 20 inch casing (B in Fig. F106A), but some of the energy propagates to the bottom of the hole. There is another seismic phase $\sim 0.1 \mathrm{~s}$ later that propagates downward at a similar velocity (C in Fig. F106A). This phase also appears to be a converted wave originating deeper (probably at $2250 \mathrm{~m}$ WRF [168.9 m WMSF]), again from acoustic waves propagating inside the casing. Another set of similar strong phases (D in Fig. F106A) are generated at $\sim 2550 \mathrm{~m}$ WRF (468.9 m WMSF) and comprise the strongest arrivals at these depths. We can also see strong phases (E in Fig. F106A) propagating upward. These phases may be reflections from the top of sections of casing that are well coupled to the formation by cement at
3500 m WRF (1418.9 m WMSF). There is a lower velocity phase (F in Fig. F106A) between 2600 and $3217 \mathrm{~m}$ WRF (518.9 and $1135.9 \mathrm{~m}$ WMSF). This phase has an apparent velocity similar to that of water. This is probably an acoustic wave propagating in the mud inside the casing. A seismic wave reflecting back from $\sim 3600 \mathrm{~m}$ WRF (1518.9 $\mathrm{m}$ WMSF) is also observed ( $\mathrm{G}$ in Fig. F106A); this corresponds to the depth of float collar near the bottom of the $133 / 8$ inch casing.

These seismic phases are all very weak in horizontal component records (Fig. F106B, F106C). There are some clear phases propagating down with apparent velocities close to those obtained from sonic logs in the horizontal component records (thick line in Fig. F106B, F106C). We picked these arrivals as the formation interval velocities. It is not clear why these phases are apparent only in horizontal components and not in the vertical. In such near-offset VSP data (offset of $60 \mathrm{~m}$ ), it is difficult to explain why compressional waves in the formation have such a large horizontal amplitude. Therefore, the picked interval velocities may not represent $P$-wave velocity of the formation but instead could represent a type of surface wave propagating along the borehole, although we deem this scenario unlikely because the velocities are too high to be surface waves.

At some depths, records are dominated by monotonic oscillation (H in Fig. F106A, F106B, F106C). This is probably due to poorly coupled sensors. The monotonic oscillation exhibits higher amplitude coincident with the arrival of acoustic waves in the casing (vertical component), and the oscillation is much weaker in the horizontal component. This observation shows that the seismometers are coupled to fluid inside the casing rather than to the casing itself.

\section{Analysis on velocity pick for zero-offset VSP data}

There was difficulty in picking the compressional wave arrival times. An initial report from Schlumberger (see C0009VSP.PDF in DOWNHOLE in "Supplementary material") described the zero-offset VSP and picked these arrival times. Although the report was very useful, it was determined that the velocities were far too high to be physically reasonable. Schlumberger revisited this issue and then provided the data in Table T21 as an estimate of the compressional wave traveltime. They interpreted the initial (very high) velocities (reported in C0009VSP.PDF in DOWNHOLE in "Supplementary material") as first arrivals of waves traveling along the casing. Schlumberger's new calculations were based on both the vertical and horizontal geophone records (see previous discussion). 
The final velocity structure provided (Table T15; Figs. F107, F108) is in good agreement with wireline seismic data and the velocities from precruise seismic processing of the 3-D seismic reflection data.

\section{Cuttings-Core-Log-Seismic integration}

\section{Seismic velocity structure and well tie}

We combined the zero-offset VSP (check shot) with wireline sonic velocity to derive a velocity-depth function at Site C0009 (Fig. F109). Check shot measurements only extend to $1137 \mathrm{~m}$ WMSF (red squares, Fig. F109). However, wireline sonic data extend to $1600 \mathrm{~m}$ WMSF (black line; Fig. F109) (refer to "Logging and data quality" for a discussion of different depth references). To derive the velocity structure from the seafloor to $2000 \mathrm{~m} \mathrm{WMSF}$, we extended check shot measurements with five velocity zones estimated from the wireline sonic data (green dashed line, Fig. F109). The velocities that we used (green dashed line) are lower than those used for seismic processing prior to the cruise (black dashed line, Fig. F109). Figure F110 illustrates one-way traveltime versus depth below the seafloor. Red squares indicate check shot measurements. We use a timedepth model (green dashed line) that combines check shot data and wireline sonic data. For the drilled sequence (below $712.7 \mathrm{~m}$ ) the traveltimes are greater below $1000 \mathrm{~m}$ WMSF in our time-depth correlation (green dashed line) than was estimated from precruise seismic processing (black dashed line) because of the lower velocities obtained from check shots than those used to process the seismic data. This is largely due to the low-velocity layer present at $\sim 1200 \mathrm{~m}$ WMSF in the wireline sonic data (Fig. F109). This layer corresponds to a zone of increased free gas in lithologic Unit III (see below; also see "Geochemistry" and "Physical properties").

We correlate the wireline logging, cuttings, and core data to time-based seismic data (Figs. F111, F112). We shifted the time-based seismic data $50 \mathrm{~ms}$ upward so that the seafloor reflector correlated to a two-way traveltime (TWT) of $2720 \mathrm{~ms}$, the TWT inferred from the check shot data for the seafloor. Four references for our correlation are presented: WRF, WMSF, SSF, and TWT. The correlation between time and depth is also presented in C0009_T1.XLS in CCLS in "Supplementary material."

Seismic Surface S1 is a prominent reflector within Unit II that corresponds to a depth of $\sim 550 \mathrm{~m}$ WMSF (see "Background and objectives;" Fig. F111). There are no wireline sonic data in this interval. Seismic Surface S2 correlates to $750 \mathrm{~m}$ WMSF, $40 \mathrm{~m}$ above the interpreted Unit II/III boundary and near the top of the depth range for which we collected wireline log data (Figs. F112, F113). Compressional velocity from the sonic $\log \left(V_{\mathrm{p}}\right)$ and bulk density $\left(\rho_{\mathrm{b}}\right)$ are shown to the right of the seismic data; these are used to compute the impedance (the product of velocity and density). The amplitude and sign of the seismic reflection are proportional to the impedance contrast for a vertically incident wave. In this part of the borehole, the obvious surface for a significant reflection lies at the Unit II/III boundary, where there is a drop in velocity and density, which results in a marked decrease in impedance (Figs. F112, F113). It is not clear why the Surface S2 reflector lies above the Unit II/III boundary. One interpretation is that there is an abrupt impedance contrast close to the base of the casing that is causing the strong reflection ( 730 $\mathrm{m}$ WMSF) but was not imaged by the logs because of the presence of the casing. Another possibility is that Surface S2 is actually slightly deeper than mapped in the region around Site C0009, where the geometry of seismic reflections within Units II and III is somewhat complicated. A third possibility is that the check shot tie is not correct at this depth.

There are several very bright reflections between 3700 and 3900 ms within Subunit IIIA, but the unit is generally less reflective than overlying units (Figs. F111, F112). In Subunit IIIB, density shows minor change; however, $V_{\mathrm{P}}$ decreases significantly (Figs. F112, F113). The compressional velocity to shear velocity ratio $\left(V_{\mathrm{p}} / V_{\mathrm{S}}\right)$ is also low in this zone (see "Physical properties"). Elevated methane concentrations derived from mud gas measurements correlate closely to this low-velocity zone (Fig. F114), and abundant wood fragments are found just below the first appearance of the low-velocity zone (Fig. F114). All of these data imply that this is a zone where free gas is present, and preliminary calculations suggest gas saturations reach $\sim 10 \%$ (see "Physical properties"). The upper part of Subunit IIIB has a relatively transparent character that corresponds to a zone with uniformly low velocity (Figs. F114, F115). The transparent character may result from lack of any contrast in impedance and/or attenuation due to the presence of gas.

Unconformity UC1 is a prominent positive (blue) reflection that lies at the base of the low-velocity zone within Subunit IIIB (Figs. F111, F112, F115). Close analysis of $P$-wave velocity, resistivity, $V_{\mathrm{P}} / V_{\mathrm{S}}$ ratios, and Poisson's ratio suggests a significant decrease in gas across the unconformity (Figs. F75, F76). Unconformity UC1 truncates underlying reflectors and can be locally correlated laterally, although biostratigraphic analysis was unable to resolve the presence 
of a hiatus, if present. We therefore interpret Unconformity UC1 to be an erosional unconformity with limited missing section.

Finally, Unconformity UC2 lies at the Unit III/IV boundary, where there is an increase in impedance (Fig. F112). The Unconformity UC2 surface actually lies slightly above the Unit III/IV boundary (Fig. F112) after applying the corrected velocity model, but this is likely to be a function of an imperfect velocity model and we would expect the surface and unit boundary to be coincident. The boundary is marked by a decrease in density and an increase in velocity; the net result is an increase in impedance with depth. XRD analysis of cuttings samples records an increase in clay fraction across this boundary (Fig. F114), and SP values decrease at the same interface. The increase in clay fraction may drive the decrease with depth in density and SP.

\section{Seismic facies}

Each lithologic unit (see "Lithology") is imaged as a distinct seismic facies. Lithologic Unit I is characterized by laterally continuous, high-amplitude seismic reflections (Fig. F115). These reflections are largely parallel; however, in the upper part of the section, they converge and onlap to the south-southeast as Unit I thins (Fig. F115). Lithologic Unit I is defined as interbedded sand and mud as inferred from the gamma ray MWD log (see "Lithology"). We interpret that the laterally continuous reflections are caused by the abundant $10-40 \mathrm{~m}$ thick sand cycles recorded in the gamma ray log. The lateral continuity of the reflections suggests that these units are well stratified and laterally extensive. The present water depth is $>2000 \mathrm{~m}$, and we interpret that Unit I was also deposited in deep water as turbidites.

Reflections in lithologic Unit II have lower frequency and slightly lower amplitude than those in overlying Unit I (Fig. F115). The reflections are not laterally continuous, and many intersect each other when traced laterally. There is one prominent and laterally continuous reflector in the upper third of lithologic Unit II that we refer to as seismic Surface S1. Although not apparent in Figure F115, Surface S1 is an onlap surface; overlying reflections terminate on this reflector to the south-southeast (apparent direction). The overall low amplitude in Unit II is broadly consistent with the interpretation that it is dominated by silty clay with silt and sand interbeds (see "Lithology").

Lithologic Unit III is a relatively transparent seismic facies (Fig. F115) with a few high-amplitude reflectors that correlate with the presence of gas (see above) in this unit. Surface S2 overlies the Unit II/III boundary by $\sim 50 \mathrm{~m}$ (Figs. F112, F113, F115). It trun- cates underlying reflectors, and overlying seismic reflectors downlap onto it with an apparent direction from south-southeast to north-northwest (Fig. F115).

Above Unconformity UC1, which lies near the base of Unit III, the seismic data are largely transparent, whereas below Unconformity UC1, high-amplitude reflectors record a distinct stratified new tilted basin (Fig. F115).

Unconformity UC2 lies at the base of Unit III; it separates reflective strata above from much less reflective but more chaotic and discontinuous reflectors below. Reflections within Unit III onlap Unconformity UC2 with an apparent north-northwest-southsoutheast direction. Lithologic Unit IV consists mainly of thin-bedded, fine-grained turbidites (see "Lithology"). Unit IV is more lithified and has more clay than overlying Unit III. It also contains interbedded mudstone and silt/sandstone interbeds, and dip increases downhole within this unit. Gamma ray values in Unit IV increase downhole, suggesting increased clay content, which is supported by XRD measurements (see "Lithology").

\section{Correlation between Sites $\mathrm{C0009}$ and $\mathrm{CO002}$}

We correlated Unconformity UC2, seismic Surfaces $\mathrm{S} 1$ and $\mathrm{S} 2$, and representative downlapping Reflectors S-A and S-B between Sites C0009 and C0002 (Table T22; Fig. F116). Surface S1 is a prominent reflection that carries laterally across the basin. Evidence of onlap is found in the vicinity of Site C0009 (Figs. F115, F116); however, it is difficult to see clear evidence of truncation or onlap to the south-southeast in the vicinity of Site C0002. At Site C0009, Surface S1 lies within the mudstone of lithologic Unit II at $620 \mathrm{~m}$ WMSF. No cuttings were recovered at this depth, and the lithologic unit is interpreted from MWD gamma ray logs only. At Site C0002, Surface S1 is shallower, at only 20 m WMSF, where it correlates with interbedded mud and ash with an age <0.5 Ma (Ashi et al., 2009) (Fig. F116).

Reflectors S-A and S-B downlap onto Surface S2 near Site C0009 (Fig. F116B), and cuttings samples acquired from this depth interval ( 710 m MSF) have an age younger than $\sim 0.9$ Ma (see "Biostratigraphy") (Fig. F116B). At Site C0002, seismic Reflectors S-A and S-B lie at $\sim 85$ and 92 mbsf, respectively, and the Unit I/II boundary, at $134 \mathrm{mbsf}$ and below Reflectors S-A and S-B, is interpreted to have an age of 0.9-1.0 Ma (Ashi et al., 2009) (Fig. F116B).

Seismic Surface S2 is a prominent seismic boundary that separates laterally continuous downlapping reflections above from a more acoustically transparent unit of variable thickness below (Fig. 
F116). Downlap proceeded with an apparent direction from south-southeast to the northnorthwest. The apparent downlap angle is steepest to the south-southeast (near Site C0002) and gradually flattens to the north-northwest (toward Site C0009). We expect that sediments above Surface S2 at Site C0009 will be younger than sediments above Surface S2 at Site C0002 because of this downlap relationship.

The seismic character of the material between Surface S2 and Unconformity UC2 can be traced between Sites C0009 and C0002, but individual surfaces are not easily interpretable, making specific correlations more difficult. Units III and IV, which lie below Surface S2, also have more variable seismic stratigraphic character than overlying units. At Site C0002, Unit III is a homogeneous mudstone that was interpreted as a condensed section of basal/early forearc basin or slope apron origin (Tobin et al., 2009b; Ashi et al., 2009). The age of Unit III at Site C0002 ranges from 1.7/2.0 to $3.65 \mathrm{Ma}$ (Fig. F116B, inset). At Site $\mathrm{C0002}$, the Unit II/III boundary lies $\sim 35 \mathrm{~m}$ above seismic Surface S2, and the Unit III/IV boundary lies slightly below Unconformity UC2 (Tobin et al., 2009b; Ashi et al., 2009) (Fig. F116B, inset). At Site C0009, Unit III ranges in age from $\sim 0.9$ to $3.8 \mathrm{Ma}$ and is five times the thickness $(\sim 500 \mathrm{~m}$ versus $\sim 100 \mathrm{~m}$ ) of Unit III at Site C0002, although it spans only twice the duration. Subunit IIIB at Site C0002 is approximately coeval with Unit III at Site C0002. Unit III at Site C0002 is composed of mudstone, with minor volcanic ash. However, Unit III at Site C0009 has some silt and ash beds. Unit III at Site C0009 is also distinguished from Unit III at Site $\mathrm{C} 0002$ by the presence of terrigenous organic matter. Unconformity UC2 is significant: age gaps of 1.4 and 1.8 m.y. are present at Sites 0002 and C0009, respectively (Fig. F116B, inset). Below Unconformity UC2, sediments are slightly older at Site C0009 (5.59 Ma) than at Site C0002 (5.04 Ma). The hiatus between deposition of Units IV and III is of approximately equal age and duration at both Sites C0009 and C0002, implying a tectonic event of regional significance at this time.

Unit IV at Site C0002 is considerably more deformed than overlying units based on observations from cores and seismic reflection data and is interpreted as accretionary prism material (Ashi et al., 2009; Tobin et al., 2009b). It also exhibits limited evidence of carbonate deposition (e.g., $\mathrm{CaCO}_{3}$ tests), suggesting deposition below the CCD. In comparison, Unit IV at Site C0009 is only mildly deformed (see "Structural geology"), and calcareous microfossil tests are present, indicating deposition above the CCD. We inter- pret Unit IV at Site C0009 as either frontally accreted trench sediment or as slope sediment deposited on the accretionary wedge or part of the earliest $\mathrm{Ku}$ mano Basin.

\section{Paleomagnetism}

Note: This section was contributed by Hirokuni Oda (Institute of Geology and Geoinformation, National Institute of Advanced Industrial Science and Technology, Central 7, 1-1-1 Higashi, Tsukuba 305-8567, Japan) and Xixi Zhao (Earth and Planetary Sciences Department, University of California Santa Cruz, 1156 High Street, Santa Cruz, CA 95064, USA).

Shipboard paleomagnetic studies for Site C0009 consisted of continuous measurements and progressive demagnetization of archive-half core sections. The natural remanent magnetization (NRM) was measured at $5 \mathrm{~cm}$ intervals for each core section (51 total), followed by alternating-field (AF) demagnetization at 10 and $20 \mathrm{mT}$ peak fields. Magnetic polarity has been assigned on the basis of the inclination of the stable remanent magnetization because of the lack of core orientation due to rotary drilling. As Site C0009 is situated at moderate latitude in the Northern Hemisphere, positive (downward directed) inclinations are taken to signify normal polarity and negative (upward directed) inclinations signify reversed polarity. As shown in Figure F117, remagnetization imparted by the coring process is commonly encountered at Site C0009: NRM inclinations are strongly biased toward vertical (mostly toward $+90^{\circ}$ ) in a majority of cores except the uppermost $30 \mathrm{~m}$ where sediments appear to be dominated by negative inclinations (Fig. F117A). Upon AF demagnetization to $20 \mathrm{mT}$, a significant decrease in intensity (about an order of magnitude, see Fig. F117B) and a shift of inclination toward shallower or negative values were observed (Fig, F117A). The negative shift in inclination is also clearly observed in histograms of inclinations for NRM and that for $20 \mathrm{mT}$ AF demagnetization and shows modes at $80^{\circ}-85^{\circ}$ and $75^{\circ}-80^{\circ}$, respectively (Fig. F118). These values are significantly different from the expected time-averaged geomagnetic field inclination at Site C0009 $\left( \pm 52^{\circ}\right)$. The absence of peaks in the negative part of the histogram may indicate the incomplete removal of coring-induced remanence and/or that perhaps the entire measured interval was deposited during a normal polarity period.

Because of the time constraints caused by the problems related to the ship's cryogenic magnetometer (see "Paleomagnetism" in the "Methods" chapter for more detailed explanation), we could not in- 
crease the level of AF demagnetization on the ship's cryogenic magnetometer to further remove the remagnetization or to collect discrete samples for stepwise thermal or AF demagnetization experiments to verify the polarity.

In summary, preliminary pass-through paleomagnetic data have revealed important magnetic signatures that await further verification in terms of age and origin. Further integrated work with shipboard micropaleontological data and structural measurements is required to constrain the timing and origin of the magnetization recorded by Site C0009 sediments.

\section{Discussion and conclusions}

\section{Geomechanics: stress and pore pressure}

We collected several data sets during riser drilling at Site C0009 that constrain both in situ stress orientation and magnitude. We also identified faults and fractures in cores and resistivity images that provide insight into deformation history (see "Structural geology"). Borehole breakouts inferred from wireline calipers in Unit IV (1285-1579.9 m WMSF) indicate that the maximum horizontal stress $\left(S_{\mathrm{H} \max }\right)$ is oriented northwest-southeast (Fig. F38). DITFs in borehole resistivity images $\sim 300-500 \mathrm{~m}$ uphole in Unit II ( 800-1000 m WMSF) are also compatible with a northwest-southeast oriented $S_{\text {Hmax }}$. This orientation for $S_{\mathrm{H} \max }$ is $\sim 90^{\circ}$ to that at Site C0002, located $\sim 20 \mathrm{~km}$ seaward in the Kumano Basin (Fig. F115) (Kinoshita, Tobin, Ashi, Kimura, Lallemant, Screaton, Curewitz, Masago, Moe, and the Expedition 314/315/316 Scientists, 2009). The emerging picture of stress state across the margin is that $S_{\mathrm{H} \max }$ is slightly oblique to the plate convergence direction (but approximately perpendicular to the trench) in the outer accretionary wedge (Fig. F38) and rotates $\sim 90^{\circ}$ within the seaward-most 15-20 km of the Kumano Basin where there is active northwest-southeast extension. Landward of this, $S_{\mathrm{Hmax}}$ rotates back to an orientation nearly perpendicular to the trench and similar to that on the outer slope.

We also obtained direct measurements of least principal stress magnitude $\left(\sigma_{3}\right)$ from a MDT hydraulic fracture test at $879 \mathrm{~m} \mathrm{WMSF}$ and an LOT at $704 \mathrm{~m}$ WMSF. In both cases, the vertical stress $\left(\sigma_{v}\right)$ is greater than the least principal stress. If we assume that the principal stresses are horizontal and vertical, then $\sigma_{3}$ is the minimum horizontal principal stress and the vertical stress is either the maximum or intermediate principal stress, depending on the value of the maximum horizontal stress. Taken together, the breakouts, DITFs, and in situ stress magnitude data indi- cate either a normal or strike-slip faulting regime. In the case of normal faults, the dominant strike would be northwest-southeast. The ratio of effective stresses $\left(\sigma_{\text {hmin }}^{\prime} / \sigma_{\mathrm{v}}^{\prime}\right)$ is significantly greater for the MDT measurement than the LOT, but we consider the MDT measurement to be slightly more reliable.

In addition to in situ stress indicators, we used resistivity images, seismic reflection data, and cores to document fault types and orientations as constraints on stress and deformation history (Fig. F42). The relative timing of different phases of faulting can be determined for some structures, but recent fault activity cannot be confirmed, except potentially where faults cut the seafloor in seismic reflection data. Fractures in FMI resistivity images trend northeast-southwest (including one documented normal fault) and we documented a range of fault types, crosscutting relationships, and orientations in cores within Unit IV. In seismic reflection data close to Site C0002, normal faults trending northeast-southwest are common, and a second less prevalent set trending northwest-southeast is also observed; many of these offset the seafloor (Moore et al., 2009) (Fig. F115). Recently active normal faults are less common in the landward part of the Kumano Basin near Site C0009, and the northwest-southeast trending set becomes slightly more common relative to the northeast-southwest trending set. The presence and orientation of normal faults in seismic reflection data (northwest-southeast trend dominant) are generally consistent with the in situ stress magnitude and orientation data. However, the dominant northeast-southwest strike of faults and fractures we documented in FMI images is not: if these structures are normal faults, they are inconsistent with the orientation of $S_{\text {Hmax }}$; whereas, if they are thrusts, they are inconsistent with the fact that $S_{\mathrm{hmin}}<S_{\mathrm{v}}$.

There are several possible explanations for this range of structural and geomechanical observations. One possibility is that the structures identified in FMI images are inactive and therefore do not relate directly to the present-day stress regime. This explanation is consistent with the fact that most of the fractures and faults measured in FMI data are resistive, suggesting they may not be active or critically stressed (e.g., Barton et al., 1995). A difference between past and in situ stress states could be related to variations in stress during the earthquake cycle or to long-term processes related to the migration of deformation. At Site C0002, long-term strain and modern stress indicators are in agreement and indicate extension normal to the margin (northwest-southeast). This state of stress could have existed at Site C0009 during an earlier phase and would explain the orientation of faults observed in FMI data. 
A second explanation is that structural observations and downhole measurements at different depths represent real changes in stress regime downhole. In this case, the stress regime would be consistent with normal faulting in the upper $900-1200 \mathrm{~m}$ WMSF and transition to one of lateral compression below this, perhaps across the boundary into Unit IV. Third, it is possible that the two horizontal principal stresses are very close in magnitude in the landward portion of the basin near Site C0009, such that $\sigma_{\text {hmin }}$ $\approx \sigma_{\mathrm{H} \max }<\sigma_{\mathrm{v}}$ (i.e., $\sigma_{3} \approx \sigma_{2}<\sigma_{1}$ ). This stress state would allow normal faulting on structures as observed in the seismic reflection data and FMI images, while also honoring the stress measurement data that indicate $\sigma_{\text {hmin }}<\sigma_{v}$. However, this hypothesis would not explain the observation of only one dominant (northeast-southwest) trend for structures in the FMI resistivity data.

\section{Forearc basin development and correlation to Site C0002: depositional and tectonic environment}

Our interpretation of new data from Site C0009, evaluated in the context of previous results from drilling in the Kumano Basin (Ashi et al., 2008), parallels the interpretation of geological and tectonic evolution initiated by the Expedition 314 and 315 scientists (Expedition 314 Scientists, 2009; Expedition 315 Scientists, 2009). Four lithologic units were described at both sites. These units (Units I and II taken together, Unit III, and Unit IV) comprise three depositional sequences (Fig. F115, F116; see "Background and objectives" and "Cuttings-Core-LogSeismic integration" for discussion of regional seismic surfaces).

At both Sites C0009 and C0002, Unit IV is composed of mudstone with thin-bedded, fine-grained turbidites. At Site C0002, the unit is significantly deformed and has limited evidence of carbonate deposition, interpreted as deposition near or below the CCD. This unit was interpreted as accretionary prism material by Expedition 314 and Expedition 315 scientists (Kinoshita, Tobin, Ashi, Kimura, Lallemant, Screaton, Curewitz, Masago, Moe, and the Expedition 314/315/316 Scientists, 2009). At Site C0009, Unit IV is weakly deformed and contains carbonate. Despite the presence of carbonate deposition and only modest deformation at Site C0009, Unit IV could represent frontally accreted prism sediment. Alternatively, this unit may represent trench-slope deposits or sediments deposited in the early Kumano Basin. Above Unit IV, Unconformity UC2 has $>1000 \mathrm{~m}$ of relief between Sites C0009 and C0002 and marks a hiatus of approximately equal age and duration at both sites ( 5.6-3.8 Ma) (Figs. F115, F116). This suggests a tectonic event of regional significance potentially related to the onset of out-ofsequence thrusting in the prism, underplating or ridge subduction.

Unit III at Site C0009 is 5 times the thickness of Unit III at Site C0002, although it spans only about twice the duration (Fig. F116). At Site C0002, Unit III is interpreted as a condensed mudstone section deposited in the early forearc basin (Ashi et al., 2009). At Site C0009, Unit III is composed of two subunits (IIIA and IIIB) and is distinguished from Unit III at Site $\mathrm{C0002}$ by the presence of silt and ash beds and abundant wood and lignite (Figs. F13, F19). Based primarily on the biostratigraphy, we interpret Subunit IIIB at Site C0009 as laterally equivalent to Unit III at Site C0002, representing early (unconformable) forearc basin or slope deposits.

Seismic Surface S2 separates laterally continuous downlapping reflections above from a more acoustically transparent unit of variable thickness below (Fig. F116A, F116B). Downlap proceeded with an apparent direction from the south-southeast to the north-northwest. Based on this observation and biostratigraphic constraints that indicate the underlying sediments are younger at Site C0009 than at Site C0002, we interpret Surface S2 as a time-transgressive downlap surface, which youngs to the northwest (landward). The apparent downlap angle is steepest to the south-southeast (near Site C0002) and gradually flattens to the north-northwest (toward Site C0009). Seismic Reflectors S-A and S-B downlap Surface S2 near Site C0009 (Fig. F116B). Above this, Units I and II define a package of sediments grading upward from mudstone (Unit II) to interbedded mudstone and sandstone (Unit I). This succession was deposited in both locations; however, it is greatly expanded at Site C0009 (Fig. F115). These strata record infilling of the Kumano Basin and the progressive migration of sediment deposition to the northwest, possibly related to slip on the megasplay fault.

\section{Plate boundary structure from the walkaway VSP experiment}

A collaborative effort between IODP CDEX and Japan Agency for Marine-Earth Science and Technology enabled a long-offset two-ship walkaway VSP experiment using an air gun source towed by the Kairei, along with a zero-offset VSP using a source at the drillship, in both cases shooting to receivers within the borehole. The walkaway VSP trackline consisted of a single line crossing the borehole, with offsets up to $30 \mathrm{~km}$, and a circular trackline around 
the borehole of $\sim 3.5 \mathrm{~km}$ radius to investigate anisotropy. The long offsets allowed refractions and reflections from the accretionary wedge, plate boundary, and subducting plate to be recorded at the wireline seismometers within the borehole to $\sim 1200 \mathrm{~m}$ DSF. Recording arrivals in the borehole environment provides a higher resolution image than surface ship and OBS acquisition because the seismometers are coupled to stiff and less attenuative formation; this configuration also allows high-fidelity measurement of shear waves converted from $P$-waves at formation boundaries. The data will allow seismic analyses of the velocity structure of the subduction zone forearc and the seismic attributes of the plate boundary in the region beneath the borehole at a depth of $\sim 10-12 \mathrm{~km}$.

\section{Insights from scientific riser operations}

Expedition 319 was noteworthy in that it marked the first riser drilling in IODP history. As noted above, this allowed us to conduct several scientific operations new to IODP, including measurement of in situ stress, permeability, and pore pressure; realtime analysis of mud gases; and analysis of cuttings to obtain sedimentological, chemical, and physical property data. Here, we briefly discuss key insights gained from each of these operations that may provide guidance in planning future scientific riser drilling.

\section{Stress, permeability, and pore pressure from MDT and LOT measurements}

In Hole C0009A, we deployed the MDT wireline logging tool to measure in situ formation pore pressure, permeability, and minimum principal stress magnitude $\left(\sigma_{3}\right)$ at several depth intervals. This was the first time that the tool had been used in IODP drilling because it is currently not usable with the small-diameter riserless borehole drilled by IODP. We conducted nine SPTs to measure formation pore pressure and fluid mobility, and three dual packer tests (one drawdown test to measure formation hydraulic properties and two hydraulic fracture tests to measure least principal stress magnitude) (Fig. F90). Successful future deployment of this tool to measure in situ pore pressure and stress magnitude deeper within the accretionary prism and in the vicinity of major fault zones will constitute a major breakthrough in understanding subduction zone fault mechanics and is a critical part of the Nankai Trough Seismogenic Zone Experiment (NanTroSEIZE) program. However, there are limitations in using the MDT tool successfully that warrant consideration, most notably that pore pressure and permeability measurements may be un- reliable in low-permeability formations $\left(k<\sim 10^{-15}\right.$ $\mathrm{m}^{2}$ ) because the time required for pressure equilibration can greatly exceed deployment time. This also highlights the value of obtaining FMI or other borehole imaging data prior to running the MDT in order to select measurement targets that will yield meaningful data.

\section{Sampling and analysis of cuttings and mud gas}

Samples from riser drilling mud, including cuttings and mud gas, were collected for the first time in IODP history during riser drilling in Hole C0009A. The results of shipboard analyses may provide guidance for future IODP riser drilling by demonstrating the types and quality of data that can be obtained from these materials, especially for shallow sediments and sedimentary rocks. In addition to basic lithologic description and biostratigraphic analysis, for sufficiently lithified cuttings (deeper than 1000 $\mathrm{m}$ DSF in $\sim 2.5$ Ma claystones) we were able to document deformation structures preserved in large $(>\sim 2$ $\mathrm{mm}$ ) cuttings, measure physical properties including porosity and density, and quantify composition by $\mathrm{XRD}, \mathrm{XRF}$, and carbonate analyses. We also conducted several experiments on cuttings and core samples to understand the sensitivity of shipboard measurements to cuttings processing techniques (including the composition of fluid used for washing and soaking time), the cuttings size fraction(s) used for analysis, and drilling mode and mud composition.

We identified several significant challenges in conducting analyses on cuttings. Comparisons between cuttings (collected from $5 \mathrm{~m}$ intervals) and wireline $\log$ data indicate a relatively small depth uncertainty of $\sim 10 \mathrm{~m}$, but mixing during mud ascent and/or cavings from uphole may occur over larger distances. We also found that cuttings may be preferentially preserved from particular lithofacies (e.g., more lithified or cohesive claystones) and thus provide a biased sampling of the formation because material from unconsolidated sands or mudstones was lost by disaggregation and could not be separated from drilling mud. Finally, we noted that absolute values for many measurements, including porosity, bulk density, and sediment geochemistry, do not accurately reflect formation properties because of physical and/ or chemical processes during circulation, retrieval, and laboratory handling. We conclude that sedimentological, physical property, and geochemical data from cuttings are useful for some applications such as defining overall lithofacies, age, characterization of mud rock provenance, basic chemistry, and firstorder compositional variations. Data from cuttings 
are probably less meaningful for other applications such as grain size assessment, detailed characterization of lithofacies, porosity determination, or detailed chemical analyses.

As one example of these issues, the high $\mathrm{pH}$ of the drilling mud and the mud composition (including additives to reduce mud loss) strongly affect measurements of carbonate, calcium content, and some other elements, as observed in XRD and XRF analyses. This also impacts relative mineral and element abundances from XRD and XRF. These effects are particularly clear when comparing measurements from cuttings and cores within the cored interval. Chemical contamination appears to be correlated with the time cuttings were exposed to drilling mud in the borehole (Fig. F20). Similarly, porosity values from cuttings are anomalously high, both with respect to their depth of origin and in comparison to $\log$ and core data, and this difference is affected by sample handling and soaking procedures (Figs. F61, F62; see also "Physical properties"). We conclude that the absolute values of compositional and physical property data from cuttings should be treated with caution but that some downhole trends may still be reliable.

We also monitored mud gas chemistry throughout riser drilling operations to document the composition and concentration of gas released from the formation as it was drilled. This method, used previously in International Continental Scientific Drilling Program drilling (e.g., Erzinger et al., 2006), was used in scientific ocean drilling for the first time during Expedition 319. One example of the value of these data comes from comparison of the mud gas, cuttings, and wireline logging data in Subunit IIIB. Increased mud gas methane concentrations are clearly correlated with increased wood content in the cuttings and with several intervals of low $V_{\mathrm{p}} / V_{\mathrm{S}}$ and Poisson's ratio observed in sonic velocity logs (Figs. F76, F77, F80; see also "Cuttings-Core-Log-Seismic integration"). Because pore water geochemical analyses are not possible on cuttings and are difficult on strongly lithified or low-porosity core samples, mud gas analysis is a promising approach for characterizing formation fluids in future deep riser drilling. Such data are important toward understanding hydrologic and geochemical processes associated with faulting and fluid flow.

\section{References}

Abbas, R., Jarouj, H., Dole, S., Junaidi, E.H., El-Hassan, H., Francis, L., Hornsby, L., McCraith, S., Shuttleworth, N., van der Plas, K., Messier, E., Munk, T., Nødland, N., Svendsen, R.K., Therond, E., and Taoutaou, S., 2004. A safety net for controlling lost circulation. Oilfield Rev., 15(4):20-27. http://www.slb.com/resources/publications/industry_articles/oilfield_review/2003/ or2003win02_lost_circulation.aspx

Angelier, J., 1994. Fault slip analysis and palaeostress reconstruction. In Hancock, P.L. (Ed.), Continental Deformation: Tarrytown, NY (Pergamon Press), 53-100.

Ashi, J., Lallemant, S., Masago, H., and the Expedition 315 Scientists, 2008. NanTroSEIZE Stage 1A: NanTroSEIZE megasplay riser pilot. IODP Prel. Rept., 315. doi:10.2204/iodp.pr.315.2008

Ashi, J., Lallemant, S., Masago, H., and the Expedition 315 Scientists, 2009. Expedition 315 summary. In Kinoshita, M., Tobin, H., Ashi, J., Kimura, G., Lallemant, S., Screaton, E.J., Curewitz, D., Masago, H., Moe, K.T., and the Expedition 314/315/316 Scientists, Proc. IODP, 314/ 315/316: Washington, DC (Integrated Ocean Drilling Program Management International, Inc.). doi:10.2204/iodp.proc.314315316.121.2009

Barton, C.A., Zoback, M.D., and Moos, D., 1995. Fluid flow along potentially active faults in crystalline rock. Geology, 23(8):683-686. doi:10.1130/0091-

7613(1995)023<0683:FFAPAF>2.3.CO;2

Borradaile, G.J., 1988. Magnetic susceptibility, petrofabrics and strain. Tectonophysics, 156(1-2):1-20. doi:10.1016/ 0040-1951(88)90279-X

Brie, A., Pampuri, F., Marsala, A.F., and Meazza, O., 1995. Shear sonic interpretation in gas-bearing sands. SPE Annu. Tech. Conf., 30595-MS. doi:10.2118/30595-MS

Brothers, R.J., Kemp, A.E.S., and Maltman, A.J., 1996. Mechanical development of vein structures due to the passage of earthquake waves through poorly consolidated sediments. Tectonophysics, 260(4):227-244. doi:10.1016/0040-1951(96)00088-1

Cowan, D.S., 1982. Origin of "vein structure" in slope sediments on the inner slope of the Middle America Trench off Guatemala. In Aubouin, J., von Huene, R., et al., Init. Repts. DSDP, 67: Washington, DC (U.S. Govt. Printing Office), 645-650. doi:10.2973/dsdp.proc.67.132.1982

Erzinger, J., Wiersberg, T., and Zimmer, M., 2006. Real-time mud gas logging and sampling during drilling. Geofluids, 6(3):225-233. doi:10.1111/j.14688123.2006.00152. $\mathrm{x}$

Expedition 314 Scientists, 2009. Expedition 314 Site C0002. In Kinoshita, M., Tobin, H., Ashi, J., Kimura, G., Lallemant, S., Screaton, E.J., Curewitz, D., Masago, H., Moe, K.T., and the Expedition 314/315/316 Scientists, Proc. IODP, 314/315/316: Washington, DC (Integrated Ocean Drilling Program Management International, Inc.). doi:10.2204/iodp.proc.314315316.114.2009

Expedition 315 Scientists, 2009. Expedition 315 Site C0002. In Kinoshita, M., Tobin, H., Ashi, J., Kimura, G., Lallemant, S., Screaton, E.J., Curewitz, D., Masago, H., Moe, K.T., and the Expedition 314/315/316 Scientists, Proc. IODP, 314/315/316: Washington, DC (Integrated Ocean Drilling Program Management International, Inc.). doi:10.2204/iodp.proc.314315316.124.2009

Flemings, P.B., Behrmann, I., Davies, T., John, C., and the Expedition 308 Project Team, 2005. Gulf of Mexico 
hydrogeology-overpressure and fluid flow processes in the deepwater Gulf of Mexico: slope stability, seeps, and shallow-water flow. IODP Sci. Prosp., 308. doi:10.2204/ iodp.sp.308.2005

Housen, B.A., Tobin, H.J., Labaume, P., Leitch, E.C., Maltman, A.J., and Ocean Drilling Program Leg 156 Shipboard Science Party, 1996. Stain decoupling across the décollement of the Barbados accretionary prism. Geology, 24(2):127-130. doi:10.1130/ 0091-7613(1996)024<0127:SDATDO > 2.3.CO;2

Isozaki, Y., and Itaya, T., 1990. Chronology of Sanbagawa metamorphism. J. Metamorph. Geol, 8(4):401-411. doi:10.1111/j.1525-1314.1990.tb00627.x

Kimura, G., Screaton, E.J., Curewitz, D., and the Expedition 316 Scientists, 2008. NanTroSEIZE Stage 1A: NanTroSEIZE shallow megasplay and frontal thrusts. IODP Prel. Rept., 316. doi:10.2204/iodp.pr.316.2008

Kinoshita, M., Tobin, H., Ashi, J., Kimura, G., Lallemant, S., Screaton, E.J., Curewitz, D., Masago, H., Moe, K.T., and the Expedition 314/315/316 Scientists, 2009. Proc. IODP, 314/315/316: Washington, DC (Integrated Ocean Drilling Program Management International, Inc.). doi:10.2204/iodp.proc.314315316.2009

Kobayashi, S., et al., 2009. Technical Report Volume 7: Drilling Program NanTroSEIZE Stage 2: IODP Expedition 319 and 322: Yokohama (CDEX JAMSTEC).

Lindsley-Griffin, N., Kemp, A., and Swartz, J.F., 1990. Vein structures of the Peru margin, Leg 112. In Suess, E., von Huene, R., et al., Proc. ODP, Sci. Results, 112: College Station, TX (Ocean Drilling Program), 3-16. doi:10.2973/ odp.proc.sr.112.130.1990

Martini, E., 1971. Standard Tertiary and Quaternary calcareous nannoplankton zonation. In Farinacci, A. (Ed.), Proc. 2nd Int. Conf. Planktonic Microfossils Roma: Rome (Ed. Tecnosci.), 2:739-785.

Meyers, P.A., 1997. Organic geochemical proxies of paleoceanographic, paleolimnologic, and paleoclimatic processes. Org. Geochem., 27(5-6):213-250. doi:10.1016/ S0146-6380(97)00049-1

Moore, G.F., Park, J.-O., Bangs, N.L., Gulick, S.P., Tobin, H.J., Nakamura, Y., Sato, S., Tsuji, T., Yoro, T., Tanaka, H., Uraki, S., Kido, Y., Sanada, Y., Kuramoto, S., and Taira, A., 2009. Structural and seismic stratigraphic framework of the NanTroSEIZE Stage 1 transect. In Kinoshita, M., Tobin, H., Ashi, J., Kimura, G., Lallemant, S., Screaton, E.J., Curewitz, D., Masago, H., Moe, K.T., and the Expedition 314/315/316 Scientists, Proc. IODP, 314/315/316: Washington, DC (Integrated Ocean Drilling Program Management International, Inc.). doi:10.2204/iodp.proc.314315316.102.2009

Mountain, G.S., Miller, K.G., Blum, P., et al., 1994. Proc. ODP, Init. Repts., 150: College Station, TX (Ocean Drilling Program). doi:10.2973/odp.proc.ir.150.1994
Nelson, E.B., and Guillot, D., 1990. Well Cementing: Sugarland, TX (Schlumberger Educational Services).

Ogawa, Y., 1980. Beard-like veinlet structure as fracture cleavage in the Neogene siltstone in the Miura and Boso peninsulas, central Japan. Sci. Rep. Dept. Geol., Kyushu Univ., 13:321-327.

Ohsumi, T., and Ogawa, Y., 2008. Vein structures, like ripple marks, are formed by short-wavelength shear waves. J. Struct. Geol., 30(6):719-724. doi:10.1016/ j.jsg.2008.02.002

Papadopulos, S.S., Bredehoeft, J.D., and Cooper, H.H., Jr., 1973. On the analysis of 'slug test' data. Water Resour. Res., 9(4):1087-1089. doi:10.1029/WR009i004p01087

Petit, J.P., 1987. Criteria for the sense of movement on fault surfaces in brittle rocks. J. Struct. Geol., 9(5-6):597-608. doi:10.1016/0191-8141(87)90145-3

Raffi, I., Backman, J., Fornaciari, E., Pälike, H., Rio, D., Lourens, L., and Hilgen, F., 2006. A review of calcareous nannofossil astrobiochronology encompassing the past 25 million years. Quat. Sci. Rev., 25(23-24):3113-3137. doi:10.1016/j.quascirev.2006.07.007

Taira, A., Katto, J., Tashiro, M., Okamura, M., and Kodama, K., 1988. The Shimanto Belt in Shikoku, Japan: evolution of Cretaceous to Miocene accretionary prism. Mod. Geol., 12:5-46.

Tobin, H., Kinoshita, M., Ashi, J., Lallemant, S., Kimura, G., Screaton, E.J., Moe, K.T., Masago, H., Curewitz, D., and the Expedition 314/315/316 Scientists, 2009a. NanTroSEIZE Stage 1 expeditions: introduction and synthesis of key results. In Kinoshita, M., Tobin, H., Ashi, J., Kimura, G., Lallemant, S., Screaton, E.J., Curewitz, D., Masago, H., Moe, K.T., and the Expedition 314/315/316 Scientists, Proc. IODP, 314/315/316: Washington, DC (Integrated Ocean Drilling Program Management International, Inc.). doi:10.2204/ iodp.proc.314315316.101.2009

Tobin, H., Kinoshita, M., Moe, K.T., and the Expedition 314 Scientists, 2009b. Expedition 314 summary. In Kinoshita, M., Tobin, H., Ashi, J., Kimura, G., Lallemant, S., Screaton, E.J., Curewitz, D., Masago, H., Moe, K.T., and the Expedition 314/315/316 Scientists, Proc. IODP, 314/315/316: Washington, DC (Integrated Ocean Drilling Program Management International, Inc.). doi:10.2204/iodp.proc.314315316.111.2009

Zoback, M.D., 2007. Reservoir Geomechanics: Cambridge (Cambridge Univ. Press).

Publication: 31 August 2010 MS 319-103 
Figure F1. Casing program, Hole C0009A. Casing depths are in DSF. TD = total depth.

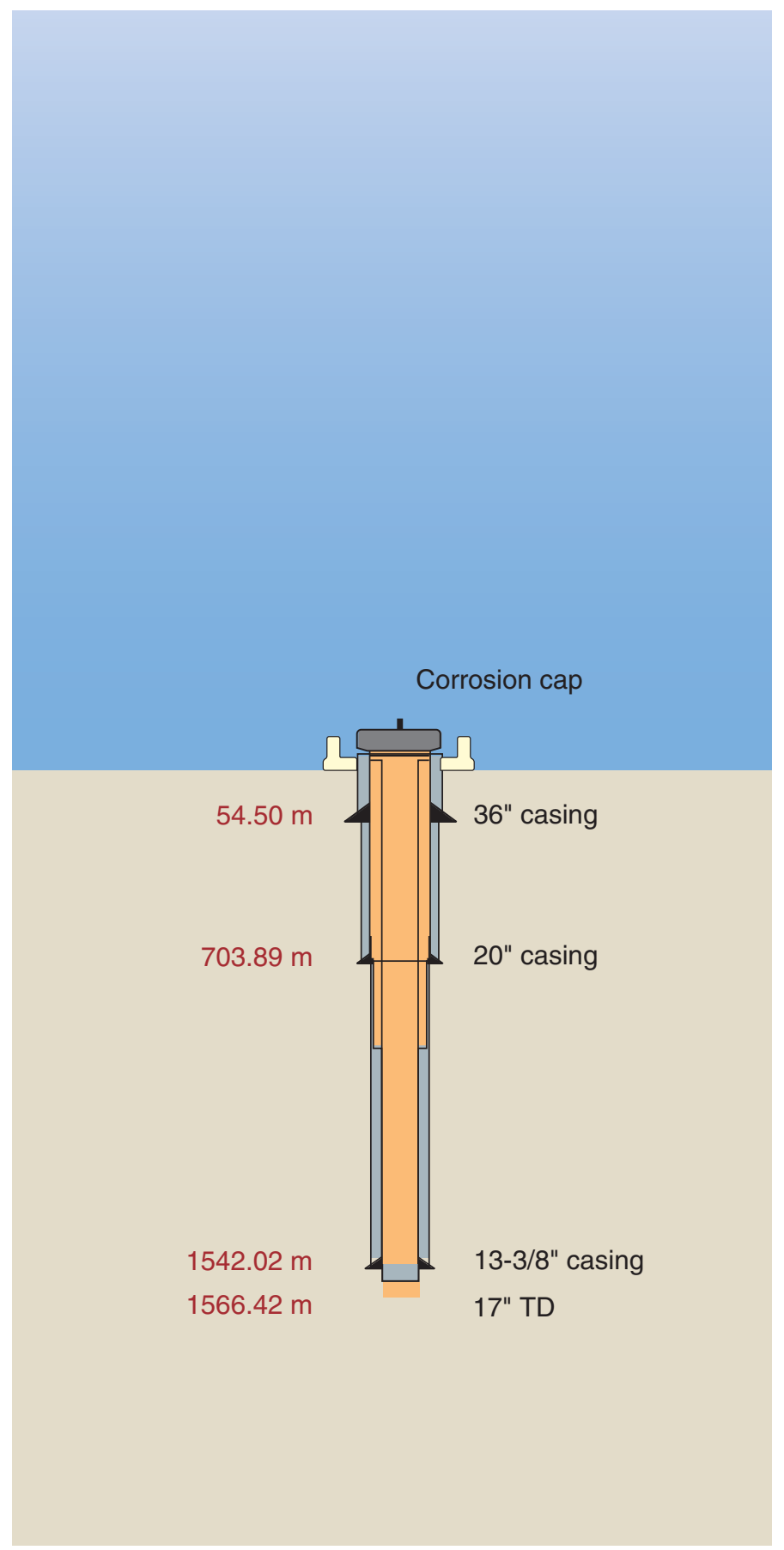


Figure F2. Example showing pressures resulting from a column of $1.07 \mathrm{~g} / \mathrm{cm}^{3}$ mud (black) in $2000 \mathrm{~m}$ water depth for riser and riserless cases (as noted). Mud pressure is much higher in the riser example because the column extends from the top of the riser (near or slightly above sea level) to the seafloor. Hydrostatic, lithostatic, and riserless mud pressures are all equal (at hydrostatic pressure) at the seafloor (2000 mbsl).

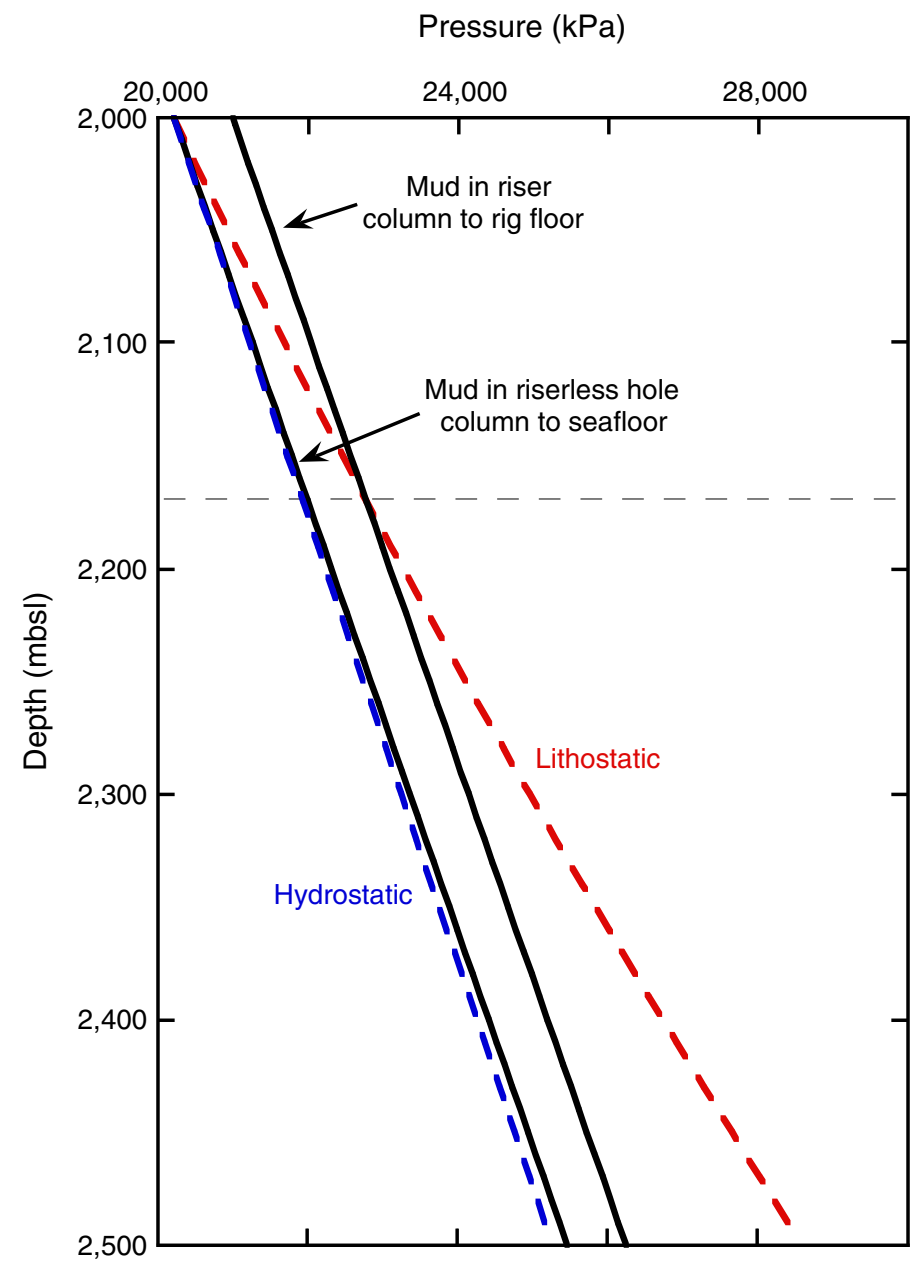


Figure F3. A. Pressure as a function of depth for 26 inch riserless hole. All pressures are referenced to seafloor, as discussed in text. B. Equivalent circulating density (ECD) computed from APWD measurements. Black symbols = APWD measured by MWD, black line = static column pressure for $1.04 \mathrm{~g} / \mathrm{cm}^{3}$ mud weight, dashed line = static column pressure for $1.20 \mathrm{~g} / \mathrm{cm}^{3}$ mud weight, red line $=$ lithostatic pressure, gray shaded region = depth of 36 inch surface casing. Note that pressures (and ECD) decrease when pipe connections are made.

A

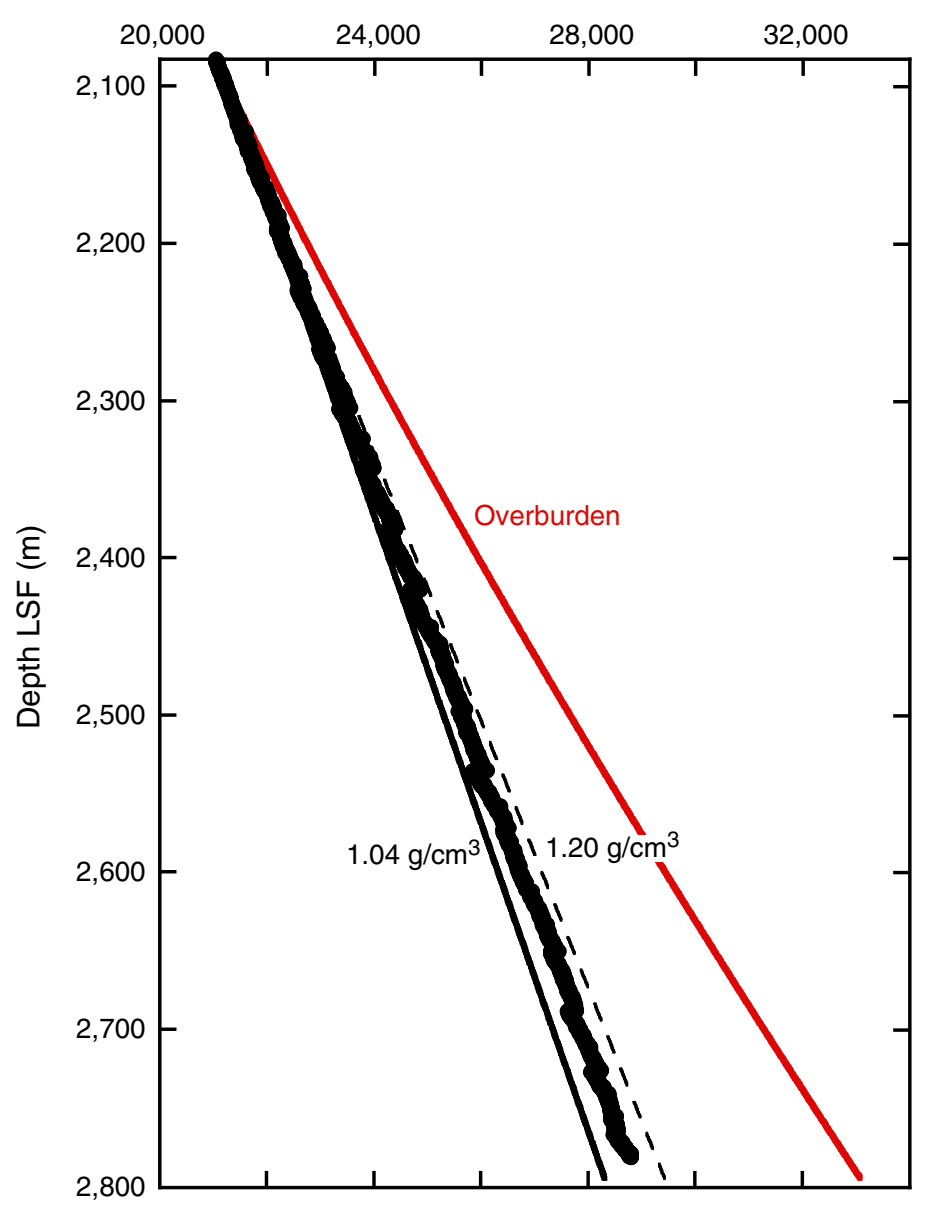

B

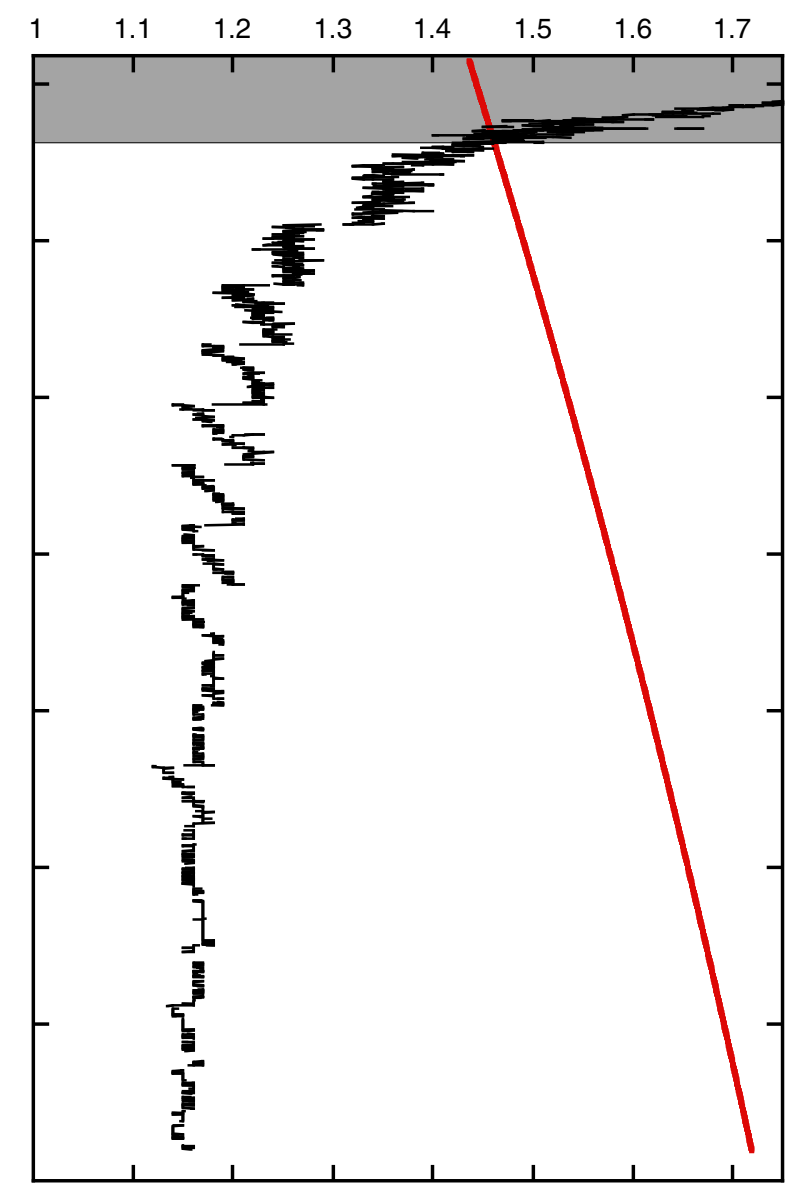


Figure F4. A. Mud loss versus time during riser operations. B. Mud loss versus mud weight.
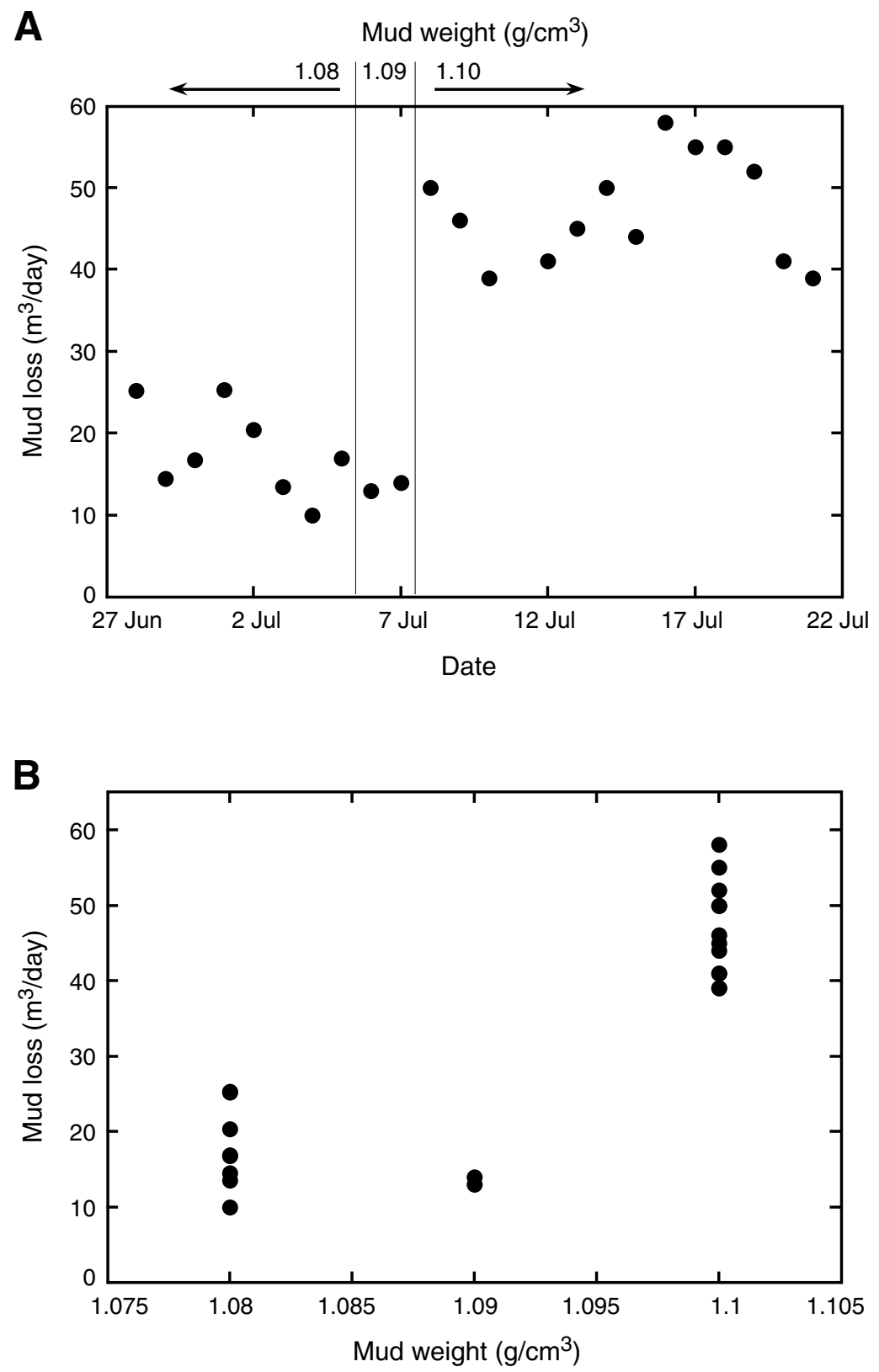
Figure F5. A. Pressure as a function of depth in $12^{1 / 4}$ inch riser hole (circles), measured by MDT tool during wireline logging Run 3. Pressures for riser drilling are referenced to rig floor (top of riser pipe, $28.3 \mathrm{~m}$ above sea level). B. Pressure versus depth in $12^{1 / 4}$ inch riser hole as in A. MDT measurements indicate static mud column pressure $=1.13 \mathrm{~g} / \mathrm{cm}^{3}$. C. Equivalent circulating density (ECD) as a function of depth in $121 / 4$ inch riser hole. Open square $=$ fracture pressure measured by LOT, solid square $=$ fracture pressure measured by MDT, blue line $=$ hydrostatic pressure $($ for comparison), red line = lithostatic pressure (for comparison), black lines = reference lines for static mud columns of $1.06,1.08,1.12$, and $1.14 \mathrm{~g} /$ $\mathrm{cm}^{3}$, yellow line $=$ intended mud weight of $1.10 \mathrm{~g} / \mathrm{cm}^{3}$, gray shaded region $=$ depth of upper 20 inch casing.

A Pressure (MPa) B

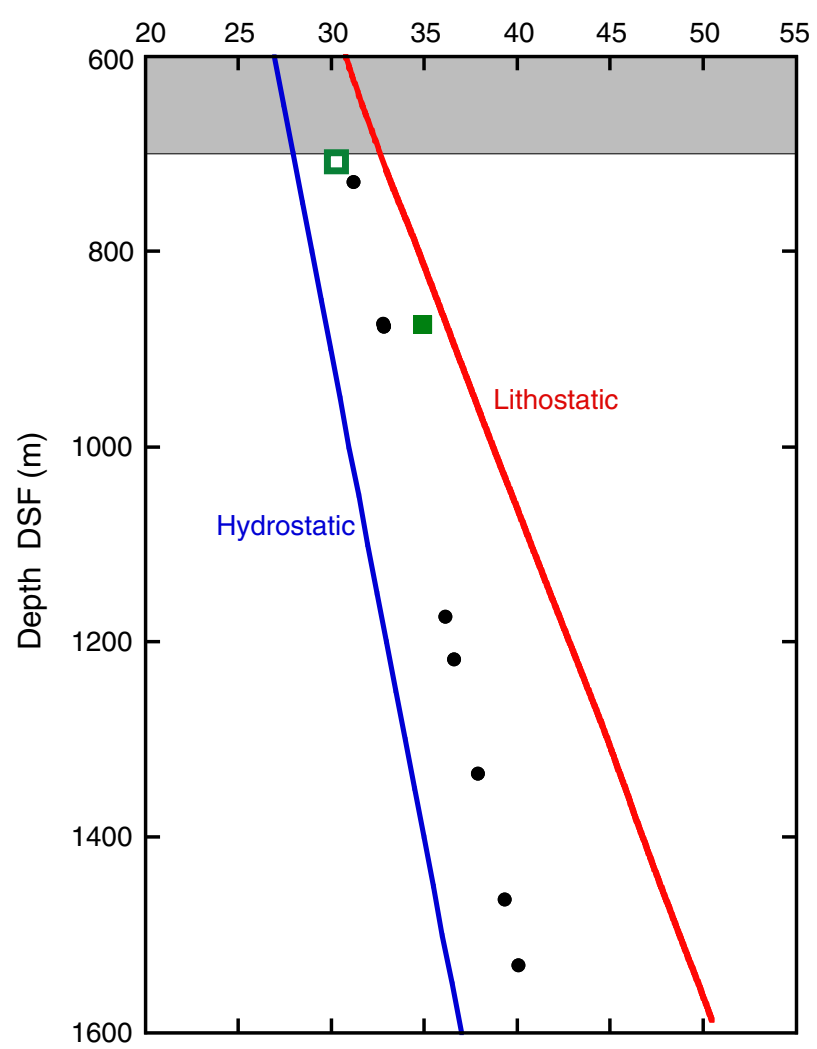

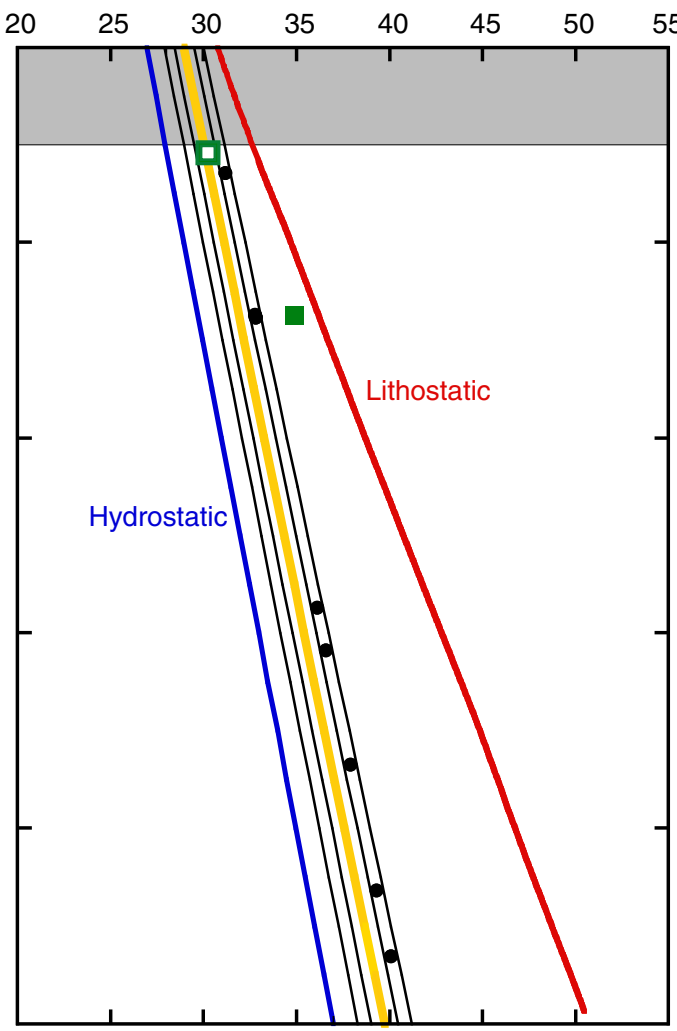

C

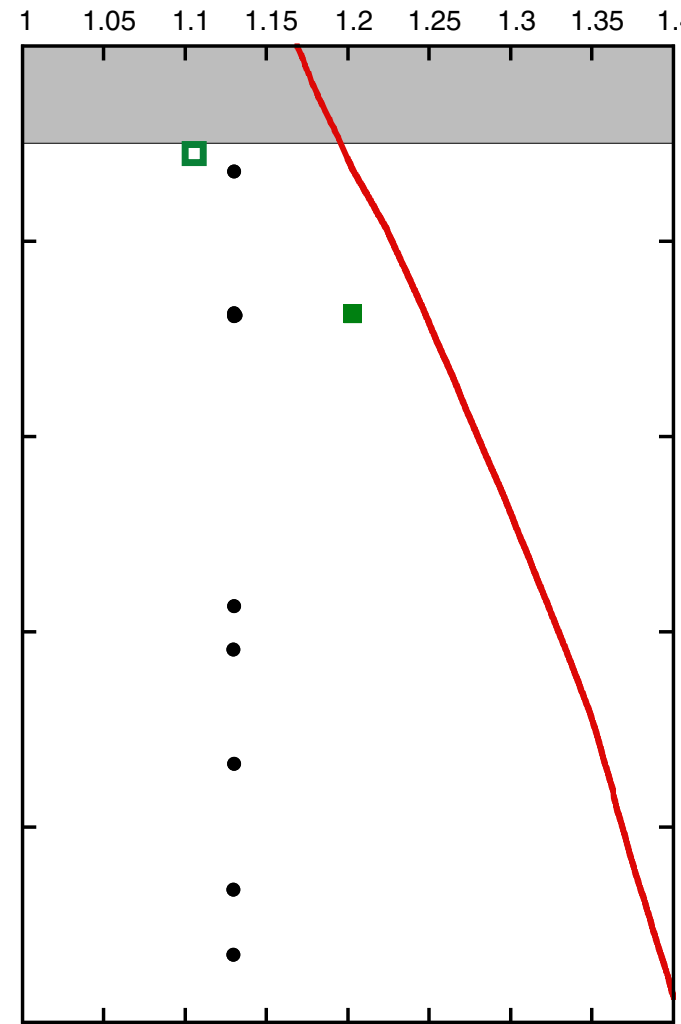


Figure F6. MWD gamma ray log, Hole C0009A.

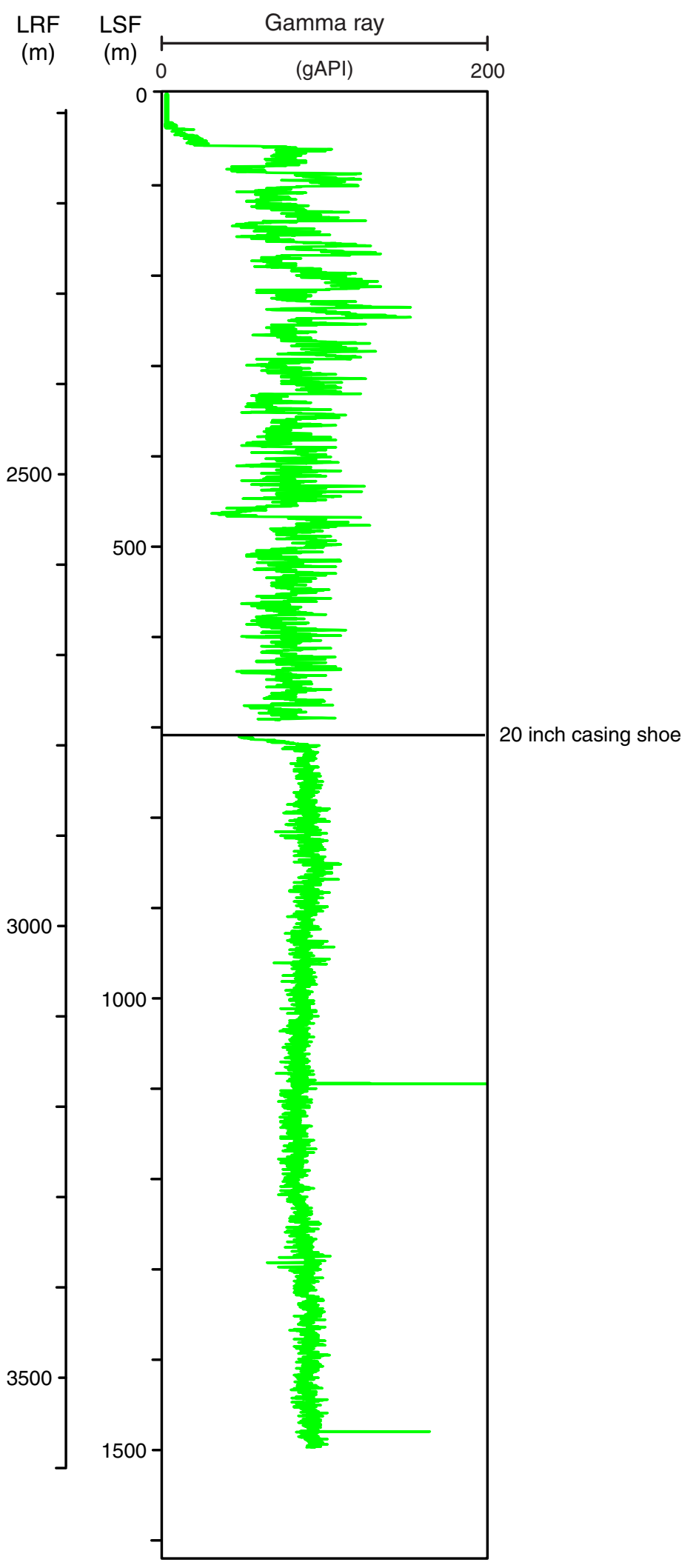


Figure F7. Composite wireline logs collected from logging Runs 1 and 2 (Drilling Phases 5 and 6; see Table T1 for Hole C0009A and their data quality indicators). From left to right: lithologic units, gamma ray, density, neutron porosity, photoelectric effect (PEF), resistivity, spontaneous potential (SP), $P$ - and $S$-wave velocity, calipers, and data quality indicators for sonic velocity, resistivity images, and other logs except neutron porosity. Data quality: green $=$ good, yellow $=$ moderate, black $=$ poor .

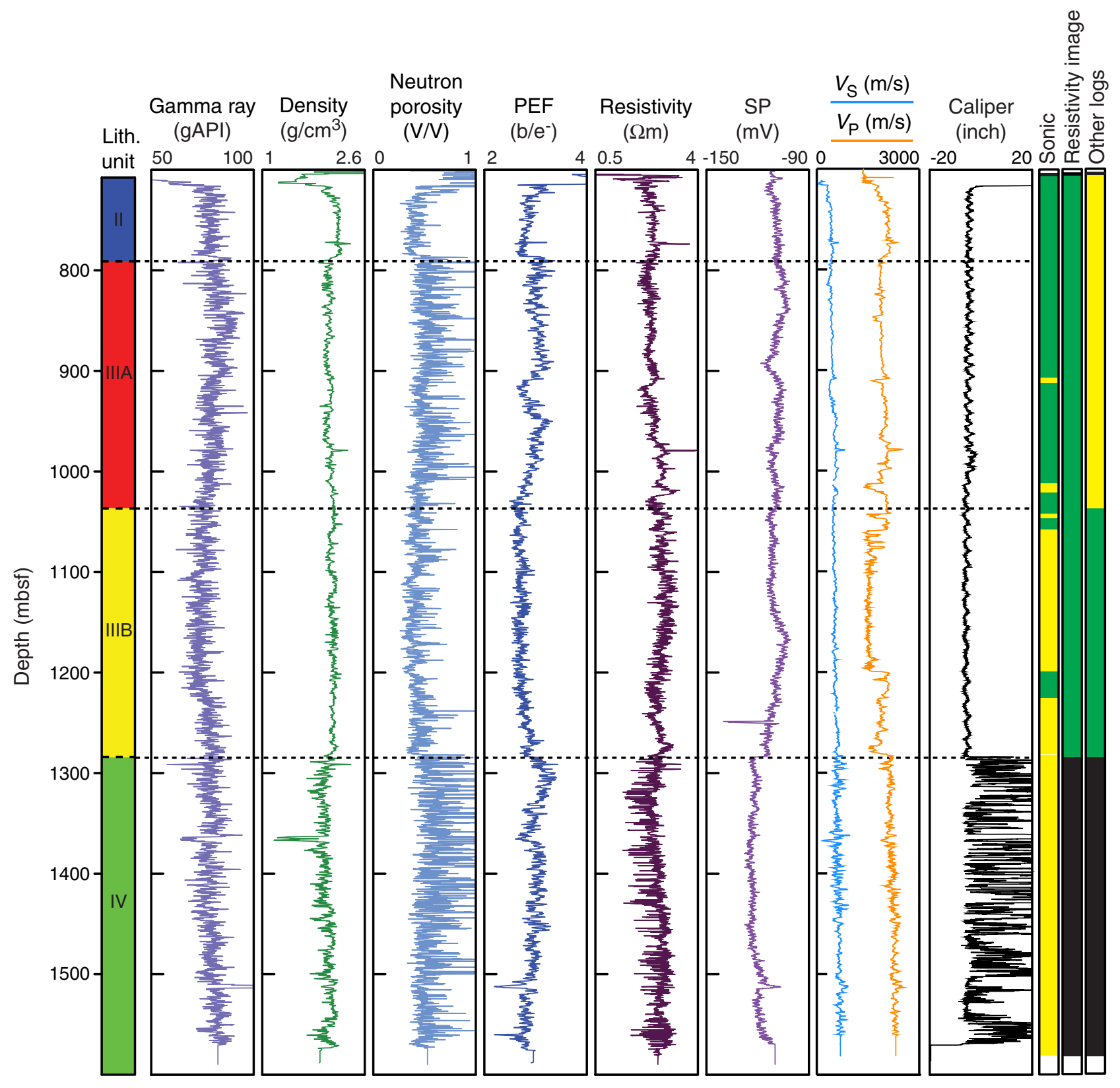


Figure F8. Downhole logging runs, Site C0009. TD = total depth, MWD = measurement while drilling, APWD = annular pressure while drilling, GR = gamma ray, PEX = Platform Express, HRLA = High-Resolution Laterolog Array, EMS = Environmental Measurement Sonde, FMI = Formation MicroImager, MDT = Modular Formation Dynamics Tester, VSP = vertical seismic profile.

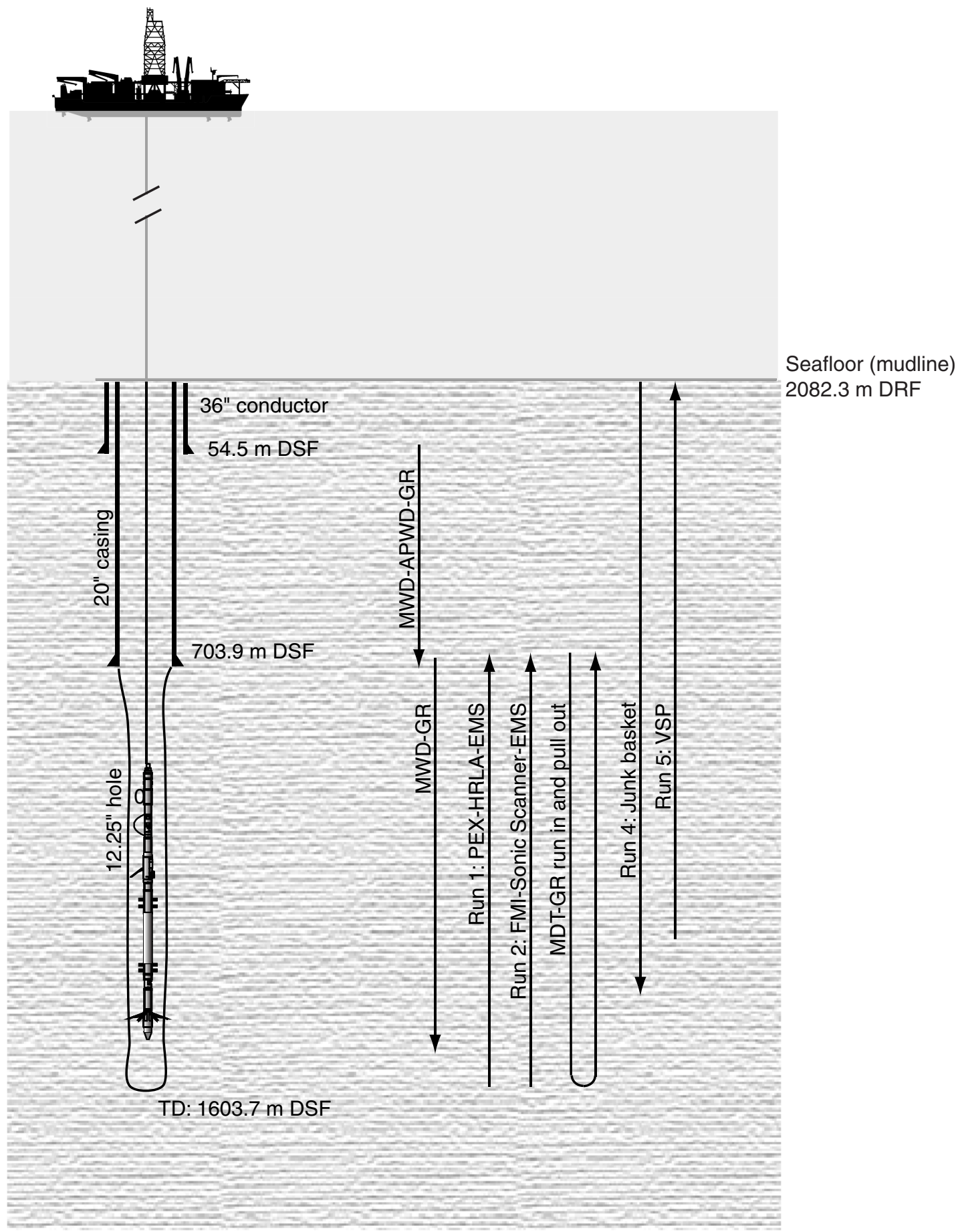


Figure F9. Hole configuration and depth around 20 inch casing shoe. LOT = leak-off test.

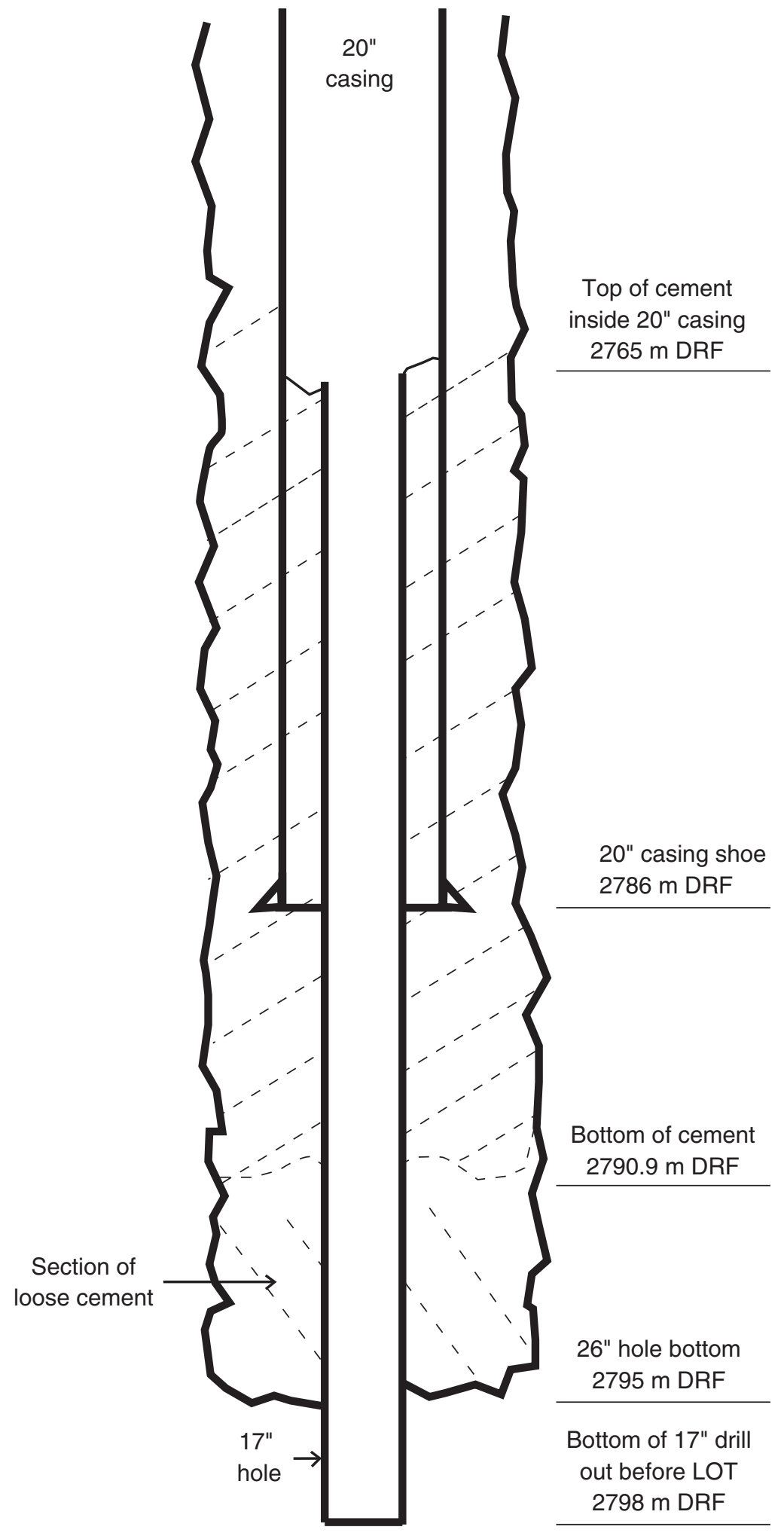


Figure F10. Wireline logs recorded in Hole C0009A, including gamma ray, minimum and maximum hole diameter, hole diameter derived from caliper, resistivity, and density, showing methods for correlating and depth-shifting of wireline log data. Note that NGR from vertical seismic profile (VSP) run was collected after completion of $13 \% 3$ inch casing.

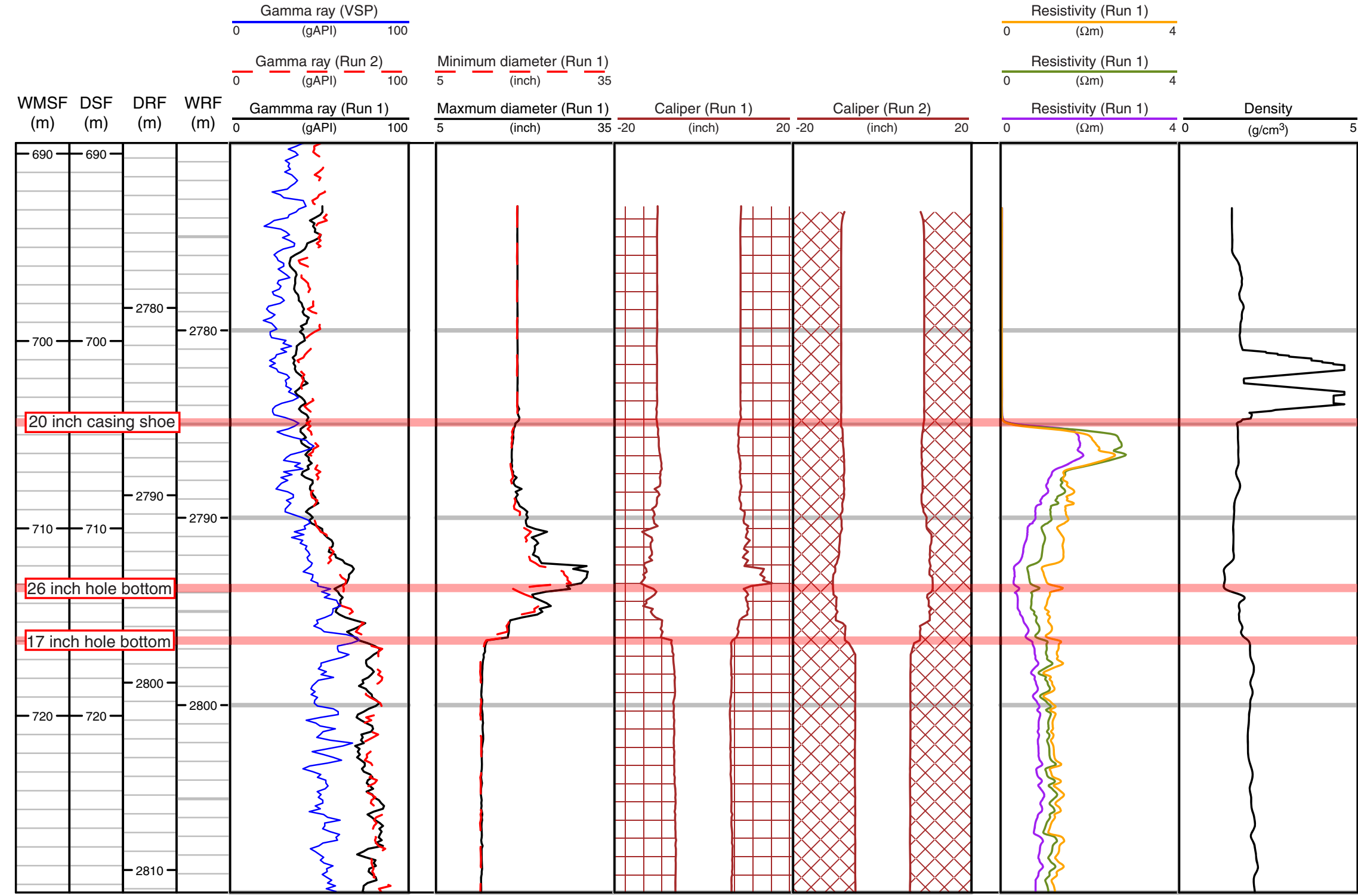


Figure F11. Diagram of reference depths (see "Introduction" in the "Methods" chapter, "Cuttings-Core-LogSeismic integration," and Table T1 in the "Expedition 319 summary" chapter) and correlation between depth scales. TD = total depth.

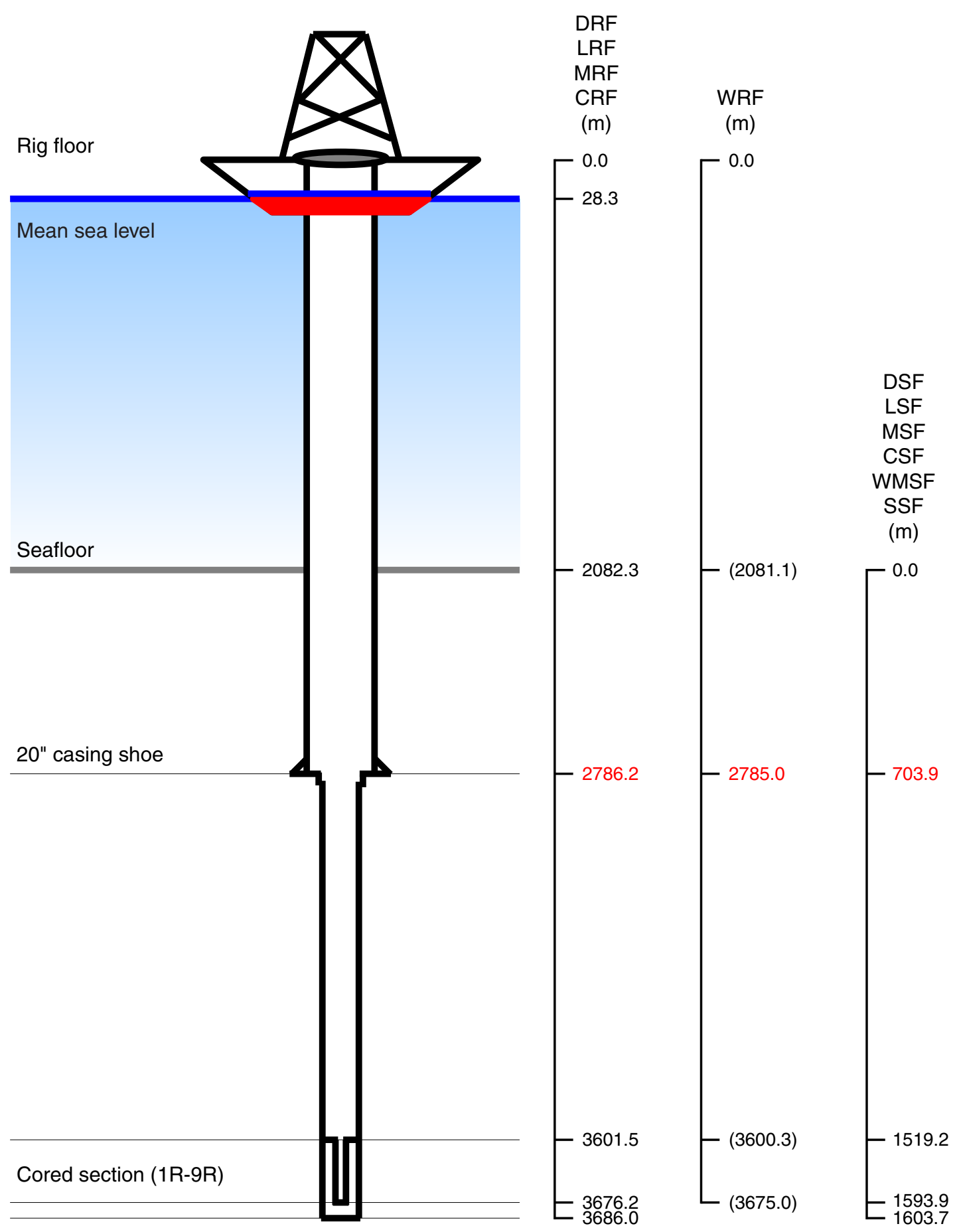

Hole bottom (TD) 
Figure F12. Wireline logging tool strings used in Expedition 319. A. Environmental Measurement Sonde (EMS)-High-Resolution Laterolog Array (HRLA)-Platform Express (PEX)-gamma ray (GR). HGNS = Highly Integrated Gamma Ray Neutron Sonde, PEF = photoelectric effect, HRMS = HighResolution Mechanical Sonde. B. Formation MicroImager (FMI)-Hostile Natural Gamma Ray Spectrometry Cartridge (HNGC)-Sonic Scanner-EMSPower Positioning Device and Caliper Tool (PPC). C. Modular Formation Dynamics Tester (MDT)-GR. D. Junk basket. CCL = casing-collar log. E. Walkaway and zero-offset vertical seismic profile (VSP). Each shuttle connected by wireline. VSI = Versatile Seismic Imager.

A

EMS-HRLA-PEX-GR

B

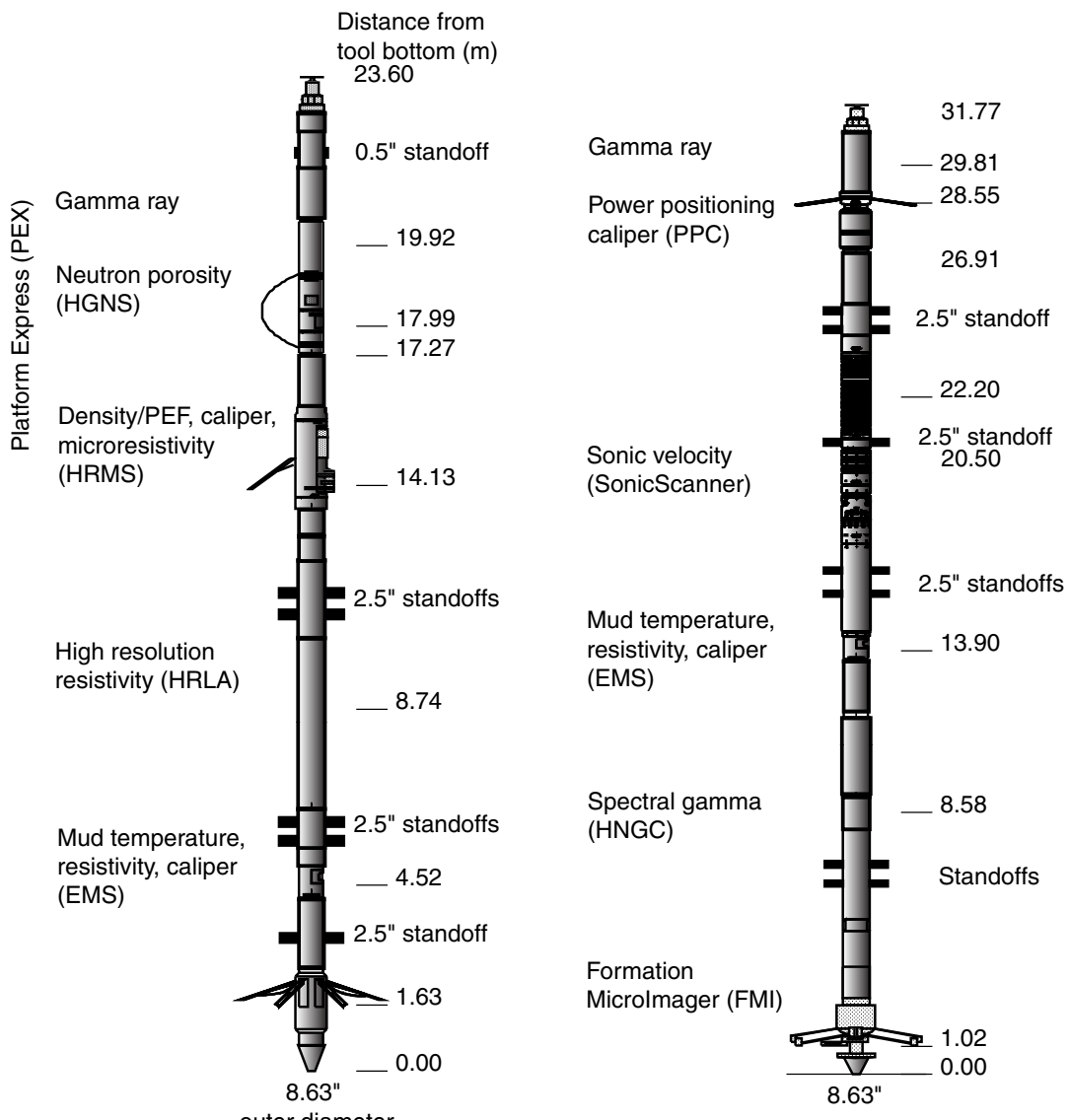

C

MDT-GR

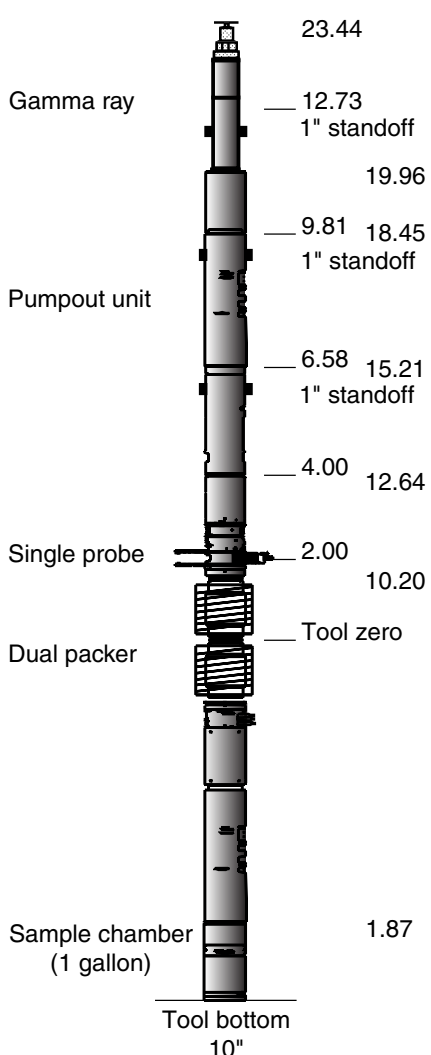

D

Junk basket
E

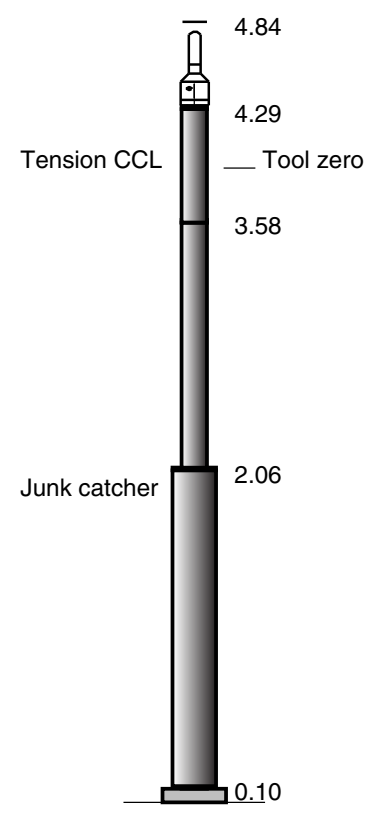


Figure F13. Interpreted lithologic changes at Hole C0009A, correlated to NGR measurements. MWD = measurement while drilling.

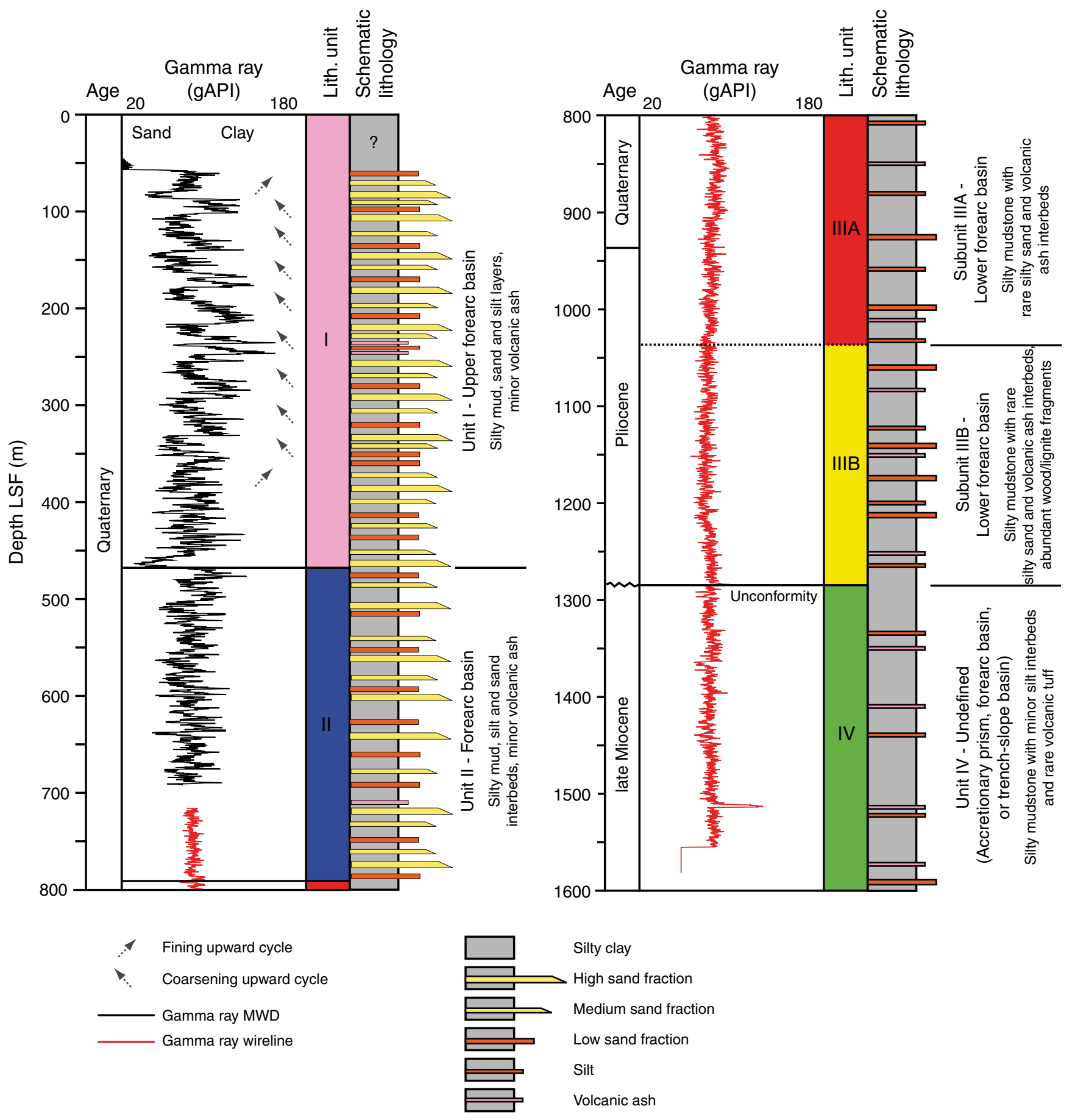


Figure F14. Binocular photographs of washed cuttings sieved to $0.25-1 \mathrm{~mm}$ and $>1 \mathrm{~mm}$ from each unit (Unit II, Subunits IIIA and IIIB, and Unit IV).

$>1 \mathrm{~mm}$
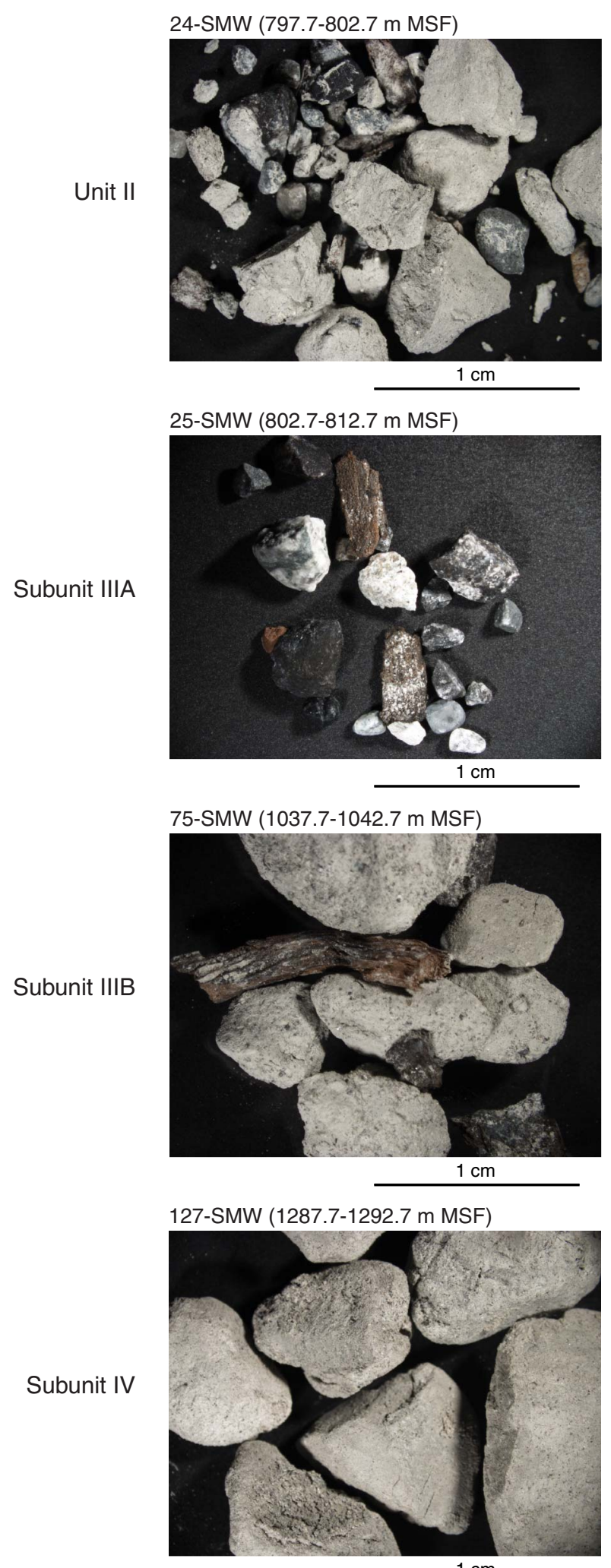

$1 \mathrm{~cm}$
0.25-1 $\mathrm{mm}$

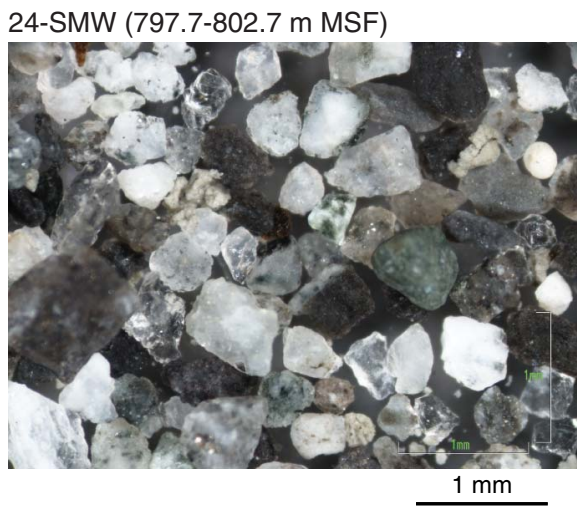

25-SMW (802.7-812.7 m MSF)

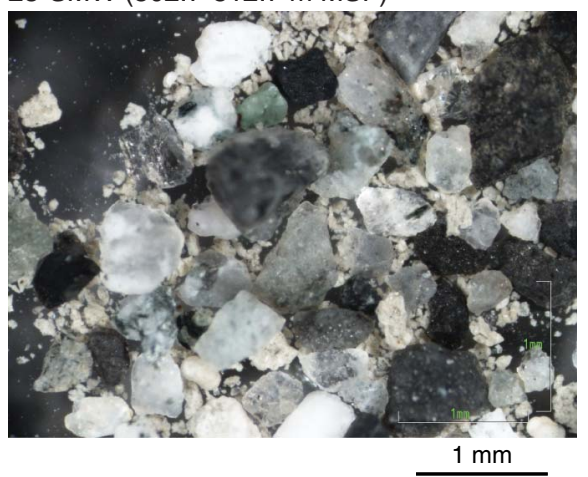

89-SMW (1107.7-1112.7 m MSF)

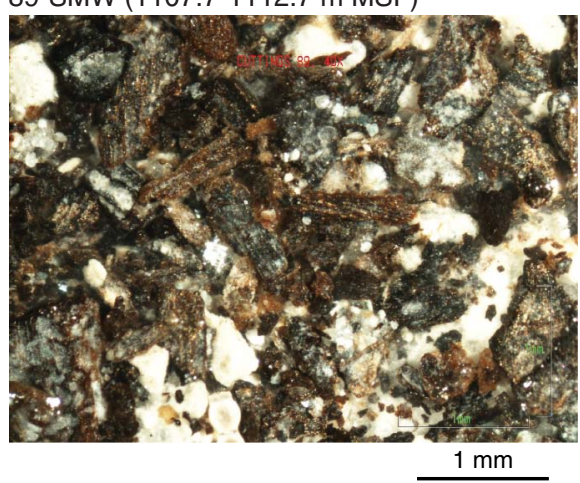

127-SMW (1287.7-1292.7 m MSF)

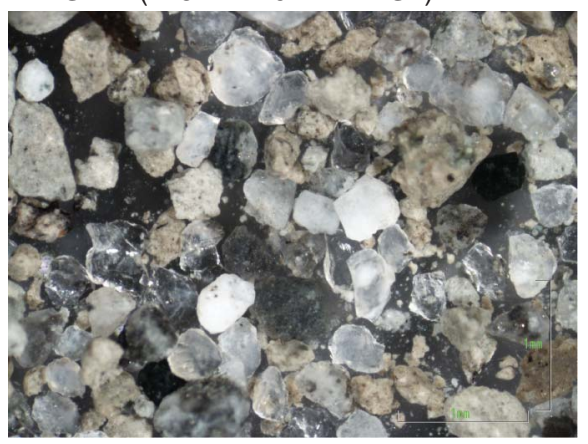

$1 \mathrm{~mm}$ 
Figure F15. Binocular photographs of fine-grained cuttings samples, Units II and III. A. Sample 319-C0009A25-SMW (802.7-807.7 m MSF, Subunit IIIA) displaying a volcanic glass fragment. B. Sample 319-C0009A-15SMW (752.7-757.7 m MSF, Unit II) highlighting a zircon. C. Sample 319-C0009A-81-SMW (1067.7-1072.7 m MSF, Subunit IIIB) with (a) pyritized wood, (b) wood/lignite, and (c) rounded glauconite. D. Grain of quartzite in Sample 319-C0009A-25-SMW (802.7-807.7 m MSF, Subunit IIIA). E. Sample 319-C0009A-134-SMW (1317.7-1322.7 m MSF, Unit IV) showing a fossil replaced by pyrite. F. Sample 319-C0009A-71-SMW (1017-1022 m MSF, Subunit IIA) showing rounded glauconite.
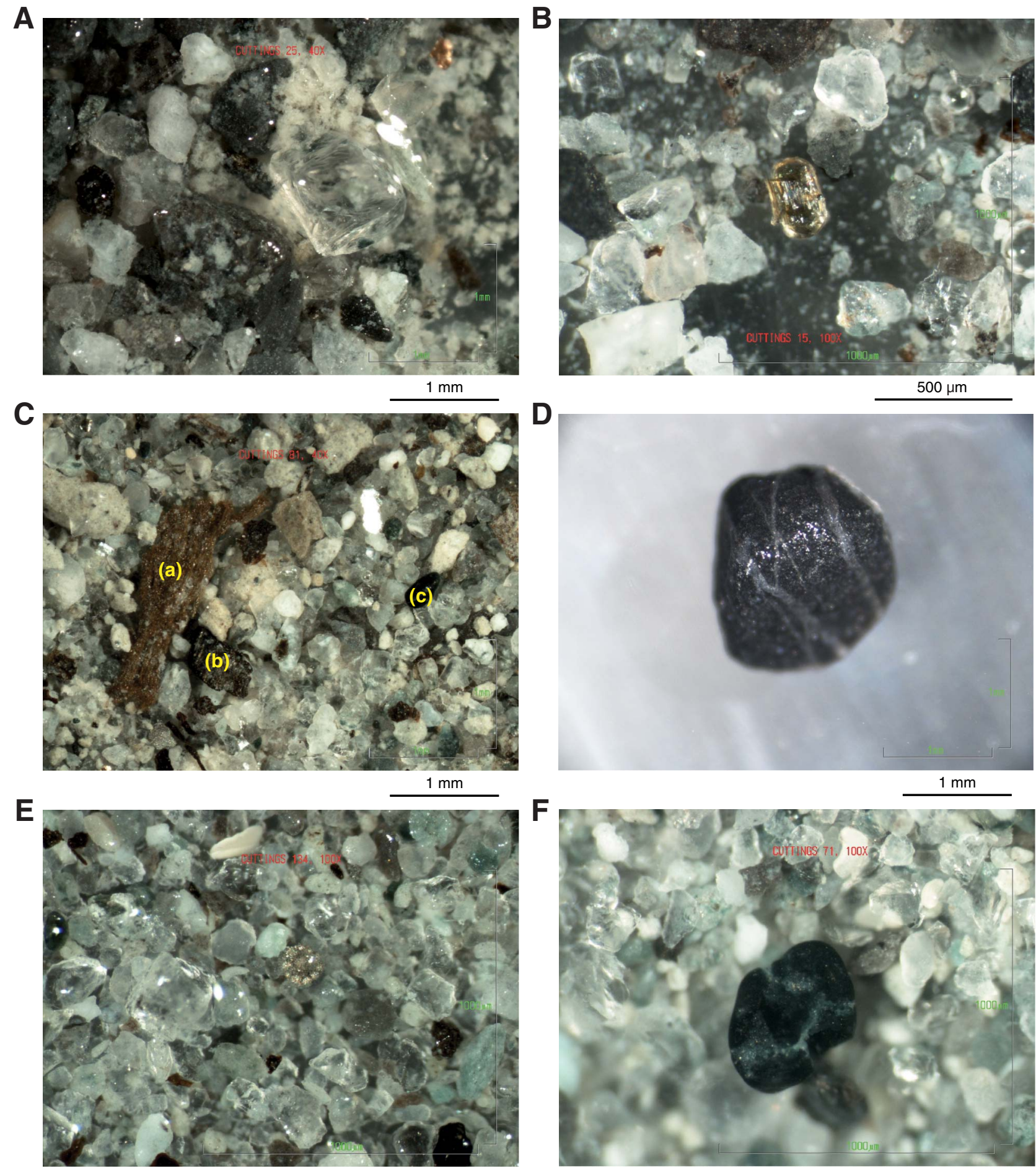

$500 \mu \mathrm{m}$

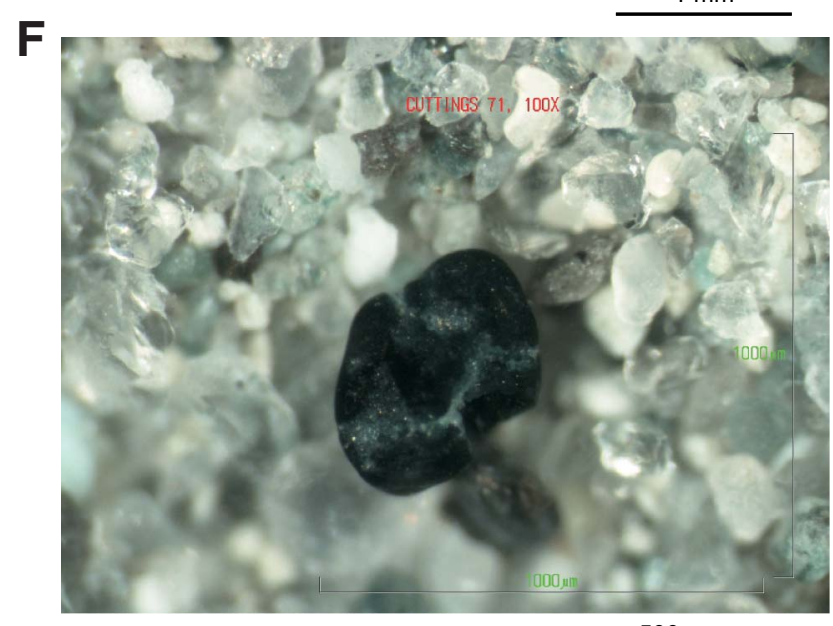

$500 \mu \mathrm{m}$ 
Figure F16. Thin section photographs of cuttings samples and core. A. Sample 319-C0009A-23-SMW (792.7797.7 m MSF, Unit II) (polarized light) with (i) sediment fragments probably reworked from Outer Zone of Japan, and (ii, iii) metasediment grains. B. Same as A in cross-polarized light. C. Sample 319-C0009A-156-SMW (1422.7-1427.7 m MSF, Unit IV) (polarized light) with sponge spicule fragments, (i) globigerins, and (ii) a fragment of mollusk. D. Same as C in reflected light, displaying pyritization of smaller organic fragments. E. Turbiditic layering in a packed biomicrite from Core 319-C0009A-06R-04 ( 1557 m CSF, Unit IV). F. Sample 319-C0009A-160-SMW (1437.7-1442.7 m MSF, Unit IV) representing a typical interturbiditic biomicrite (silty claystone) with (i) globigerins and (ii) radiolarians.
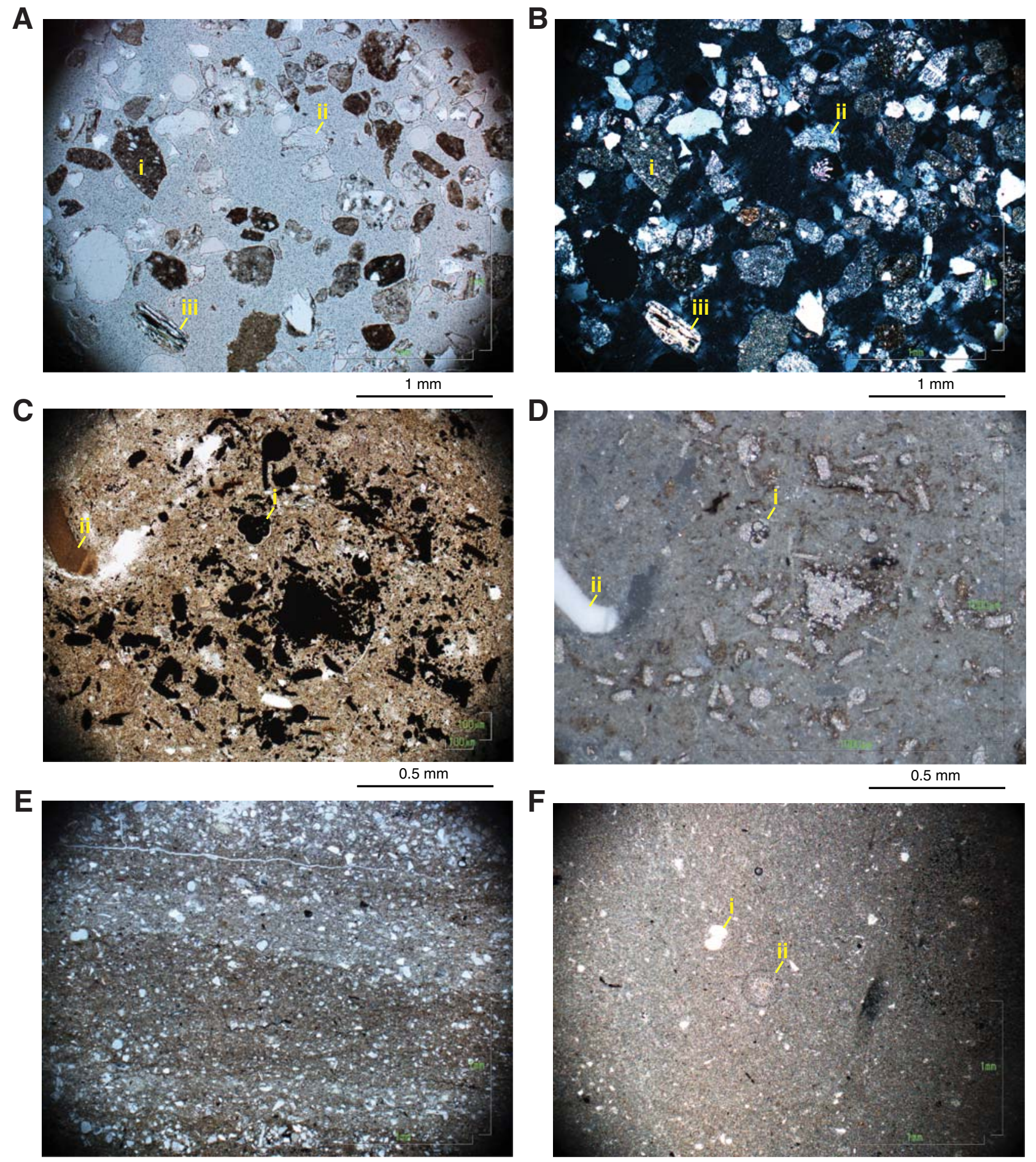

$1 \mathrm{~mm}$

$1 \mathrm{~mm}$ 
Figure F17. Macroscopic observations on cuttings samples (eye and binocular microscope). Raw data given in C0009_T1.XLS in LITHOLOGY in "Supplementary material."

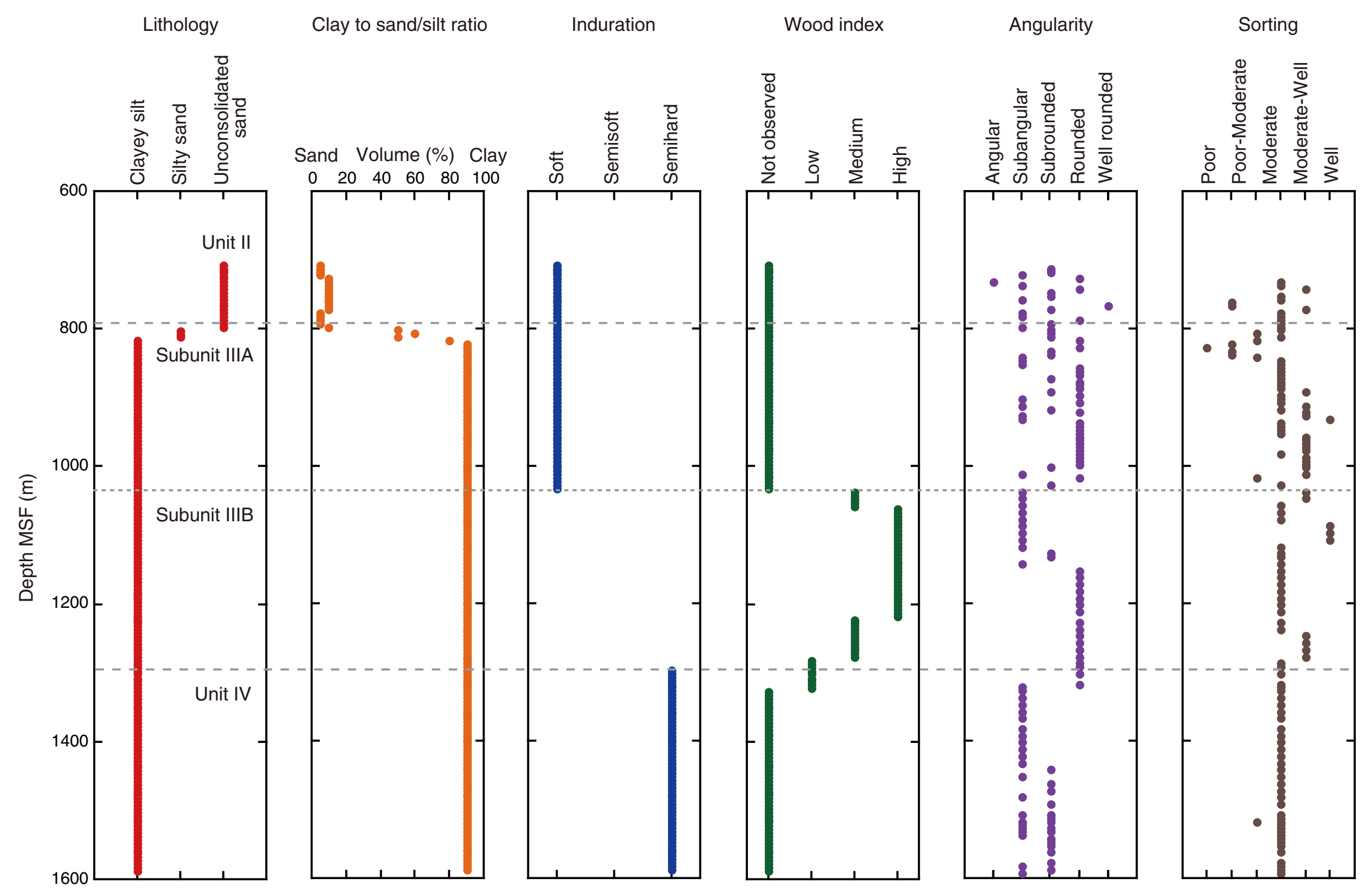


Figure F18. Grain abundances in cuttings samples (estimated from smear slides). Raw data given in C0009_T2.XLS in LITHOLOGY in "Supplementary material." $\mathrm{R}=$ rare, $\mathrm{F}=\mathrm{few}, \mathrm{C}=$ common, $\mathrm{A}=$ abundant, $\mathrm{D}=$ dominant.

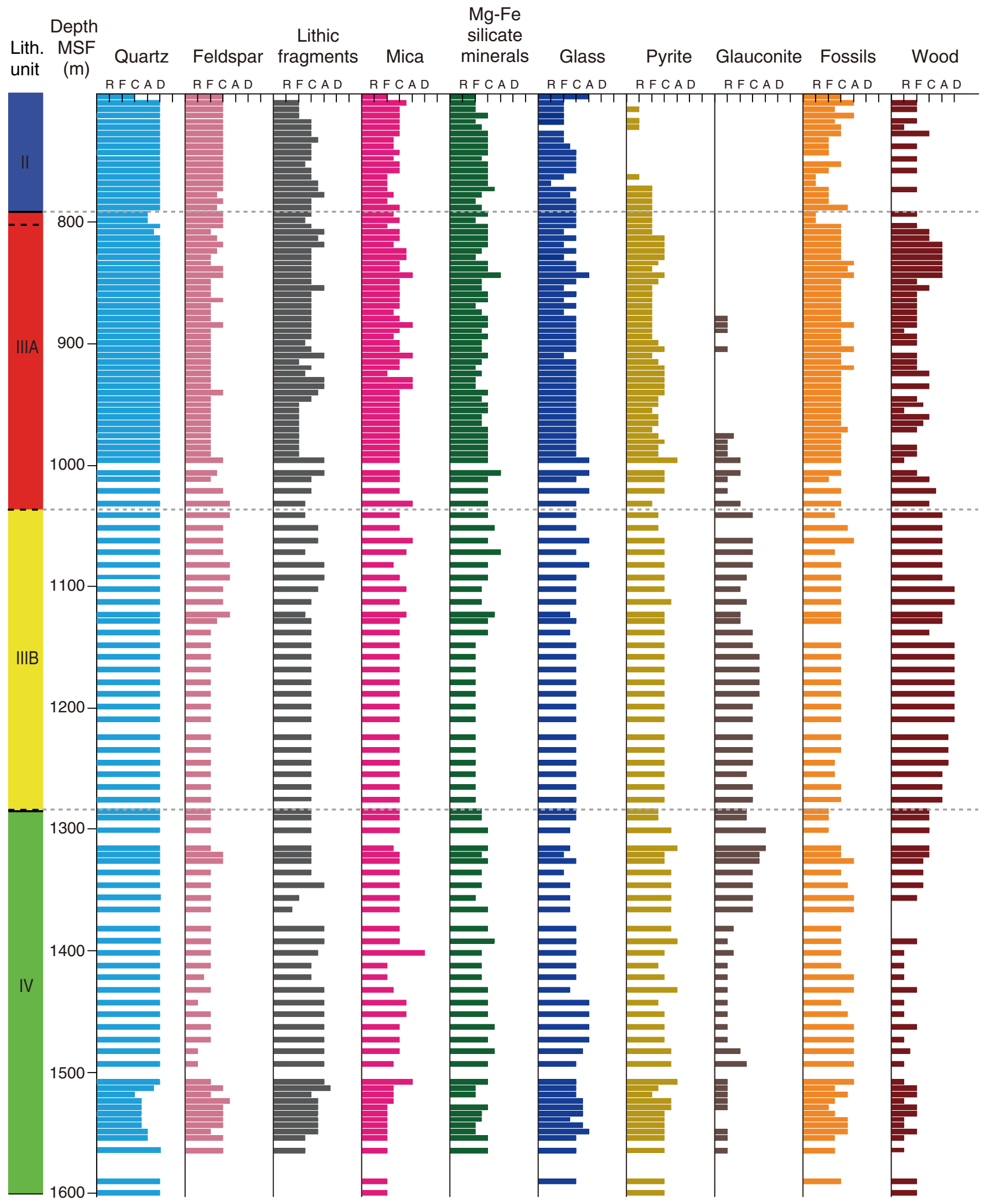


Figure F19. Selected wireline logging data, cuttings and mud gas analyses, and units recognized in Hole C0009A. Solid lines $=$ boundaries defined from wireline logging data, dashed lines $=$ boundaries defined from cuttings samples. XRD $=\mathrm{X}$-ray diffraction, LOI $=$ loss on ignition, $\mathrm{XRF}=\mathrm{X}$-ray fluorescence, $\mathrm{PEF}=$ photoelectric effect, $\mathrm{SP}=$ spontaneous potential.

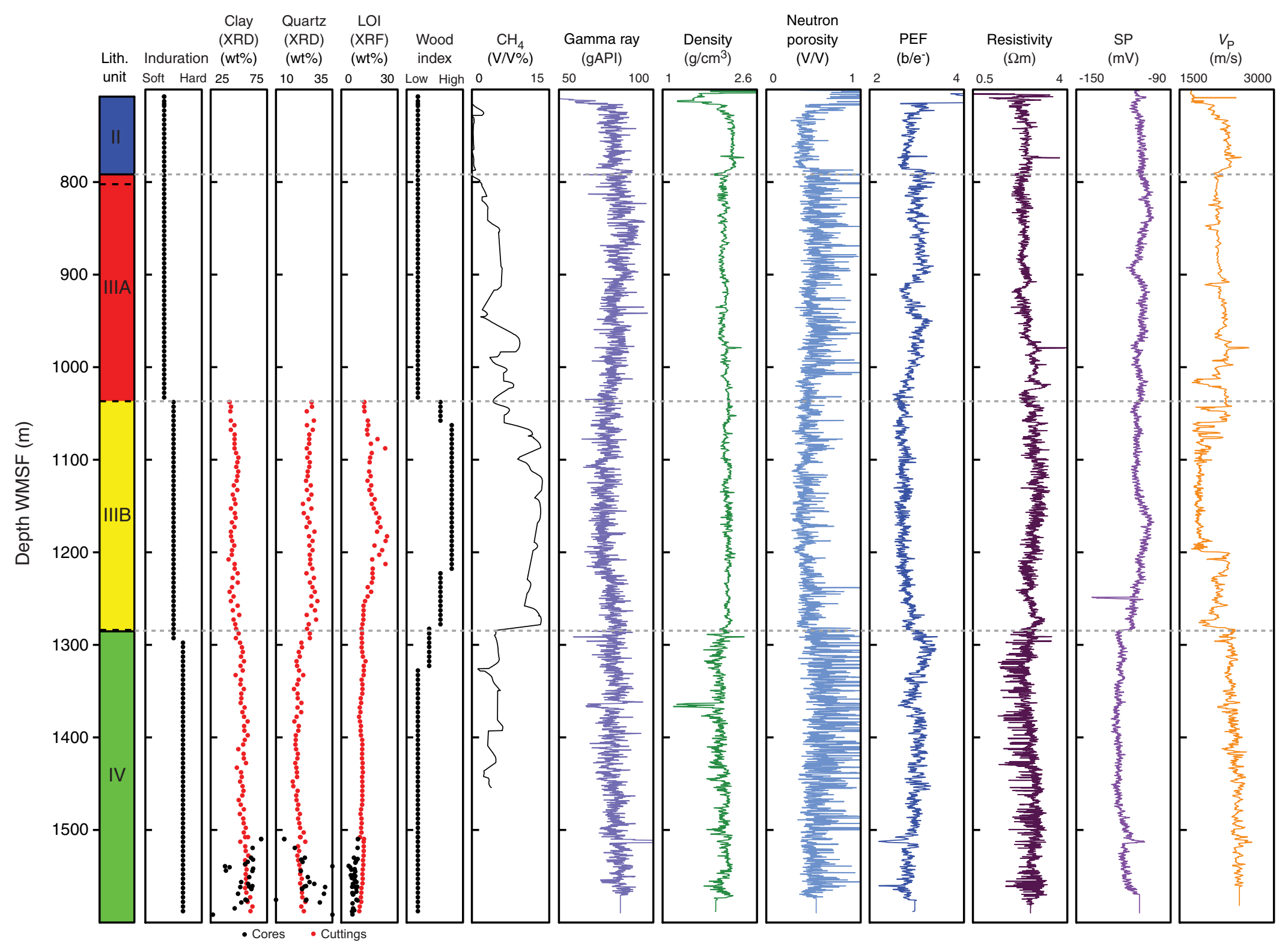


Figure F20. Bulk powder XRD of cuttings (drilling Phases 2 and 3) and core samples. Cuttings depths are in MSF, core depths are in CSF. Mineral compositions normalized to $100 \mathrm{wt} \%$. Raw data given in C0009_T3.XLS in LITHOLOGY in "Supplementary material."

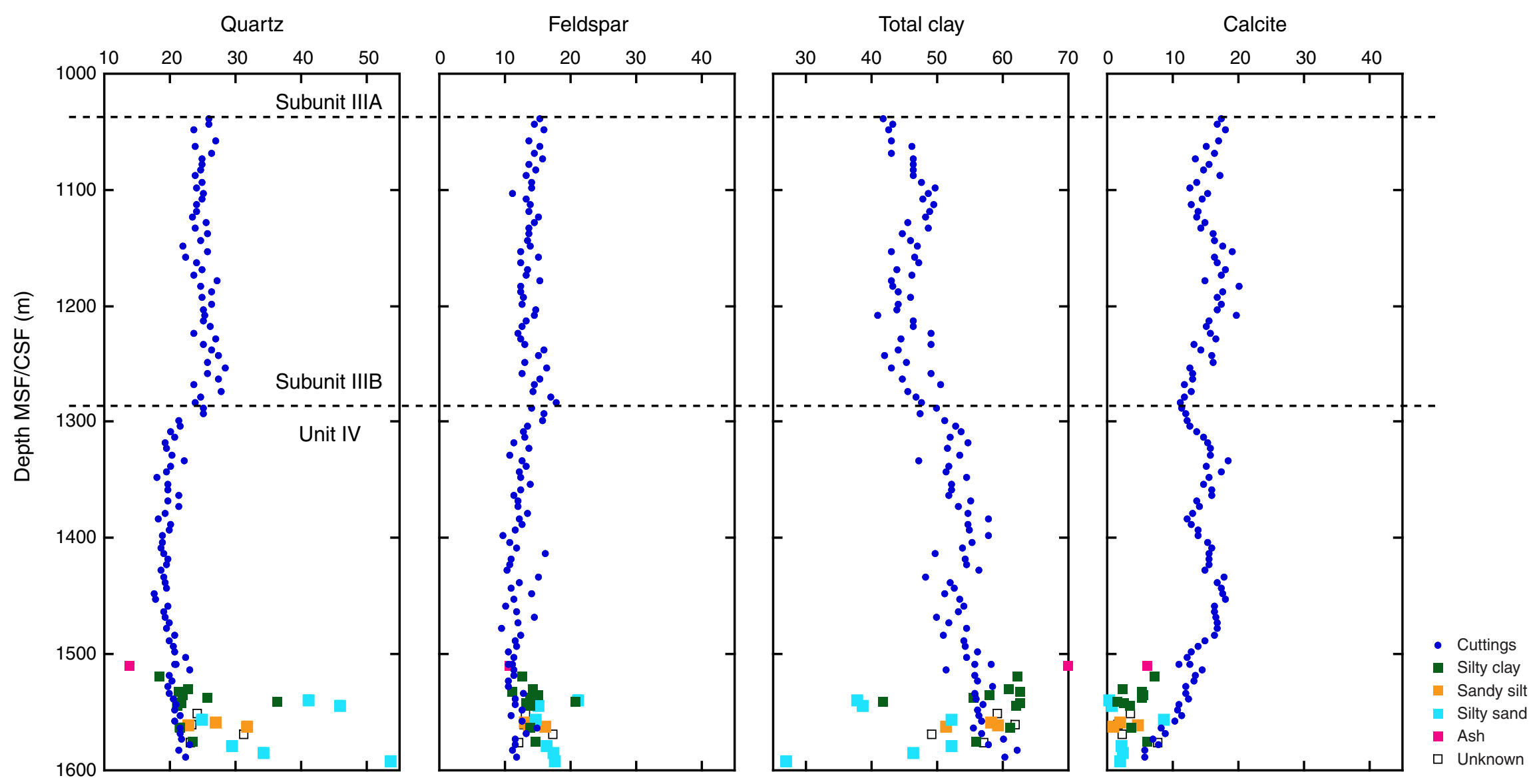


Figure F21. Bulk chemical compositions (XRF) normalized to $100 \mathrm{wt} \%$ (raw data given in C0009_T4.XLS in LITHOLOGY in "Supplementary material"). LOI = loss on ignition.

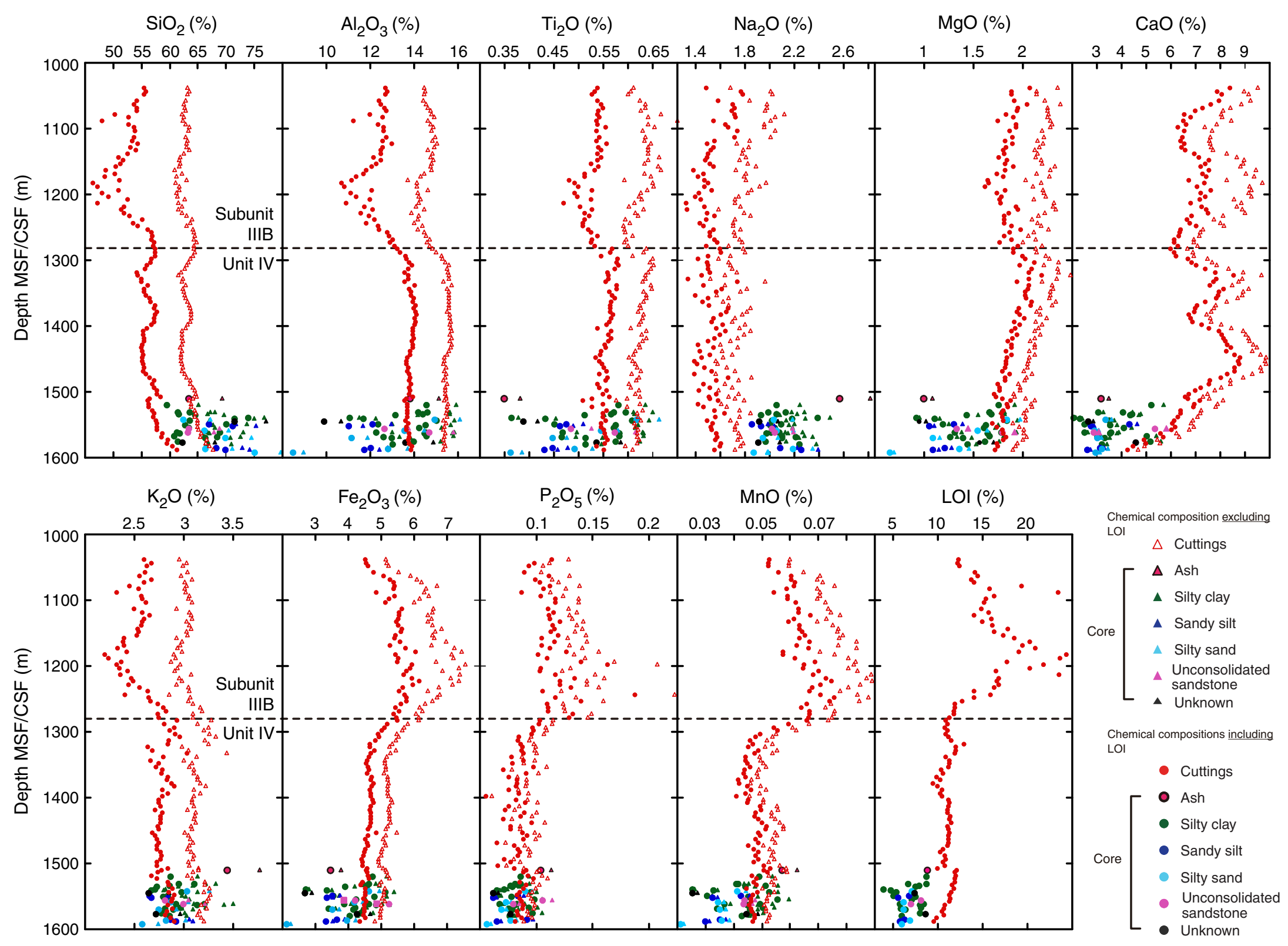


Figure F22. Lithologic synthesis of core between 1509.7 and $1593.9 \mathrm{~m} \mathrm{CSF}$. Four lithofacies are documented. Locations of images shown in Figure F23.

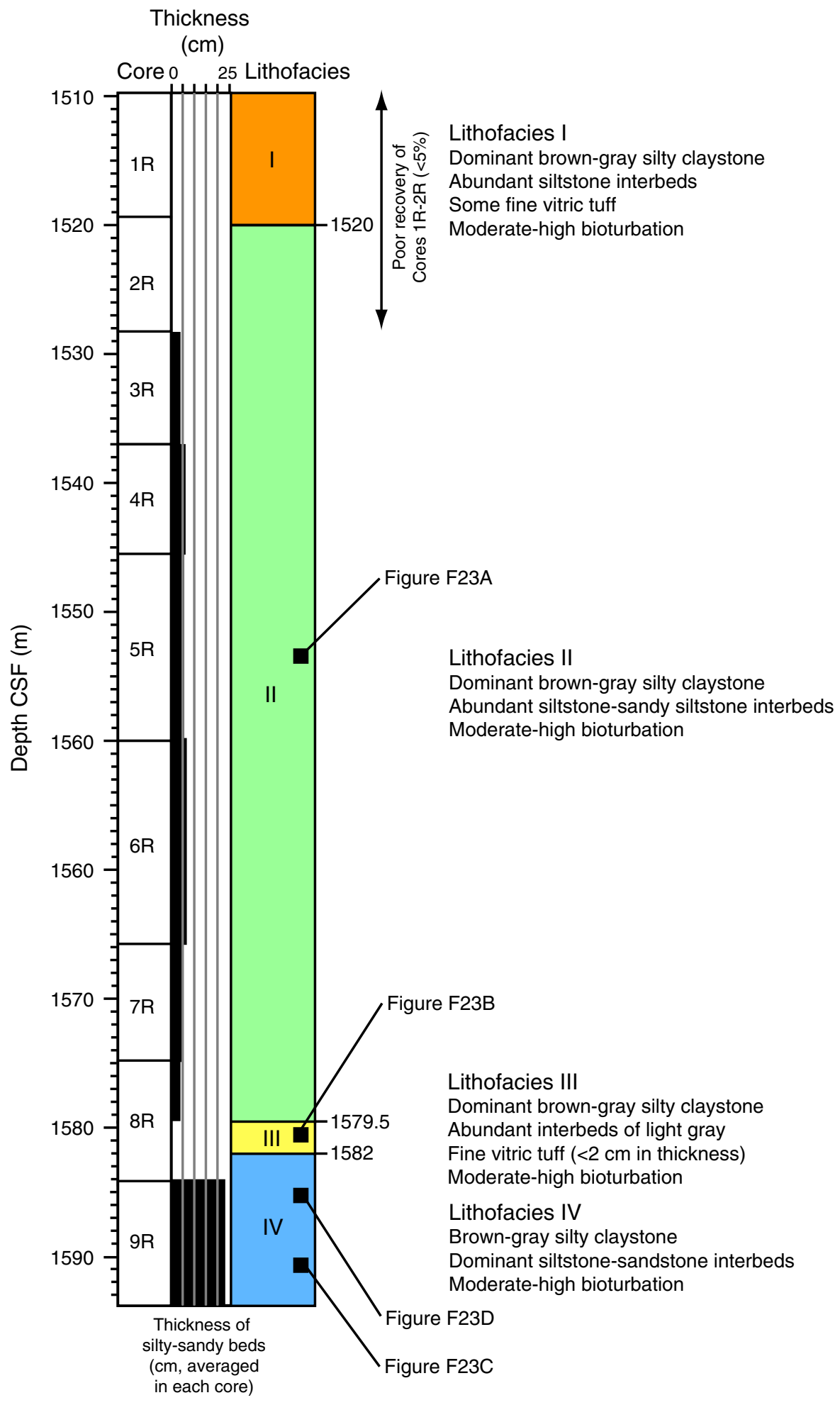


Figure F23. Lithofacies of cores. A. Bioturbated silty claystone with (i) Chondrites ichnosp. and (ii) Zoophycos ichnosp. (Core 319-C0009A-05R-07, $~ 30 \mathrm{~cm}$, Lithofacies II on Fig. F22). Burrows preferentially filled with sponge spicules. B. Interbeds of fine vitric tuff (light layers) and silty claystone (dark layers) (Core 319-C0009A08R-06, $75 \mathrm{~cm}$, Lithofacies III on Fig. F22) with (i) spectacular convolute bedding. (Continued on next page.)
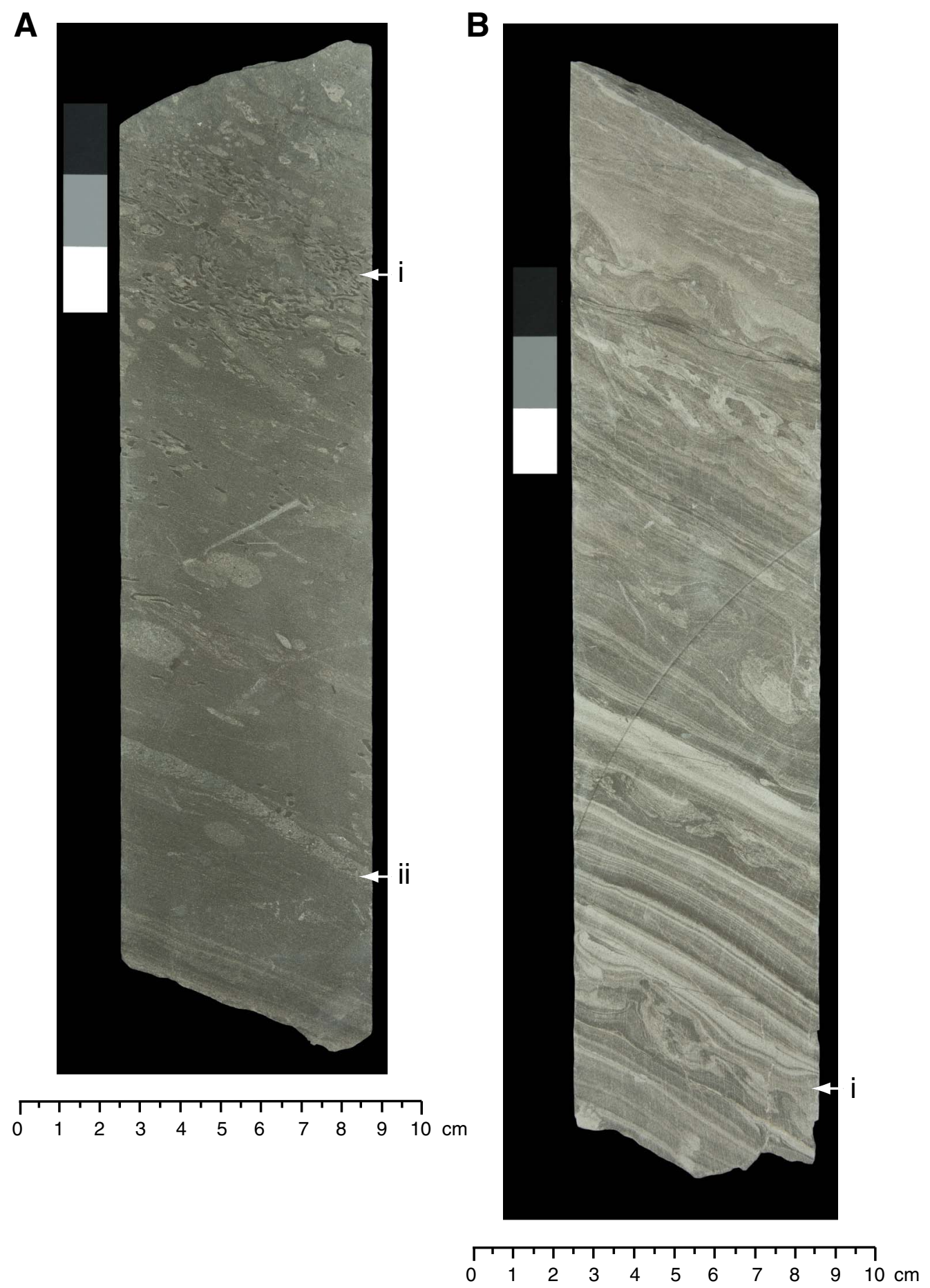
Figure F23 (continued). C. Siltstone layers with (i) parallel laminae and basal erosional contact interpreted as Bouma D interval and (ii) bed-parallel dark layer (or "shear zone," see "Structural geology") (Core 319. C0009A-09R-06, $\sim 130 \mathrm{~cm}$, Lithofacies IV on Fig. F22). D. Siltstones and sandstones with (i) bioturbationloading structures, (ii) cross-laminated bed interpreted as Bouma $\mathrm{C}$ interval, and (iii) poor consolidation of coarser sediments (Core 319-C0009A-09R-02, 60 cm, Lithofacies IV on Fig. F22).
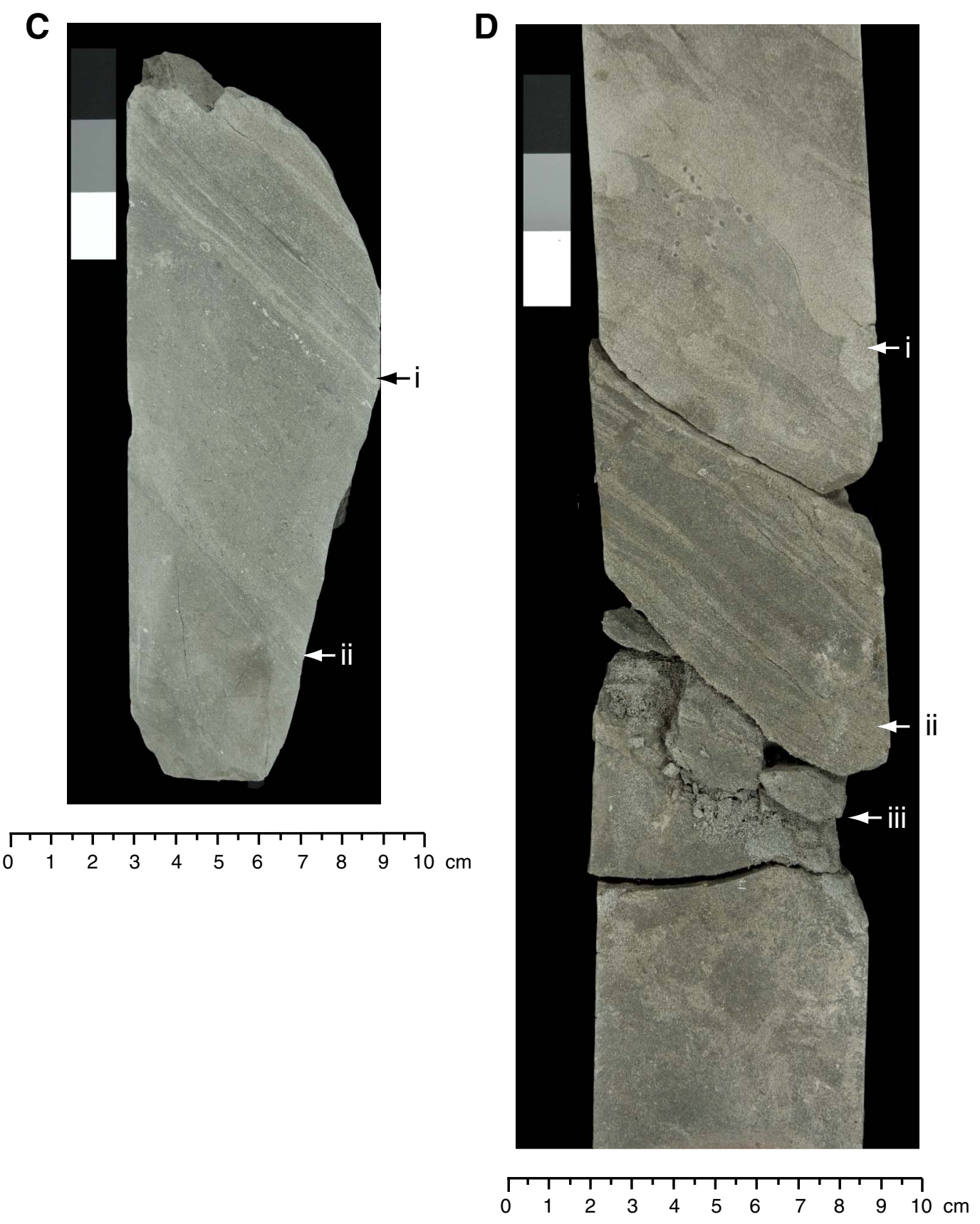
Figure F24. Clay mineral analysis obtained by bulk powder XRD. $\mathrm{Sm}=$ smectite, $\mathrm{Chl}=$ chlorite, $\mathrm{Il}=$ illite cps $=$ counts per second.

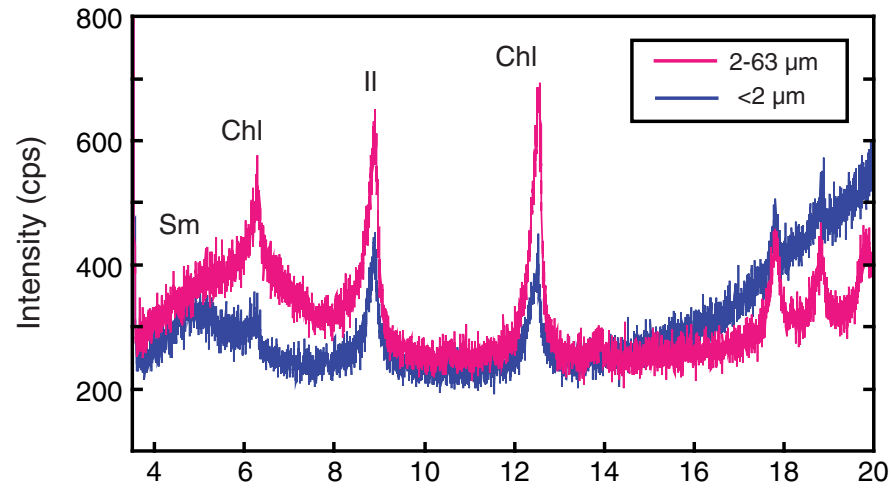

46-SMW

( 902.7-907.7 m MSF)

Unit III

(Subunit IIIA)

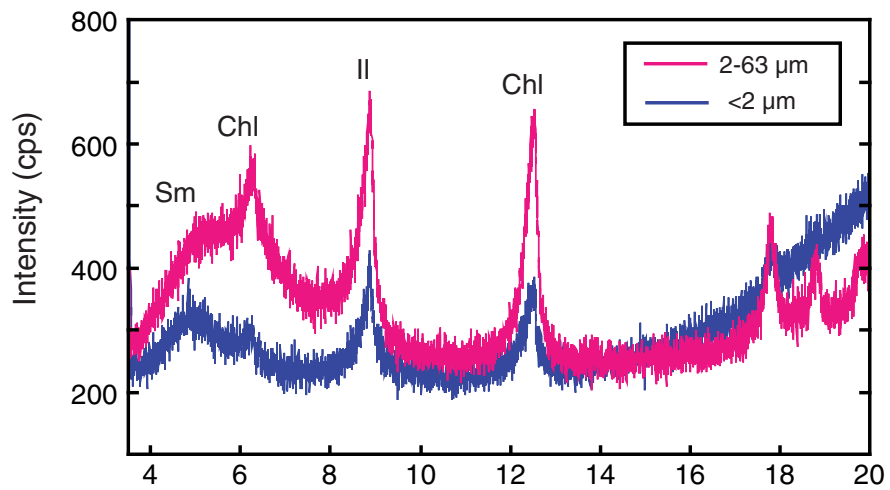

85-SMW

( 1087.7-1092.7 m MSF)

Unit III

(Subunit IIIB)

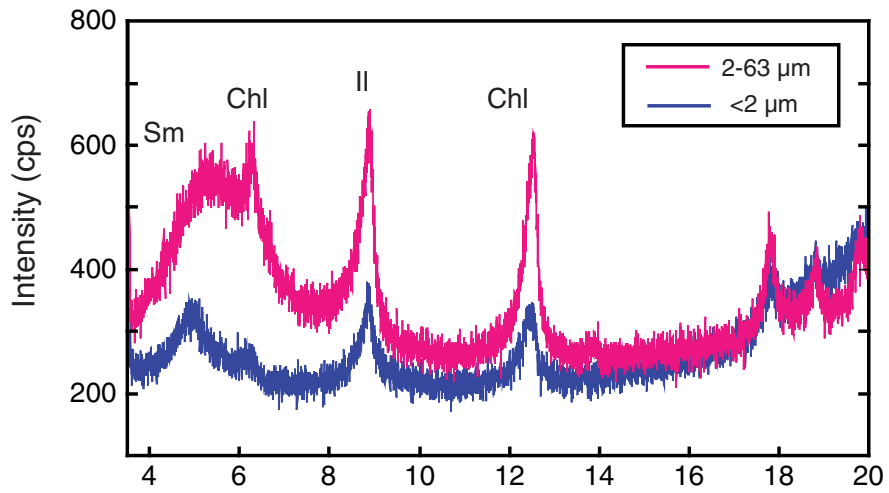

123-SMW

( 1267.7-1272.7 m MSF)

Unit III

(Subunit IIIB)

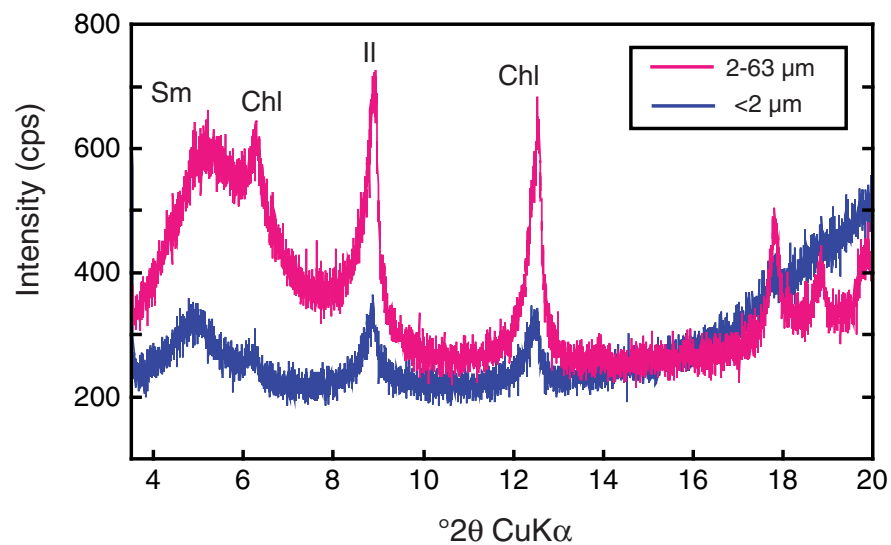

129-SMW

( 1297.7-1302.7 m MSF)

Unit IV 
Figure F25. Slickensided surfaces on cuttings from $>4 \mathrm{~mm}$ size fraction. A. Striated surface on a grain, Sample 319-C0009A-88-SMW (1102.7 m MSF; all depths hereafter are "top depths" of cutting sampling interval). B. Two slickensided surfaces, Sample 319-C0009A-129-SMW (1297.7 m MSF). C. Polished (but not striated) surface, Sample 319-C0009A-137-SMW (1332.7 m MSF). D. Planar surface not polished or striated (possibly a bedding plane), Sample 319-C0009A-136-SMW (1327.7 m MSF).
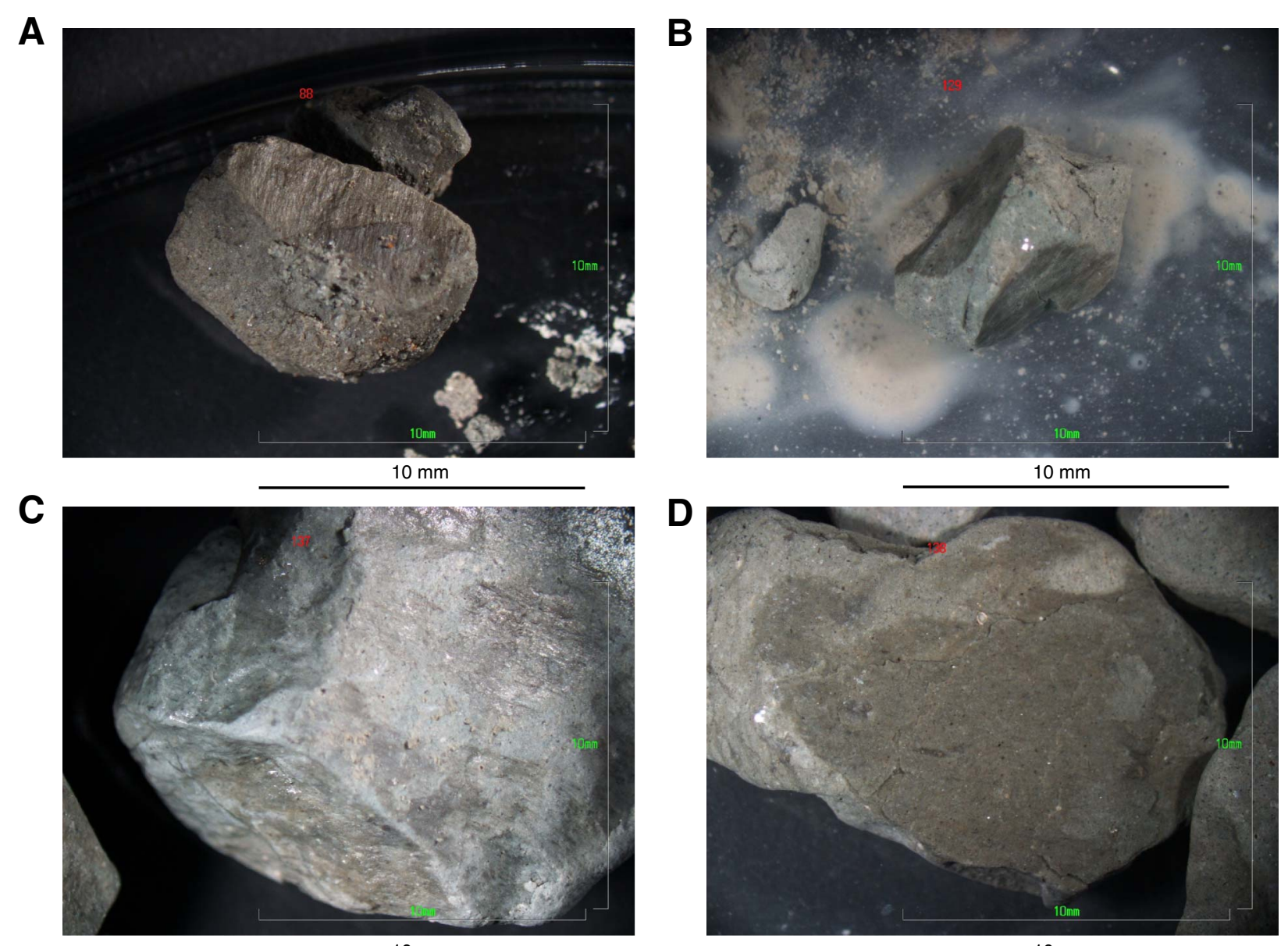

$10 \mathrm{~mm}$

$10 \mathrm{~mm}$ 
Figure F26. Structures in cuttings samples from $>4 \mathrm{~mm}$ size fraction. A. Dark layers (possibly bedding) in a grain, Sample 319-C0009A-91-SMW (1117.7 m MSF). B-E. Vein structures, (B) Sample 319-C0009A-137-SMW (1332.7 m MSF), (C) Sample 319-C0009A-140-SMW (1347.7 m MSF), (D) Sample 319-C0009A-143-SMW (1363.6 m MSF), and (E) Sample 319-C0009A-141-SMW (1352.7 m MSF). F. Web structure, Sample 319-C0009A160-SMW (1442.7 m MSF), showing offset part of web structure.
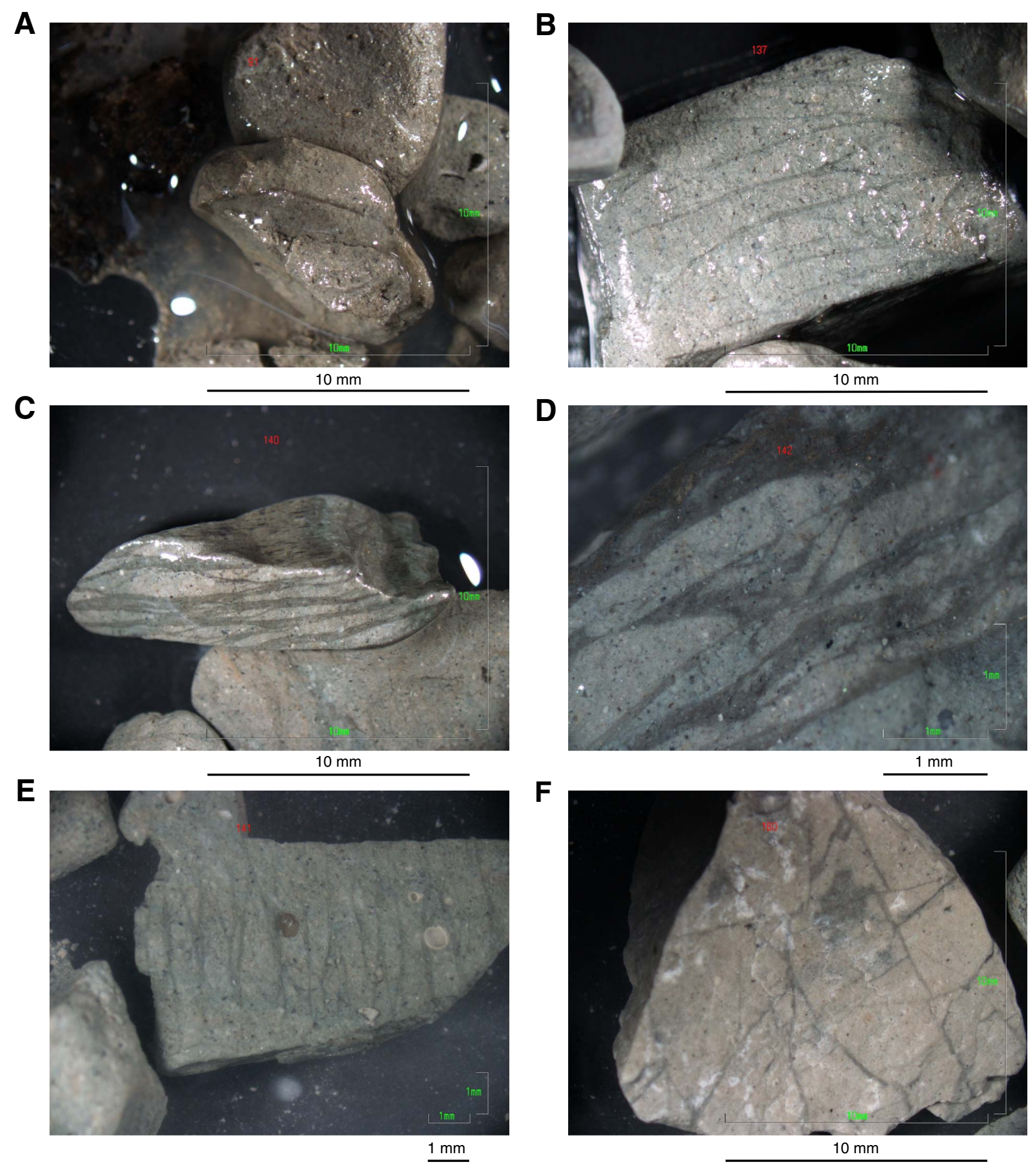
Figure F27. Microstructure of cuttings samples. A. Vein structure in plane-polarized light, Sample 319-C0009A141-SMW (1352.7 m MSF). B. Vein structure highlighted by opaque minerals (predominantly pyrite), Sample 319-C0009A-142-SMW (1357.7 m MSF). C. Vein structure with preferred orientation of opaque minerals, Sample 319-C0009A-156-SMW (1422.7 m MSF). D. Tip of thin vein structure with local fracture, Sample 319C0009A-156-SMW (1422.7 m MSF).
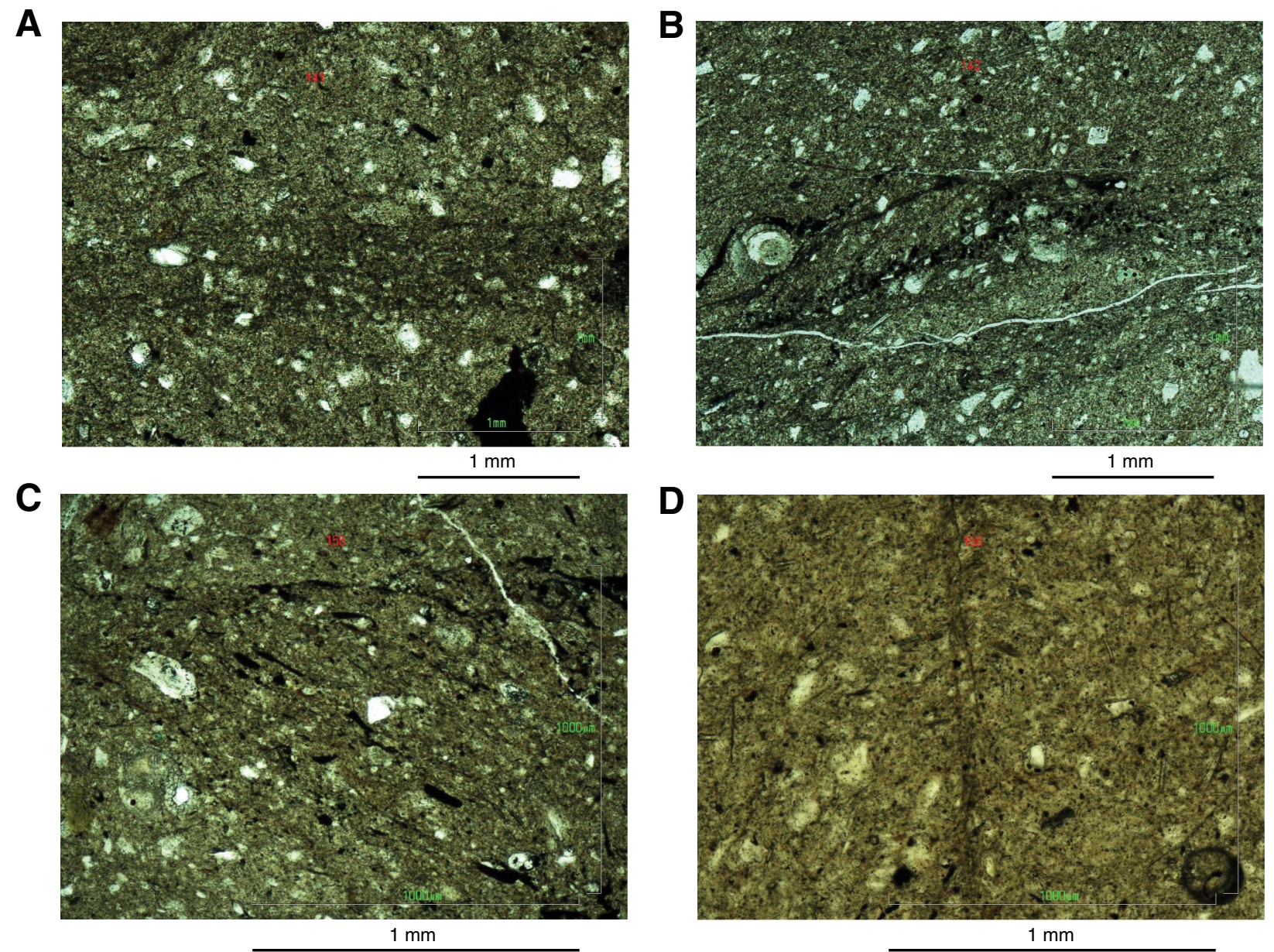
Figure F28. Depth distributions of vein structures, slickensides, and web structures within cuttings samples (see C0009_T2.XLS in STRUCGEOL in "Supplementary material"). Vein structures are most widespread in cuttings recovered between 1300 and 1475 m MSF.

Numbers of structures in 20 grain cuttings sample

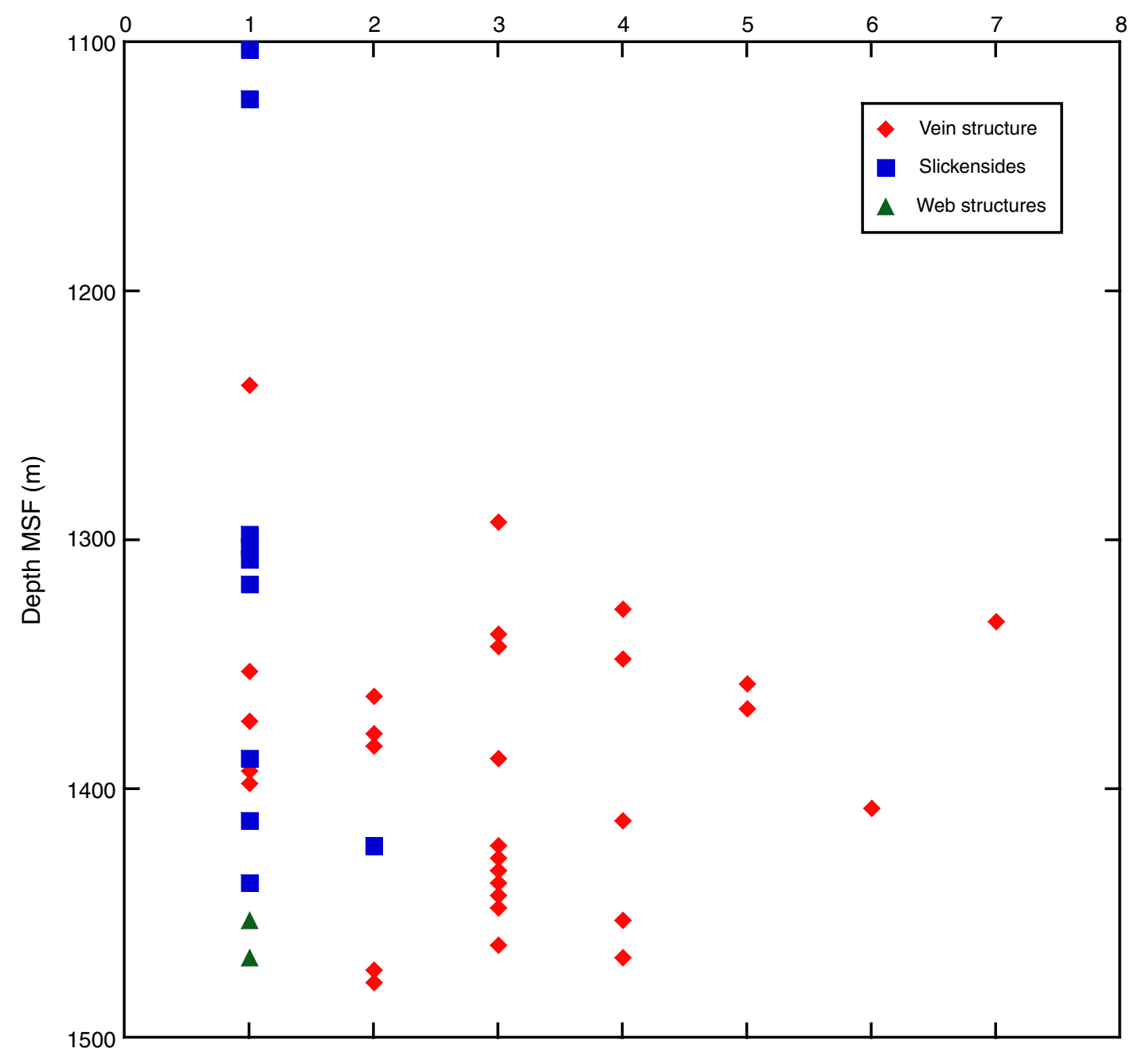


Figure F29. Examples of structures from cores. A. Bedding, bioturbated planar fabrics, bedding parallel shear zone (interval 319-C0009A-5R-6, 70-87 cm). B. Faults with thrust displacement (interval 319-C0009A-8R-7, $78-93 \mathrm{~cm})$. (Continued on next page.)

A

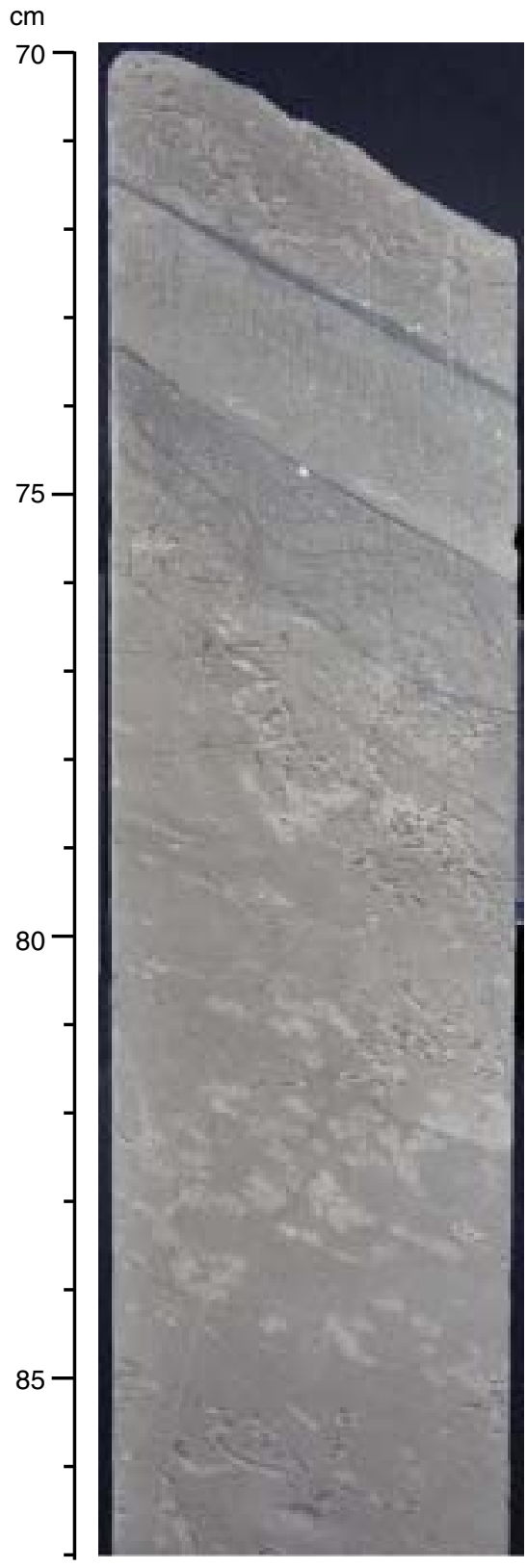

B

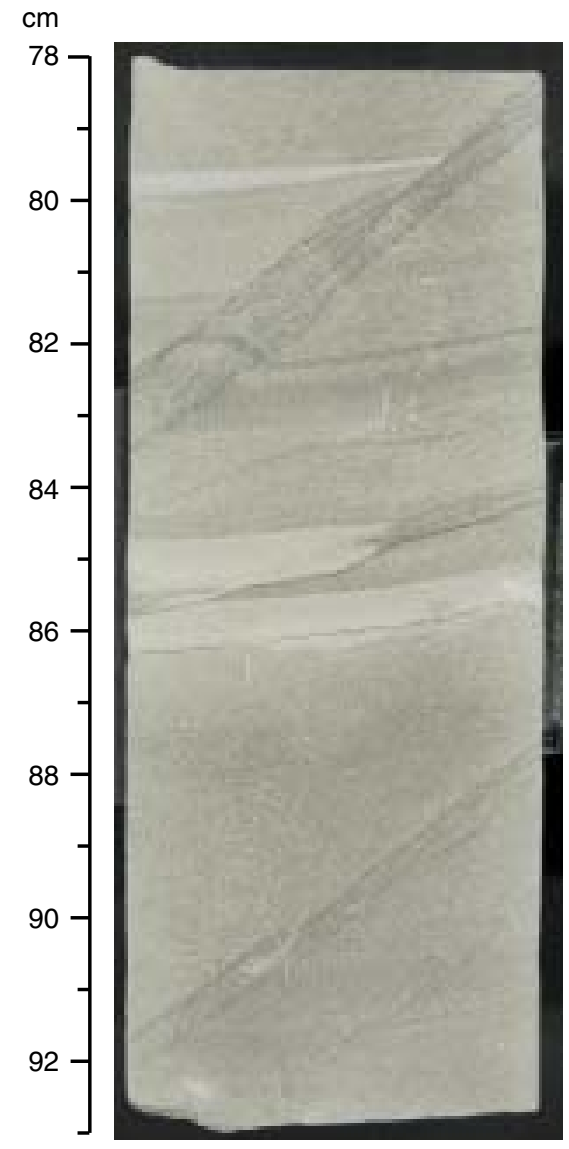


Figure F29 (continued). C. Slickenlined fault showing fresh surface (interval 319-C0009A-5R-1, 11-21 cm). D. Fault with normal displacement (interval 319-C0009A-8R-5, 104-111 cm).

C

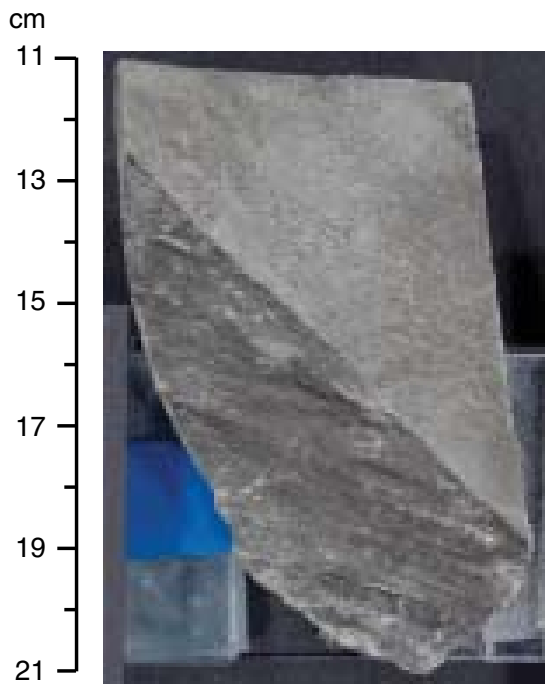

D

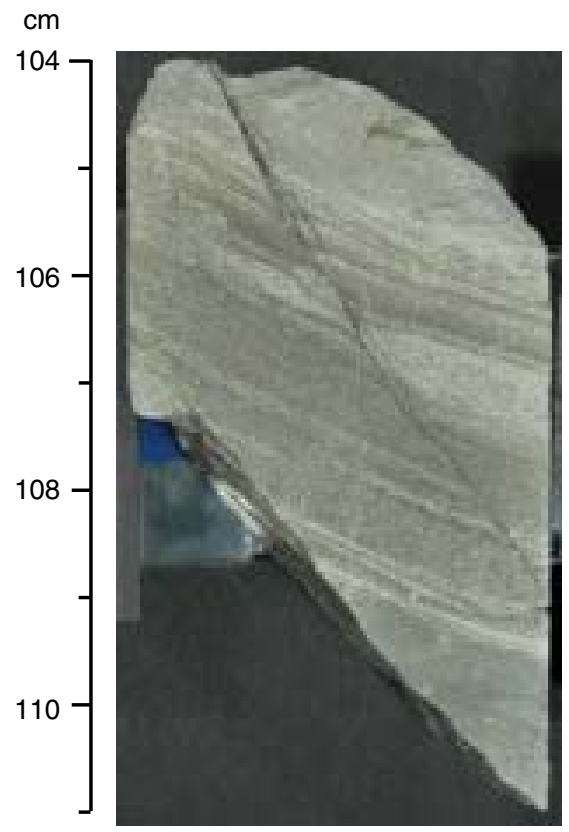


Figure F30. Photomicrographs of veins at high angles to bedding (Sample 319-C0009A-2R-1, 10.0-13.0 cm). Top of core is at top of page and bedding is shallowly dipping to the right. A, B. Lower power images of veins. C, D. Higher magnification images. Clay-sized component of vein fillings is finer grained than surrounding sediment and optically irresolveable.
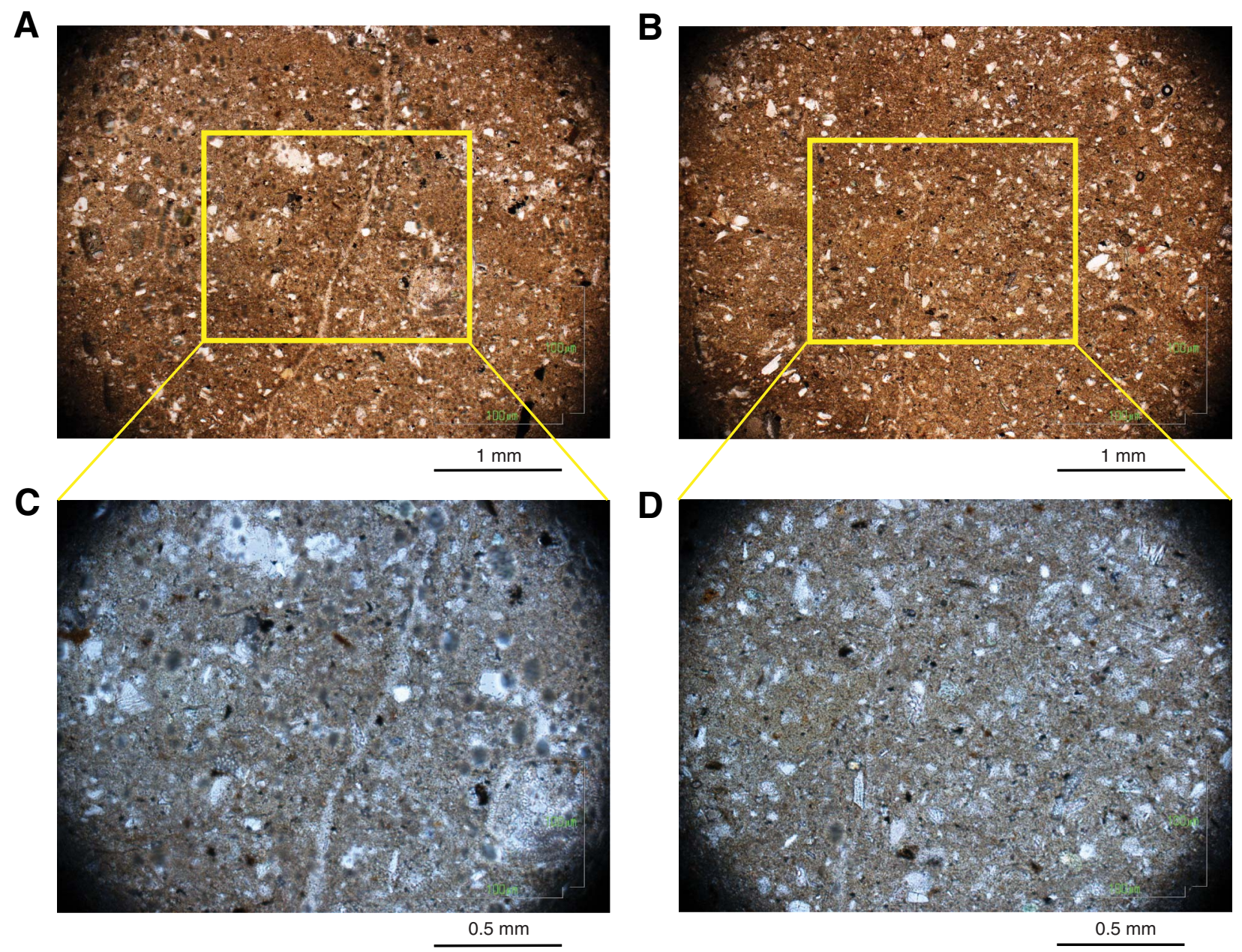
Figure F31. Photomicrographs of shear zones. Top of core is at top of page. Bedding is shallowly dipping to the right, except in A where it is shallowly dipping to the left. A, C, E. Sample 319-C0009A-6R-1, 38.0-41.0 cm. B, D. Sample 319-C0009-6R-4, 71.0-76.0 cm). (A) Bedding-parallel layer across bottom right corner, and shear zone in upper left that is not bedding parallel. (B) Bedding-parallel zone with no evidence of shear. (C) Beddingparallel layer across base of photo with Riedel (R) shears exhibiting sinistral shear within shear zone. (D) Shear zone forming gouge layer in a normal fault, indicated by offset of white layer at the top. (E) Shear zone forming gouge layer in a reverse fault, cutting a folded coarse-grained bed.

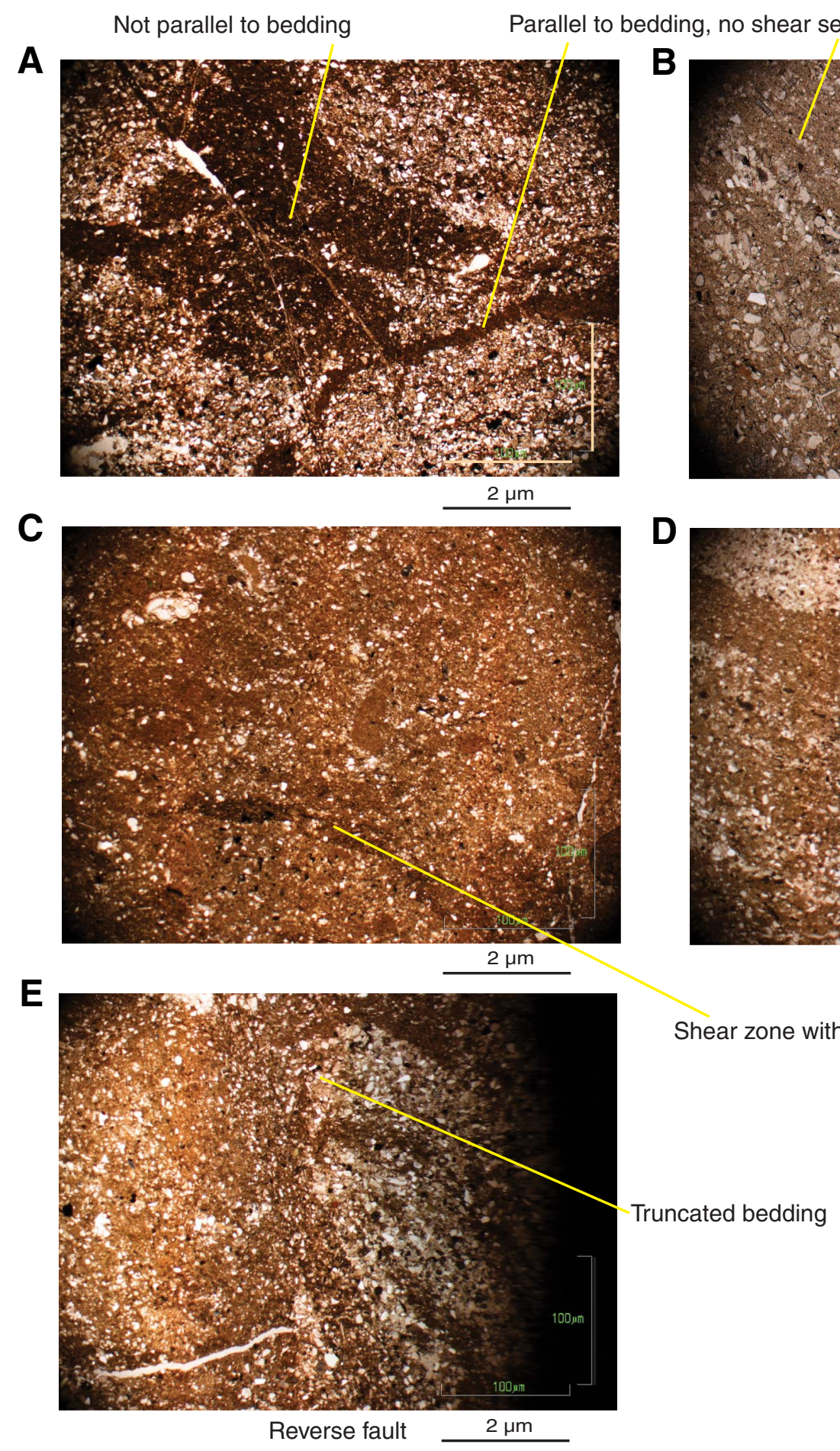


Figure F32. Photomicrographs of bedding-parallel shear zone showing R shears and sense of slip (Sample 319-C0009-5R-6, 73.0-75.5 cm). Stratigraphic up is top of page. A. Shear zone has a discrete fine-grained layer where most shearing occurs. R shear orientation suggests a sinistral sense of slip for entire shear zone. Small angle between primary shear and R shear because of core face being oblique to true dip direction. B. Discrete shear zones and location of C. C. Primary shear zone is oblique to an R shear that has two fractured grains. Orientation of R shear suggests a sinistral sense of slip.

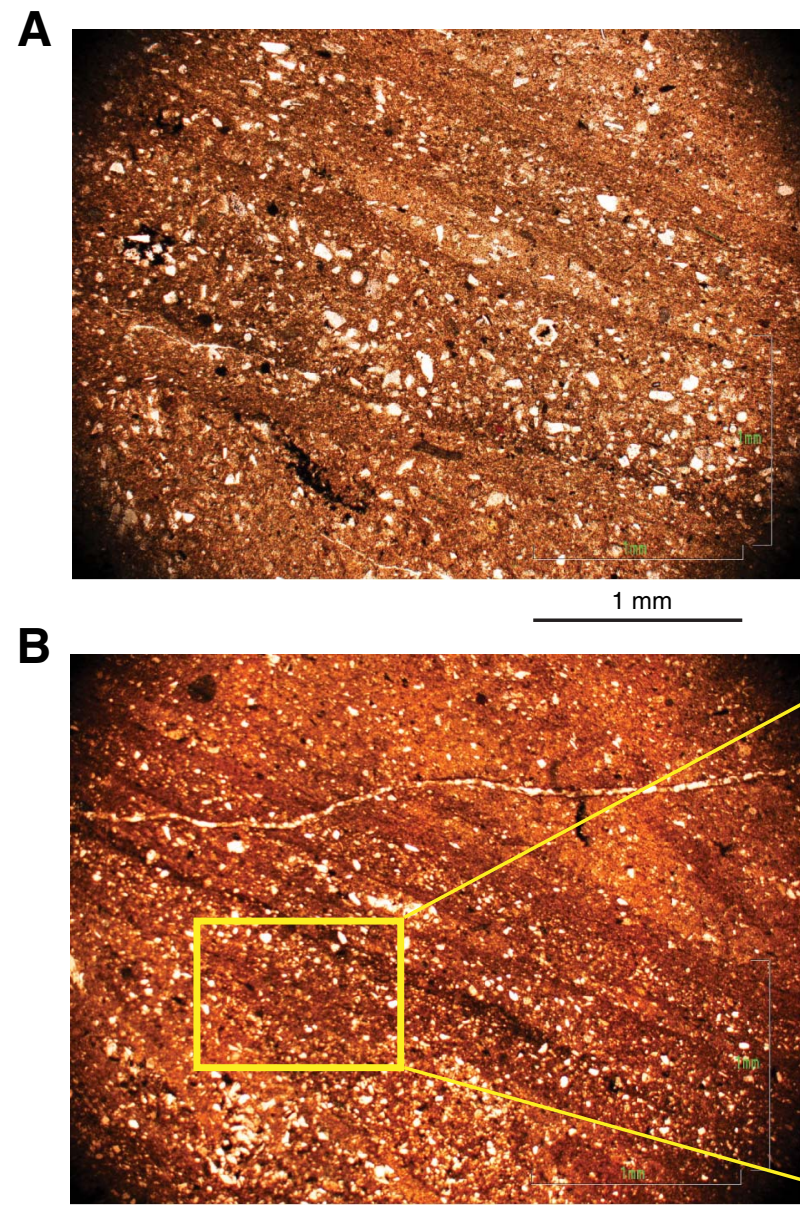

$2 \mathrm{~mm}$

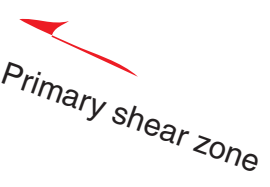

Rshear

\section{C}

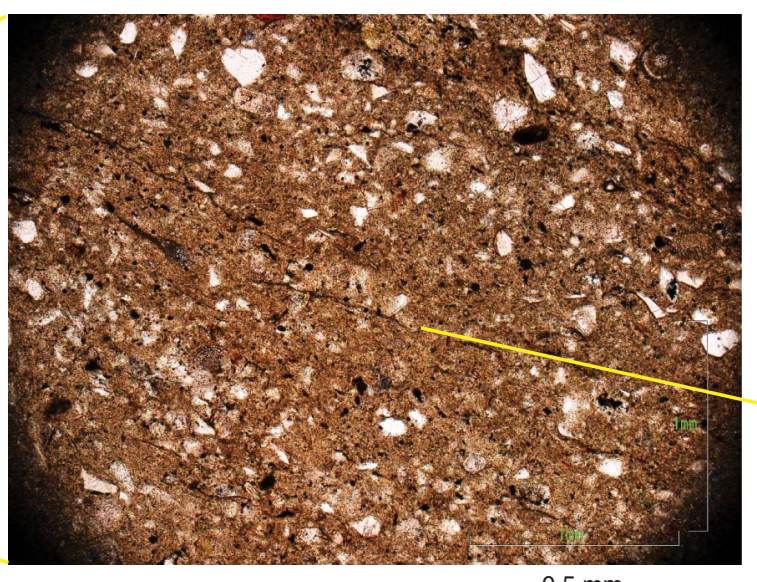

$0.5 \mathrm{~mm}$
Primary shear zone

$R$ shear with

fractured grain 
Figure F33. XRD plots comparing geochemistry of (A) strata above, (B) bedding-parallel shear zone, and (C) strata below. Quartz fraction is the major difference between layers. Strata above and within shear zone are indistinguishable. Strata below has a peak near $56^{\circ} 2 \theta$ that is not in A or B. Similarity between layers suggests material in shear zone has been derived from surrounding undeformed material and has undergone grain-size reduction. cps $=$ counts per second.
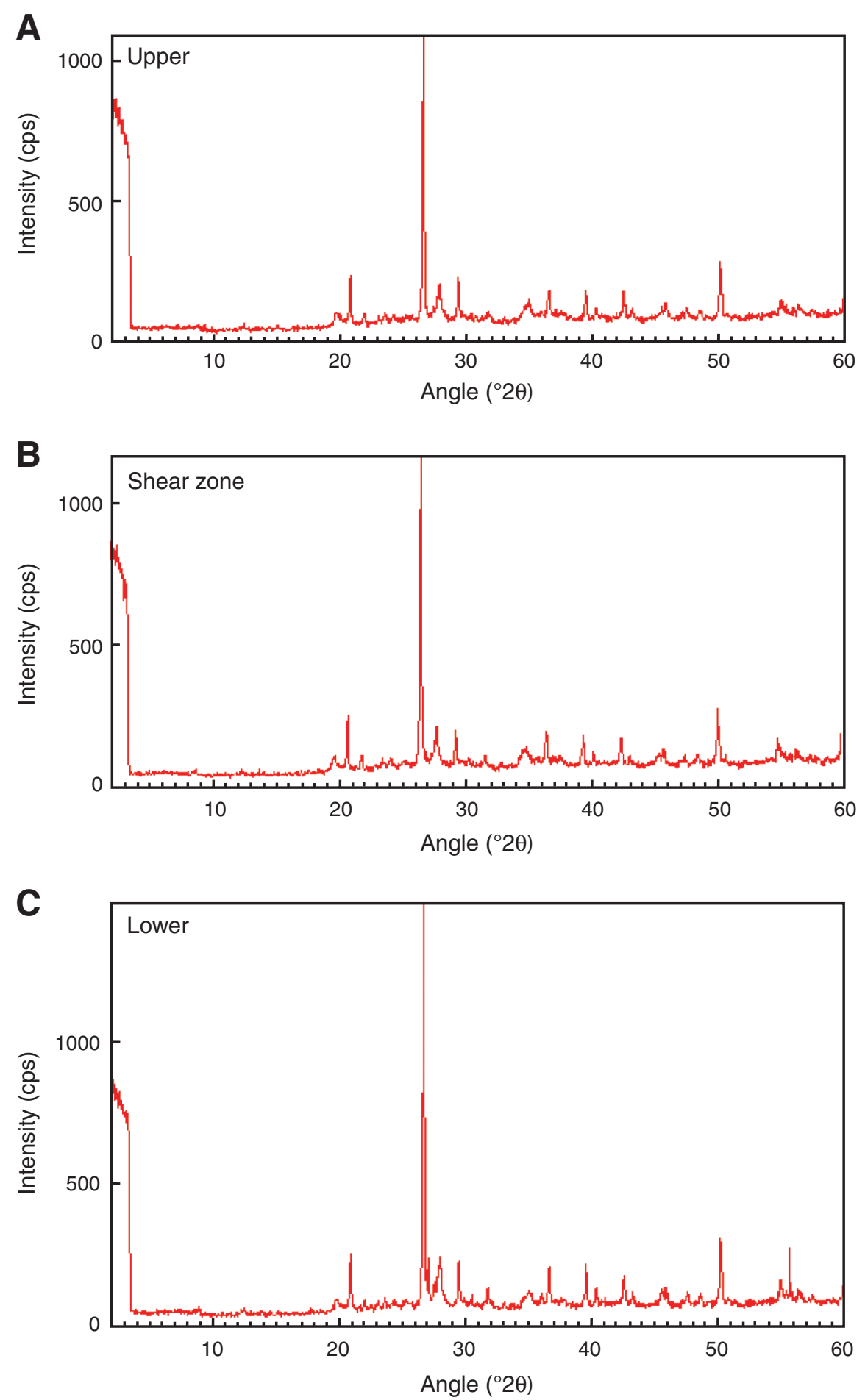
Figure F34. Histograms of dips of structural features from cored section. A. Bedding with a modal dip between $20^{\circ}$ and $40^{\circ}$. B. Shear zones with a modal dip between $20^{\circ}$ and $40^{\circ}$ (reflecting that a number of shear zones are bedding parallel). C. Faults with bimodal dips of $10^{\circ}-30^{\circ}$ and $50^{\circ}-70^{\circ}$. D. Slickenlined faults with bimodal dips of $20^{\circ}-40^{\circ}$ and $50^{\circ}-60^{\circ}$.

A

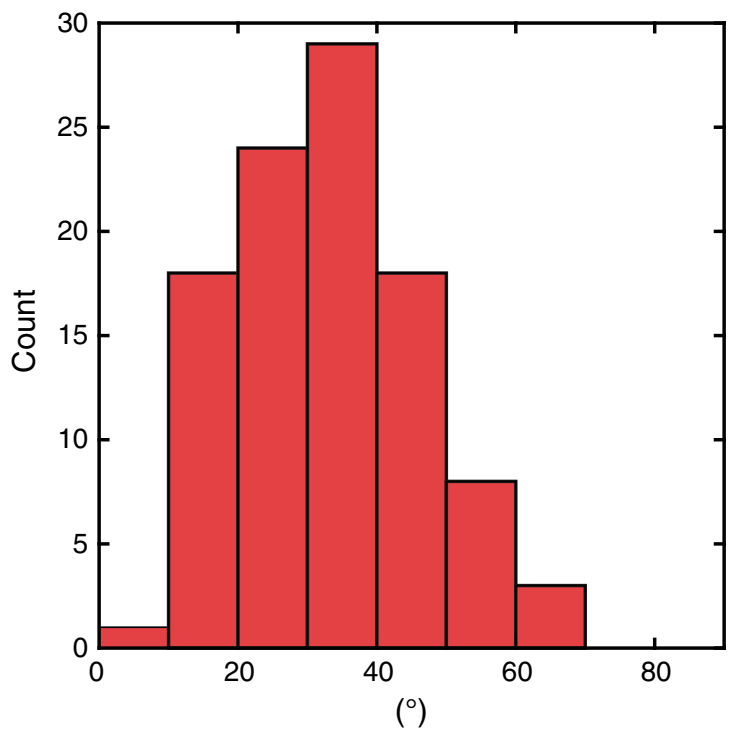

C

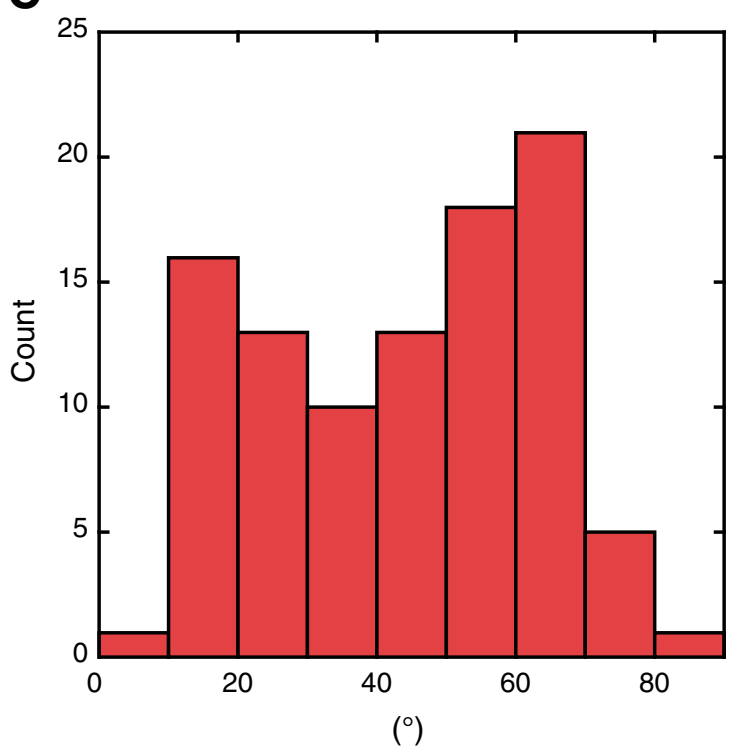

B

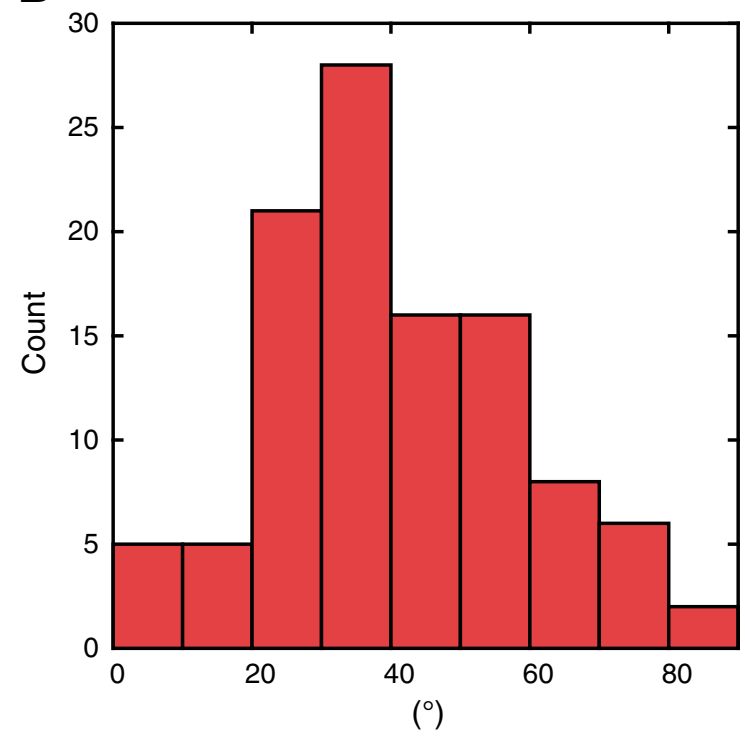

D

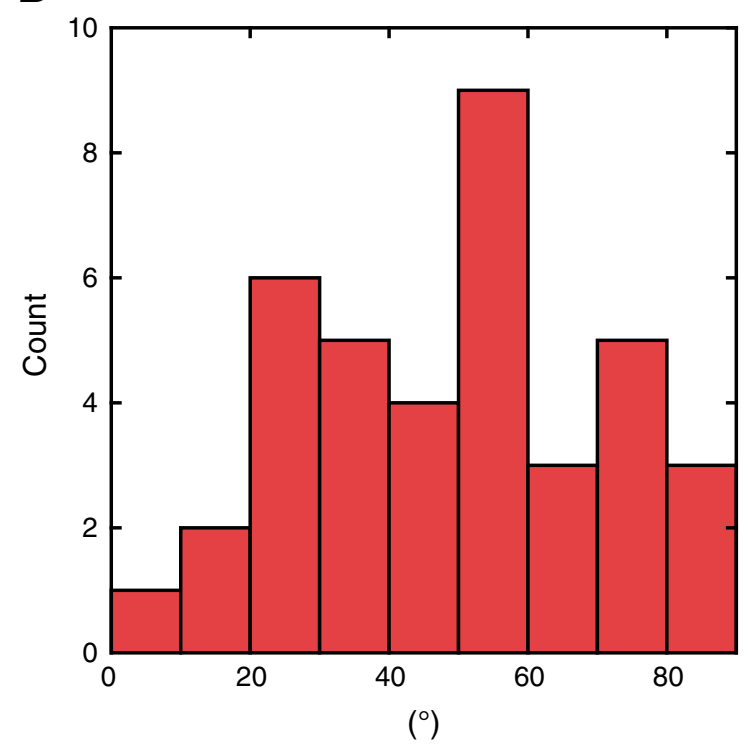


Figure F35. Comparison of bedding dips from cored section and those interpreted from Formation MicroImager (FMI) resistivity log. No dips could be resolved in FMI data from 1560 to $1580 \mathrm{~m}$ WMSF.

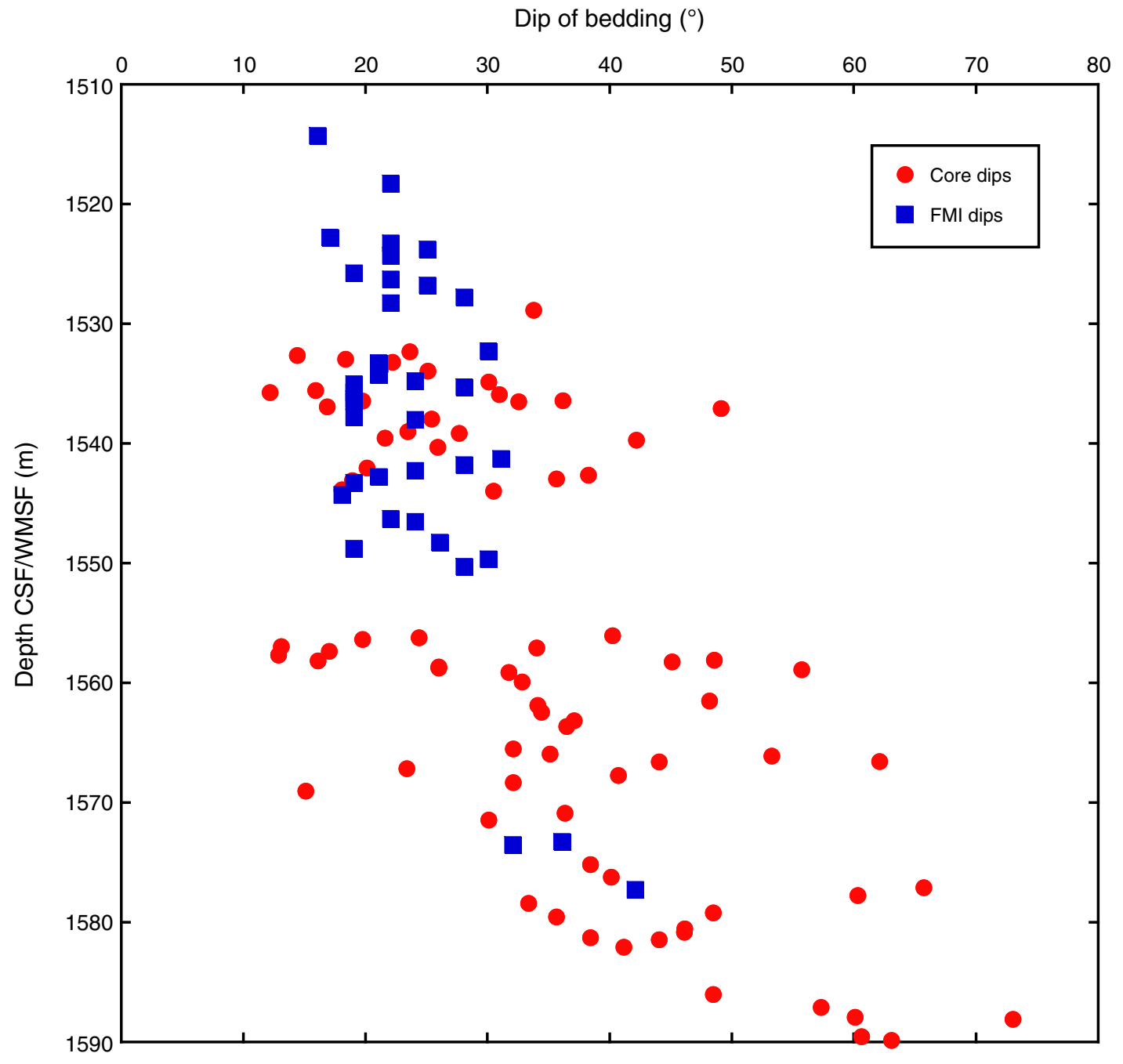


Figure F36. Anisotropy of magnetic susceptibility (AMS) data. A. Occurrences versus ratio of maximum to minimum principal axes of AMS ellipsoid. B. Ratio of maximum to intermediate principal axes of AMS ellipsoid versus ratio of intermediate to minimum principal axes. Plot is similar to a Flinn diagram; therefore, strain in these samples is oblate. C. Inclination of minimum axis versus depth showing values decreasing with depth.
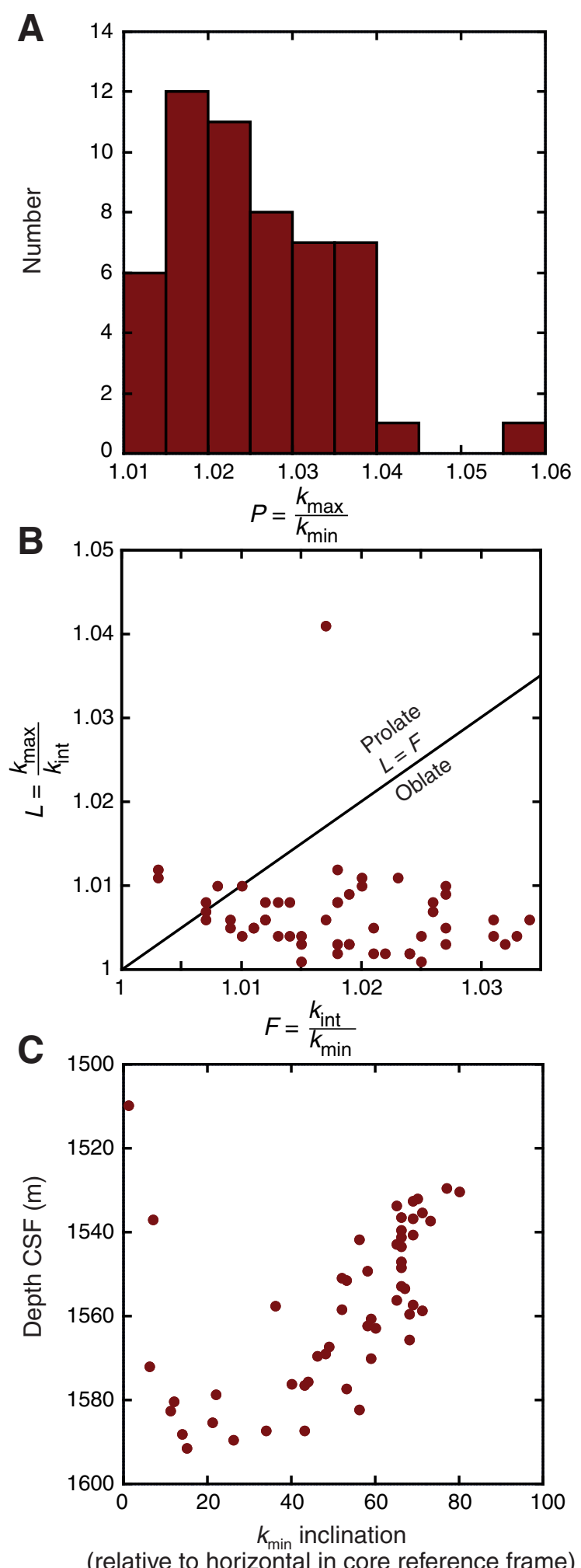
Figure F37. Caliper measurements from FMI tool in lower part of Site C0009. Left column shows width of Calipers 1 and 2. Note that below $1285 \mathrm{~m}$ WMSF one caliper is larger than the other in specific intervals. Right column shows orientation of FMI Pad 1 on Caliper 1.

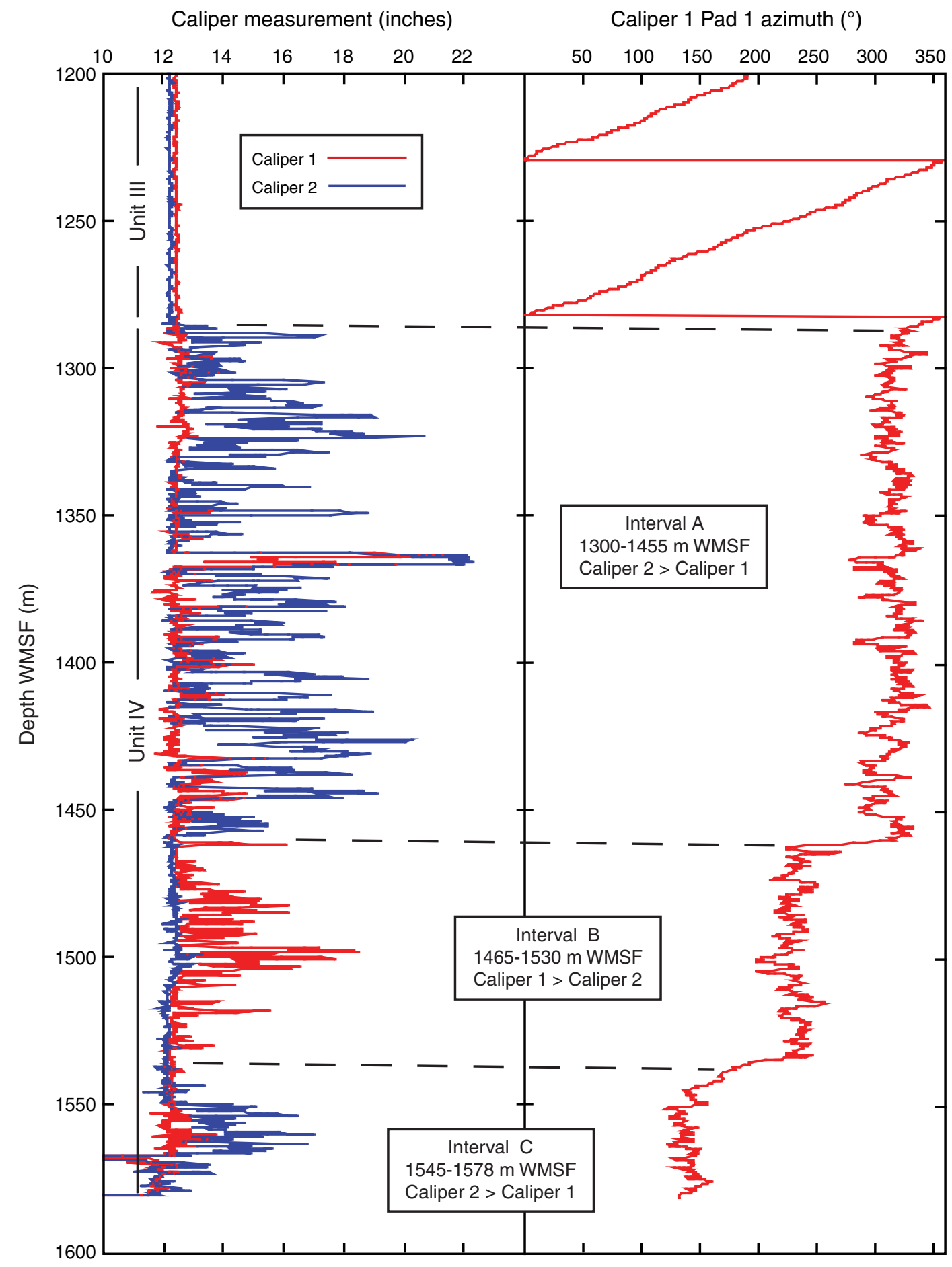


Figure F38. Orientation of $S_{\mathrm{Hmax}}$ determined from breakouts at Site C0009 and sites drilled during Expedition 314. GPS = Global Positioning System.

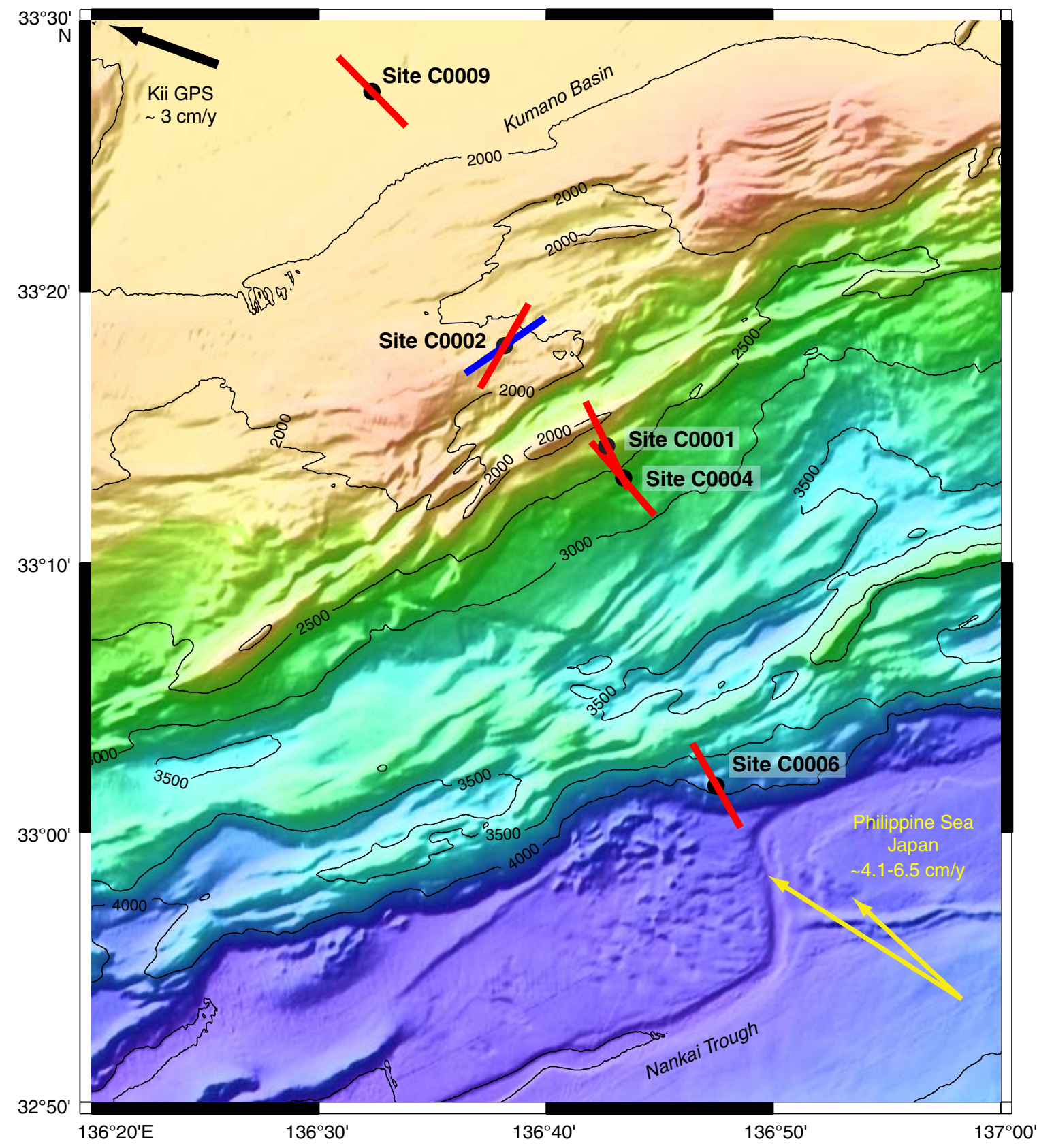


Figure F39. A. Example of vertical fracture in FMI data that is apparently normal to core. Fracture may represent DITF. B. Example of breakout as defined by Caliper 1 (C1) > Caliper 2 (C2) (right column). In left column note that low-resistivity signal is not localized on either pad pair, preventing accurate mapping of breakouts from FMI data.

A

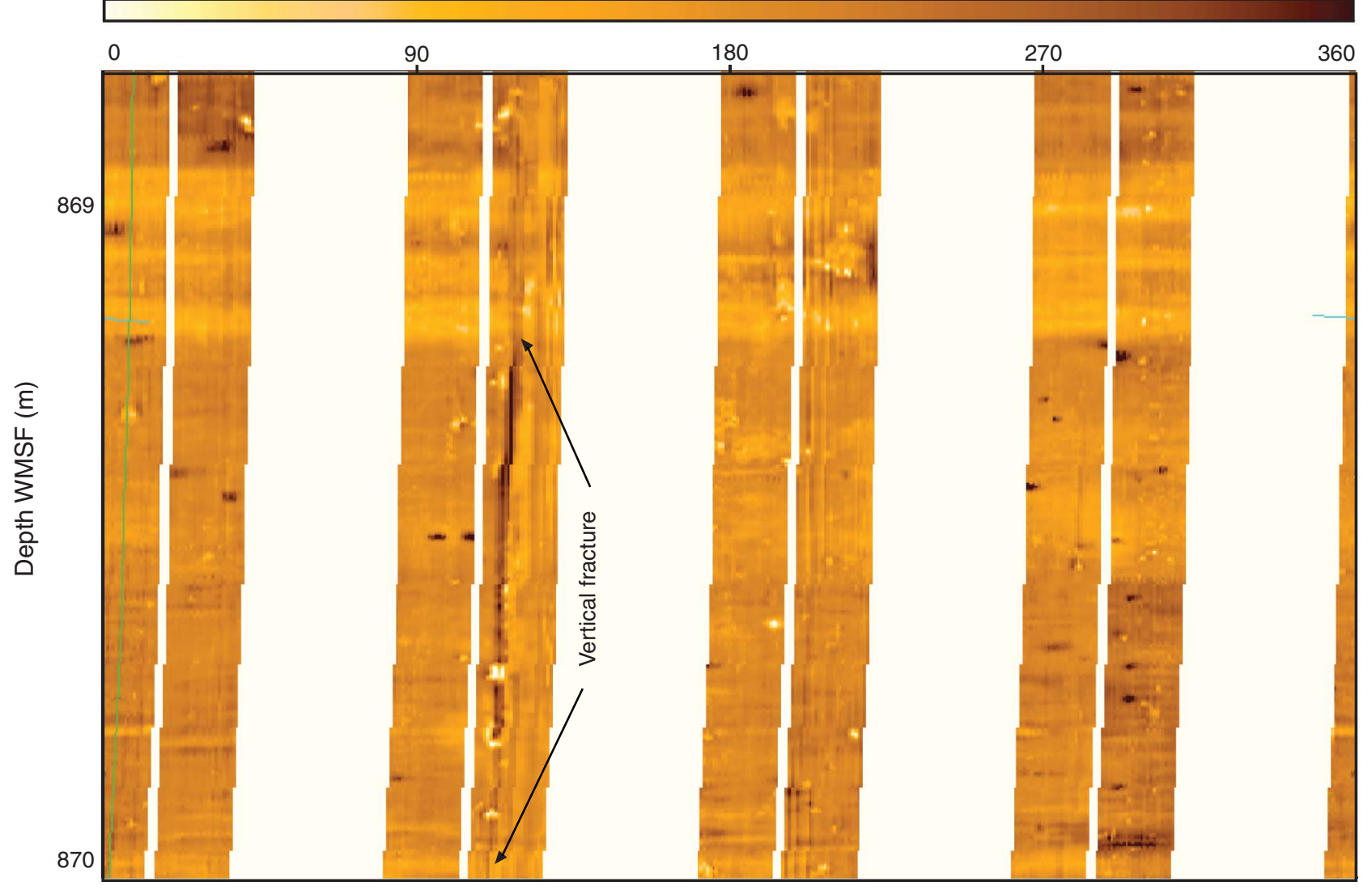

B

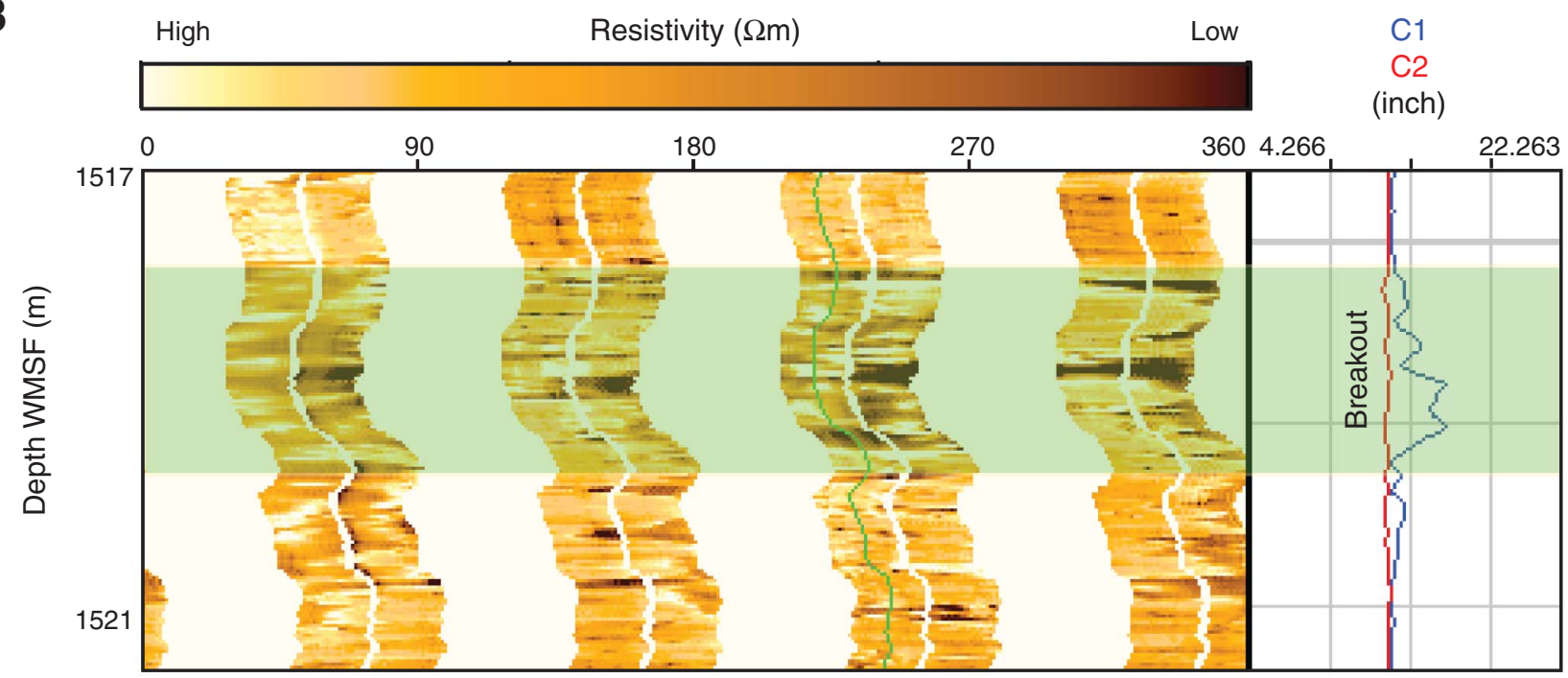


Figure F40. Histogram of vertical fractures measured between 800 and $1000 \mathrm{~m}$ WMSF (see also C0009_T4.XLS in STRUCGEOL in "Supplementary material"). Fractures may be DITFs.

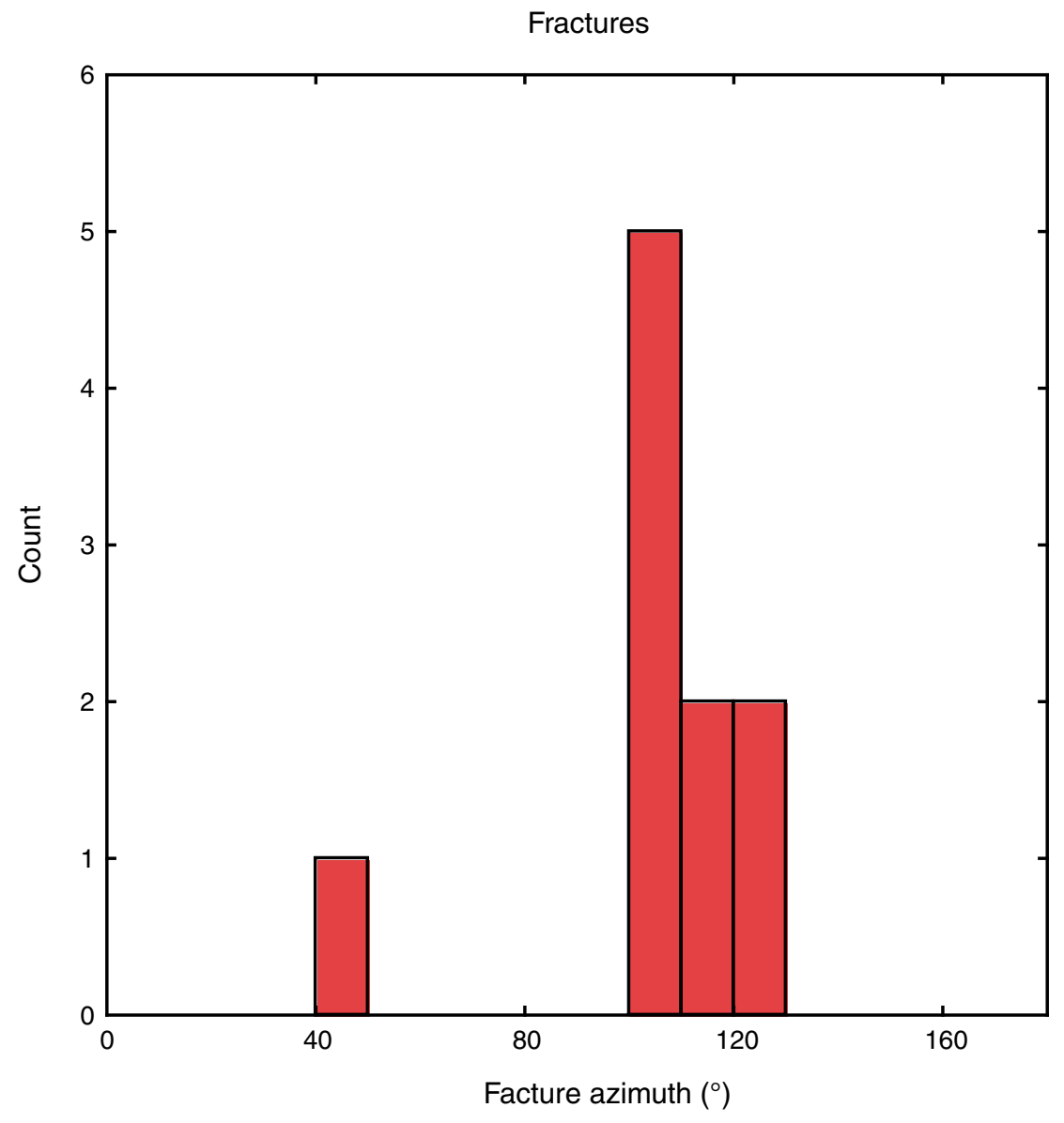


Figure F41. FMI data of bedding attitudes from 897 to $1644 \mathrm{~m}$ WMSF (see also C0009_T5.XLS in STRUCGEOL in "Supplementary material"). A. Contour stereonet plot of poles to bedding for all 189 measurements. B. Rose diagram of dip directions for all bedding attitudes. Bedding dips shallowly to the north-northwest.

A

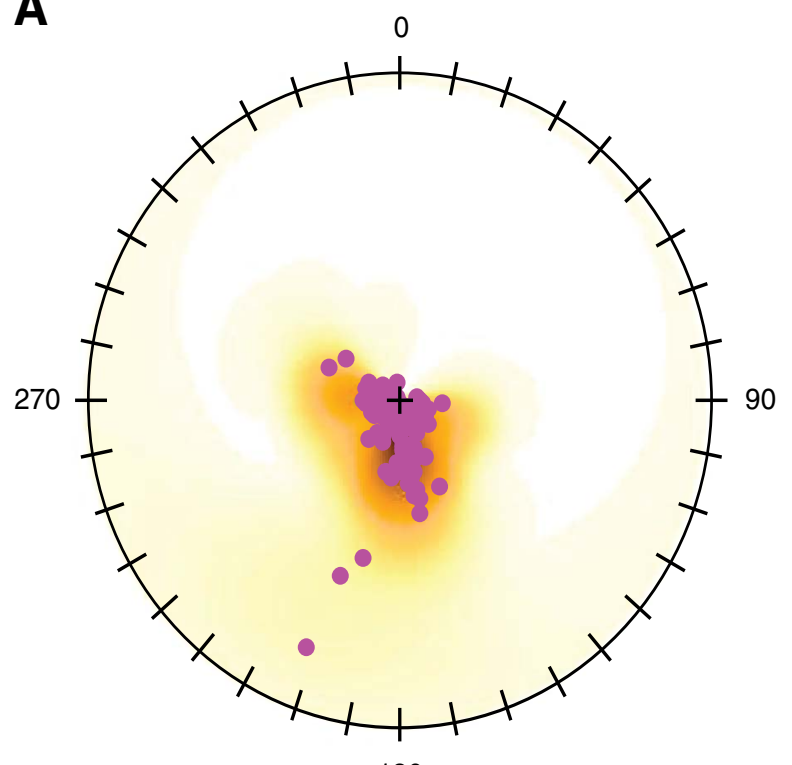

180
B

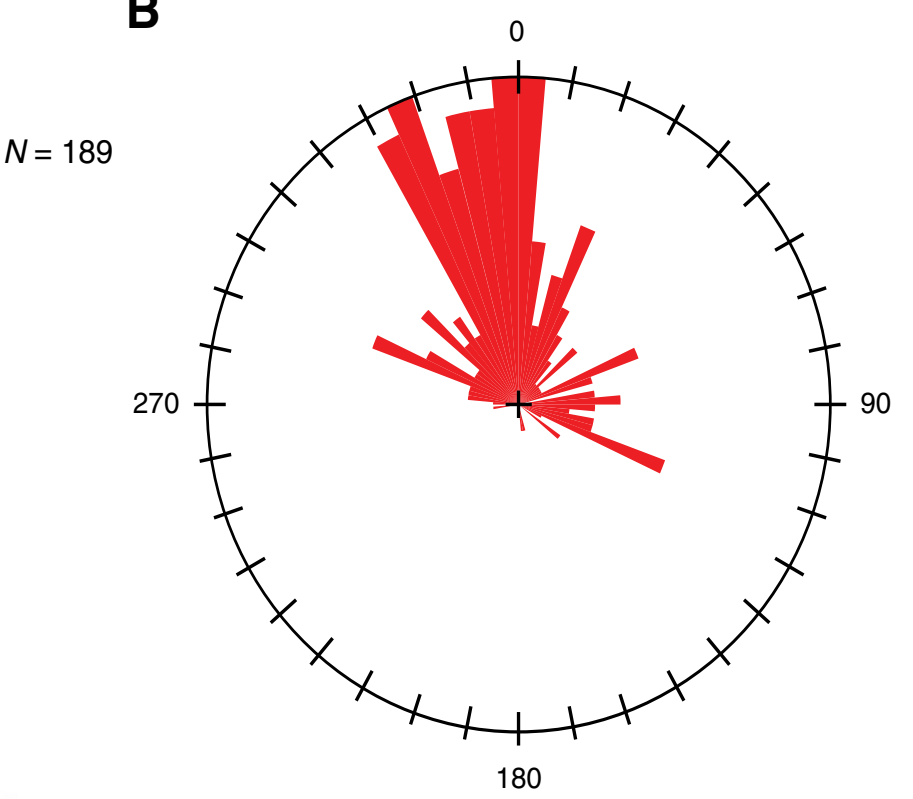


Figure F42. FMI data of fault attitudes from 897 to $1644 \mathrm{~m}$ WMSF (see also C0009_T6.XLS in STRUCGEOL in "Supplementary material"). A. Contour stereonet plot of poles to fault planes. B. Rose diagram of dip directions for all faulting attitudes. Faults dip moderately to shallowly to the northwest.

A

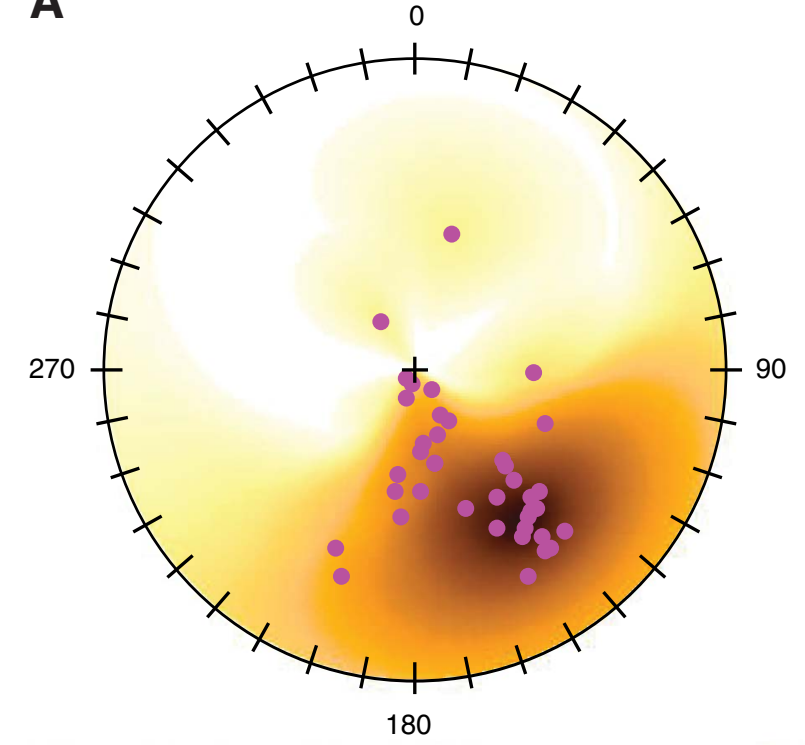

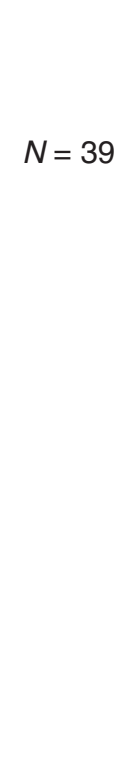

B

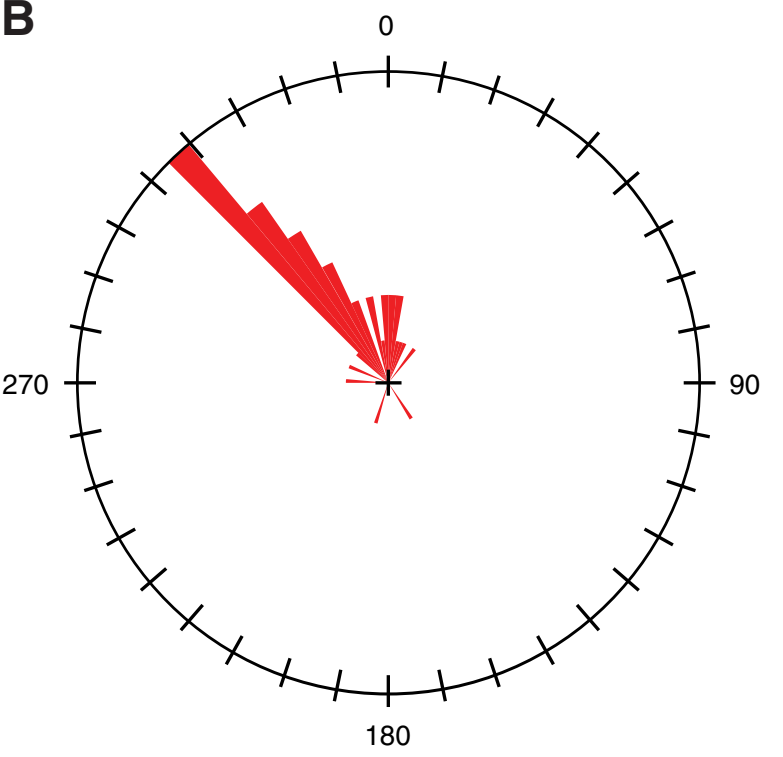


Figure F43. FMI data of bedding attitudes, Subunit IIIA. A. Contour stereonet plot of poles to bedding. B. Rose diagram of dip directions for all bedding attitudes. Bedding dips shallowly to the north-northeast.

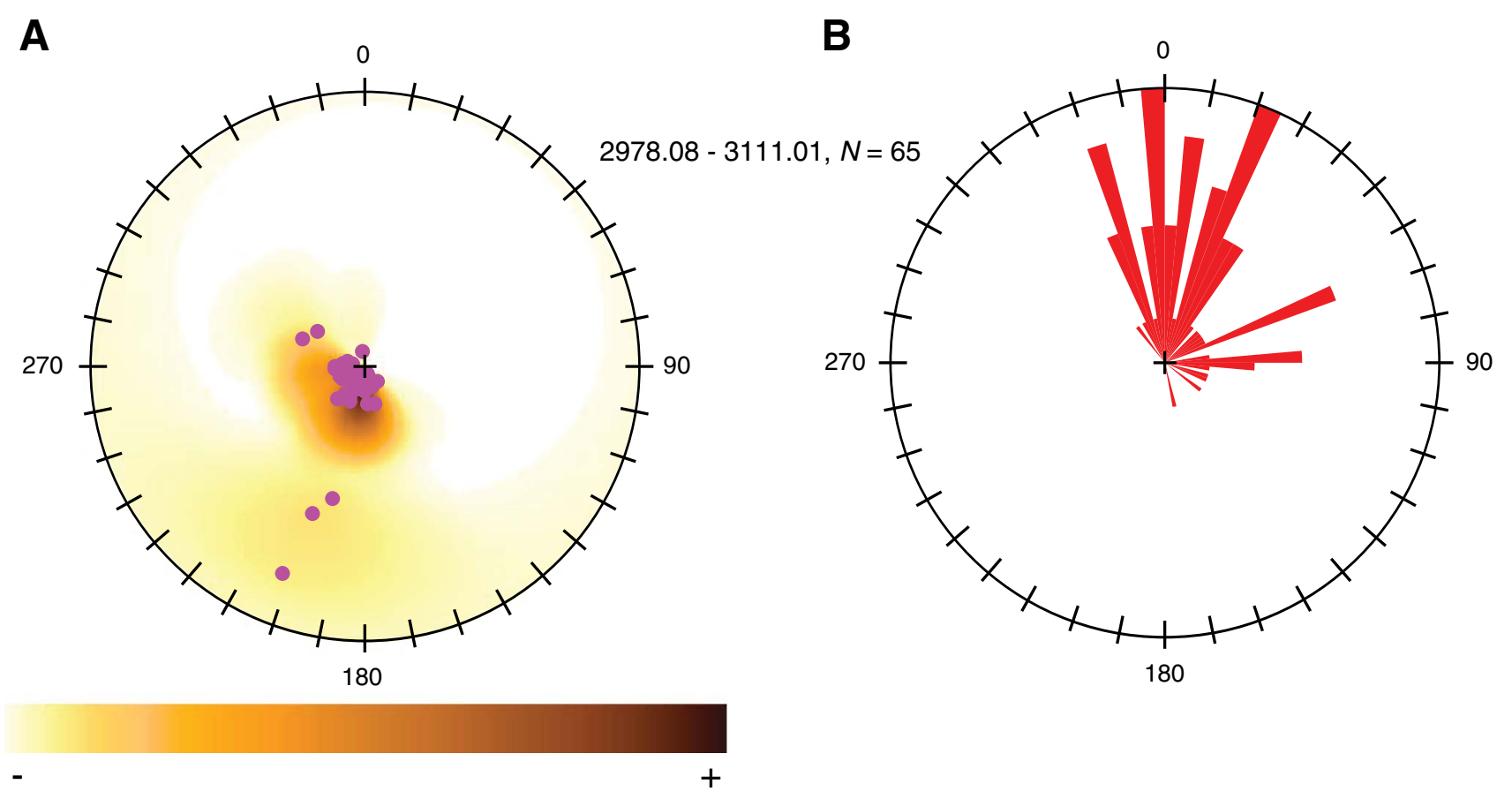


Figure F44. FMI data of bedding attitudes, Subunit IIIB. A. Contour stereonet plot of poles to bedding. B. Rose diagram of dip directions for all bedding attitudes. Bedding dips shallowly to the northwest.

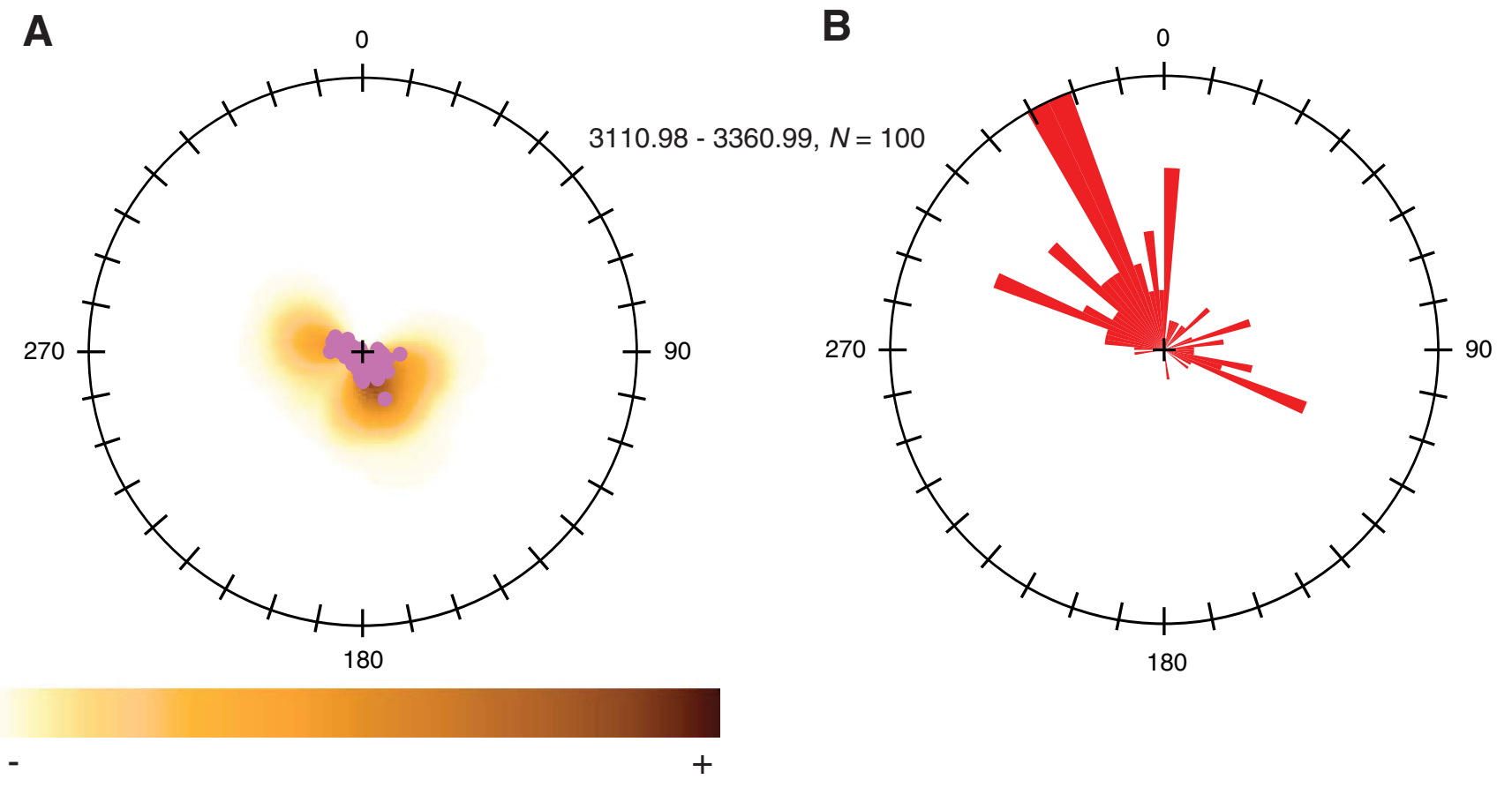


Figure F45. FMI data of bedding attitudes, Unit IV. A. Contour stereonet plot of poles to bedding. B. Rose diagram of dip directions for all bedding attitudes. Bedding dips shallowly to moderately to the north northwest.

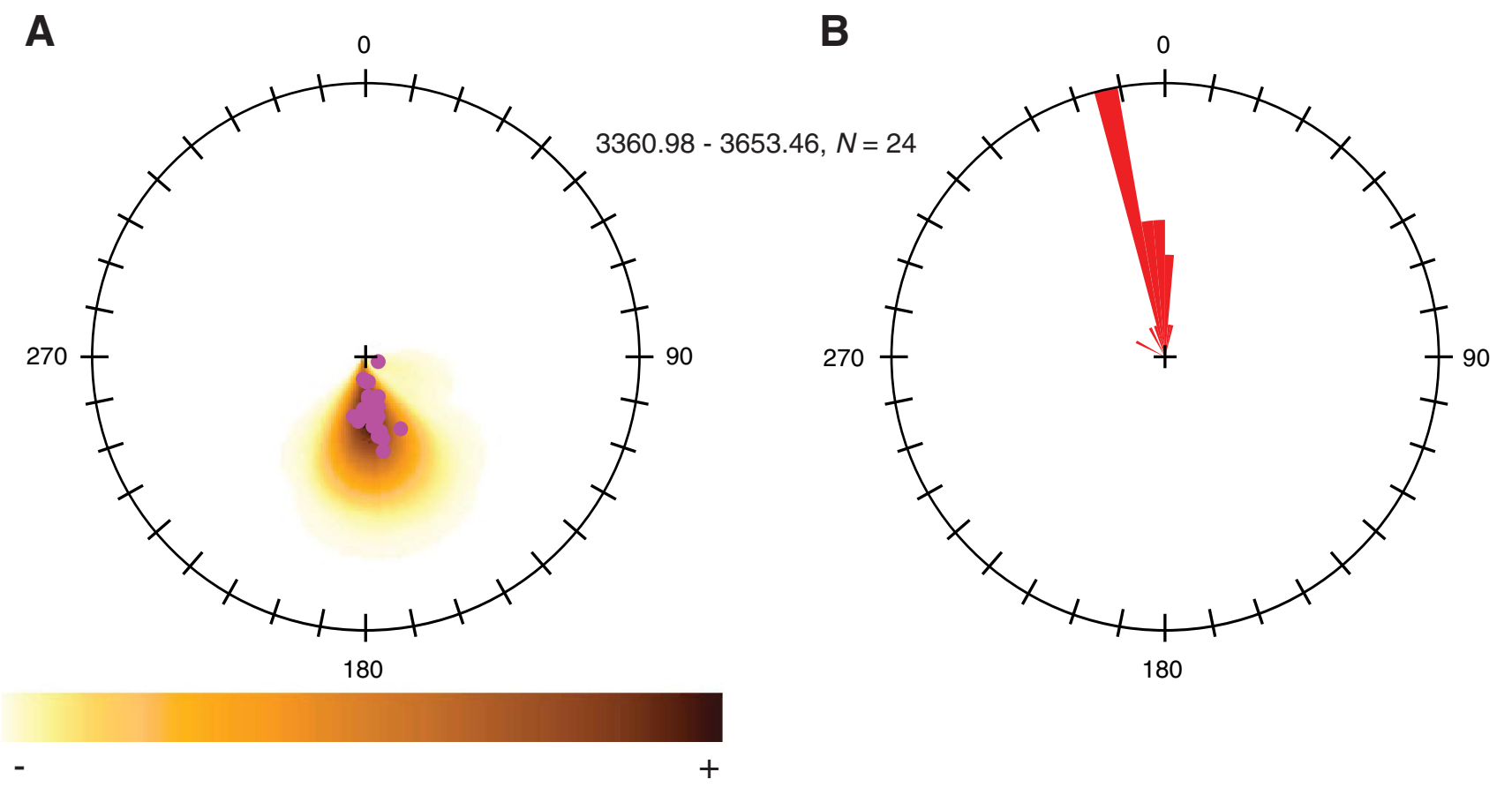




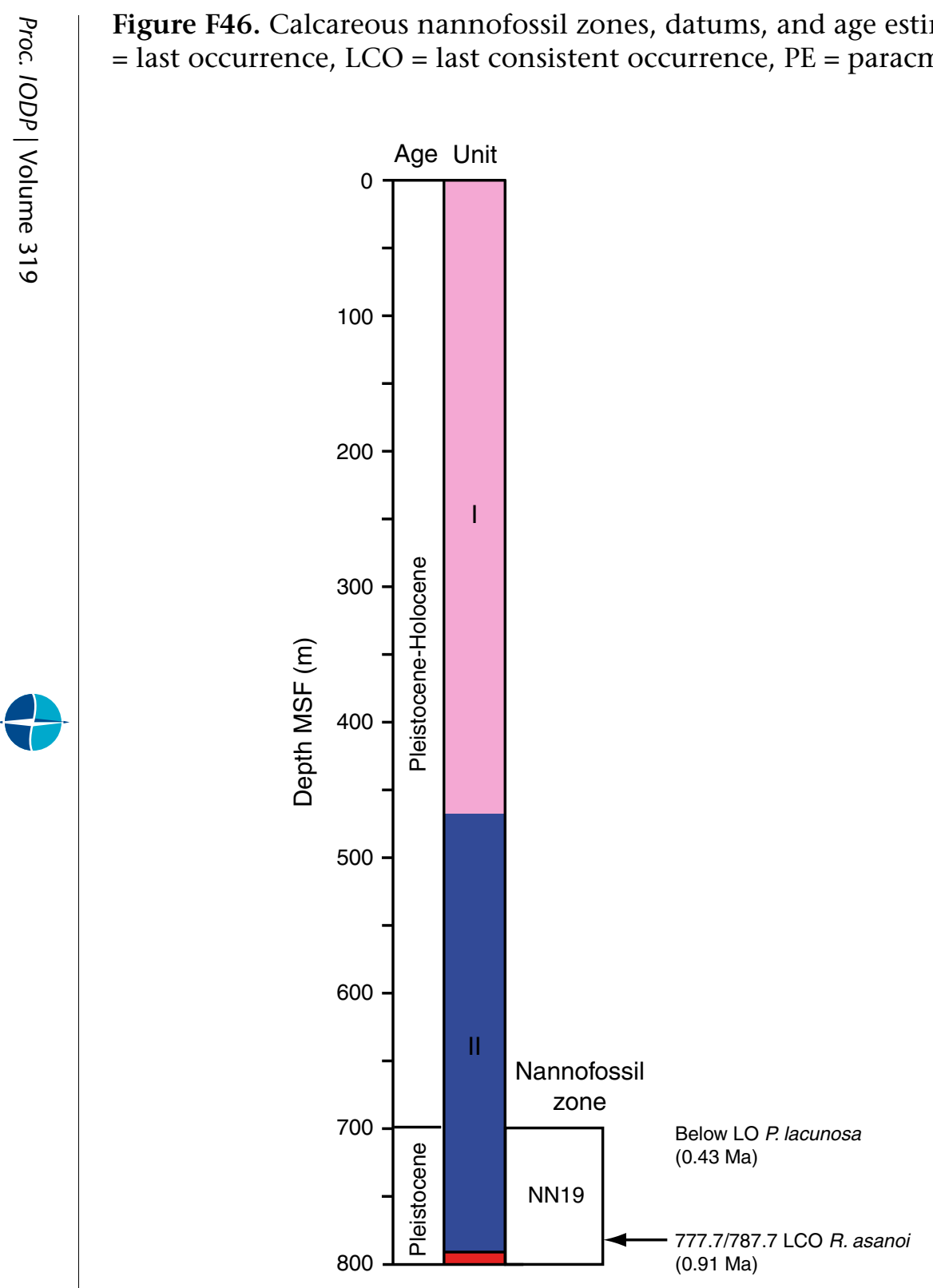

$$
\text { end. }
$$

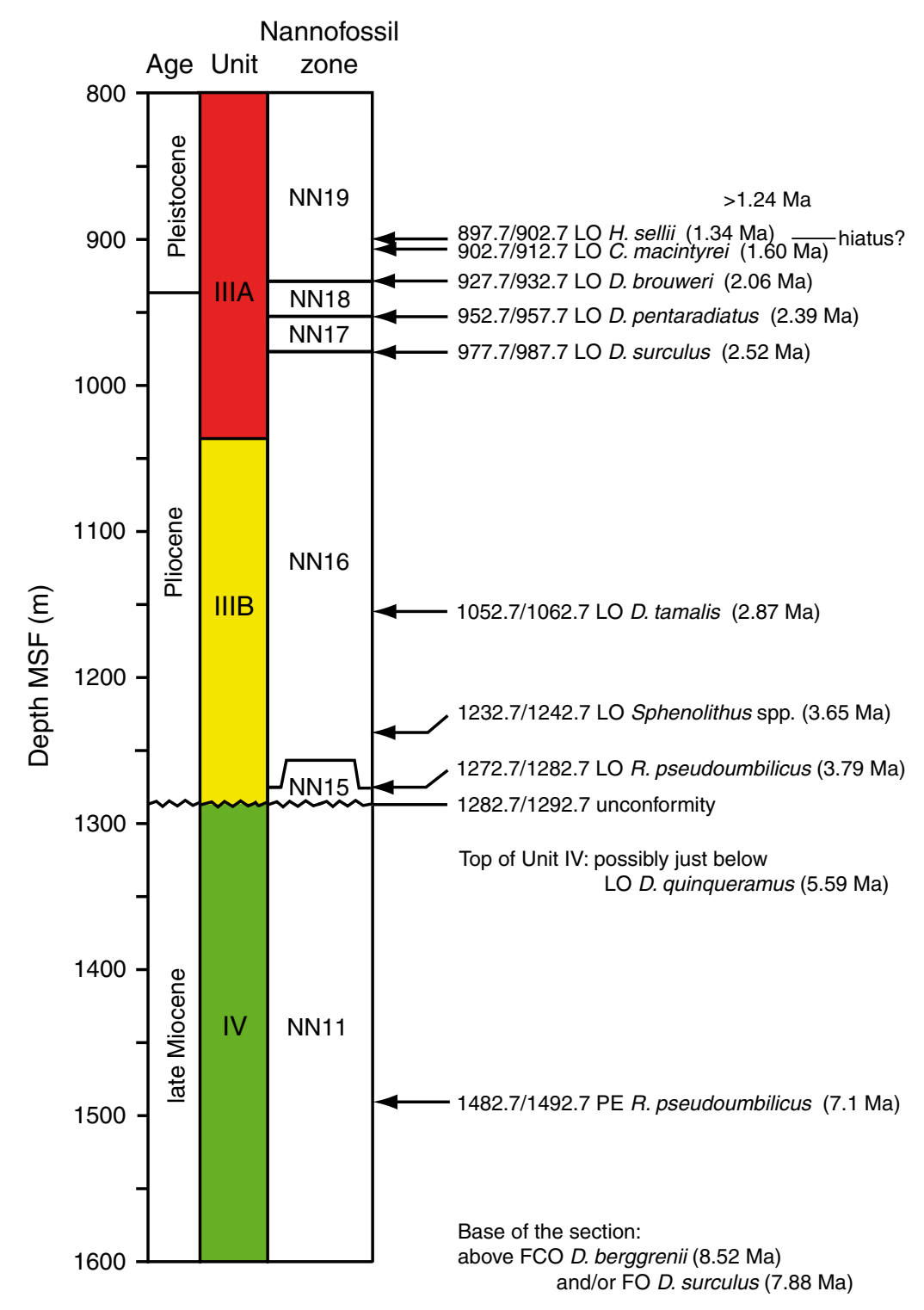


Figure F47. Age-depth plot of calcareous nannofossil events and approximated sedimentation rates, Hole C0009A. Open square $=$ calcareous nannofossil datums. Compaction effects of sediments were not considered and sedimentation rates in Unit IV may be lower than reported because no dip corrections were made.

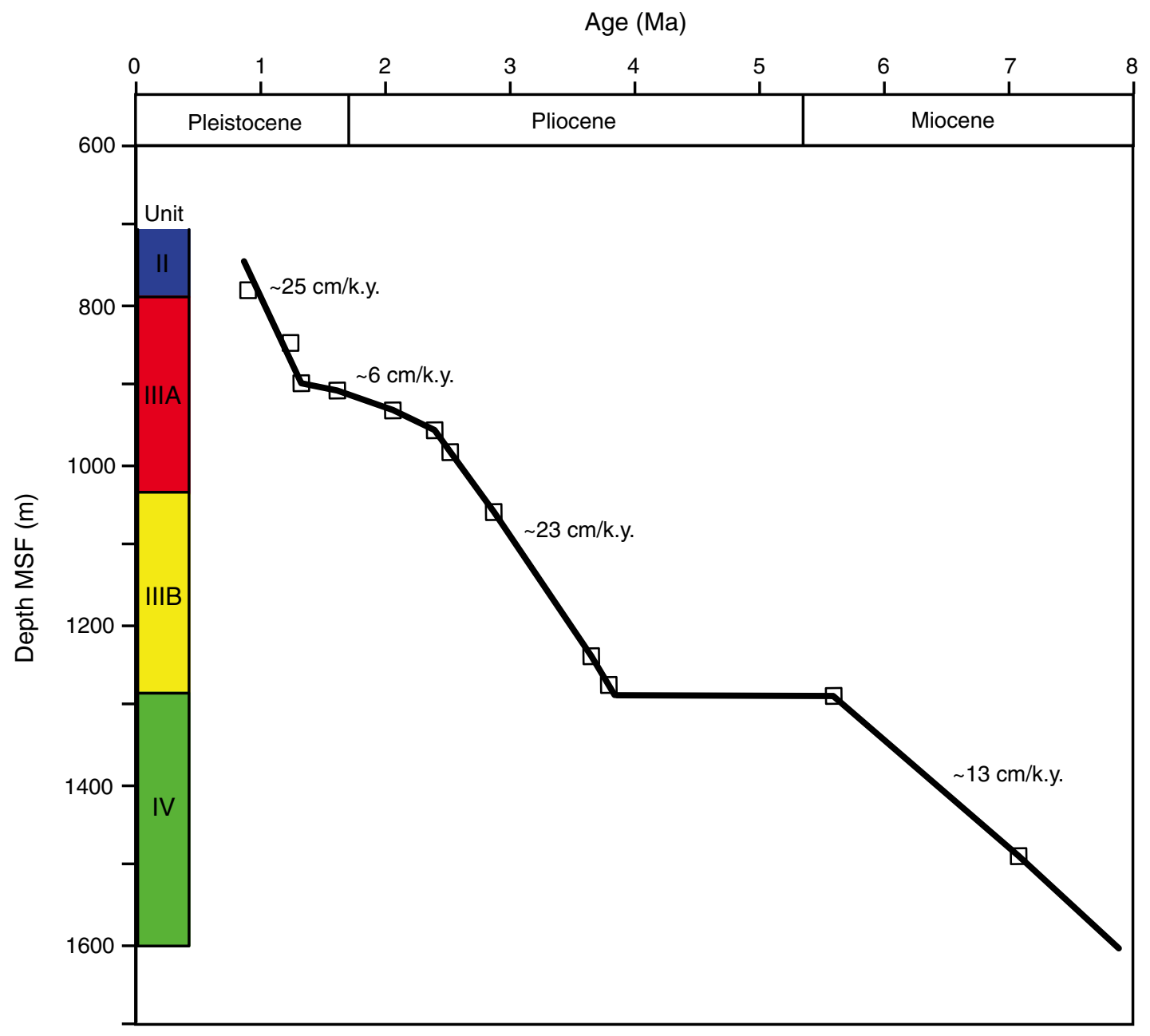


Figure F48. Methane distribution in drilling mud gas during Phase 2 (destructive drilling from 703 to $1510 \mathrm{~m}$ MSF) and Phase 8 (opening hole from 703 to 1569 m MSF) as well as relative abundance of woody fragments from visual observations of drill cuttings. Drilling mud gas measurements during Phase 8 were disturbed below $1260 \mathrm{~m}$ MSF and thus not shown here. $\mathrm{D}=$ dominant, $\mathrm{A}=$ abundant, $\mathrm{C}=$ common, $\mathrm{F}=$ few.
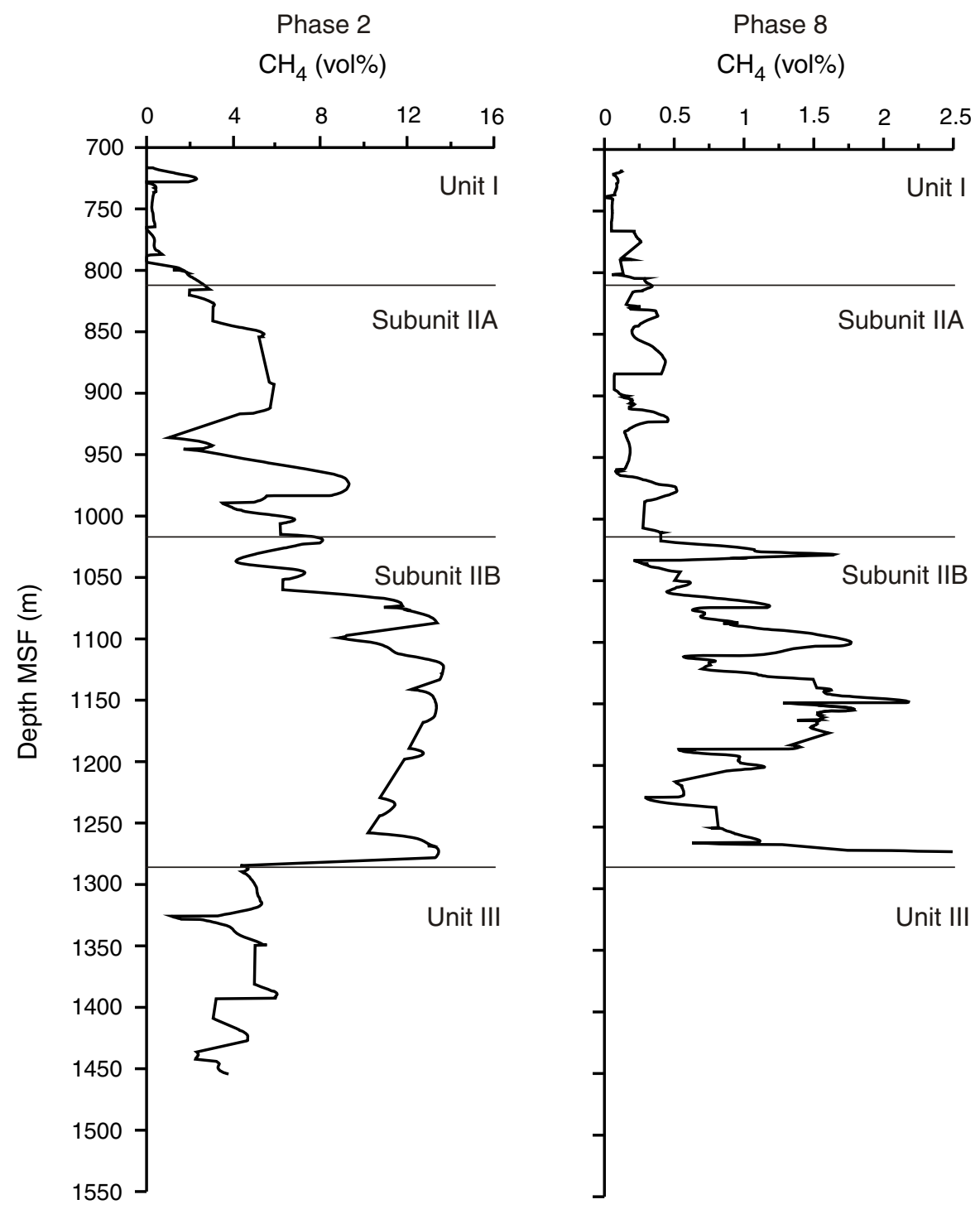

Relative abundance of wood fragments based on visual analysis of cuttings

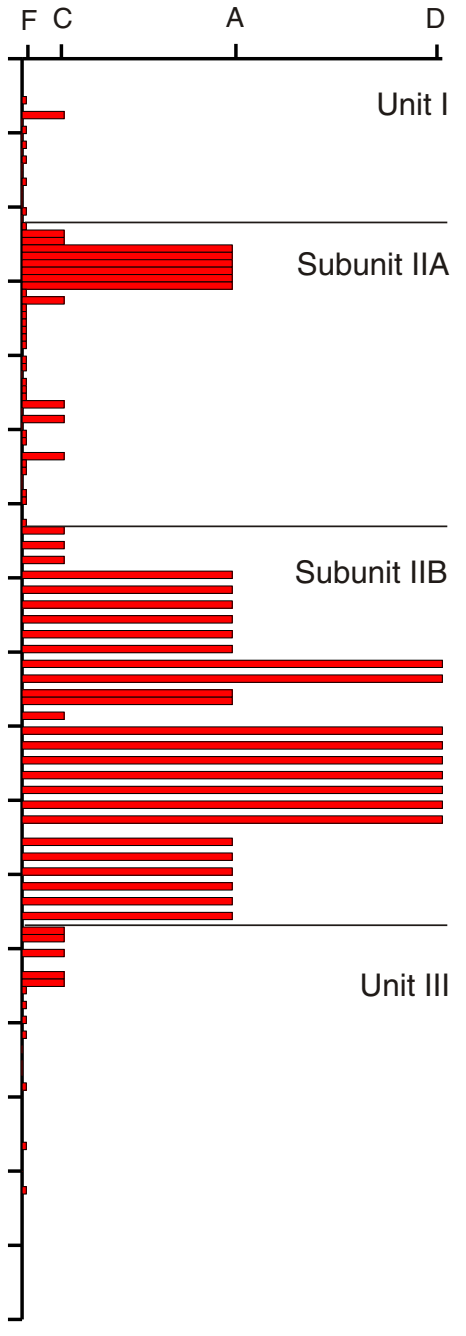


Figure F49. $\mathrm{CH}_{4} /\left(\mathrm{C}_{2} \mathrm{H}_{6}+\mathrm{C}_{3} \mathrm{H}_{8}\right)$ ratio during drilling Phase 8 .

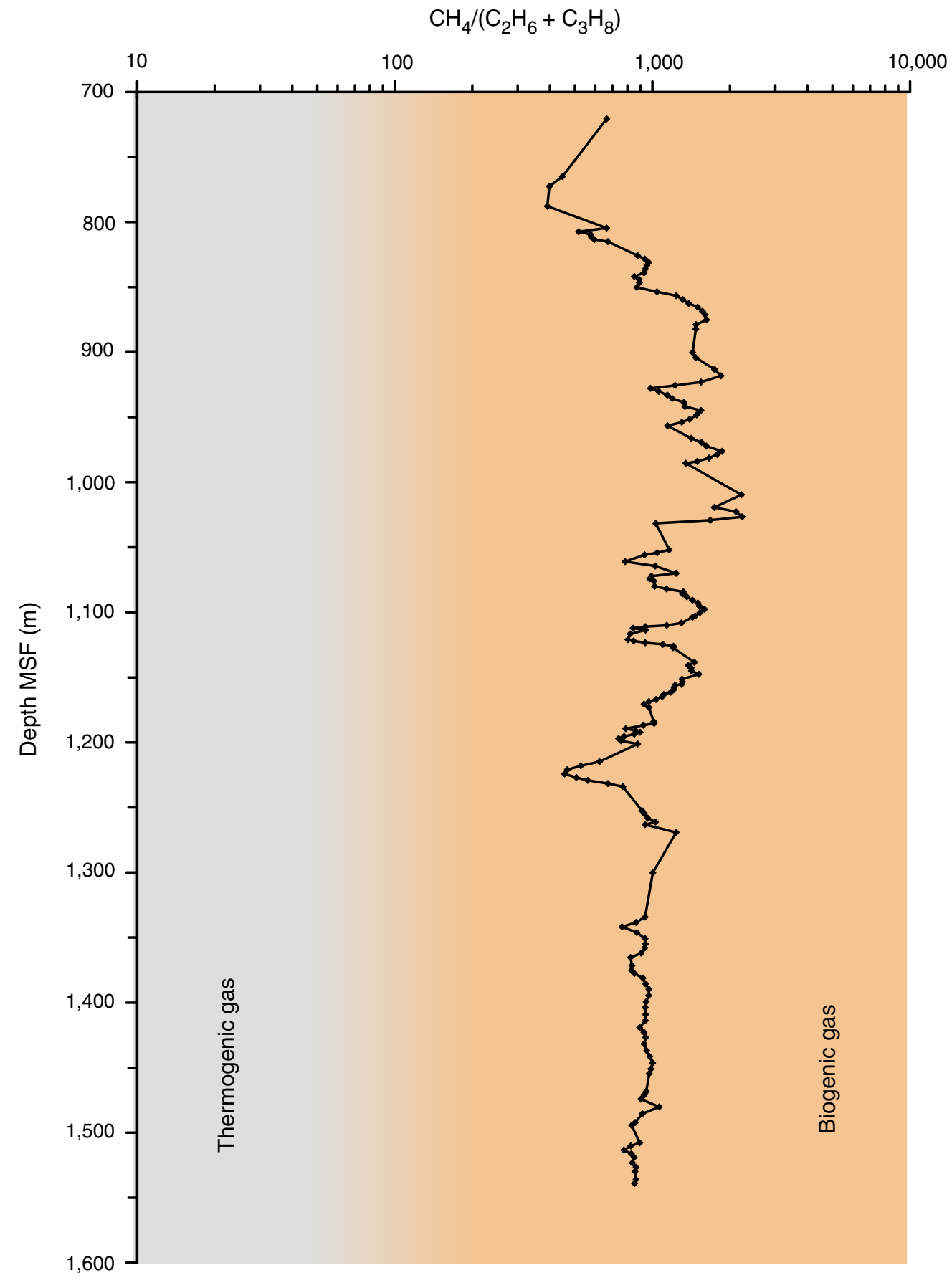


Figure F50. Poisson's ratio calculated from $V_{\mathrm{p}} / V_{\mathrm{S}}$ (red) and measured methane concentration (black) with depth during drilling Phase 2.

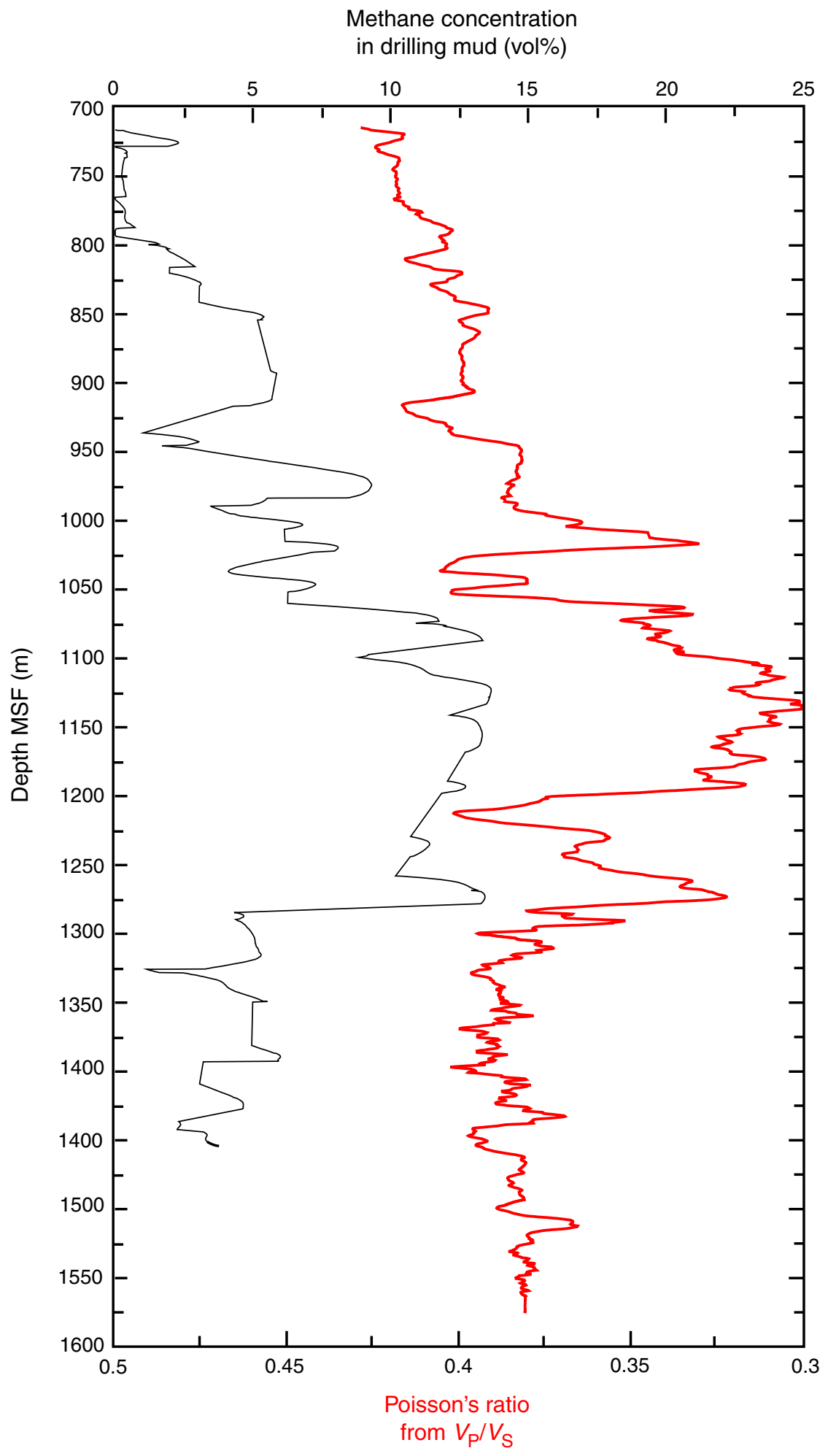


Figure F51. $\mathrm{CaCO}_{3}$, total organic carbon $(\mathrm{TOC})$, total nitrogen $(\mathrm{TN})$, and TOC/TN ratio, Site C0009. Red $=$ cuttings samples, blue $=$ core samples. Cuttings depths are in MSF, core depths are in CSF.
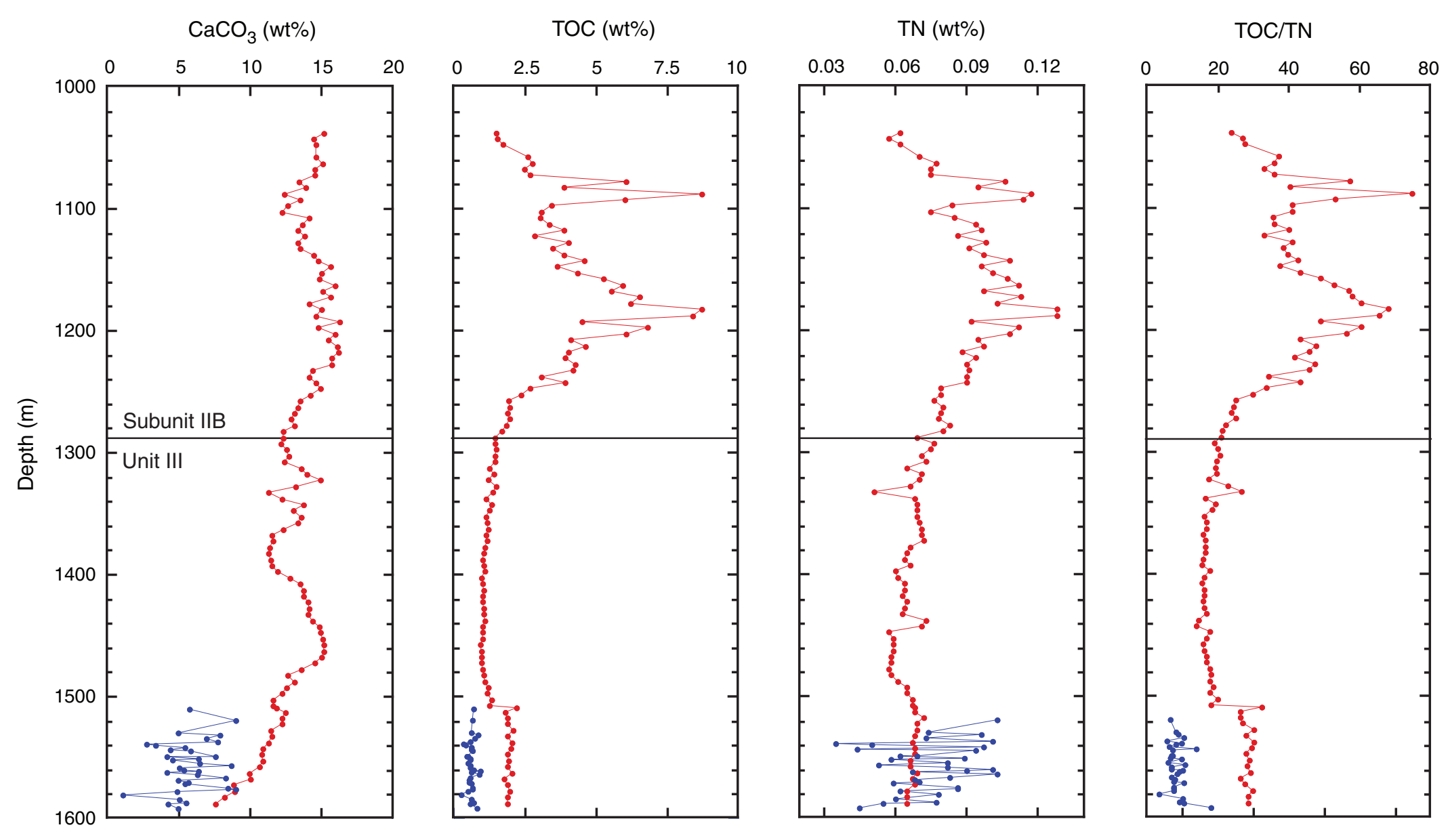
Figure F52. Measured anion and major cation concentrations of interstitial water from core samples, Site C0009.
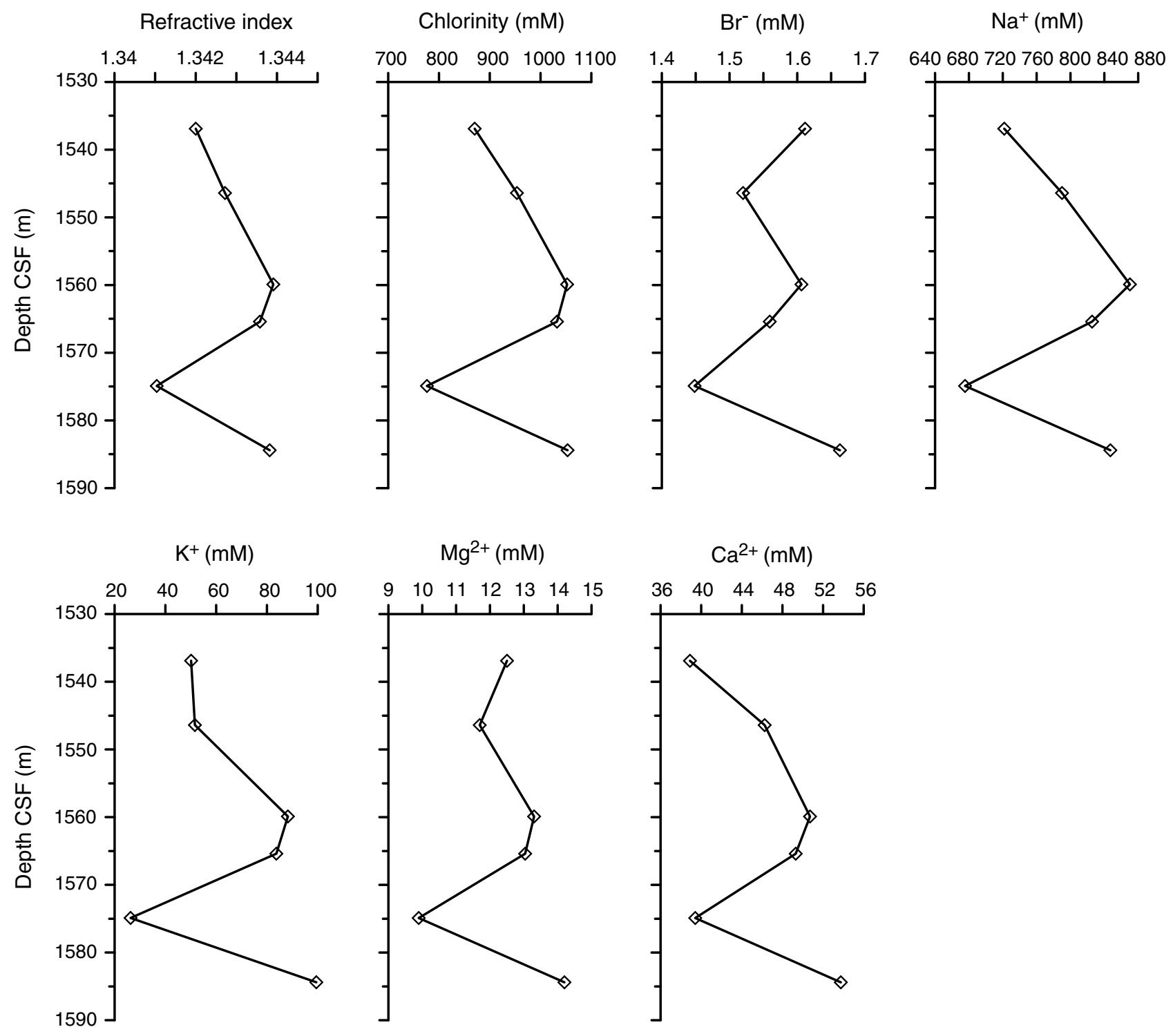
Figure F53. Measured minor cation concentrations of interstitial water from core samples, Site C0009.

$\mathrm{Li}^{+}(\mu \mathrm{M})$

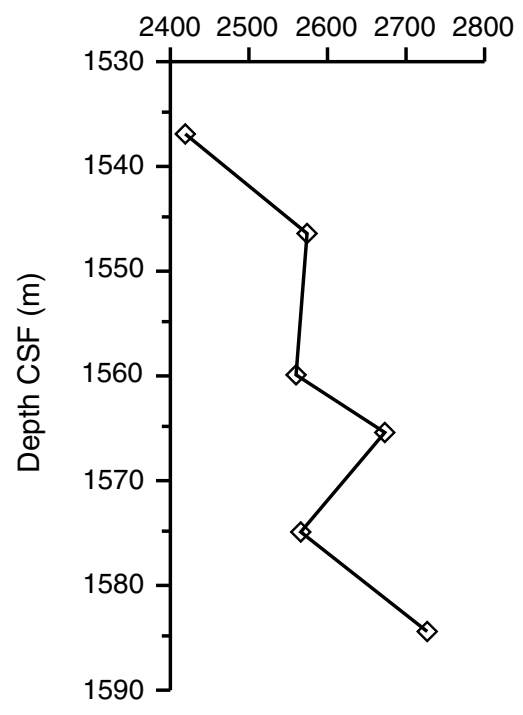

Si $(\mu \mathrm{M})$

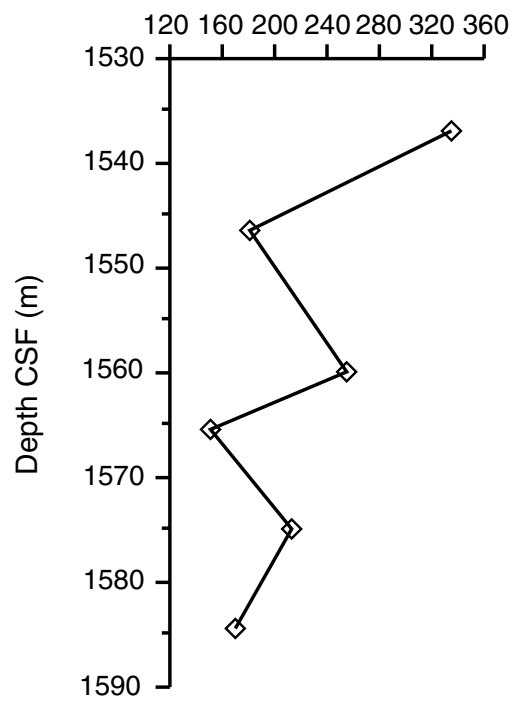

B $(\mu \mathrm{M})$

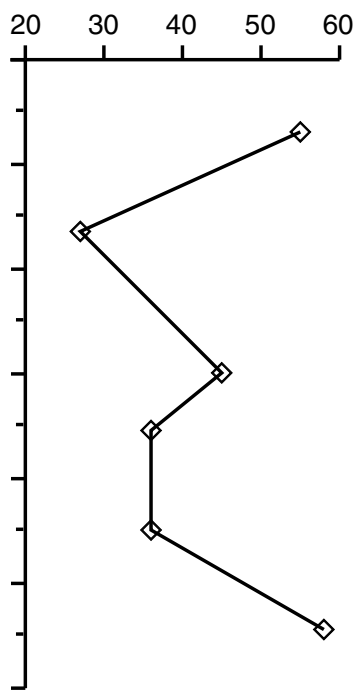

$\mathrm{Sr}^{2+}(\mu \mathrm{M})$

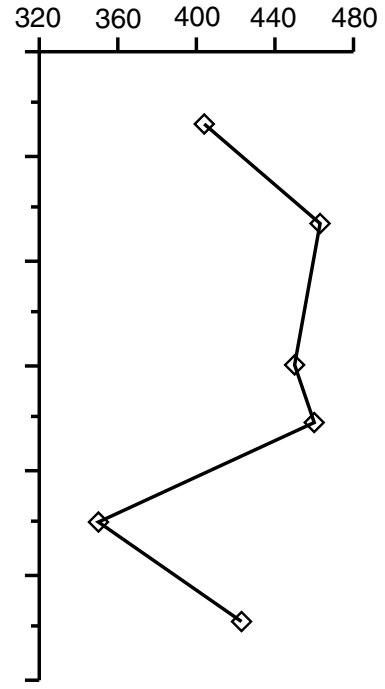

$\mathrm{Mn}^{2+}(\mu \mathrm{M})$

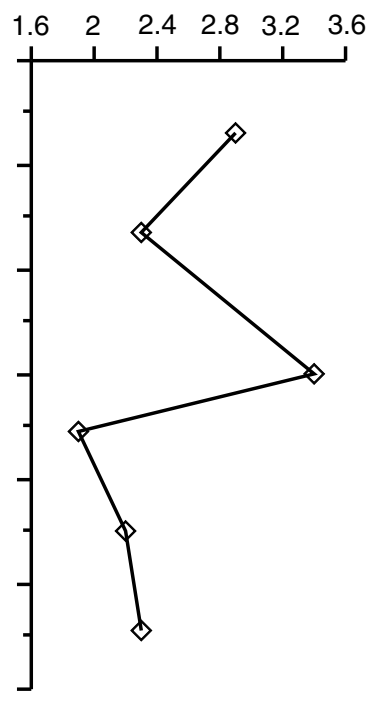

$\mathrm{Ba}^{2+}(\mu \mathrm{M})$

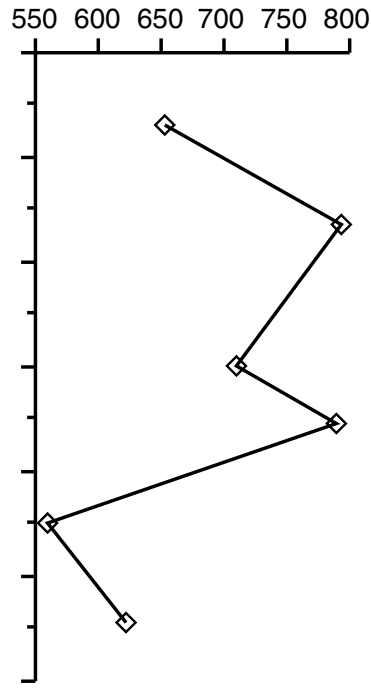


Figure F54. Measured trace element concentrations of interstitial water from core samples, Site C0009.
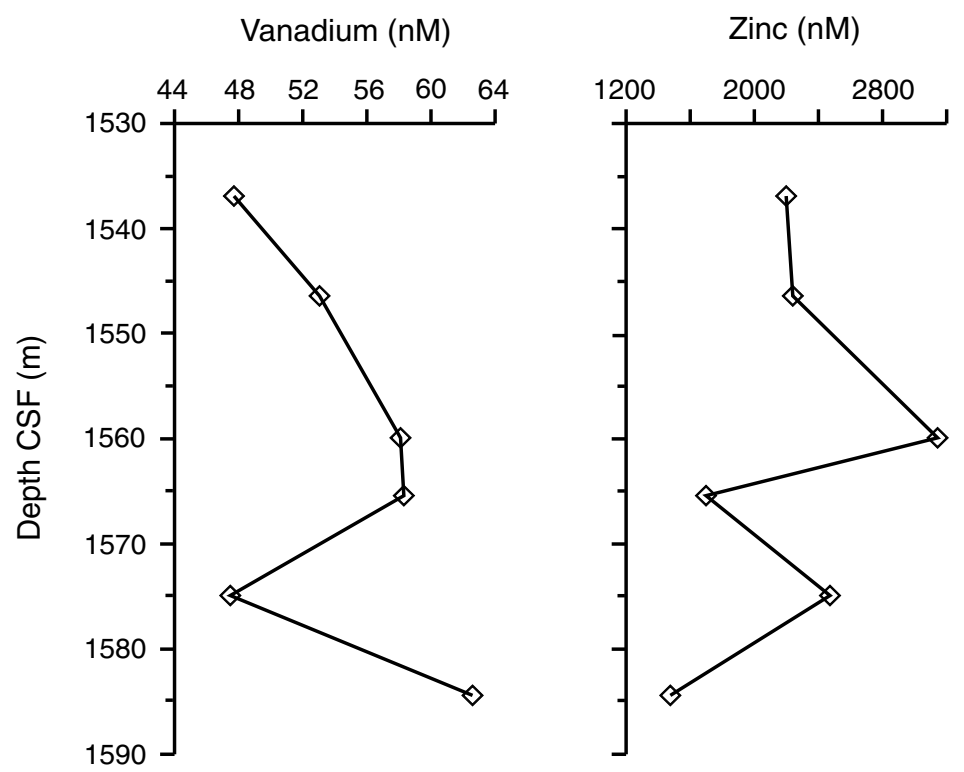

Rubidium (nM)
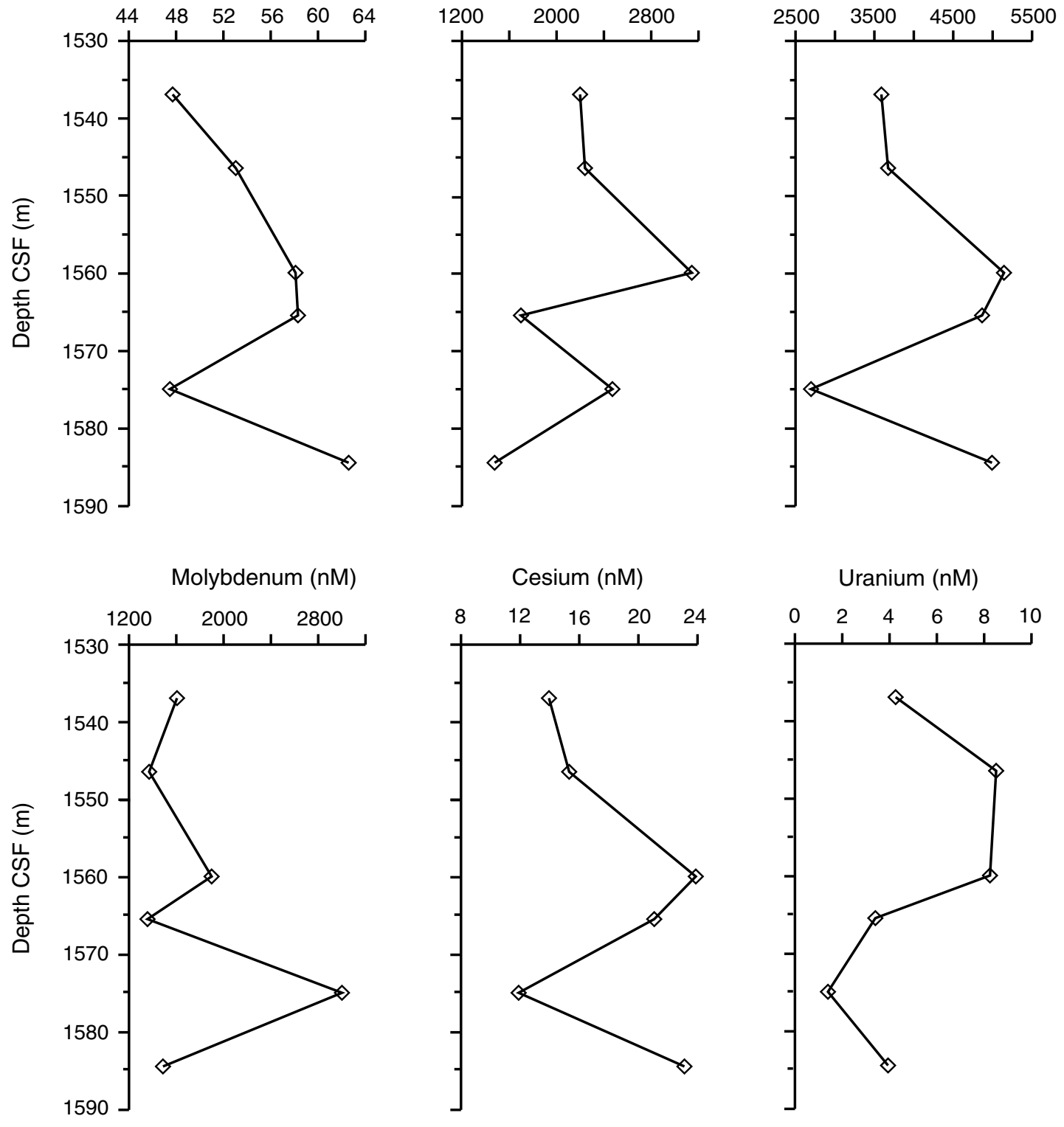
Figure F55. Whole-round multisensor core logger (MSCL-W) results from cored interval, Hole C0009A. A. Bulk density with discrete core sample densities from MAD for comparison. B. Magnetic susceptibility. C. Natural gamma ray (NGR). cps = counts per second. D. $P$-wave velocity. E. Electrical resistivity.

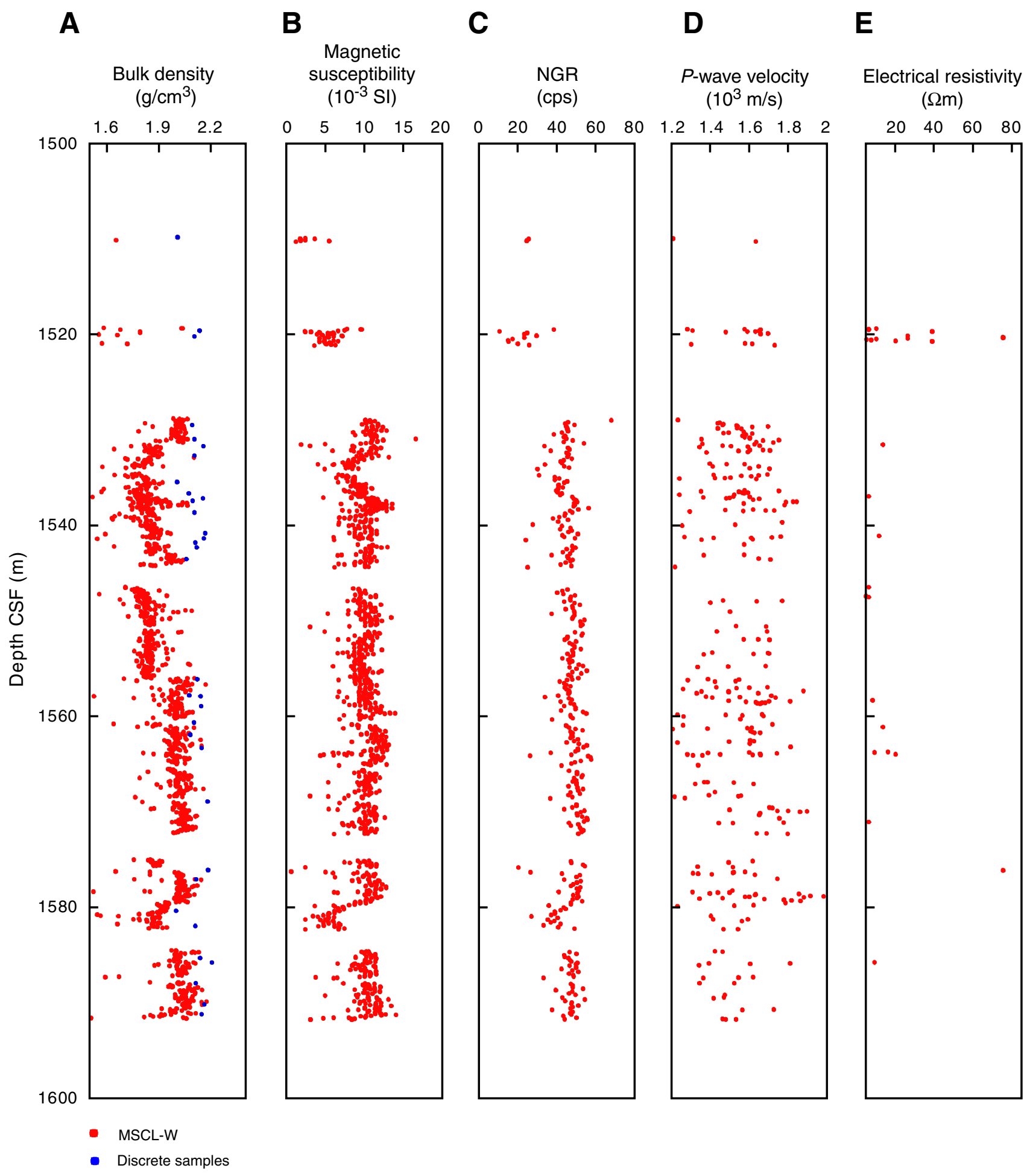


Figure F56. MAD data versus depth from cuttings samples. A. Fractional porosity. B. Bulk density. C. Grain density.

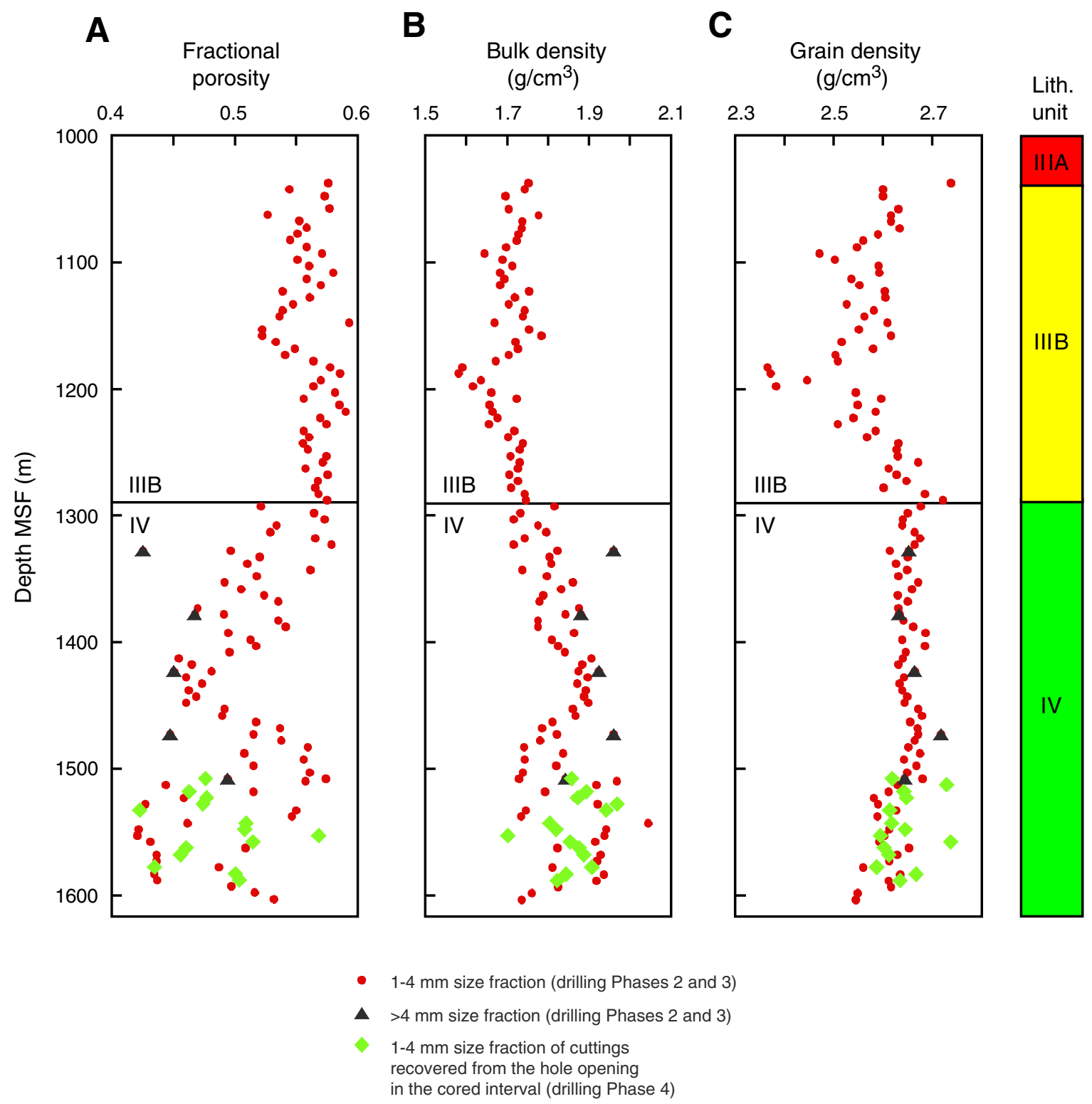


Figure F57. Grain density data derived from cuttings versus total organic carbon (TOC). In Subunits IIIA and IIIB, there is negative correlation between TOC and grain density.

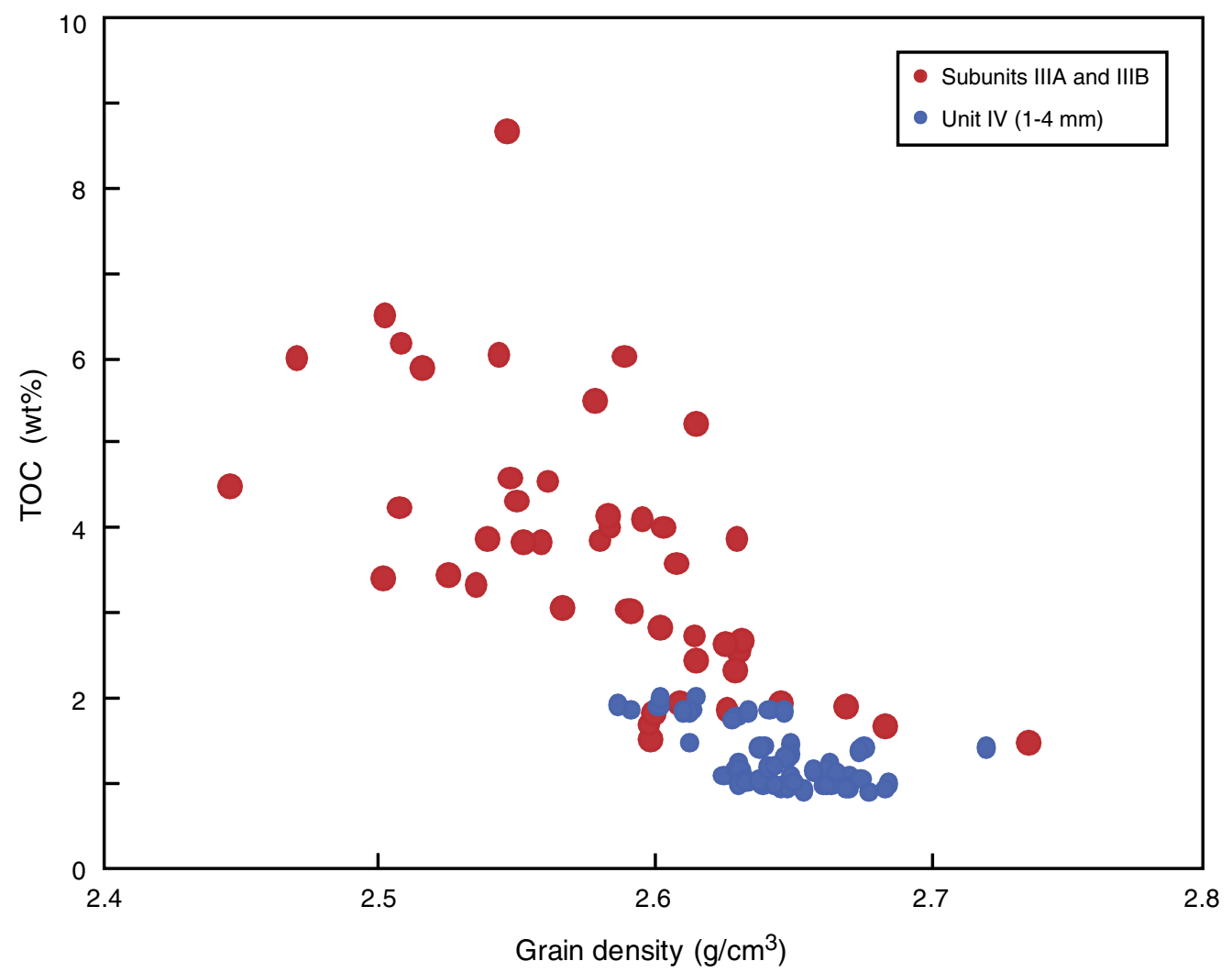


Figure F58. Fractional porosity of cuttings samples versus soaking time.

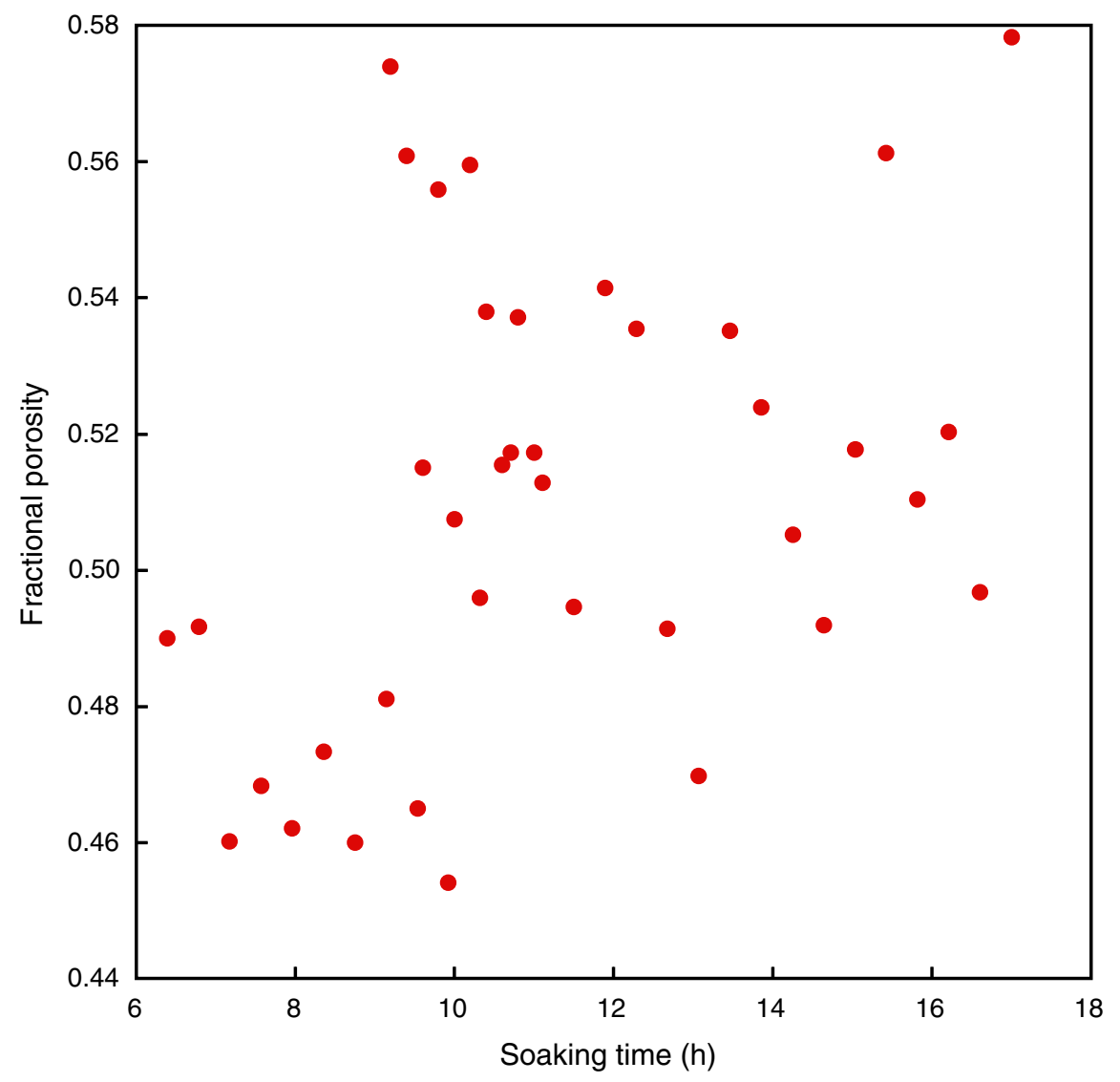


Figure F59. A. Location of Modular Formation Dynamics Tester (MDT) measurements relative to other log data. Hydraulic fracture tests taken at 877 m WMSF (Test MDT_080) and $1534 \mathrm{~m}$ WMSF (Test MDT_074). One dual packer drawdown test taken at 1541 m WMSF (Test MDT_073). All other measurements are single probe test (SPT) measurements. (Continued on next page.)

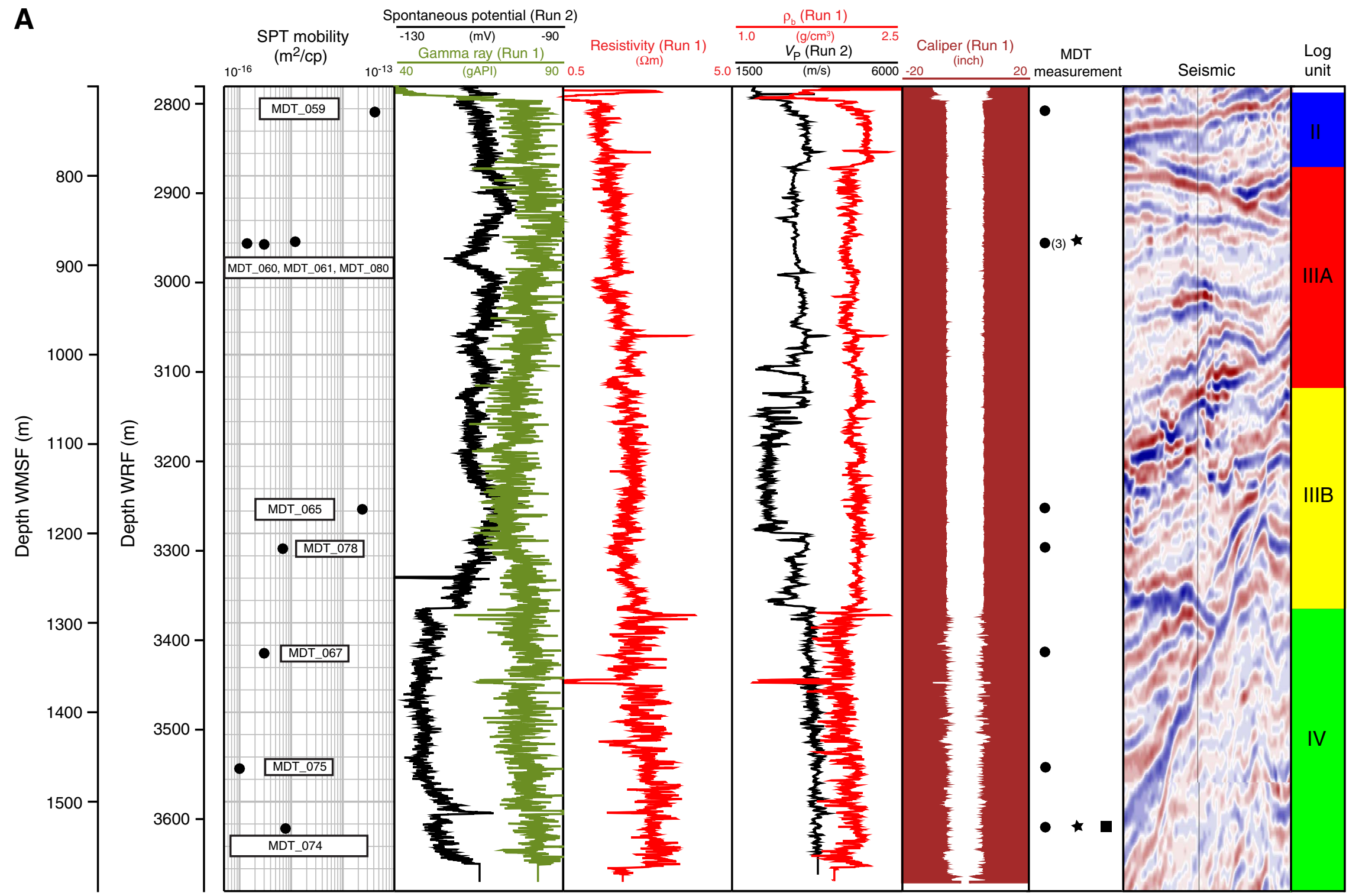


Figure F59 (continued). B. Expanded view of the cored interval. MDT = Modular Formation Dynamics Tester. Circle $=$ SPT measurement, star $=$ hydraulic fracture measurement, square = dual packer drawdown.

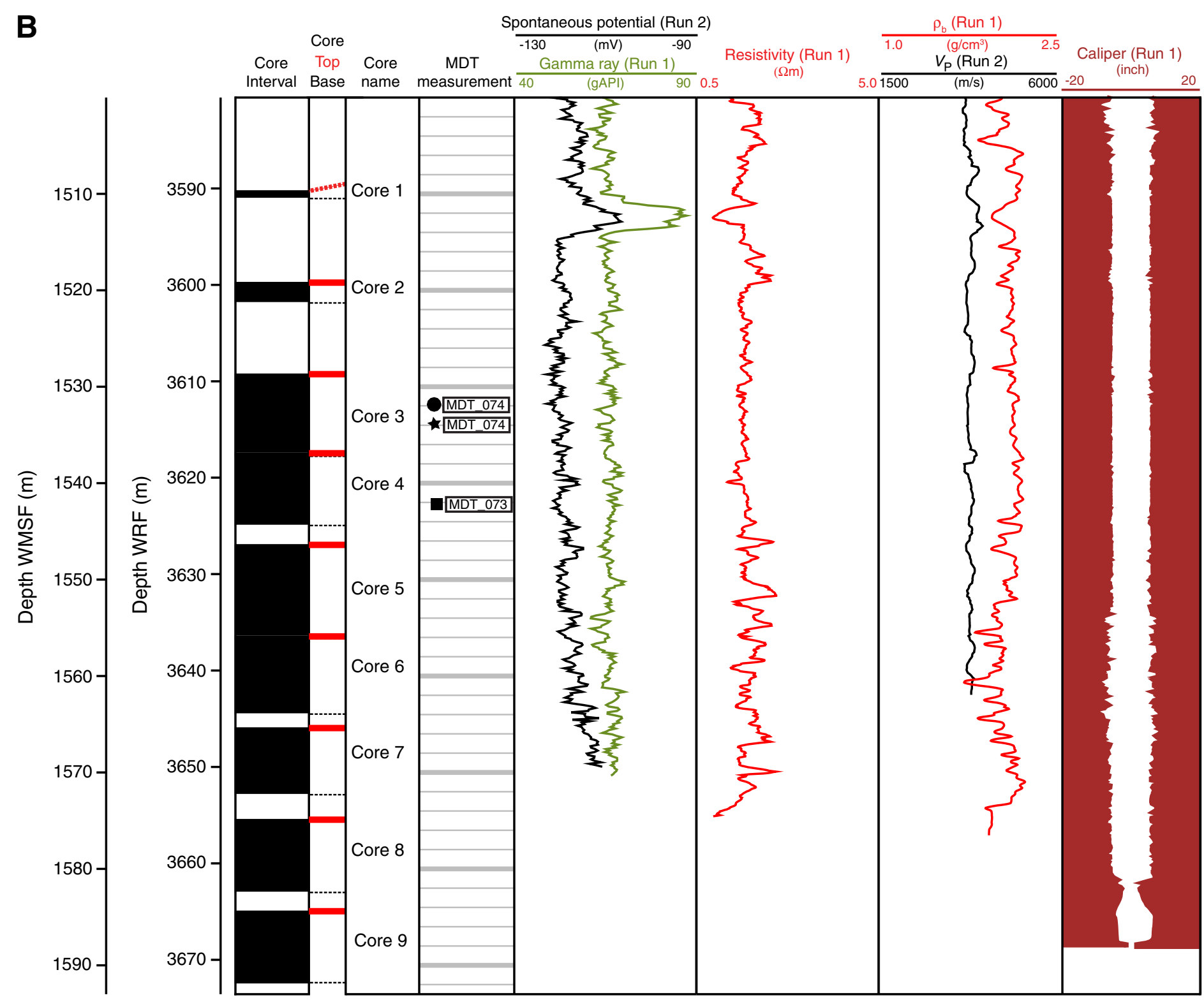


Figure F60. MAD data versus depth for samples from cores, Unit IV. A. Fractional porosity. B. Bulk density. C. Grain density. Red = ash-rich layers.

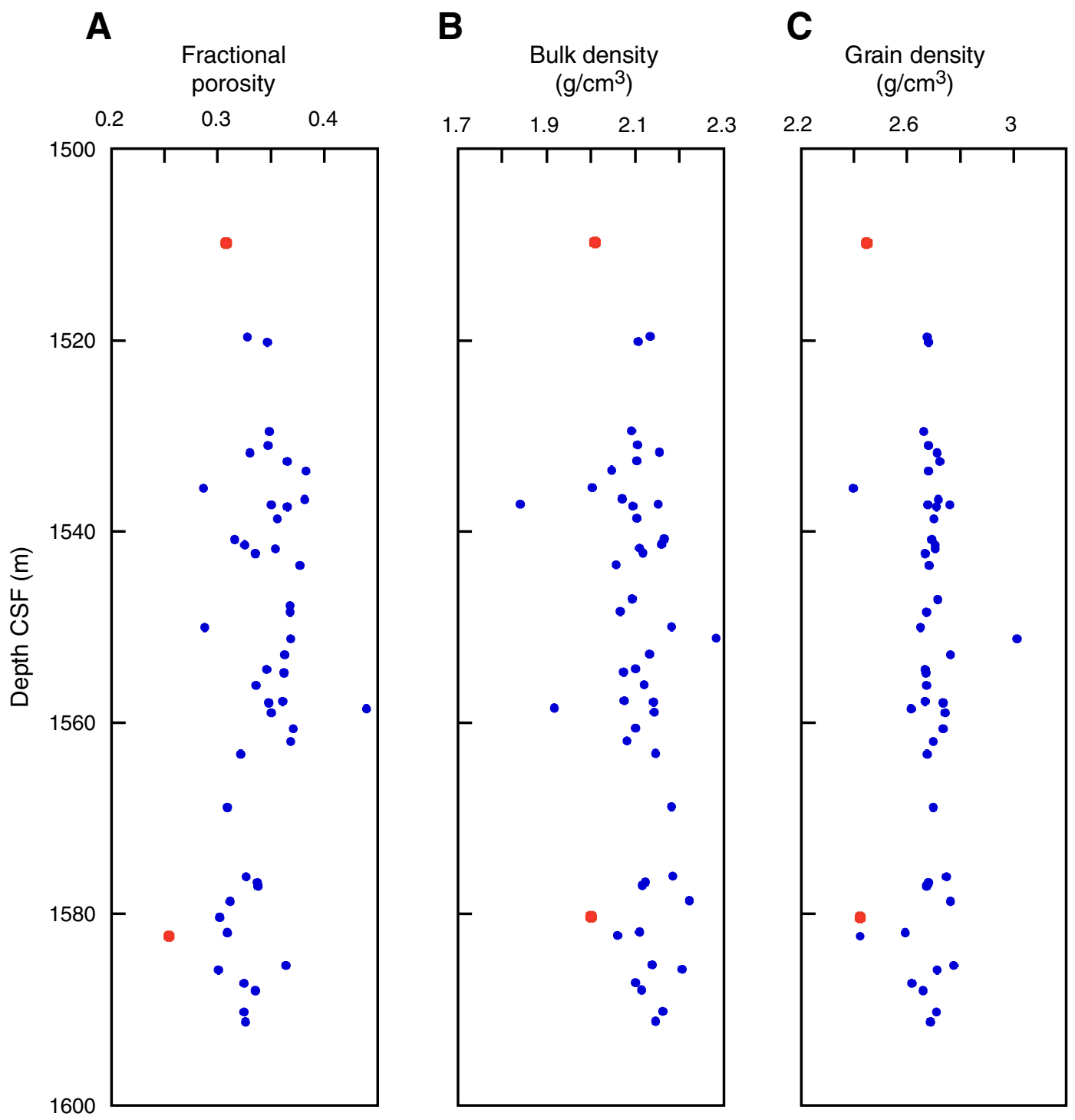


Figure F61. Fractional porosities from core and cutting samples. Fractional porosities from core samples exhibit lower values (30\%-35\%) than those from cuttings (drilling Phases 3 and 4; see Table T1). Core depths are in CSF, cuttings depths are in MSF.

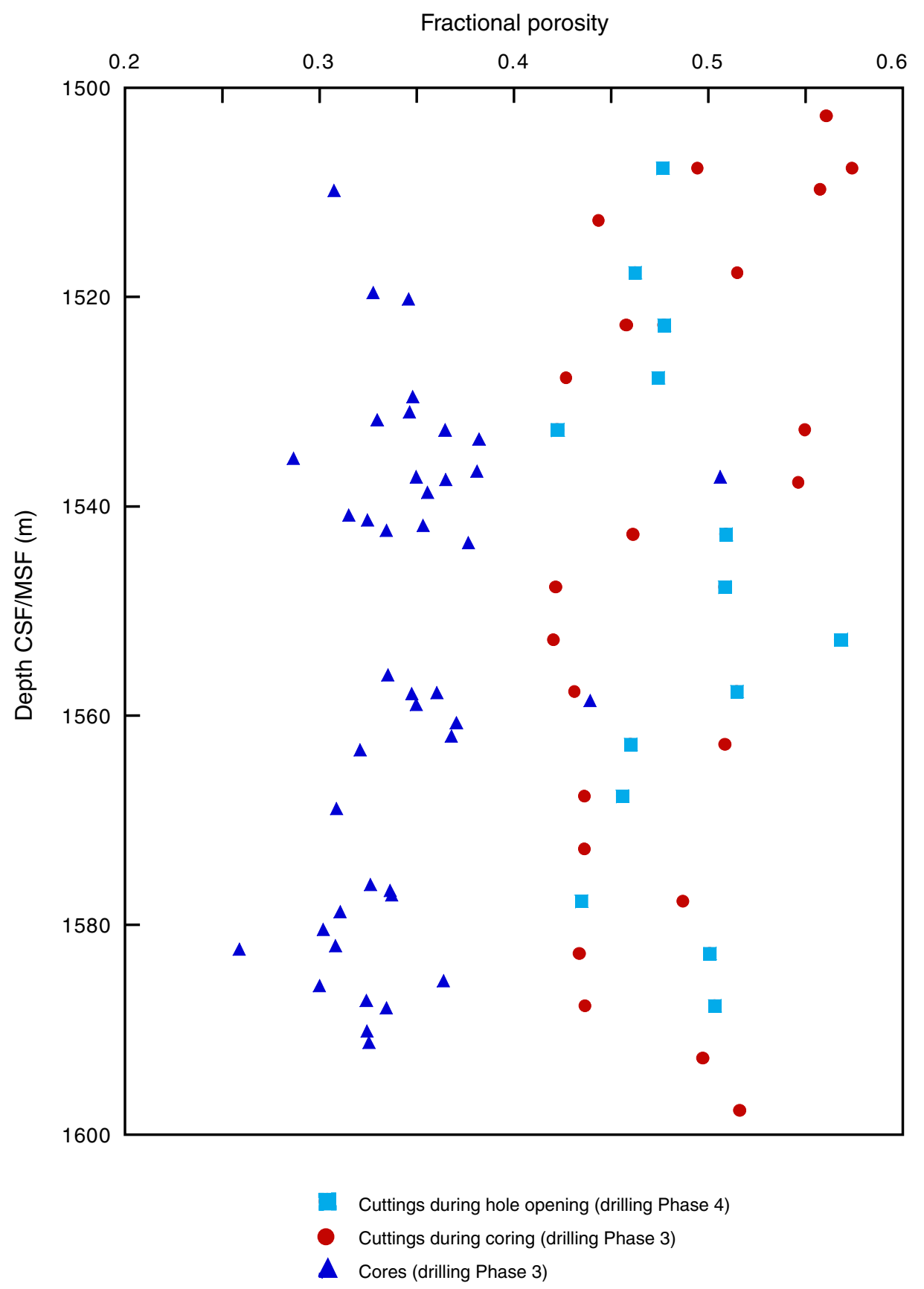


Figure F62. Measured porosity on cuttings versus core samples from cored interval (1510-1594 m CSF). Cuttings data are from first hole opening in cored interval (drilling Phase 4).

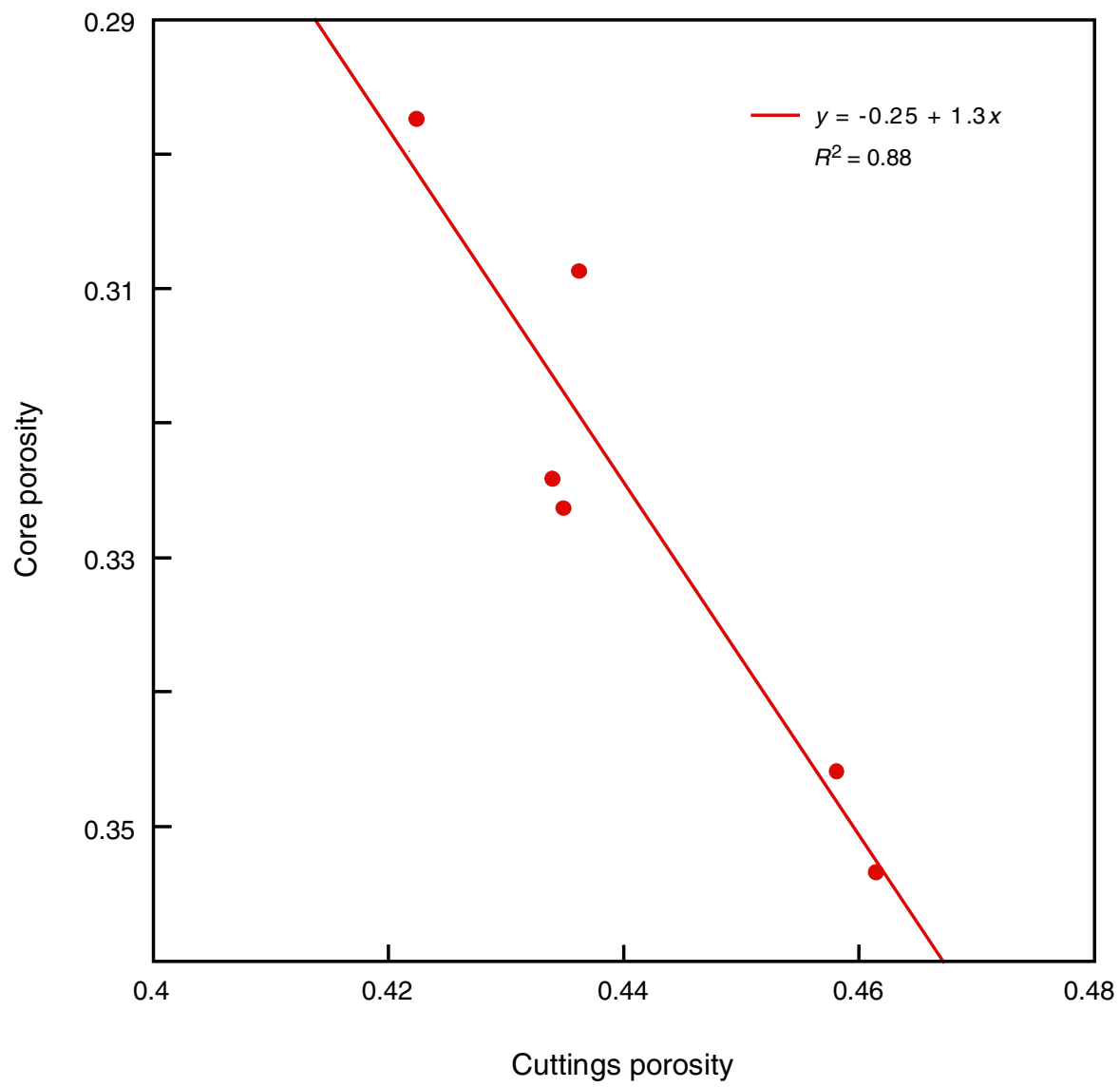


Figure F63. A. Variation of $P$-wave velocity with depth within cored interval. B. Anisotropy of $P$-wave velocity with depth.

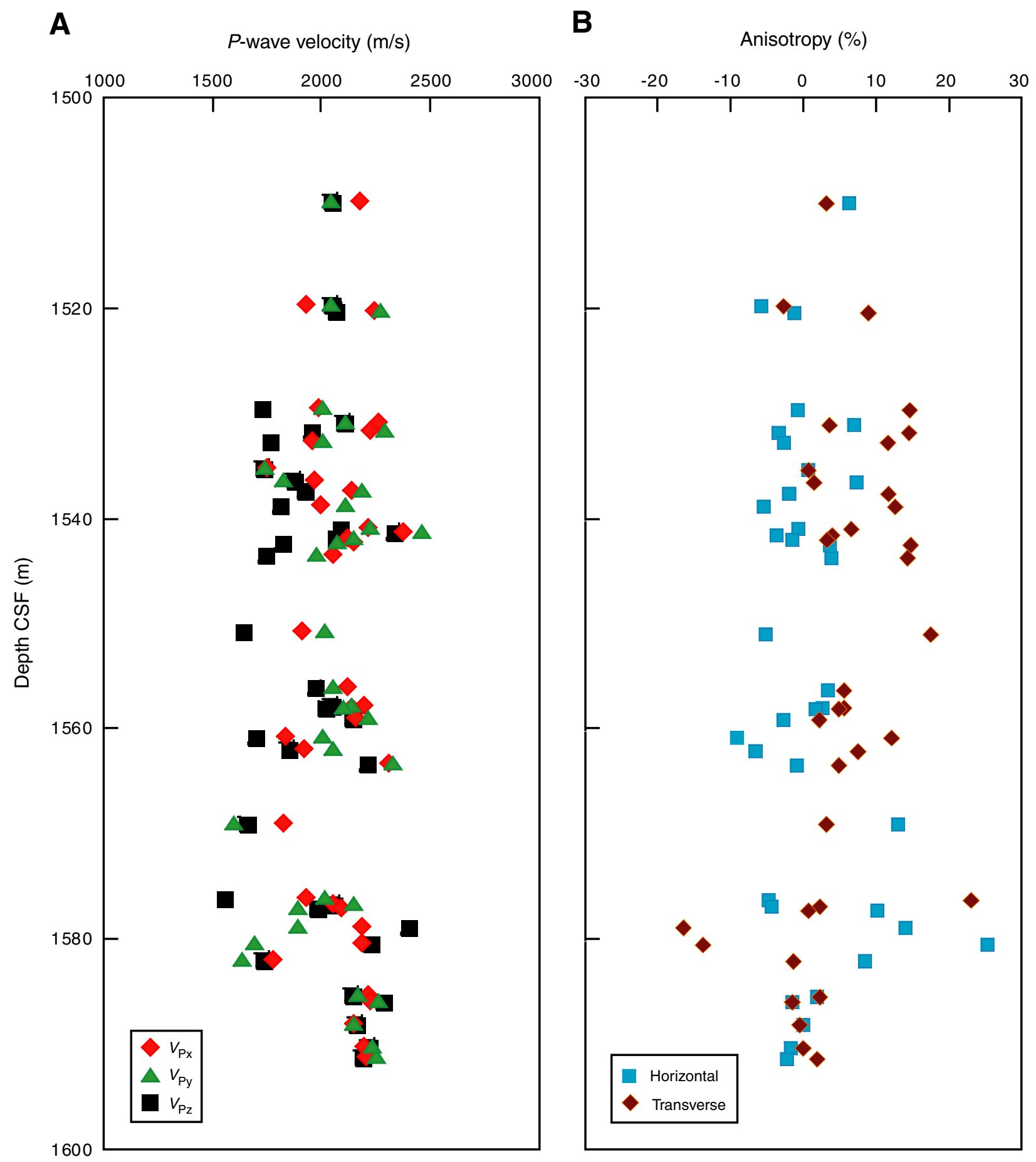


Figure F64. $P$-wave velocity versus fractional porosity from discrete samples in cored interval. Abnormally low $P$-wave velocity values reflect volcanic ash layers, also characterized by low porosity. Open symbols $=$ horizons with high volcanic ash content.

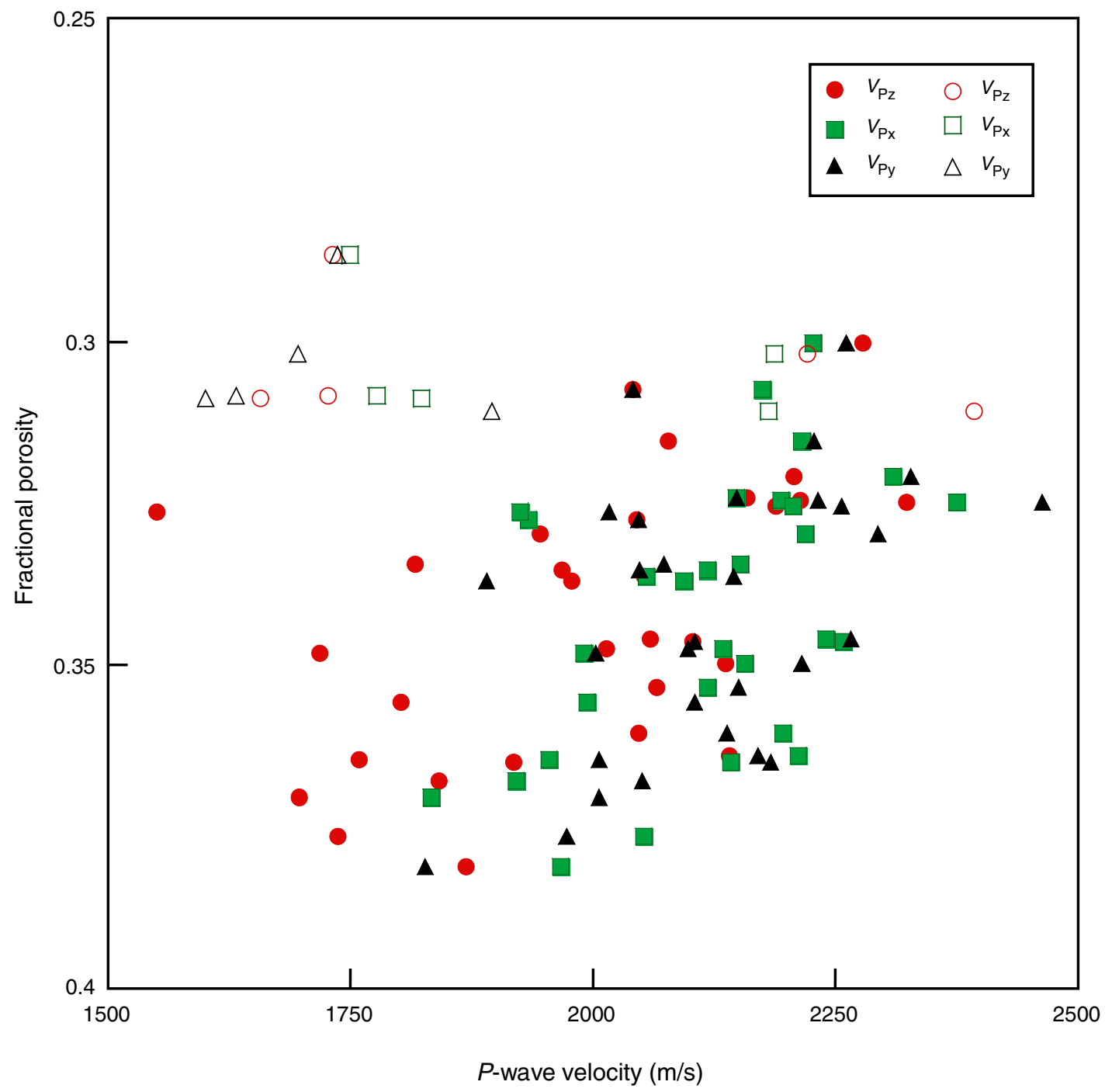


Figure F65. Thermal conductivity of core samples versus depth.

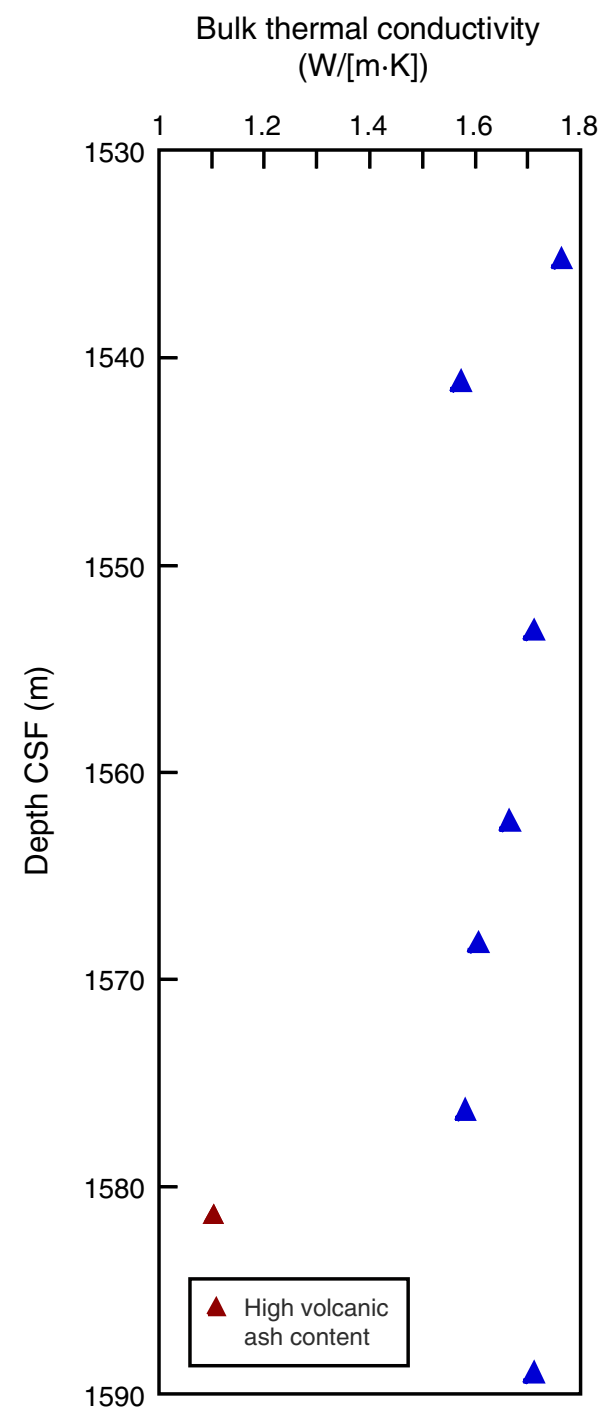


Figure F66. Natural gamma ray (NGR) measured by MSCL in cuttings (red dots; depths in MSF), shown with downhole logging data (black line; depths in WMSF). Logging data are converted to counts per second (cps) for comparison with MSCL-W data using a relationship derived for terrigenous sediments: NGR $(\mathrm{cps})=(\mathrm{NGR}$ [gAPI]) - 12)/2.12 (Mountain et al., 1994).

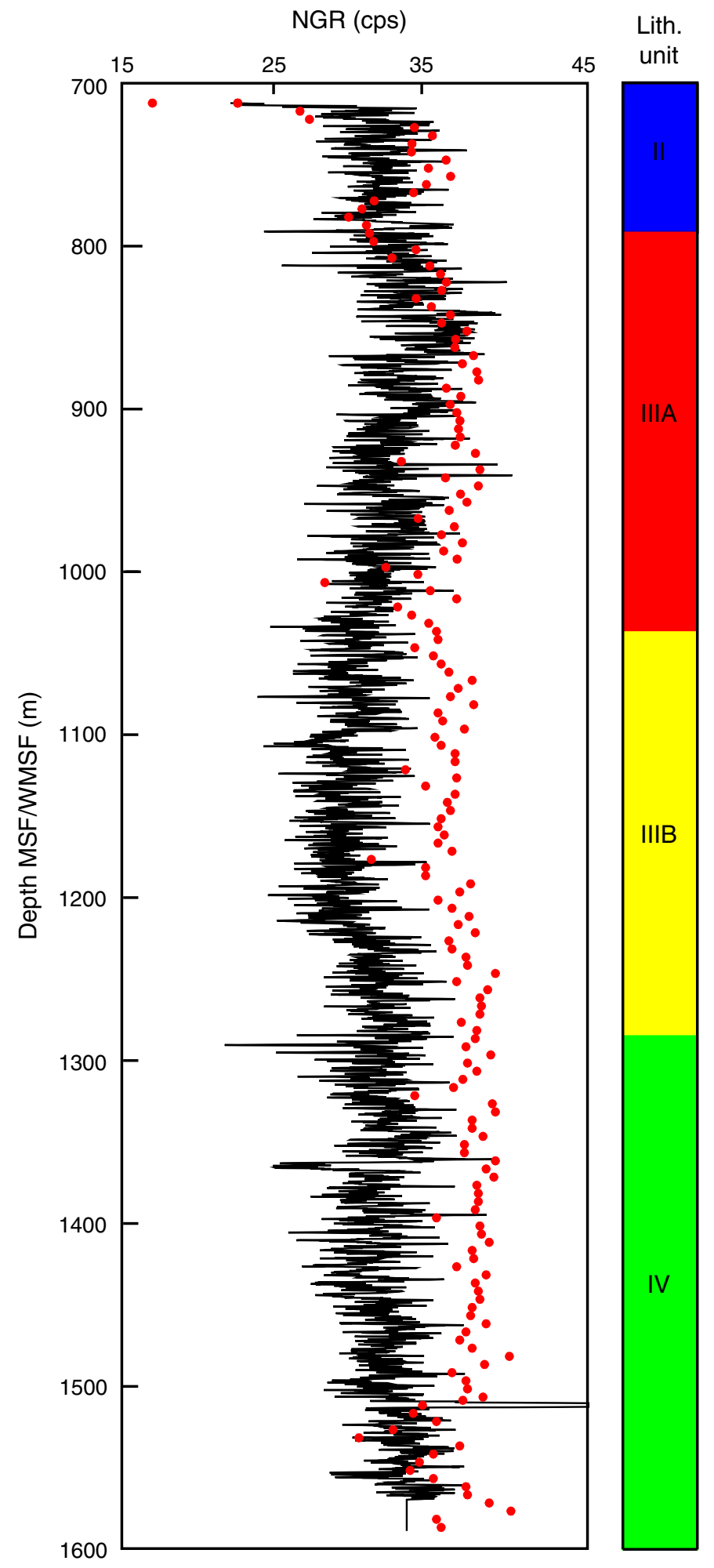


Figure F67. Mass magnetic susceptibility (MMS) data for cuttings.

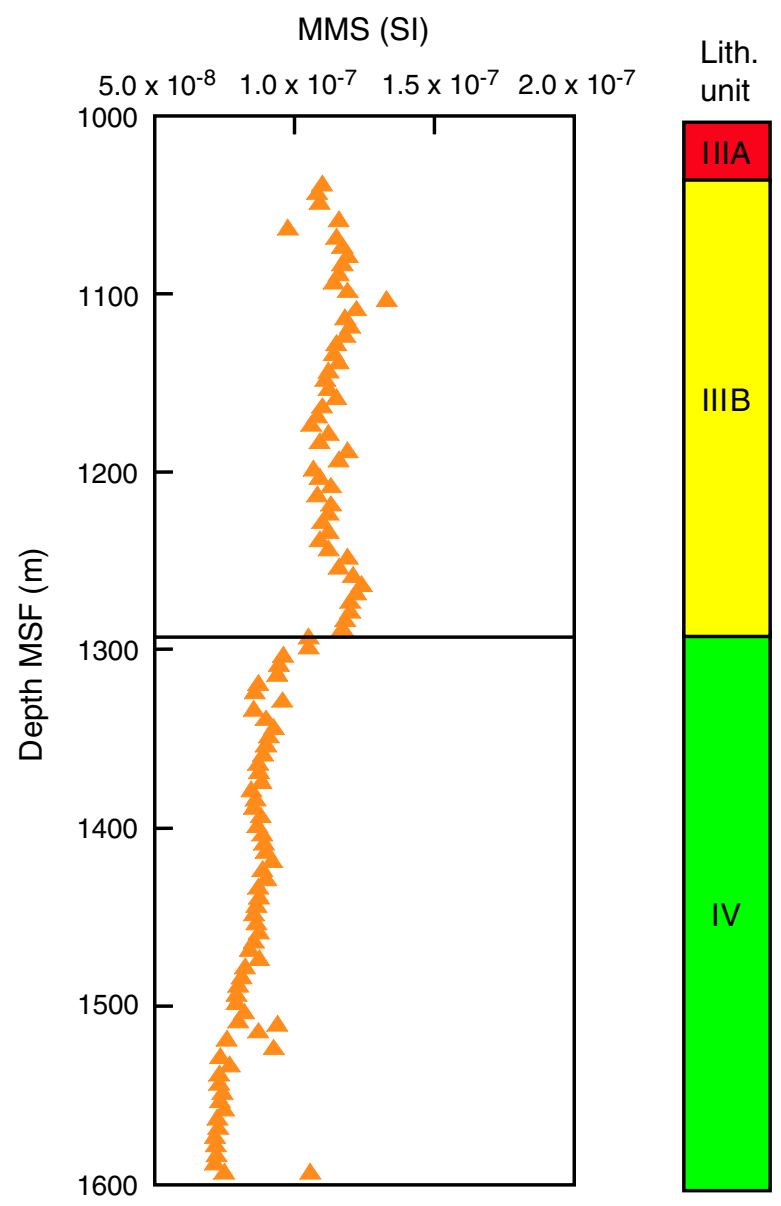


Figure F68. Neutron porosity log profile.

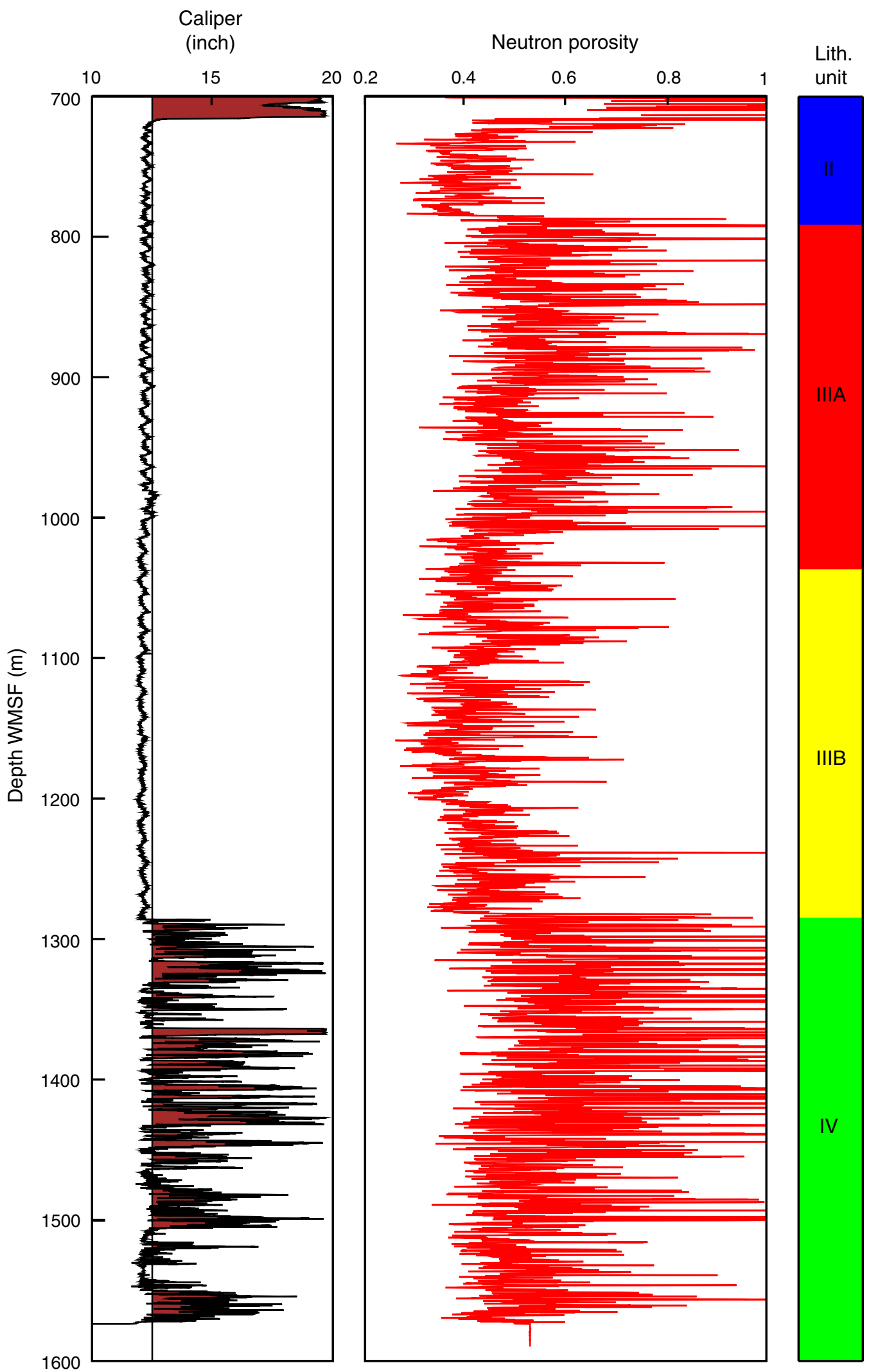


Figure F69. Bulk density log profile and bulk density profile filtered to eliminate data from locations where hole diameter $>12.5$ inches. These logs exhibit sharp changes at unit boundaries and there are few reliable data in Unit IV.

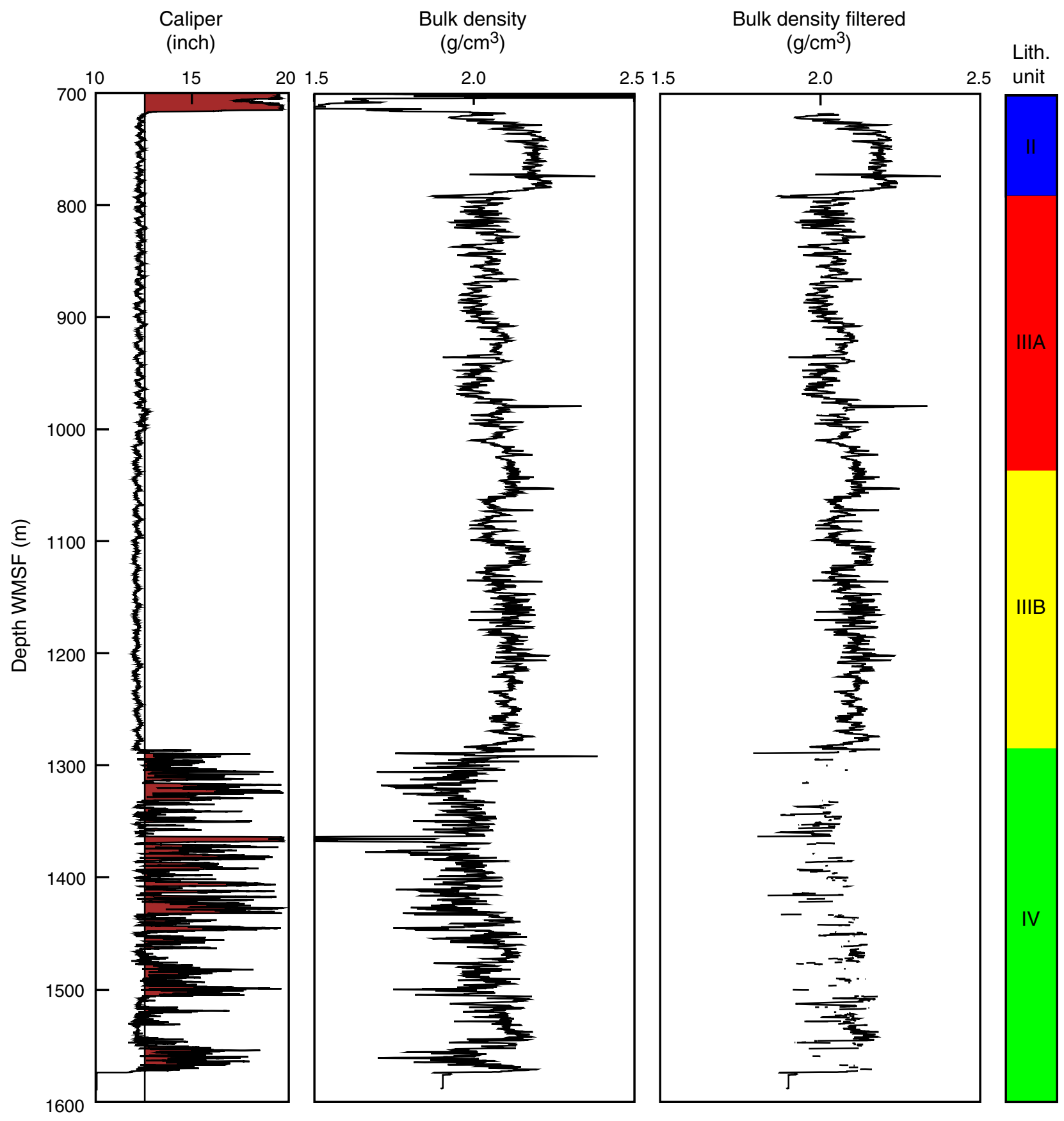


Figure F70. Neutron porosity (red) and density-derived porosity (black) profiles.

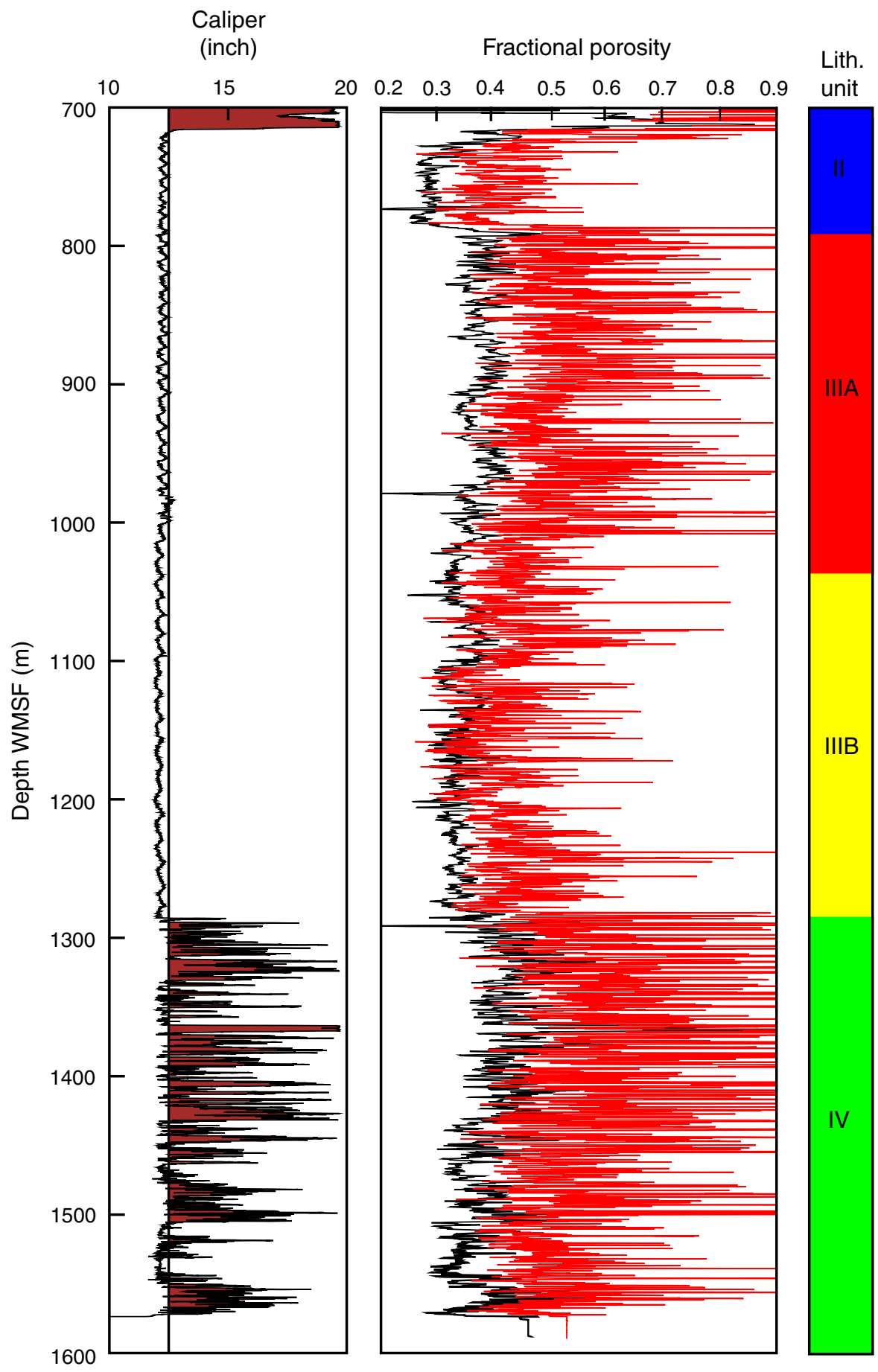


Figure F71. Filtered density-derived porosity log (black line; for calipers $<12.5$ inches) compared with MAD porosity measured on cores (blue dots) and cuttings (red dots).

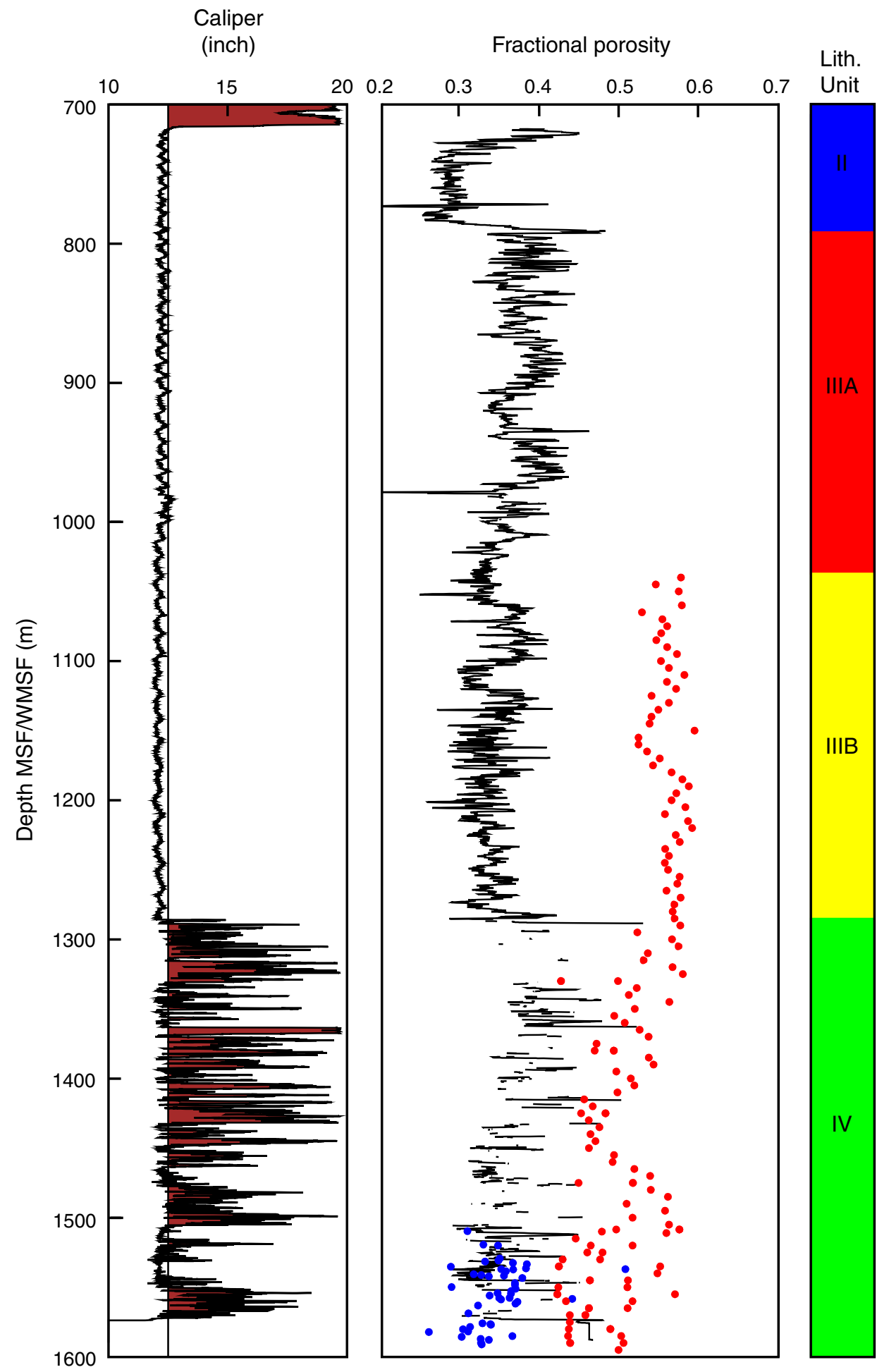


Figure F72. True resistivity log profile showing large-scale fluctuations throughout hole.

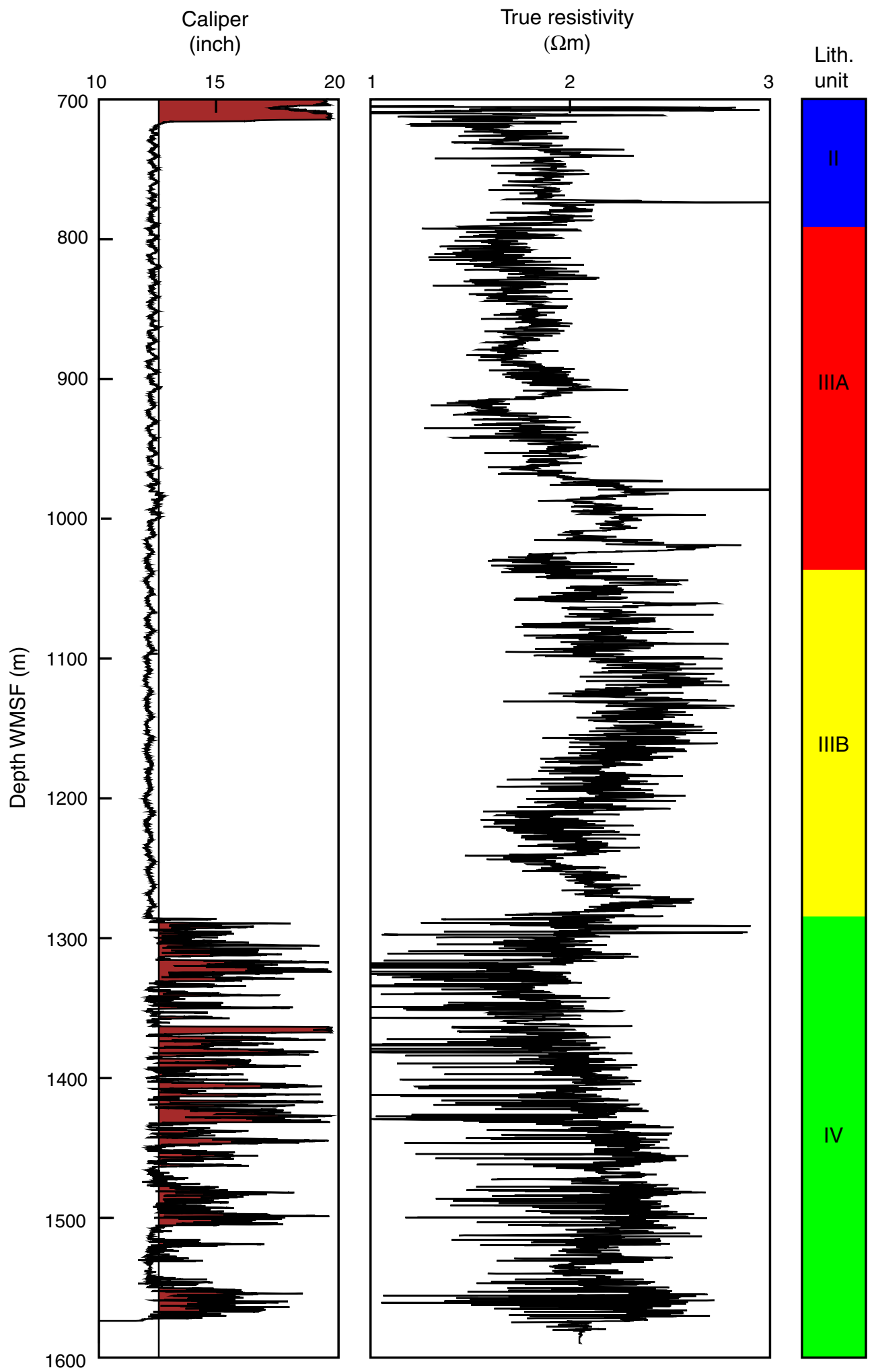


Figure F73. Thermal conductivity versus depth and synthetic temperature profile (see text for computation).

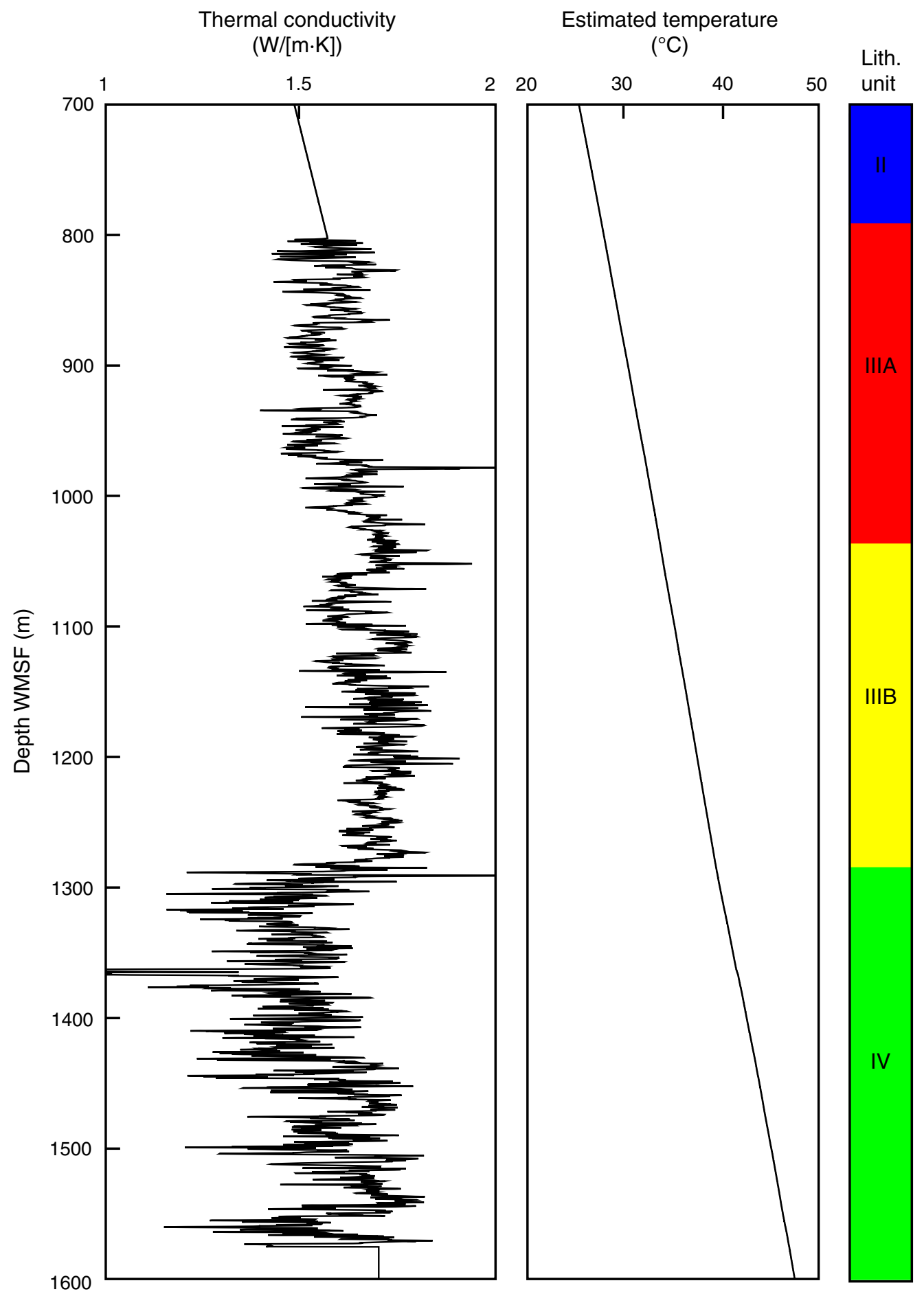


Figure F74. True resistivity-derived porosity (black) computed from Archie's law with parameters $a=1$ and $m$ $=2.4$, and filtered density-derived porosity (red) profiles compared with MAD porosity measured on cores (blue dots).

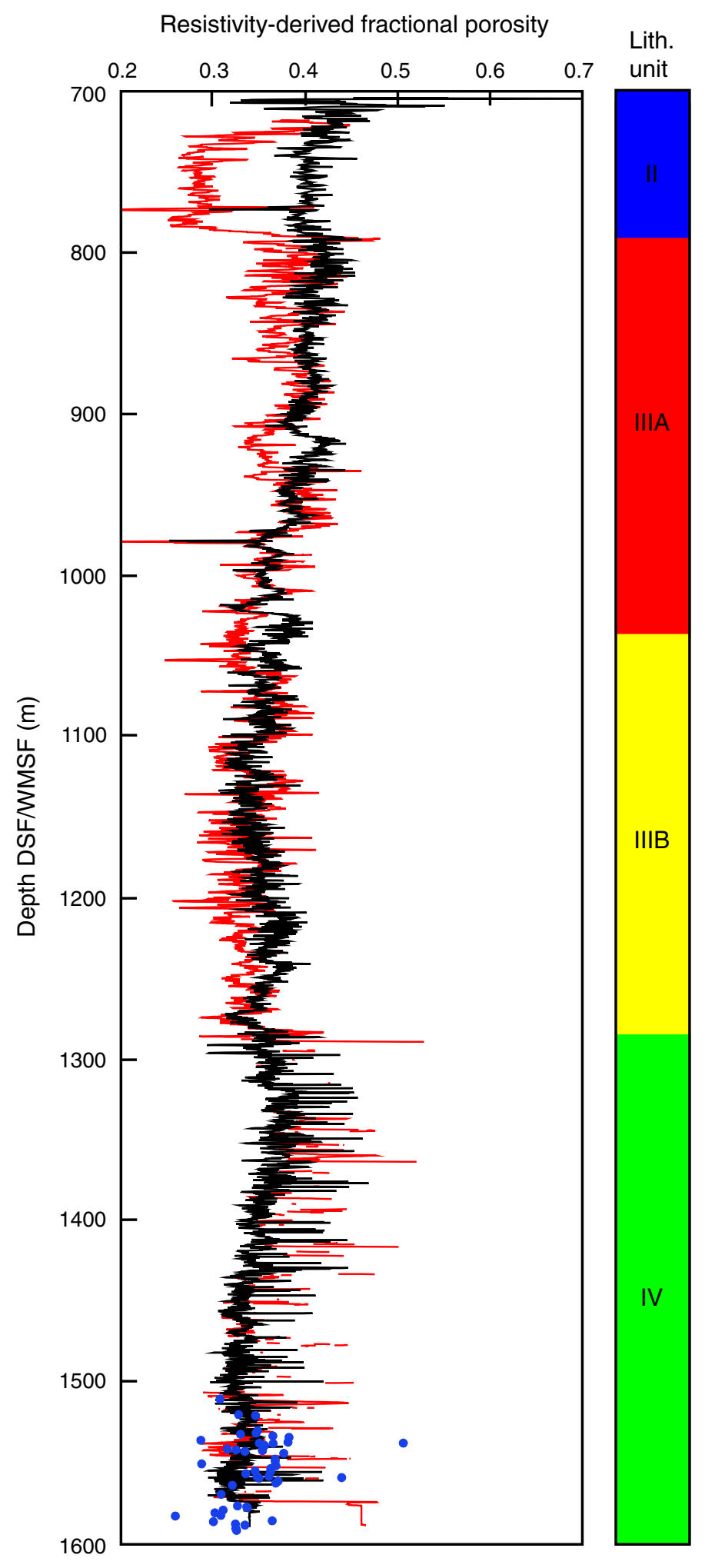


Figure F75. $P$-wave (blue) and $S$-wave (red) velocity. Drops in $P$-wave velocity suggest gas-enriched zones.

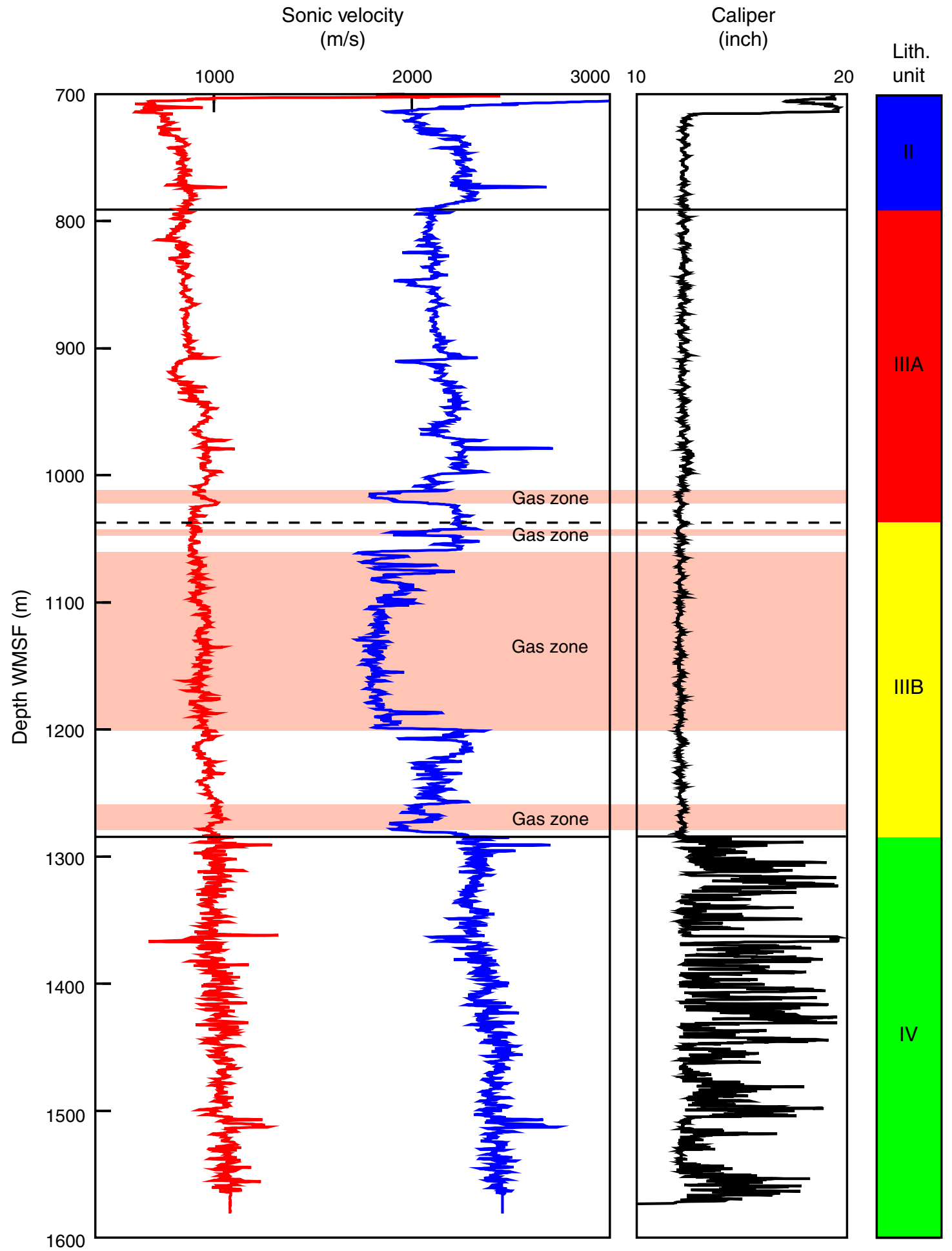


Figure F76. $V_{\mathrm{P}} / V_{\mathrm{S}}$ ratio and Poisson's ratio calculated from $P$ - and $S$-wave velocity. Lower $V_{\mathrm{p}} / V_{\mathrm{S}}$ and decreases in Poisson's ratio suggest gas-enriched zones.

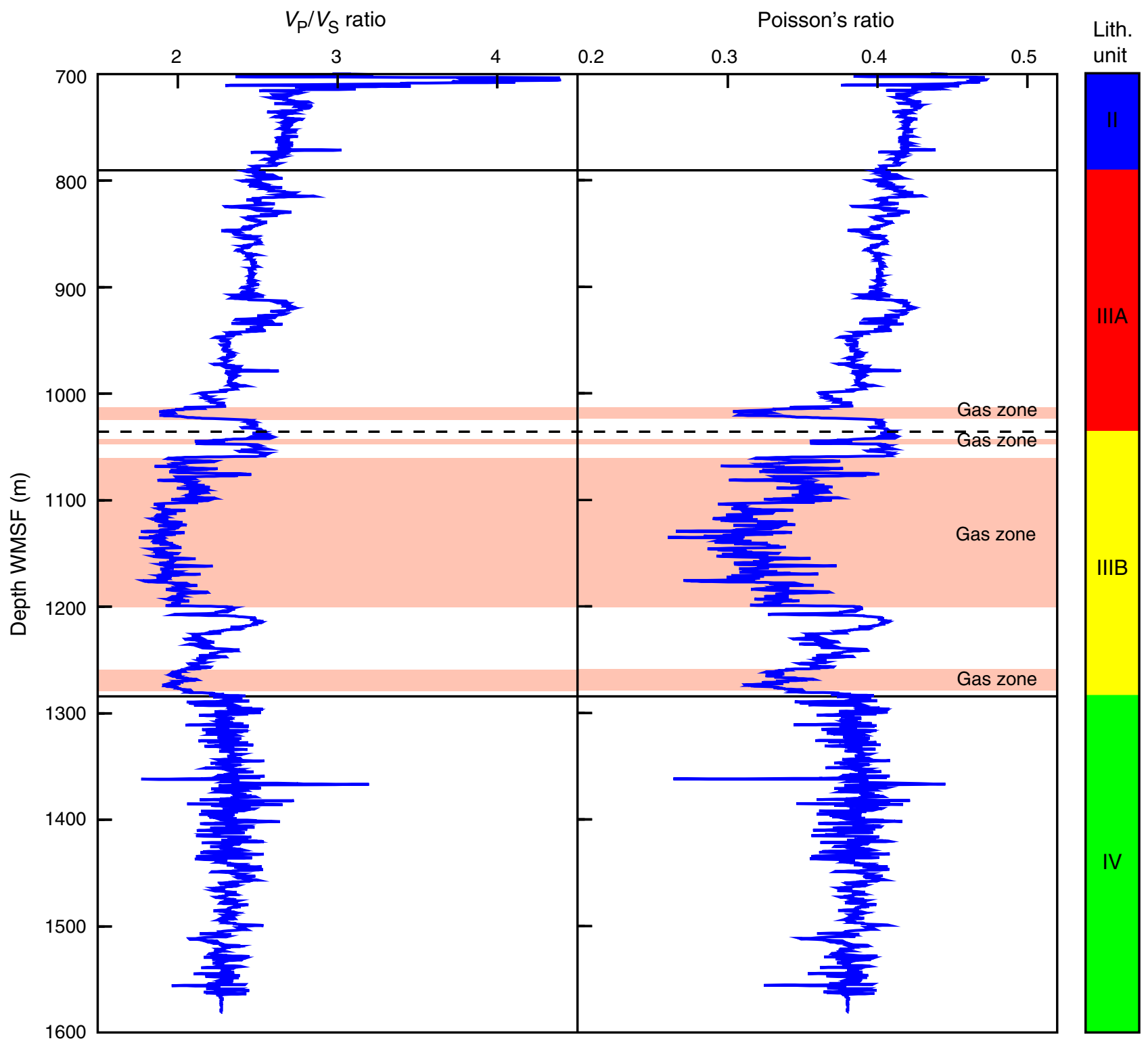


Figure F77. Resistivity and $P$-wave velocity depth profiles. Note increases in resistivity coincident with decreases in velocity suggesting gas-rich zones.

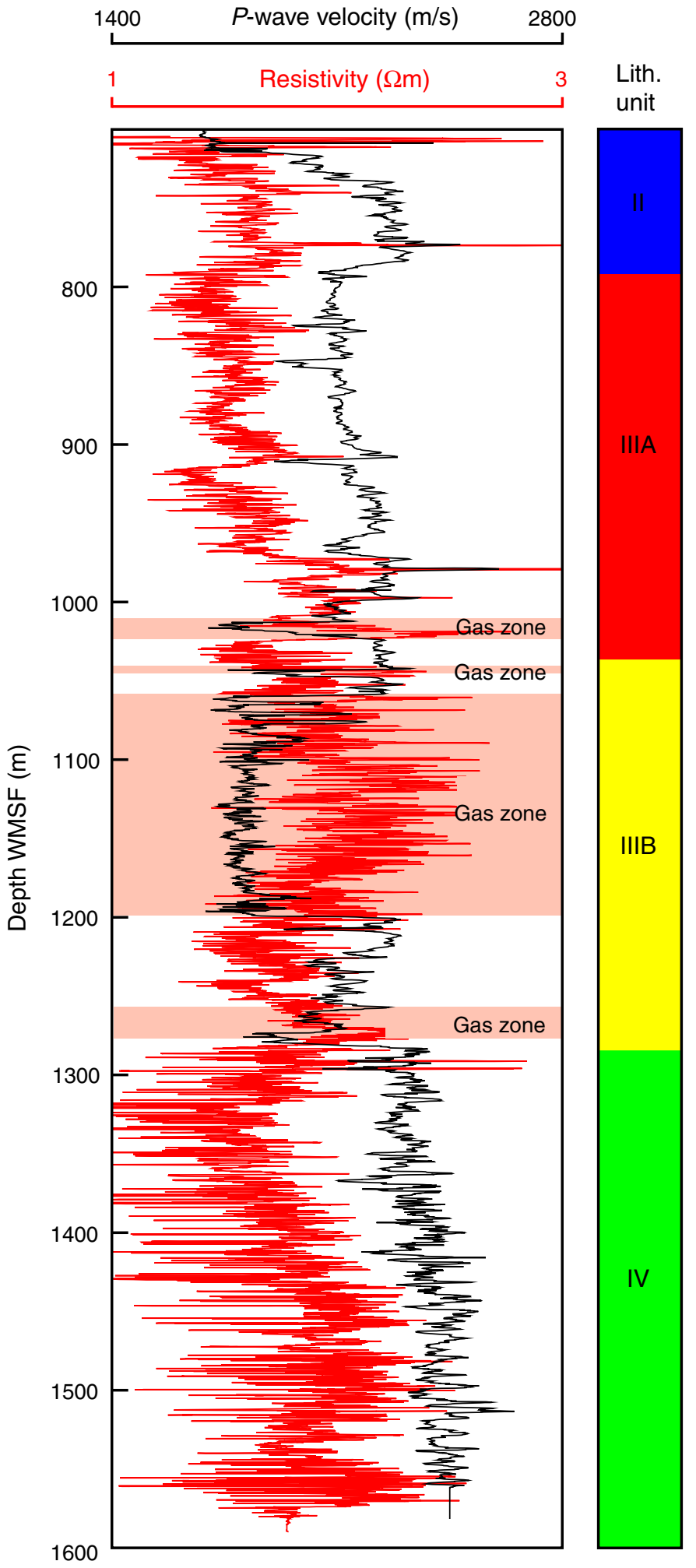


Figure F78. Stoneley wave velocity and $S$-wave velocity depth profiles.

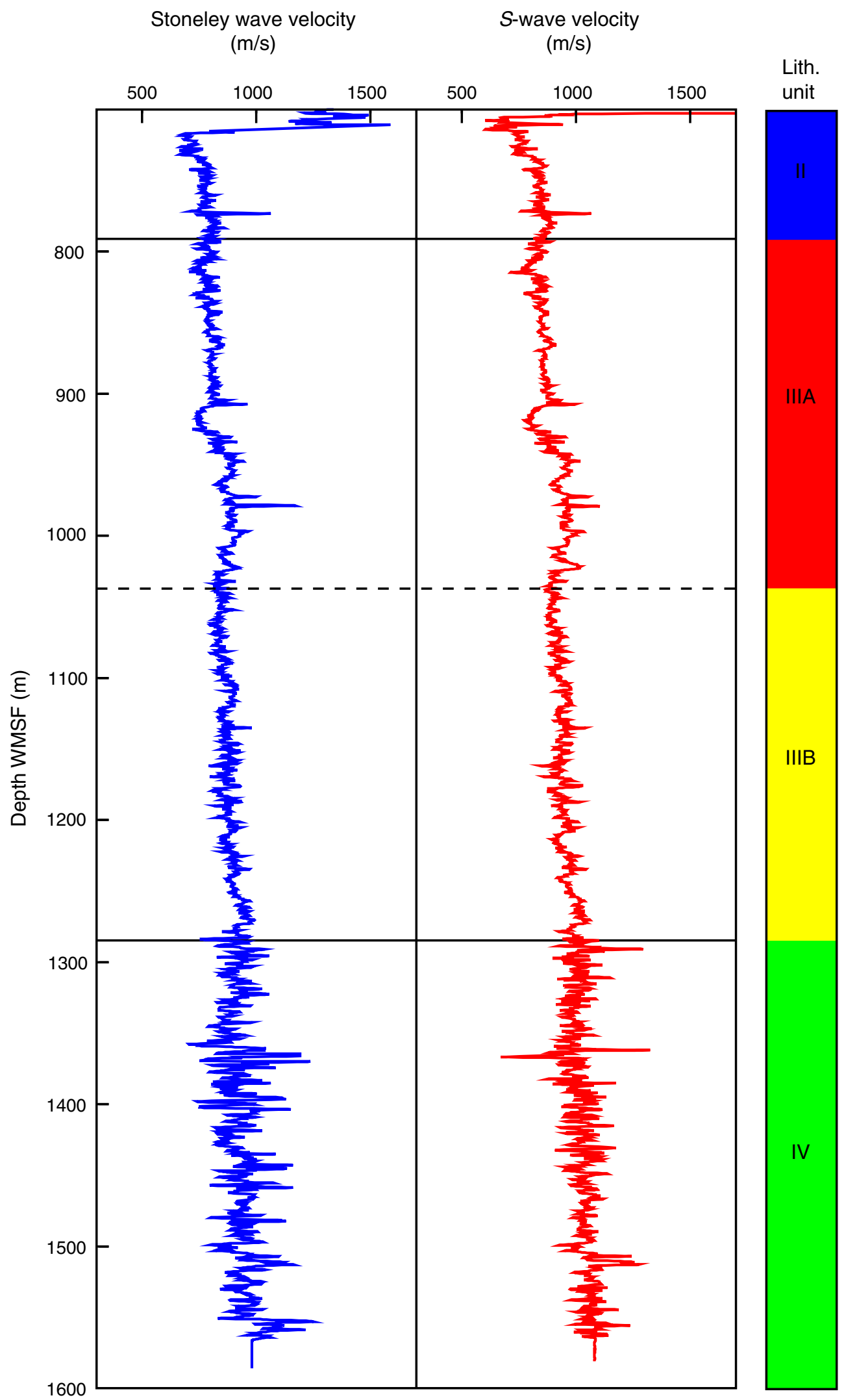


Figure F79. A. Sonic $P$-wave velocity versus resistivity-derived porosity. B. Sonic $P$-wave velocity versus filtered density-derived porosity.
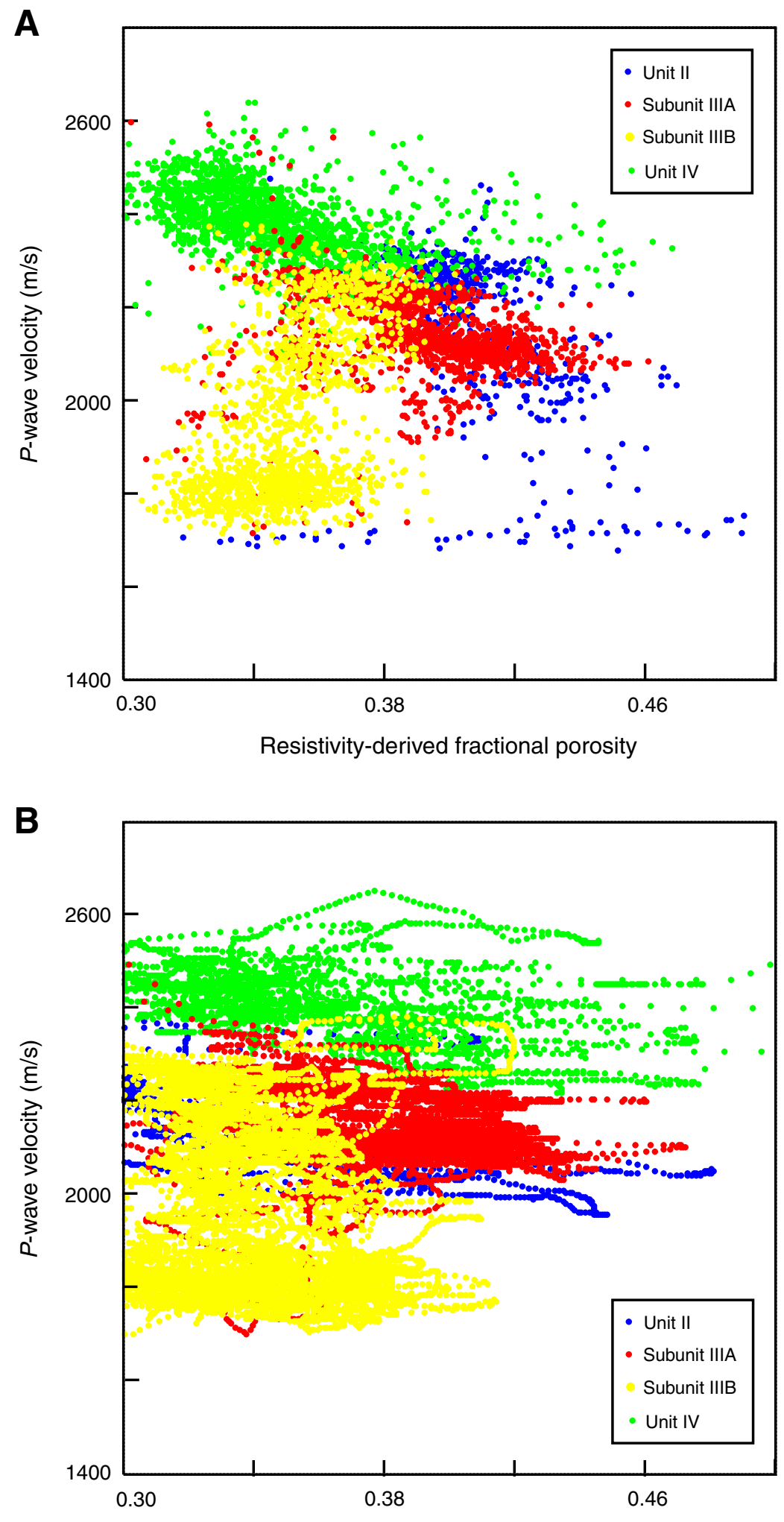

Filtered density-derived fractional porosity 
Figure F80. Cross-plot of $V_{\mathrm{P}} / V_{\mathrm{S}}$ versus $P$-wave slowness $\left(1 / V_{\mathrm{P}}\right)$. Subunit IIIB is affected by gas saturation. Solid line $=$ theoretical solution for full water saturation $\left(S_{\mathrm{w}}=100 \%\right)$, circles $=$ expected $V_{\mathrm{p}} / V_{\mathrm{S}}$ and slowness for porosities $(\phi)$ of $0 \%, 10 \%$, and $20 \%$, dashed line = effect of gas as computed by Reuss equation, computed for a porosity of $25 \%$ and shows that Subunit IIIB data are consistent with $S_{\mathrm{w}}=90 \%$, and a gas saturation of $10 \%$.

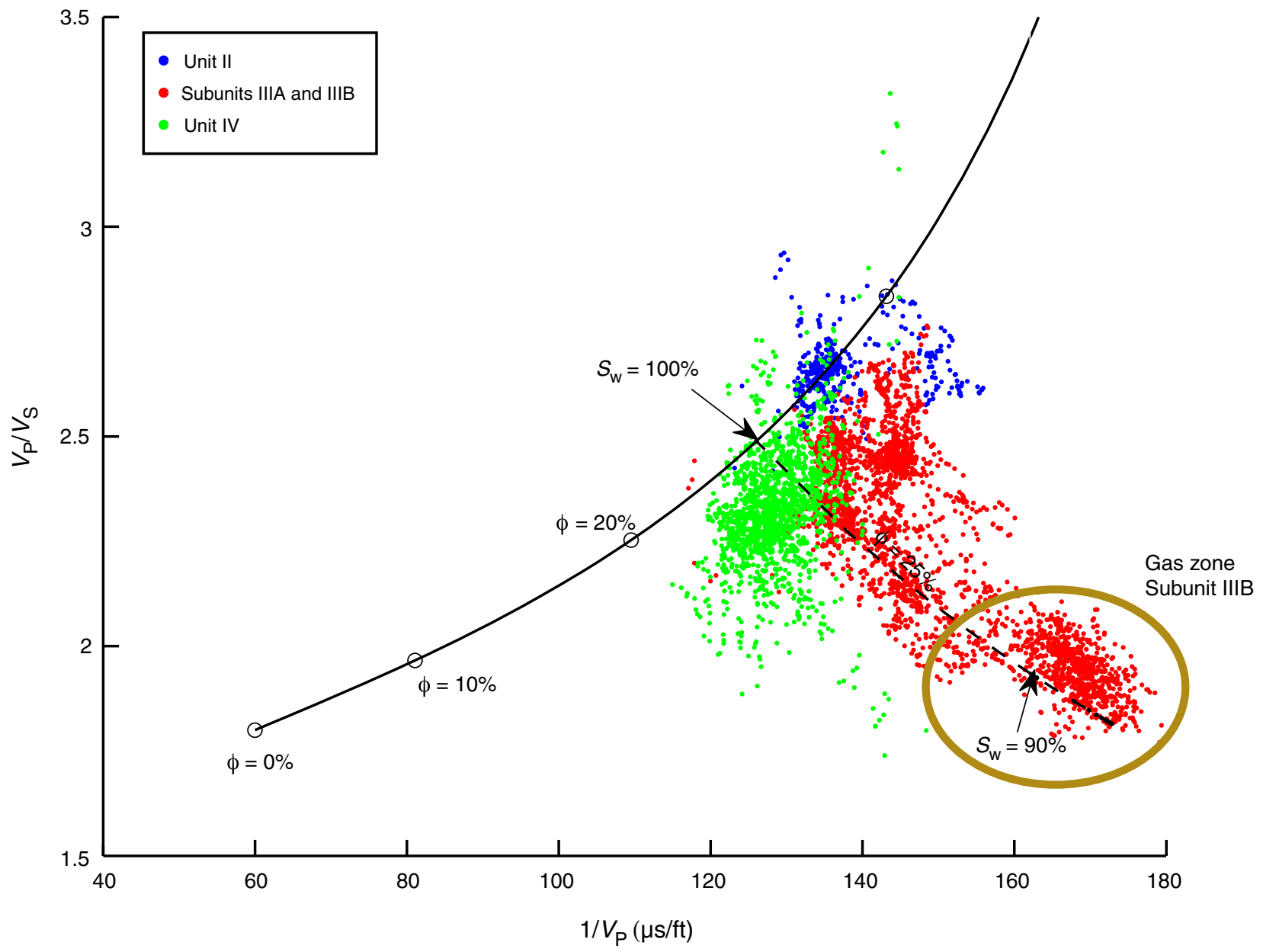


Figure F81. Pressure and flow rate for MDT single probe Test MDT_059LTP (729.9 m WMSF).

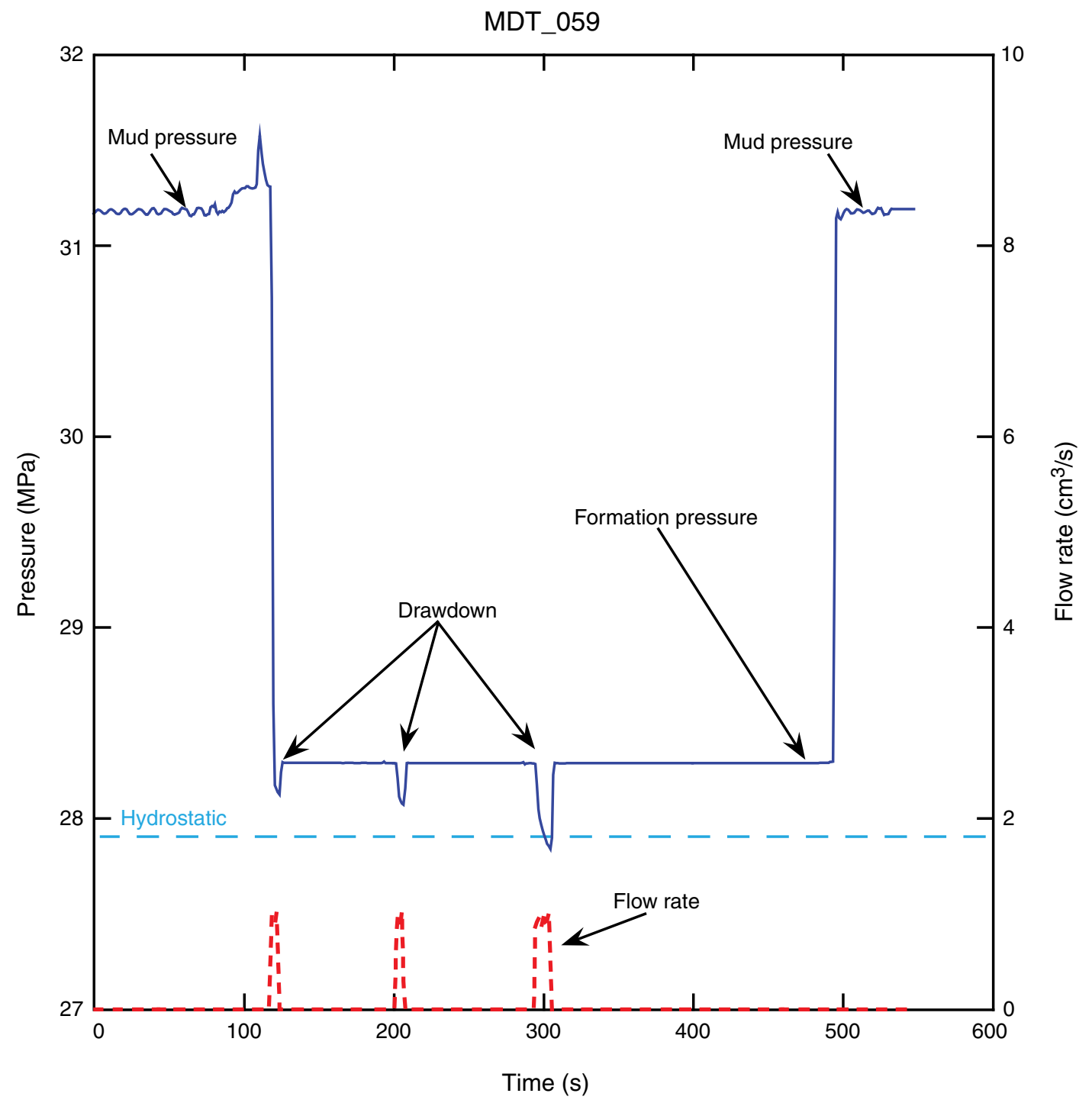


Figure F82. Pressure and flow rate for MDT single probe Test MDT_060LTP (876.9 m WMSF).

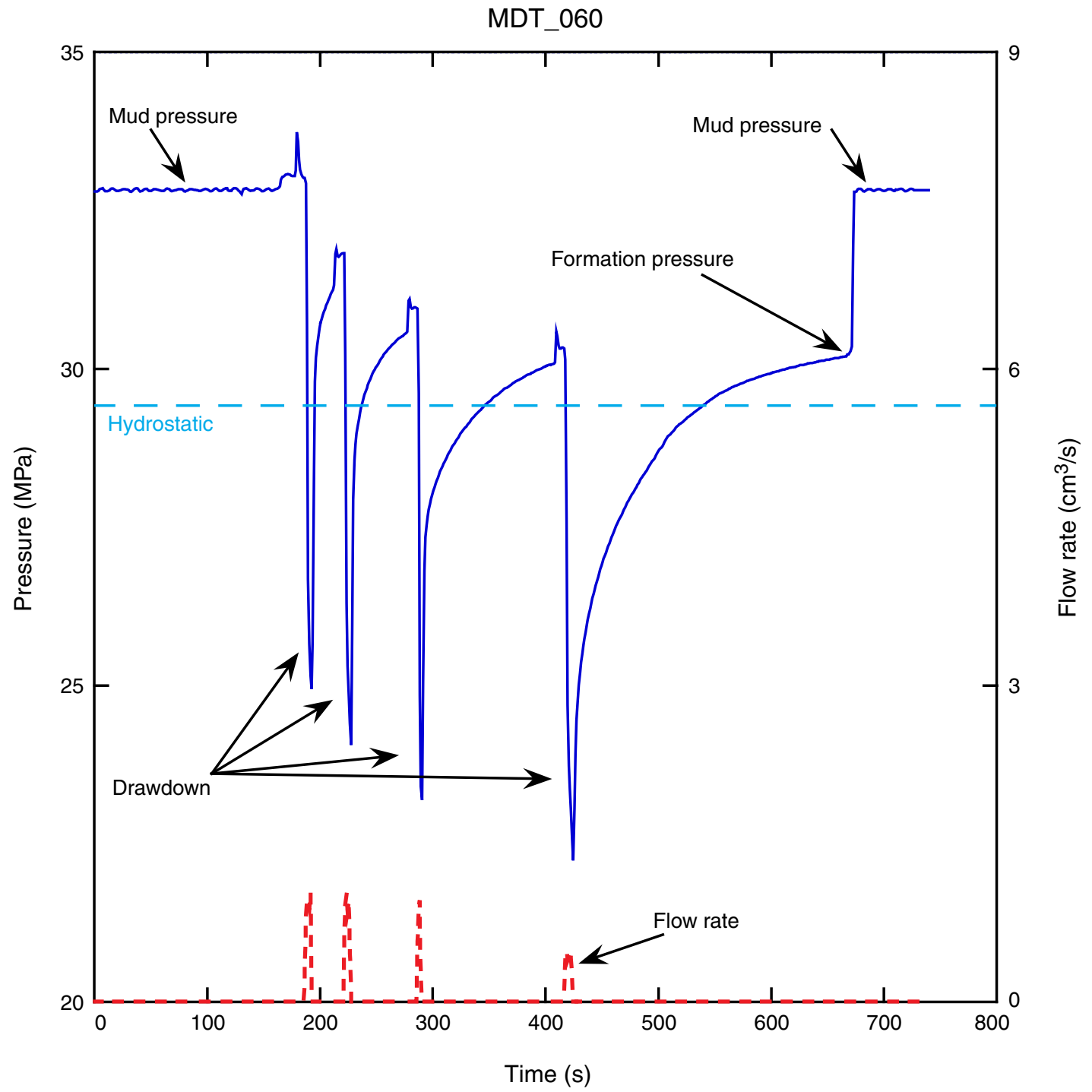


Figure F83. Pressure and flow rate for MDT single probe Test MDT_061LTP (877.9 m WMSF).

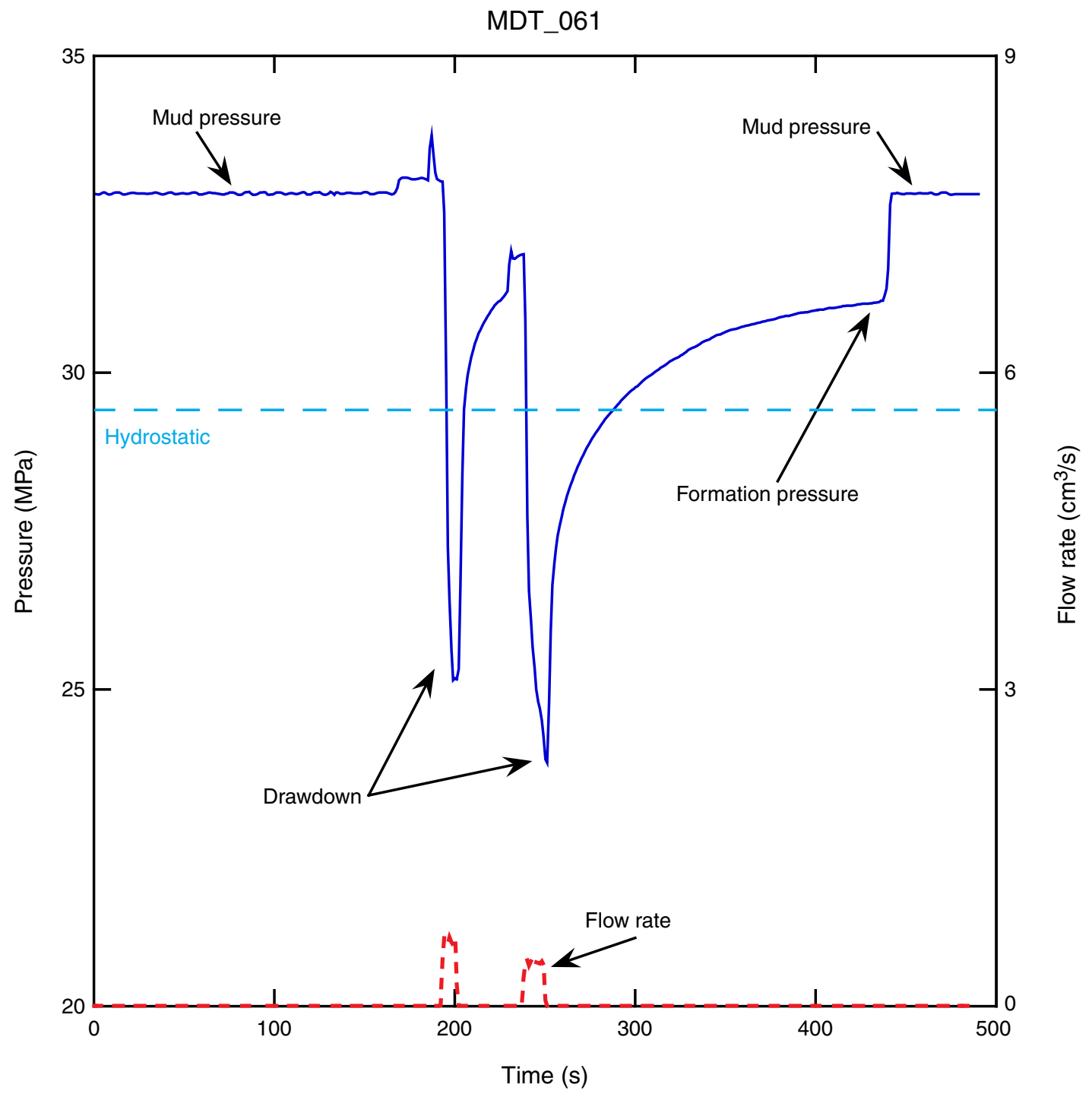


Figure F84. Pressure and flow rate for MDT single probe Test MDT_065LTP (1175.0 m WMSF).

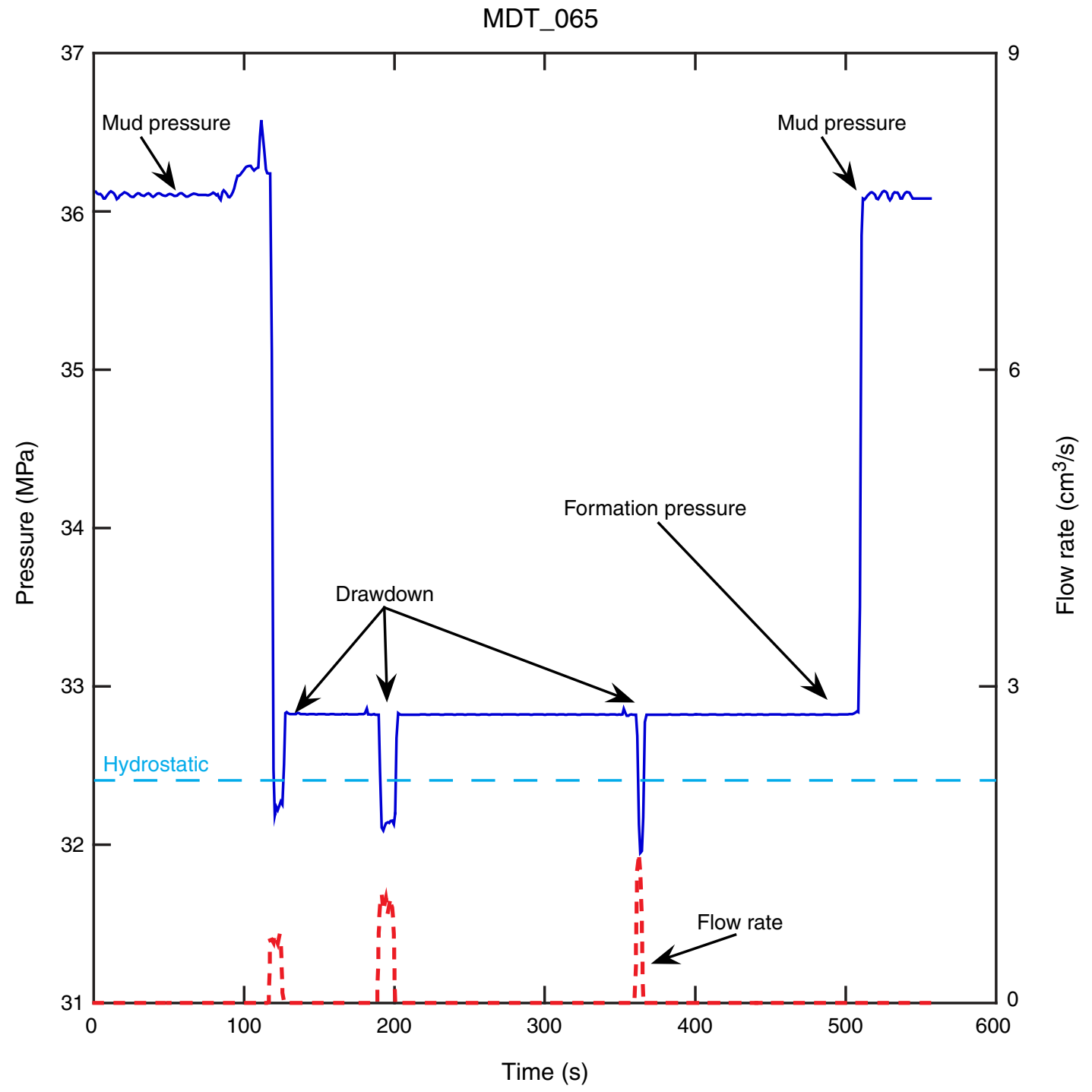


Figure F85. Pressure and flow rate for MDT single probe Test MDT_067LTP (1335.9 m WMSF).

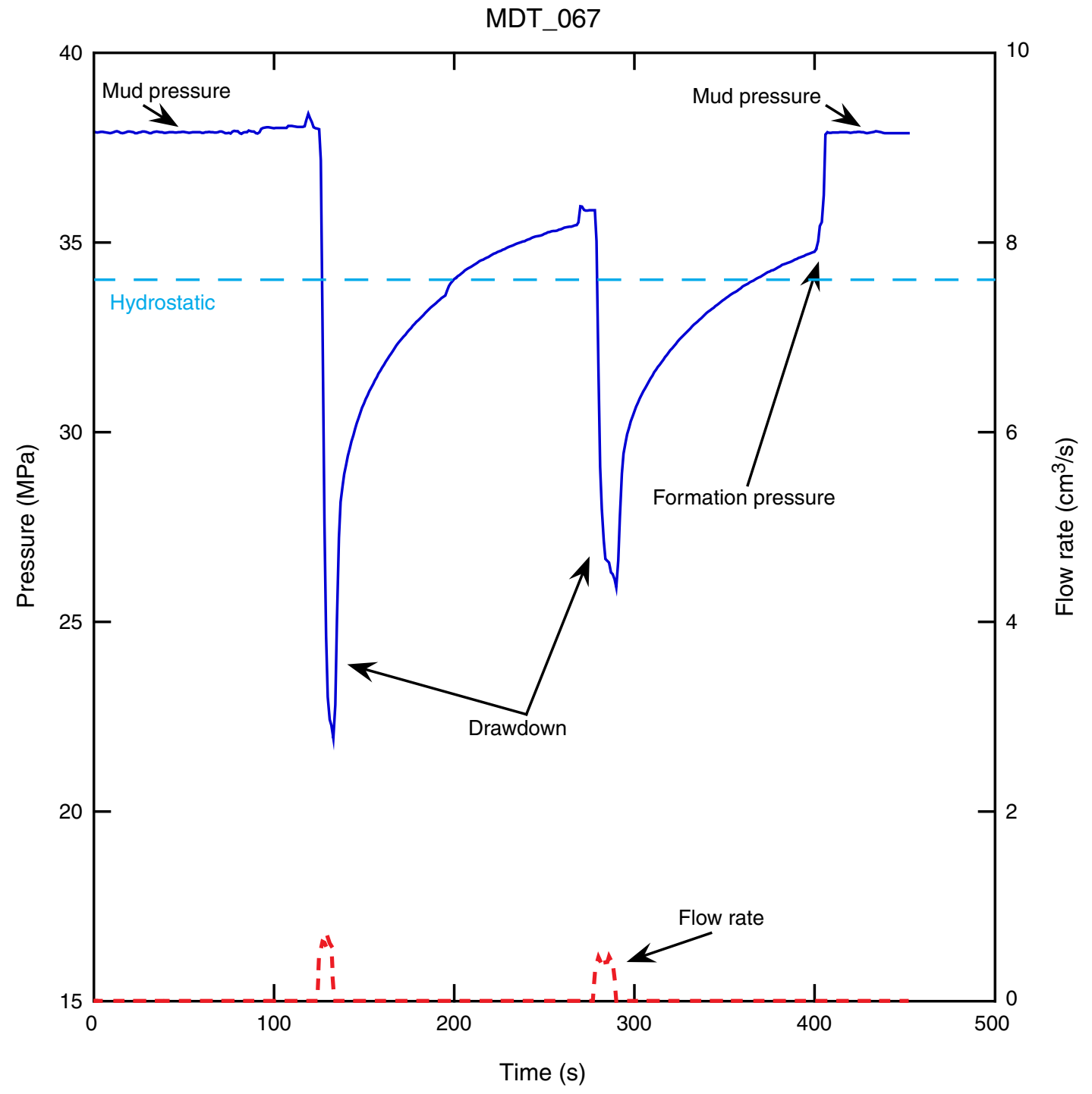


Figure F86. Pressure and flow rate for MDT single probe Test MDT_074LTP (1531.9 m WMSF).

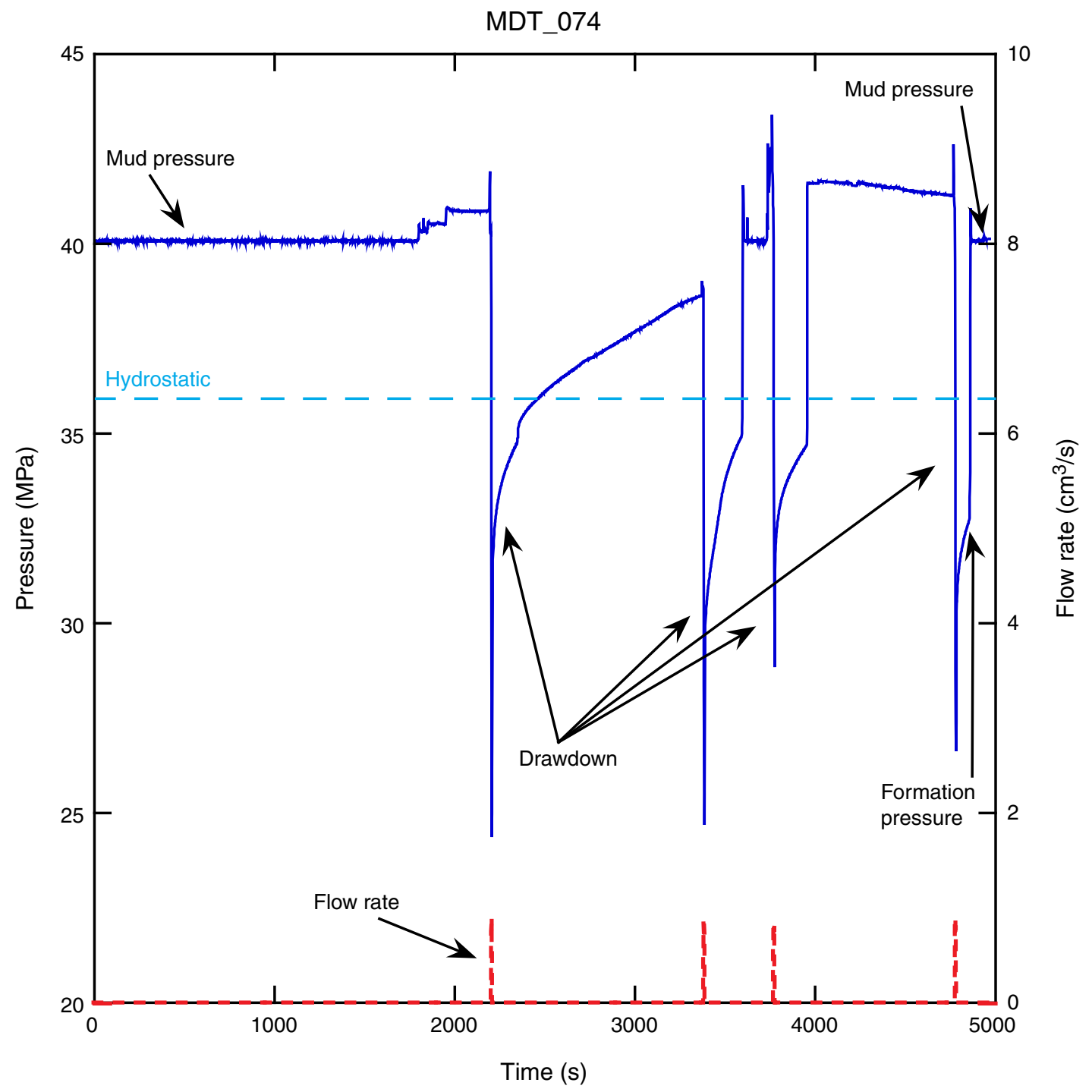


Figure F87. Pressure and flow rate for MDT single probe Test MDT_075LTP (1464.9 m WMSF).

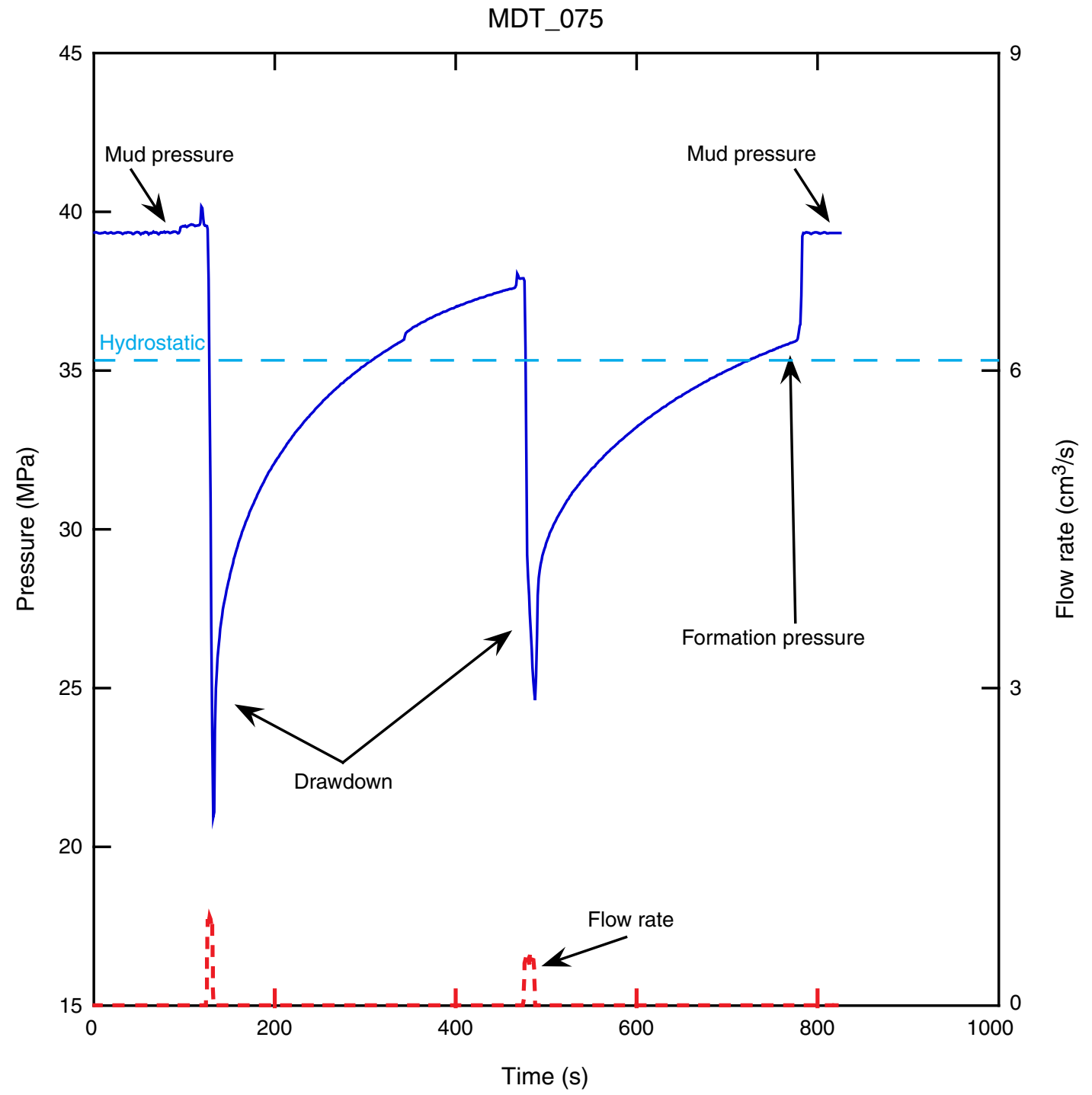


Figure F88. Pressure and flow rate for MDT single probe Test MDT_078LTP (1218.9 m WMSF).

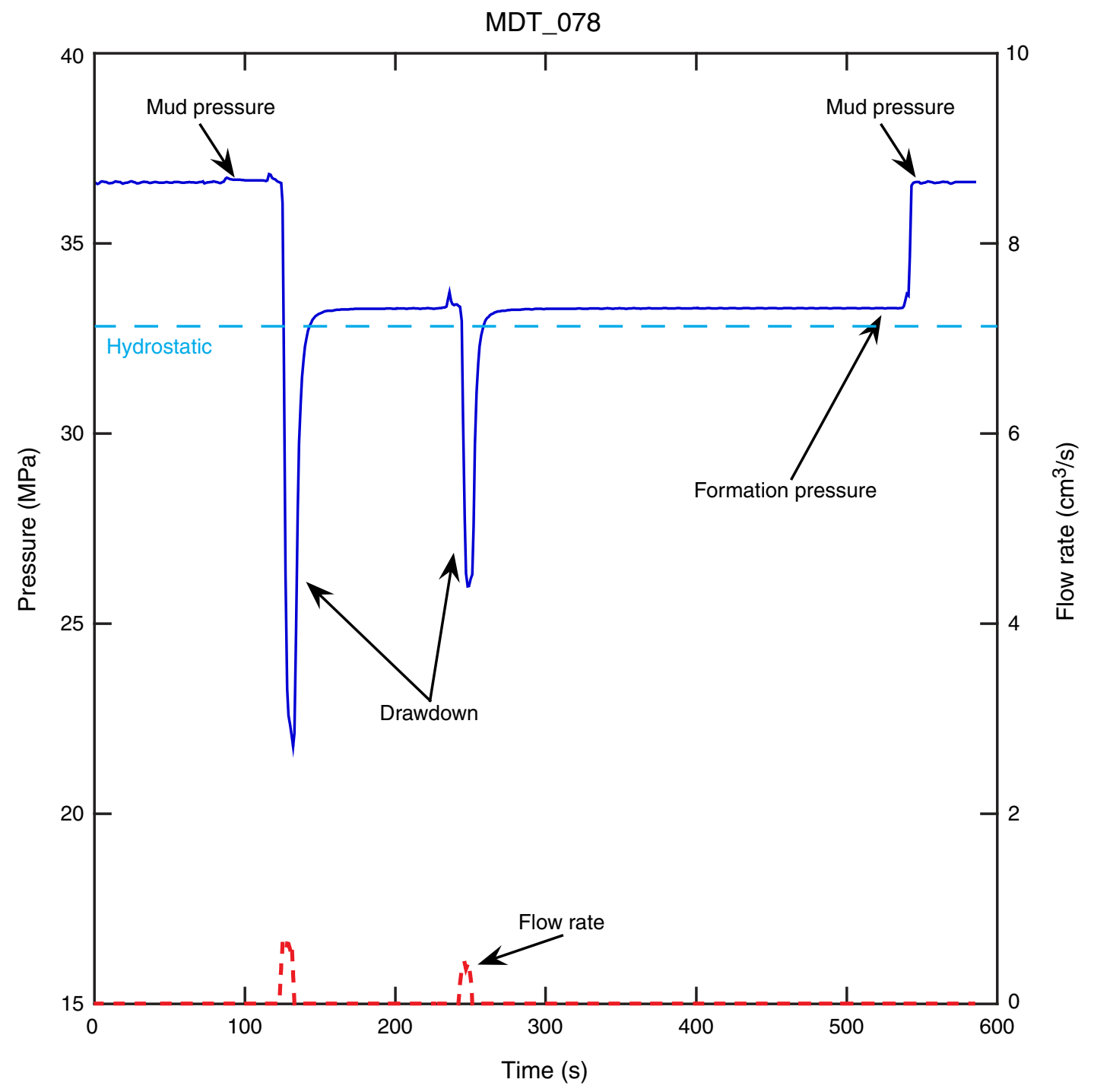


Figure F89. Pressure and flow rate for MDT single probe Test MDT_080LTP (874.9 m WMSF).

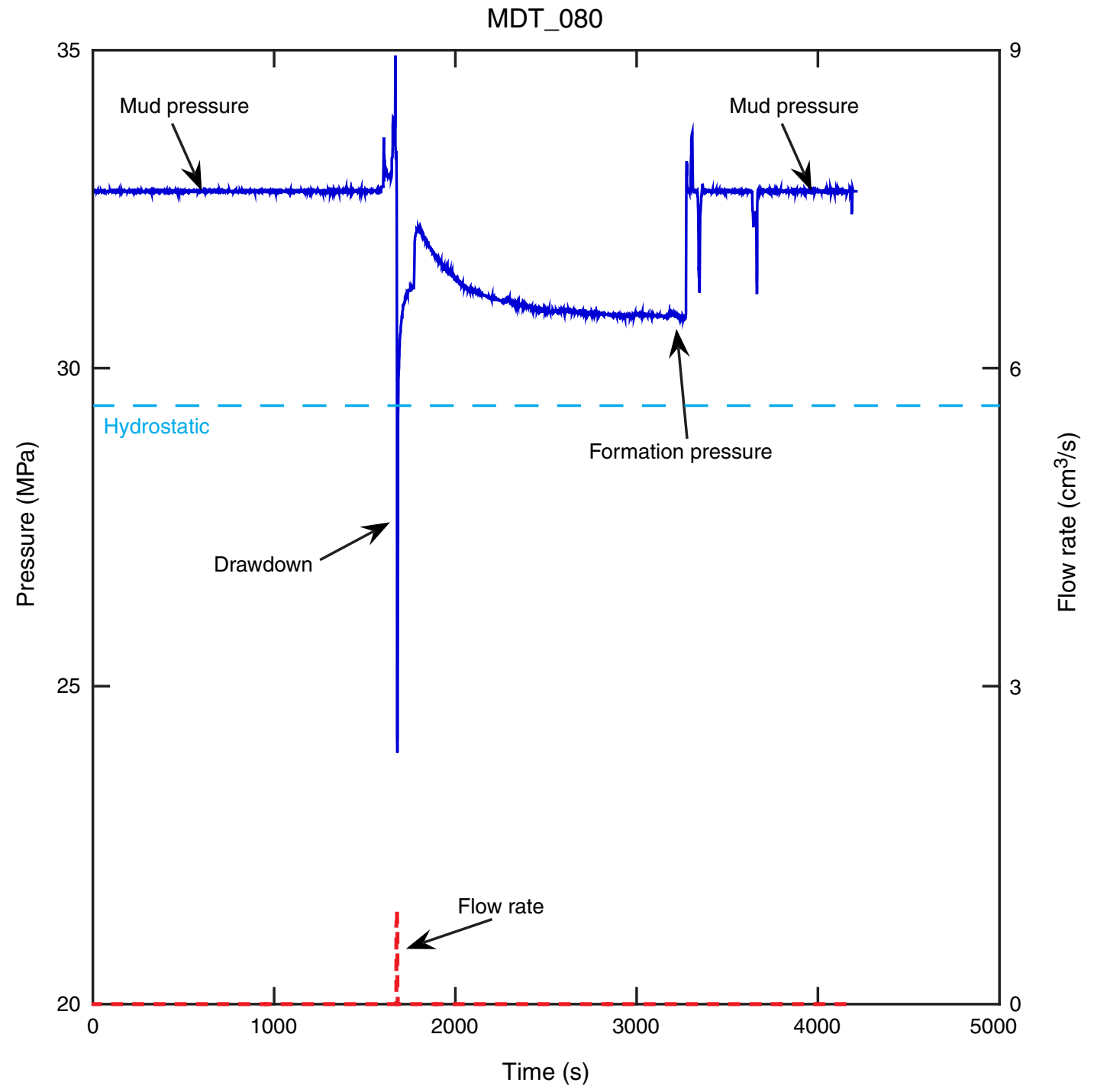


Figure F90. A. Pressure and stress plot versus depth for MDT measurements. Solid line = hydrostatic pressure calculated by assuming both seawater and pore water density of $1023 \mathrm{~kg} / \mathrm{m}^{3}$; dashed line = overburden stress $\left(\sigma_{v}\right)$ calculated by assuming constant sediment bulk density of $1650 \mathrm{~kg} / \mathrm{m}^{3}$ to $475 \mathrm{~m}$ WMSF, using MAD data acquired at Expedition 314 Site C0002 from 475-703.9 m WMSF and wireline bulk density acquired at Site C0009 for remainder of hole; red triangles = last pressures recorded during final pressure build-up of single probe tests (SPTs); green circles = pressure of mud in borehole measured by MDT tool at each SPT location (after test); black squares = least principal stress $\left(\sigma_{3}\right)$ interpreted from wireline packer hydraulic fracture test; orange diamond = least principal stress estimated from LOT. B. Drawdown mobility interpreted from SPT tests. Schlumberger suggests values $<10^{-15} \mathrm{~m}^{2} / \mathrm{cp}$ may be unreliable. $10^{-5} \mathrm{~m}^{2} / \mathrm{cp}=1 \mathrm{md} / \mathrm{cp}$.

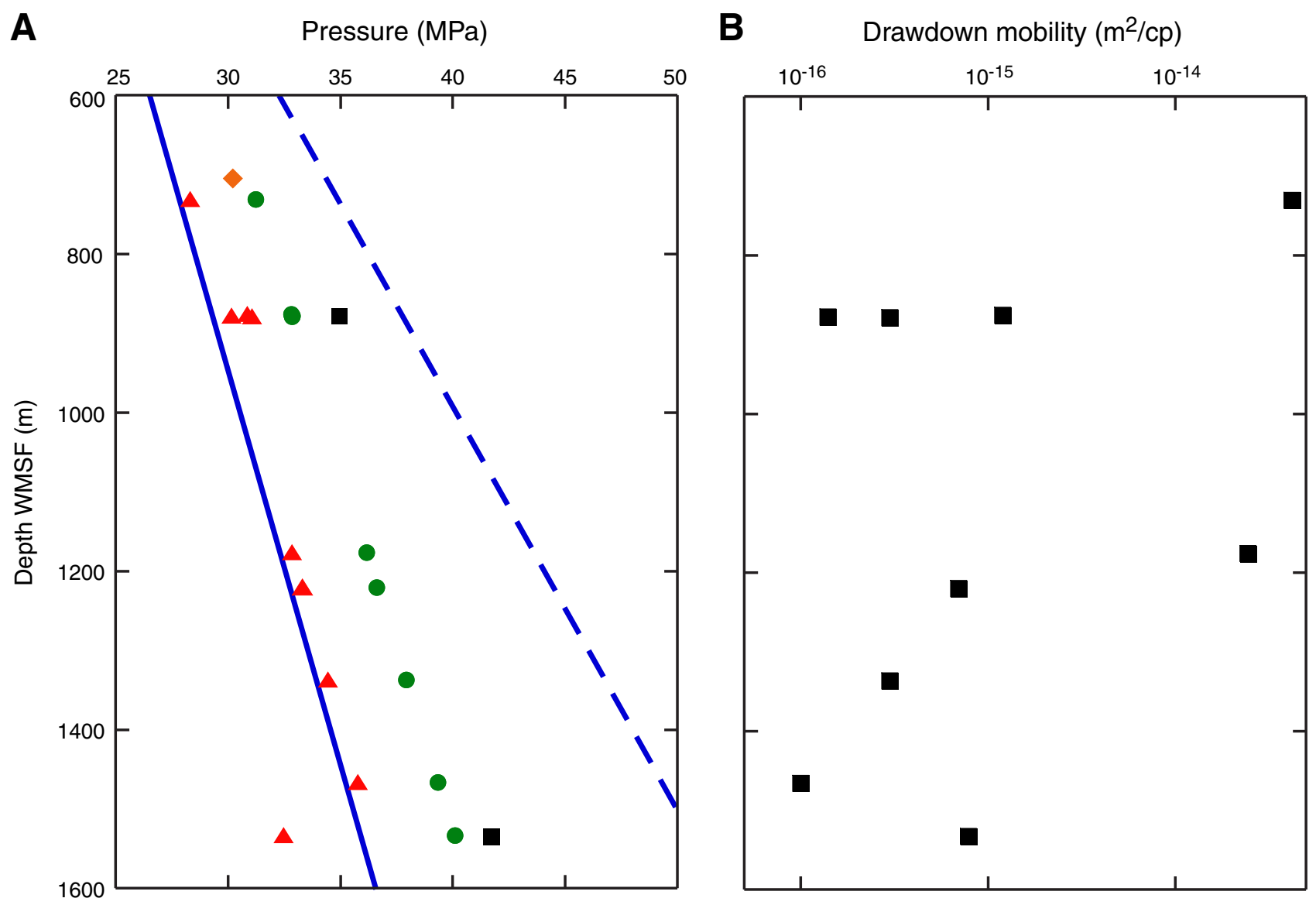


Figure F91. Dual packer drawdown Test MDT_073LTP (1540.9 m WMSF).

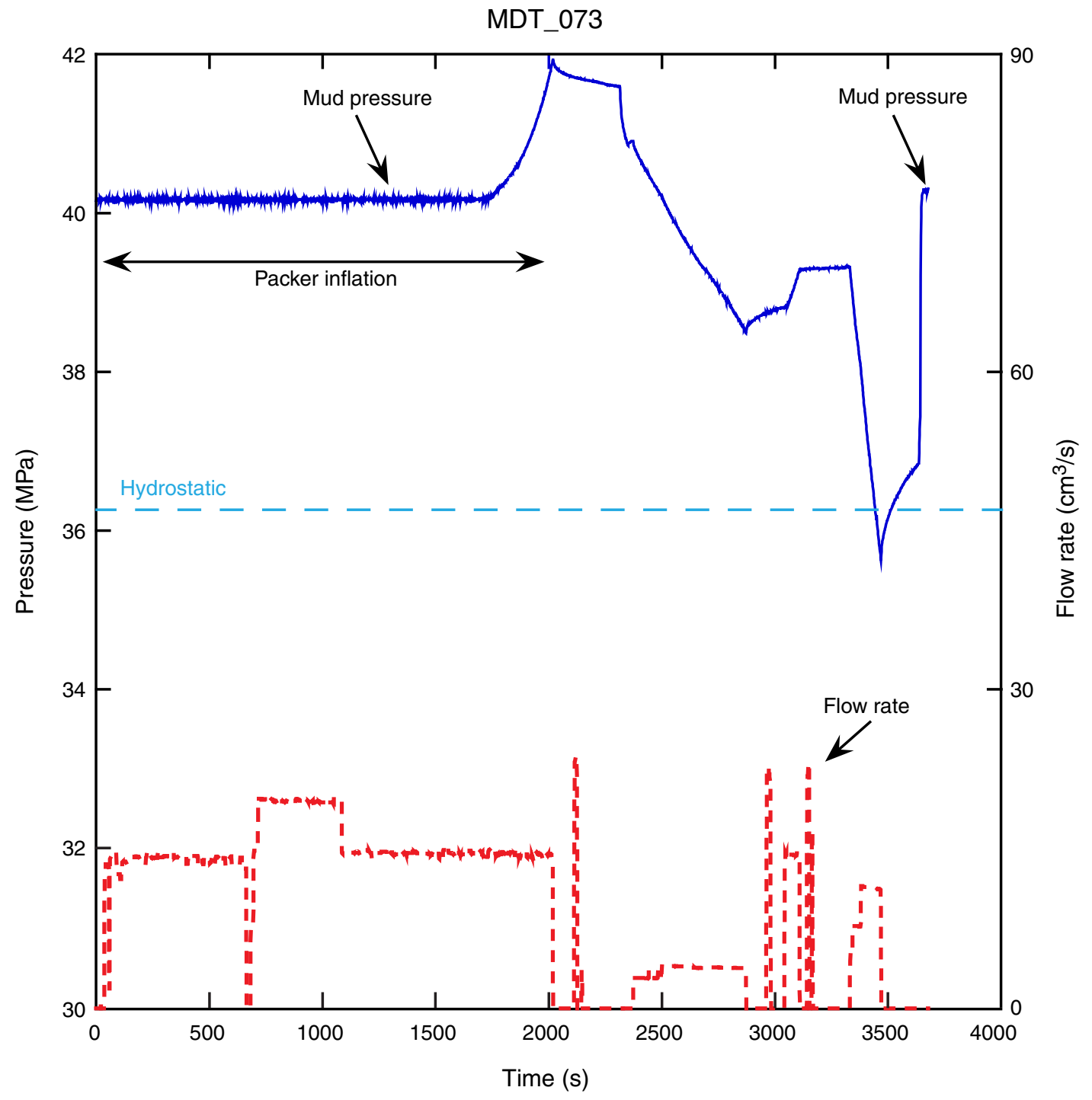


Figure F92. Expanded view of build-up for dual packer drawdown Test MDT_073LTP (1540.9 m WMSF).

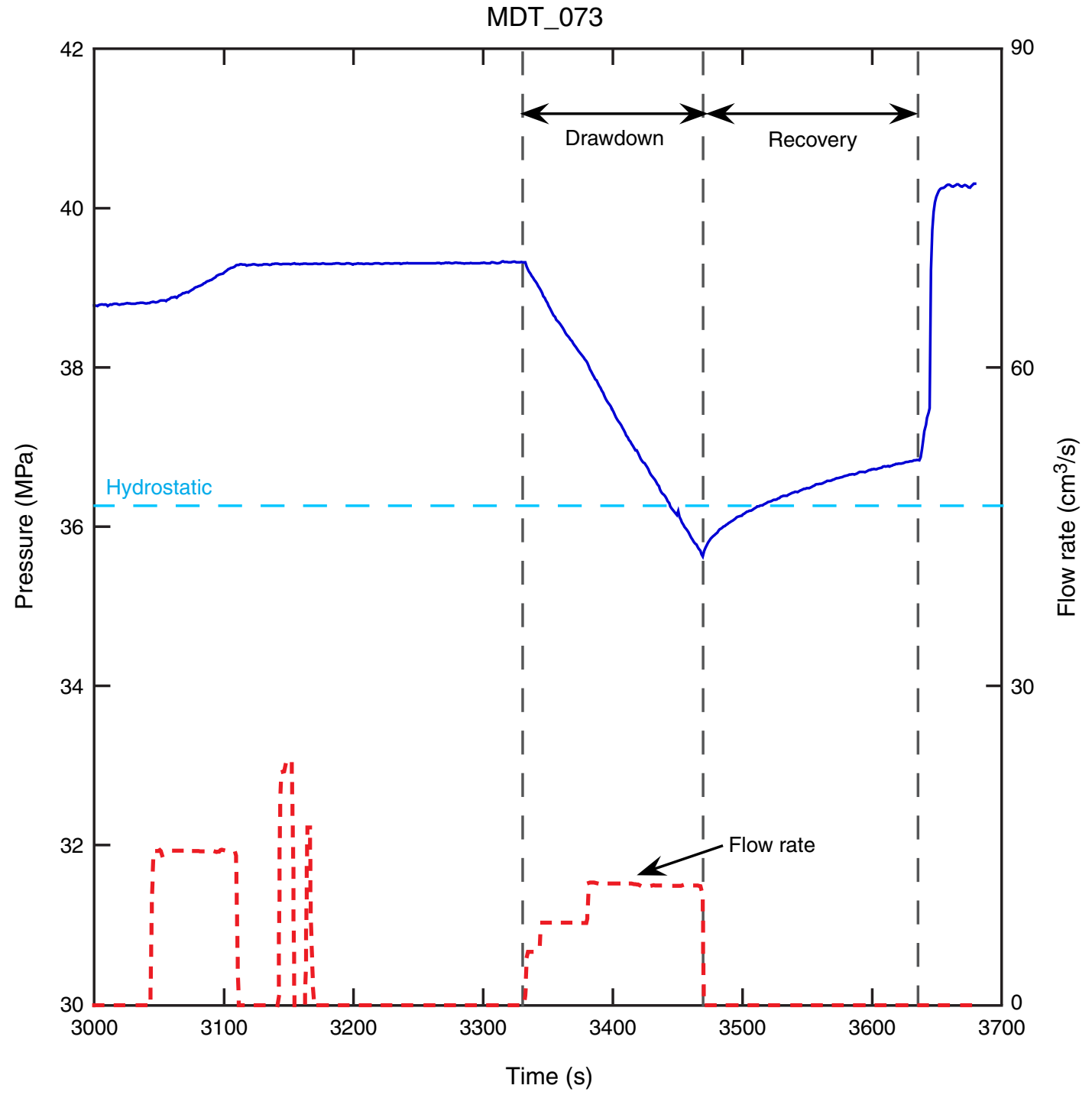


Figure F93. Curve fit for permeability calculation. See "Dual packer drawdown test results" for discussion.

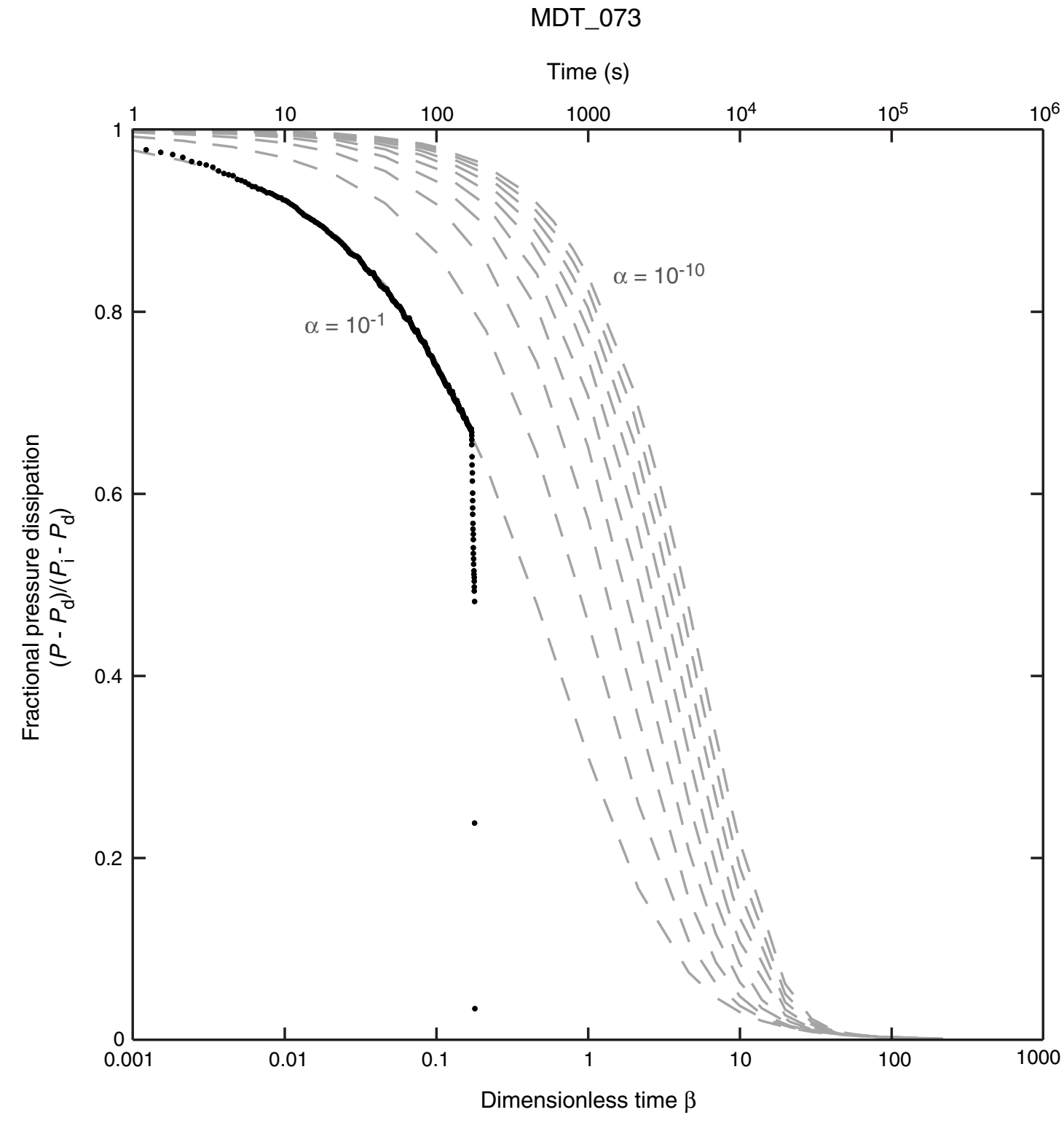


Figure F94. Pressure and flow rate for hydraulic fracture Test MDT_074 (1533.9 m WMSF). ISIP = instantaneous shut in pressure.

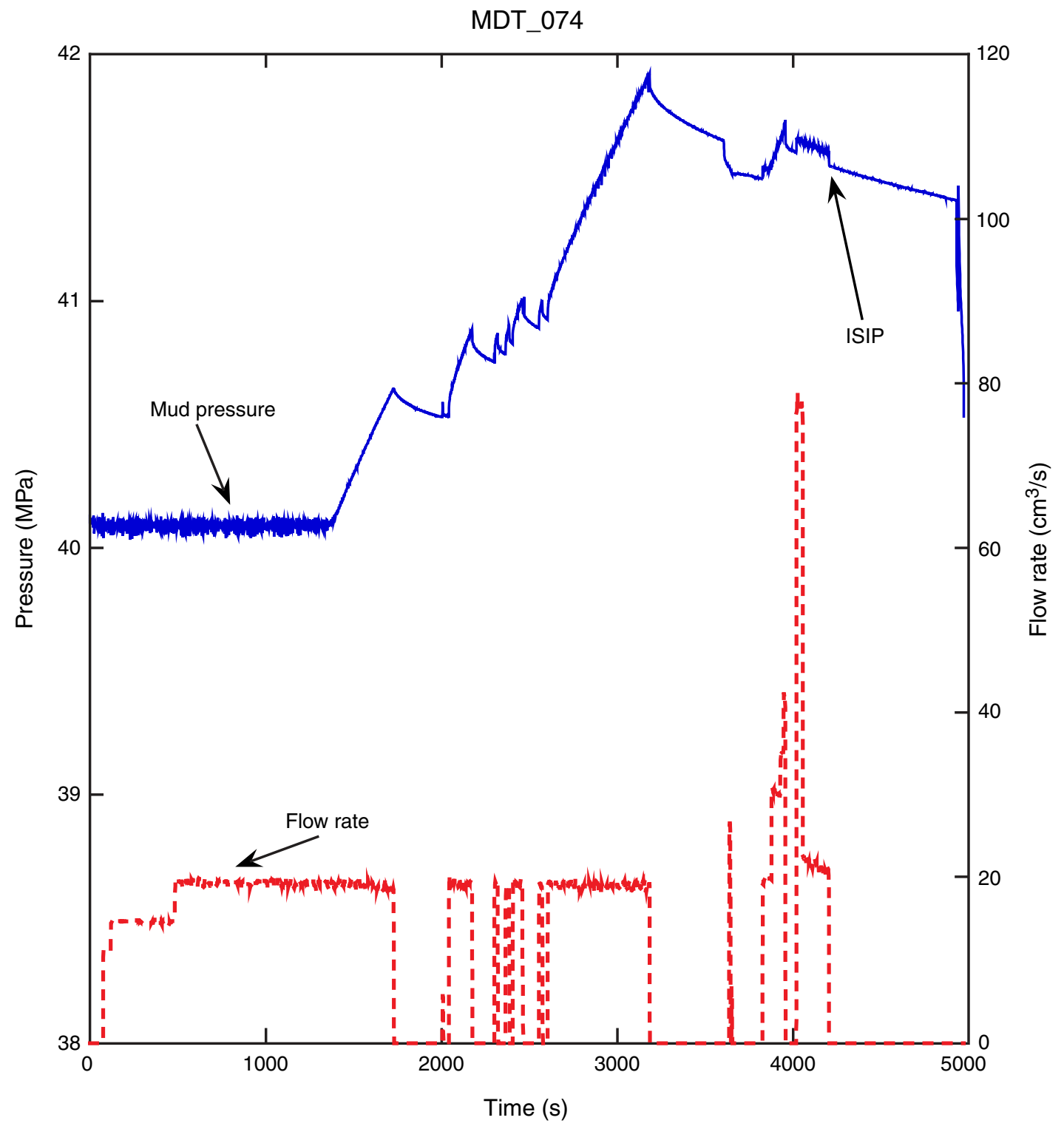


Figure F95. A. Pressure and flow rate for hydraulic fracture Test MDT_080 (876.9 m WMSF). (Continued on next page.)

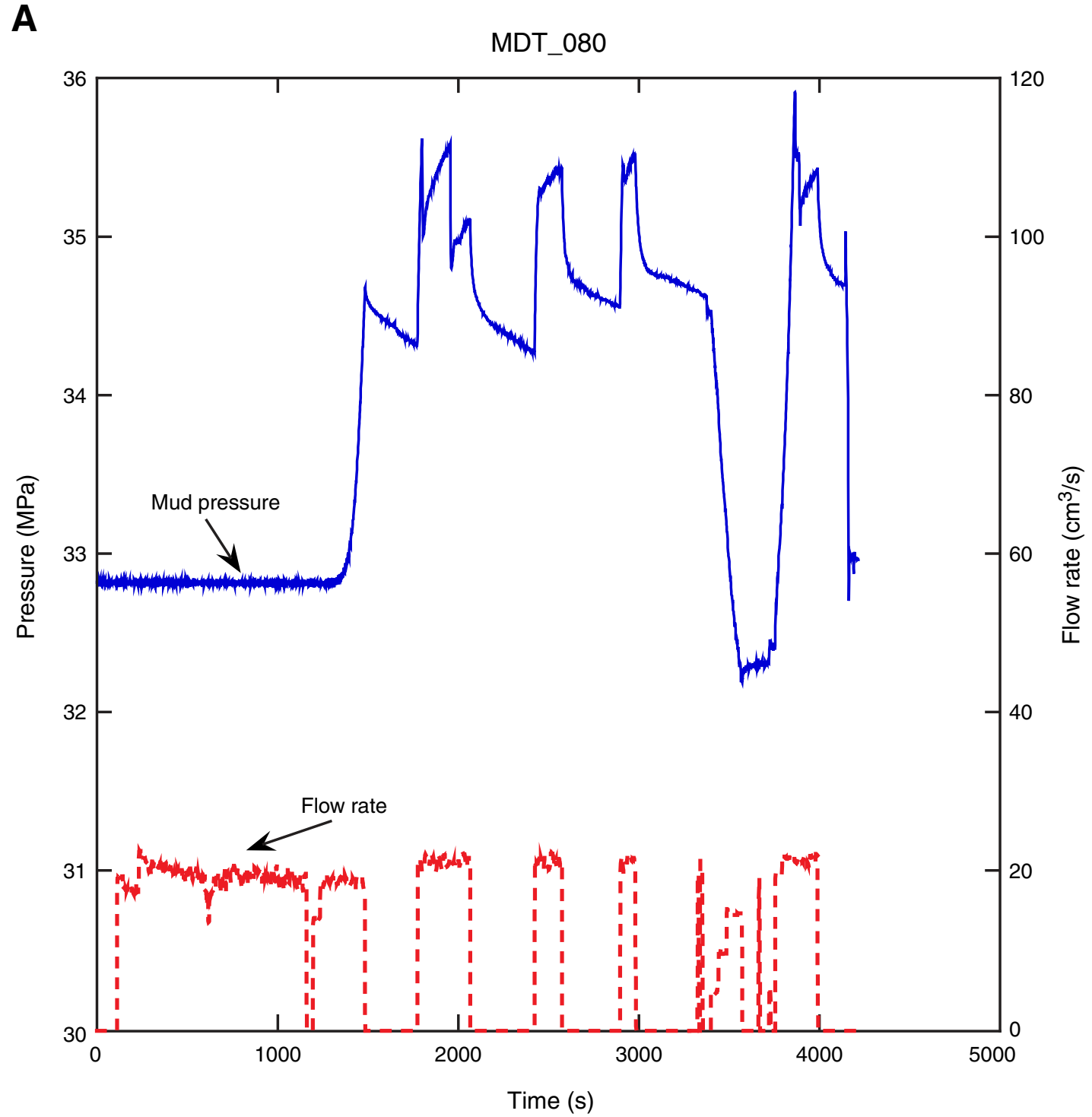


Figure F95 (continued). B. Expanded view of hydraulic fracture Test MTD_080 $(876.9$ m WMSF $)$. Blue circle = instantaneous shut in pressure (ISIP).

B

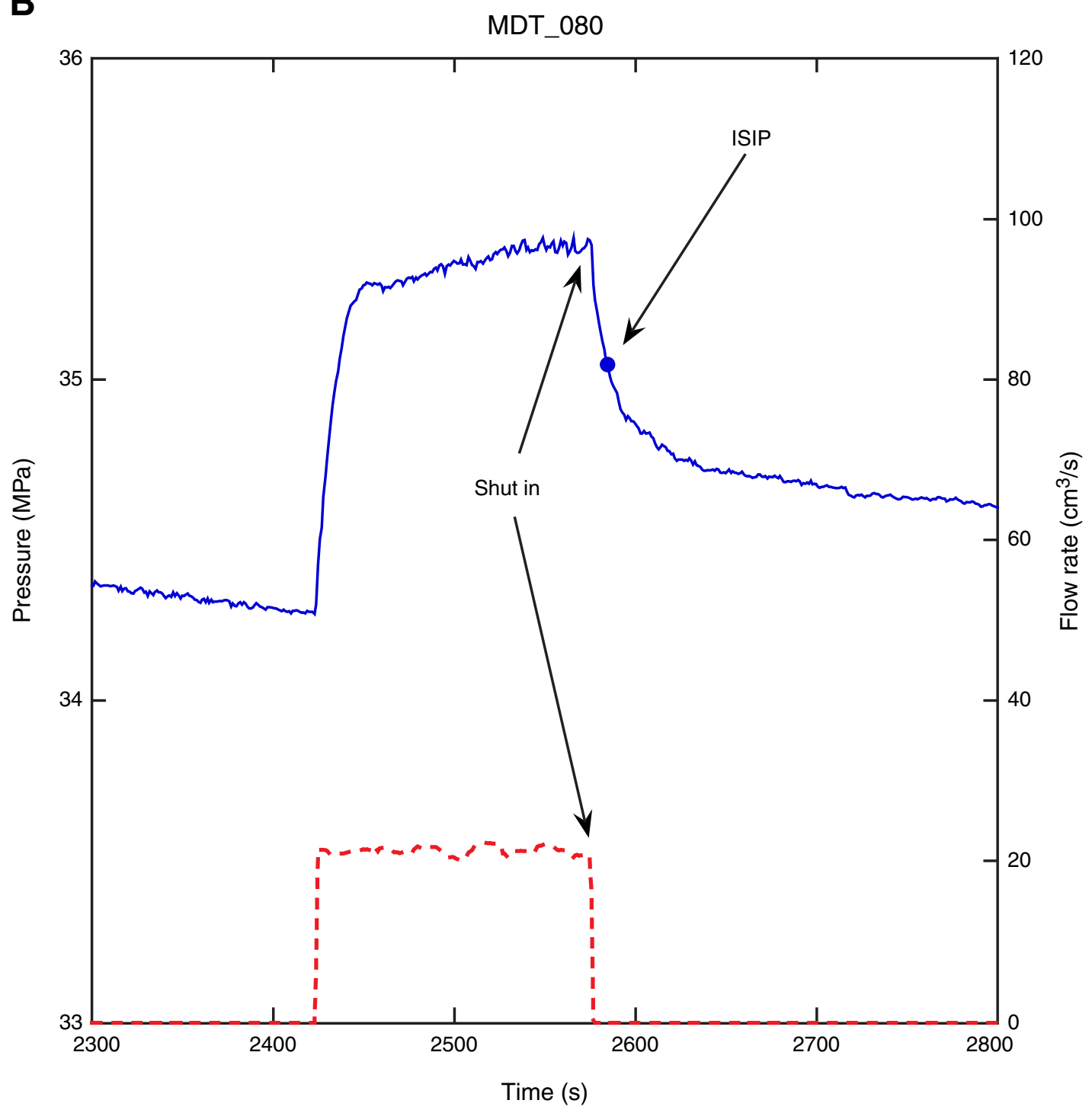


A

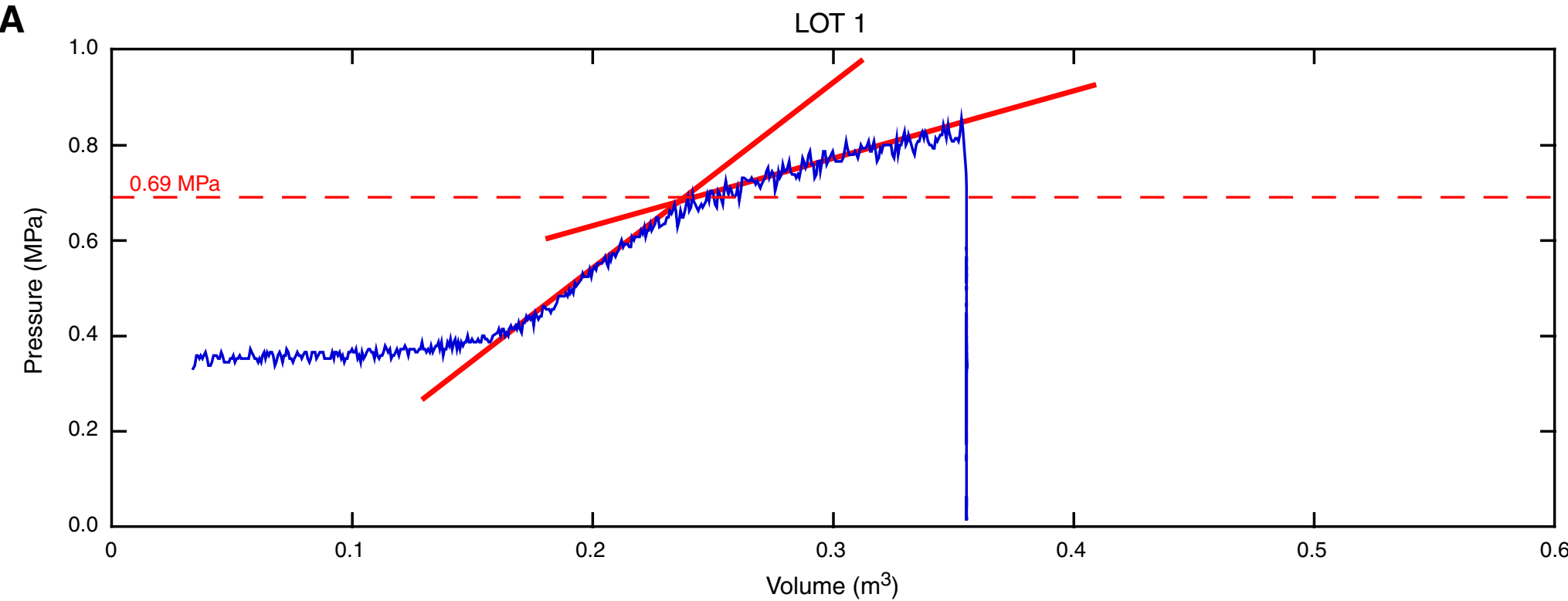

B

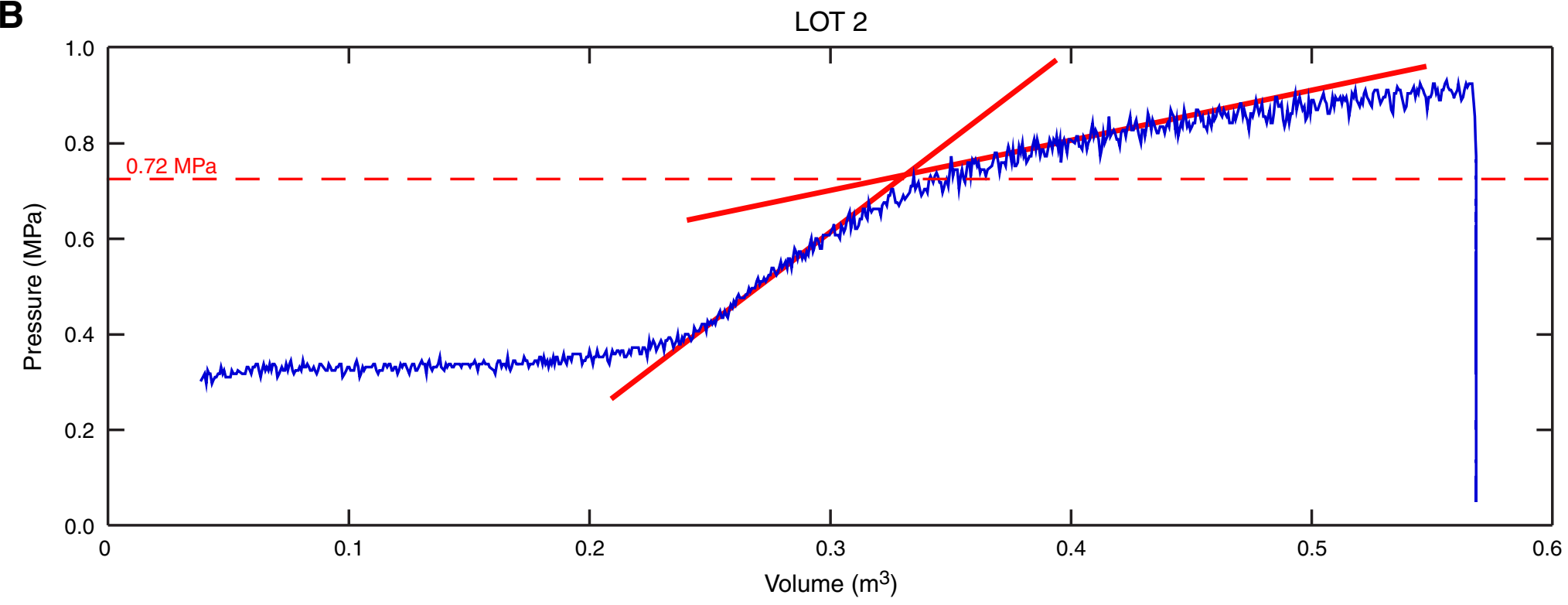


Figure F97. Temperature profile obtained during three wireline logging runs. MDT = Modular Formation Dynamics Tester, $\mathrm{RIH}=$ run in hole, $\mathrm{POOH}=$ pull out of hole. For comparison, estimated temperature from Figure F73 is included in plot.

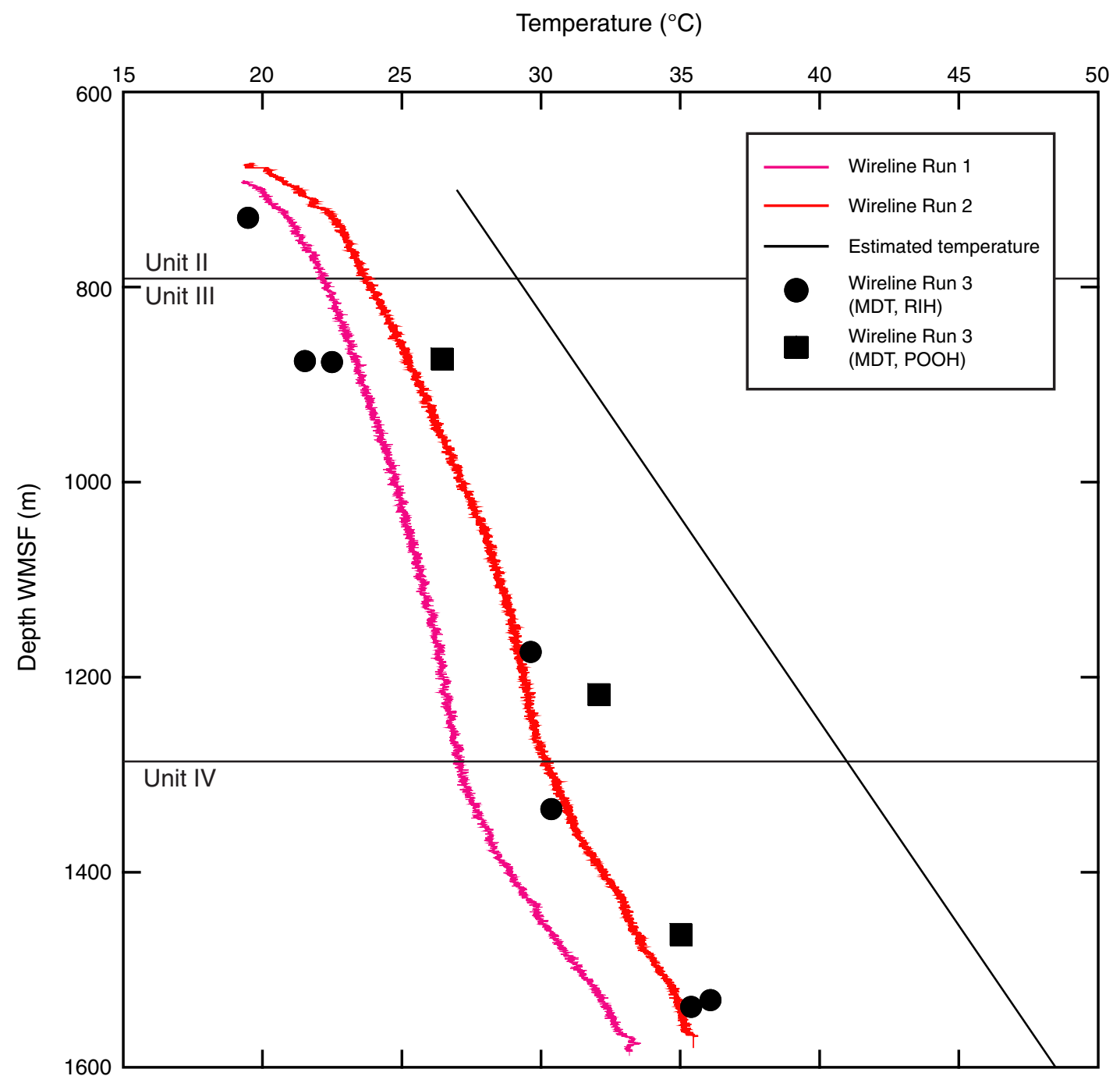


Figure F98. Air gun shot lines (red) and location of eight OBSs (yellow) and three BBOBSs (orange). Area enclosed by black line $=3$-D survey.

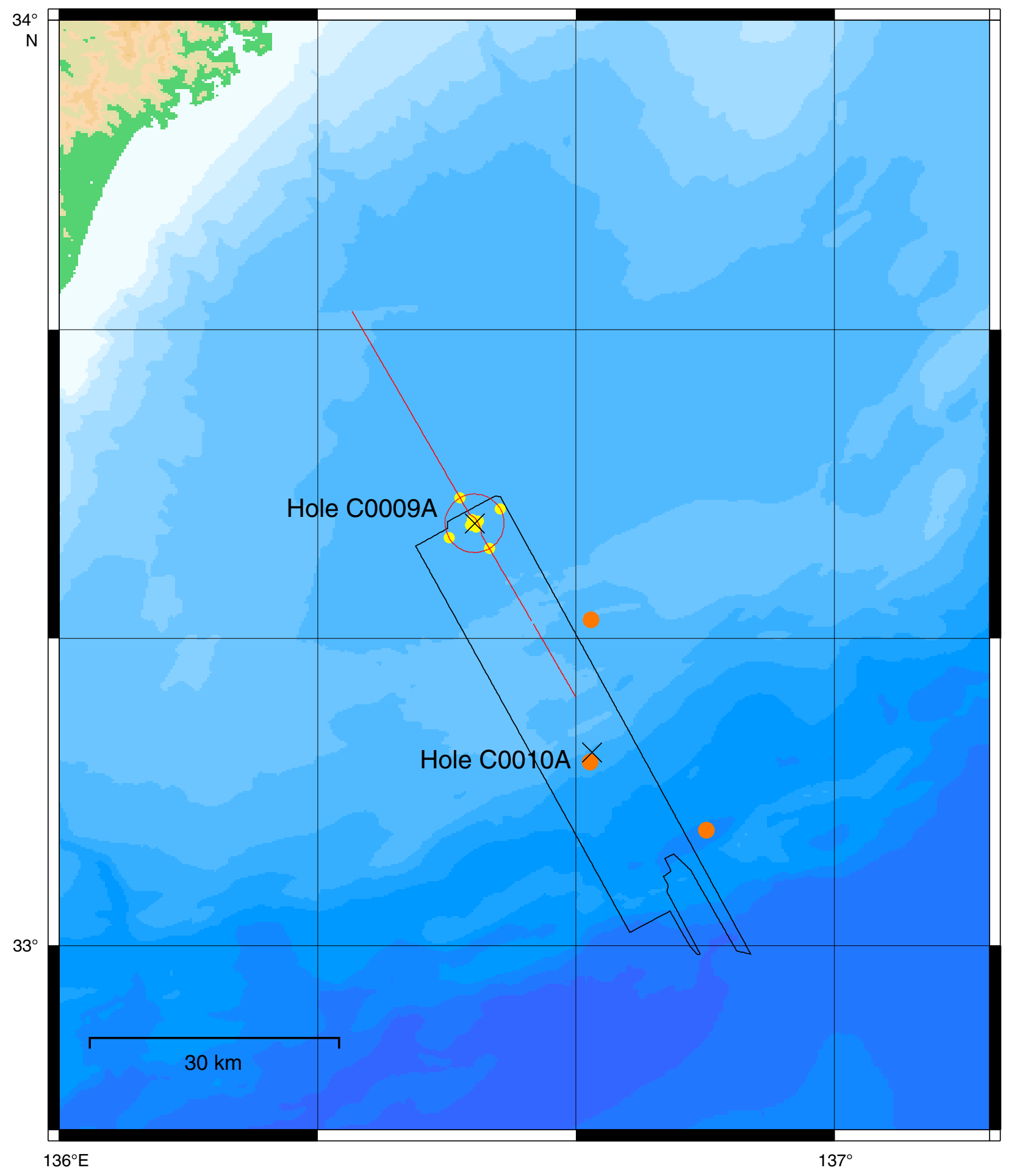


Figure F99. Cross-sectional view of borehole seismometer (Versatile Seismic Imager [VSI]) array location installed in Hole C0009A overlaid on seismic cross section. Yellow circles = locations of OBSs deployed by the Kairei.

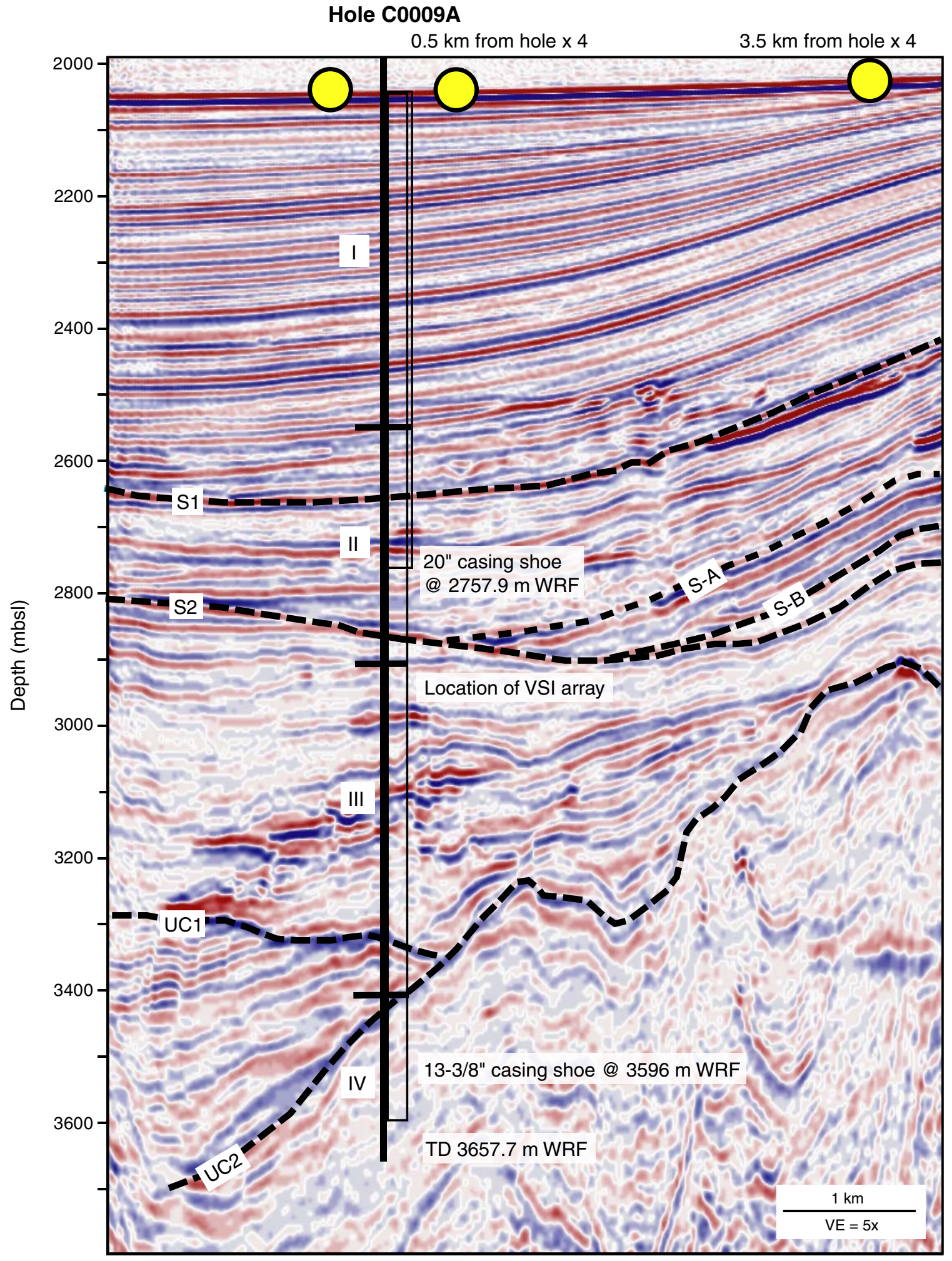


Figure F100. Plot of circle shooting data from the VSI seismometer at $3217 \mathrm{~m}$ WRF for vertical and one horizontal component $(y)$, shown with direction of shotpoint; north (N), east (E), south (S), and west (W). Records are bandpass filtered at 4-200 Hz. Distance from air gun shotpoints from the Kairei were maintained at $3.5 \mathrm{~km}$ from borehole.
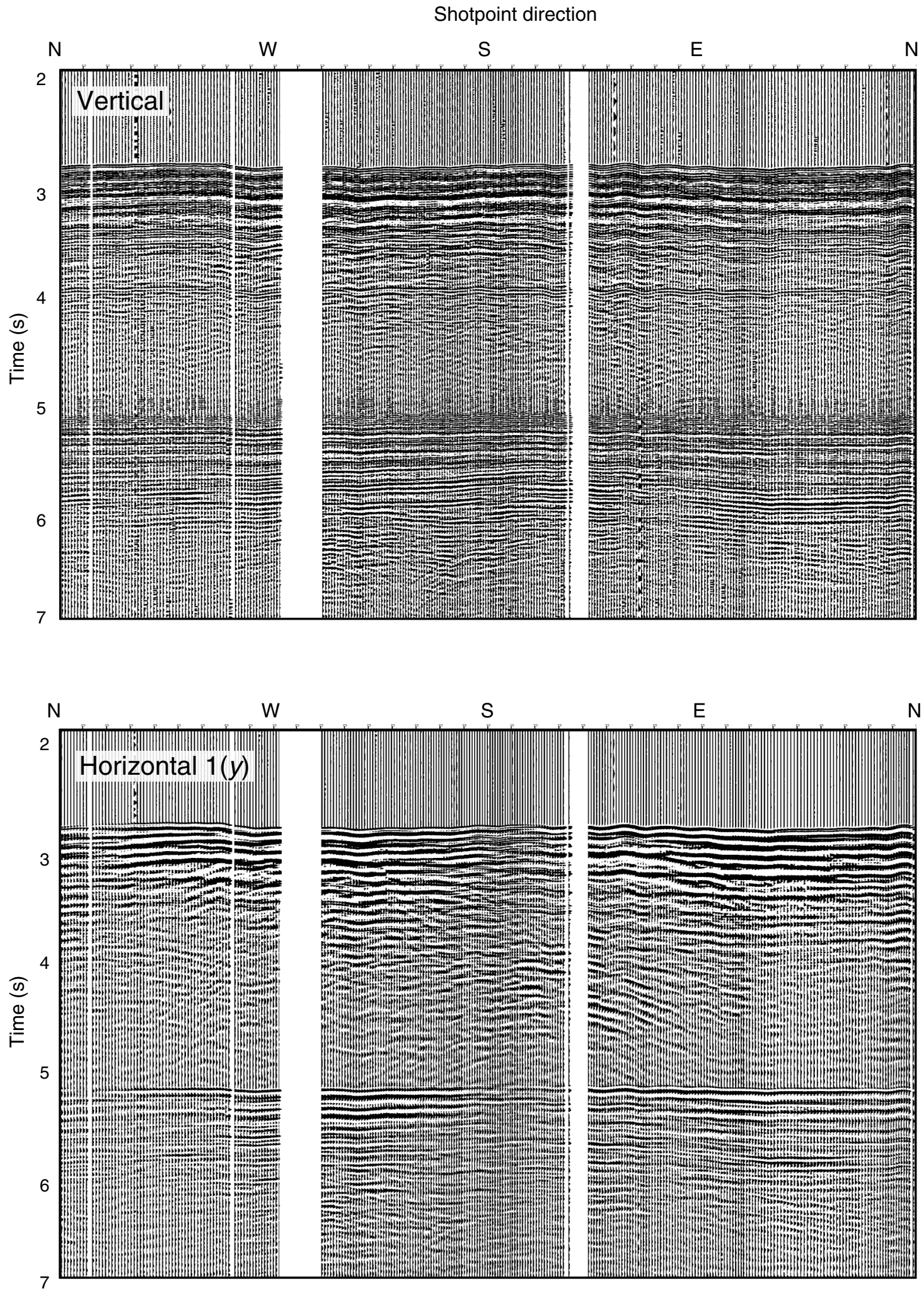
Figure F101. Relationship of amplitude and polarity of the first motion for circle shooting seismic record of $y$ horizontal component at $3217 \mathrm{~m}$ WRF. Crosses = measured amplitude and sign data from records bandpass filtered at $4-10 \mathrm{~Hz}$, dashed line = cosine curves fitted to the measurement to estimate orientation of seismometer.

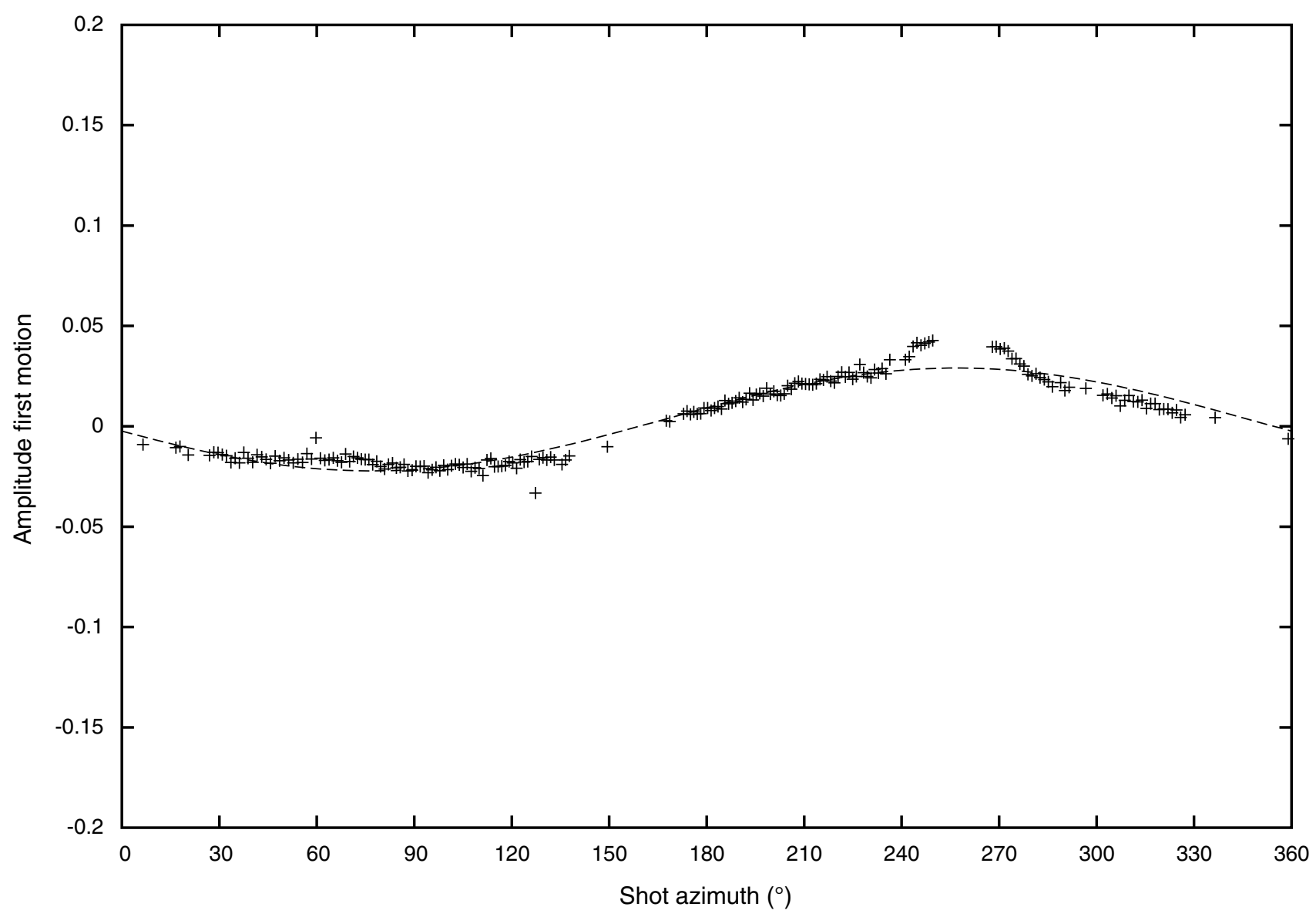


Figure F102. Vertical seismic record section from a seismometer at $3004 \mathrm{~m}$ DRF in walkaway VSP experiment, Hole C0009A. Records are bandpass filtered at $4-30 \mathrm{~Hz}$, and time is reduced by $4 \mathrm{~km} / \mathrm{s}$. Gain proportional to distance is applied to records to illuminate reflections from deep horizons.

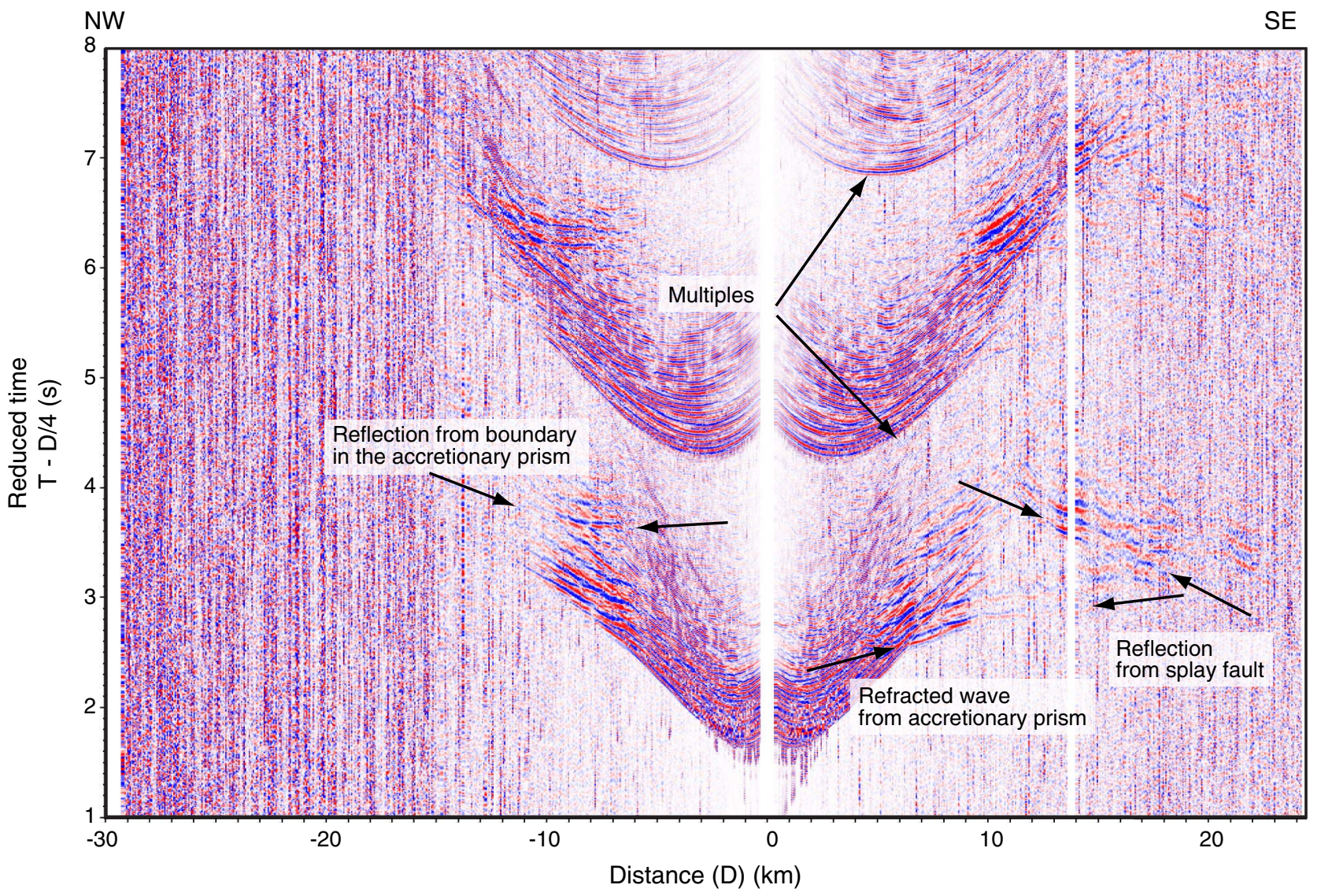


Figure F103. Seismic record section from a seismometer at $3004 \mathrm{~m}$ DRF in walkaway VSP experiment, Hole C0009A. Records are bandpass filtered at $4-30 \mathrm{~Hz}$, and time is reduced by $4 \mathrm{~km} / \mathrm{s}$. Gain proportional to distance is applied to records to illuminate reflections from deep horizons. Records were oriented to transverse and radial component using the angles by the first motion records of circle shooting data. A. Transverse horizontal component. B. Radial horizontal component.

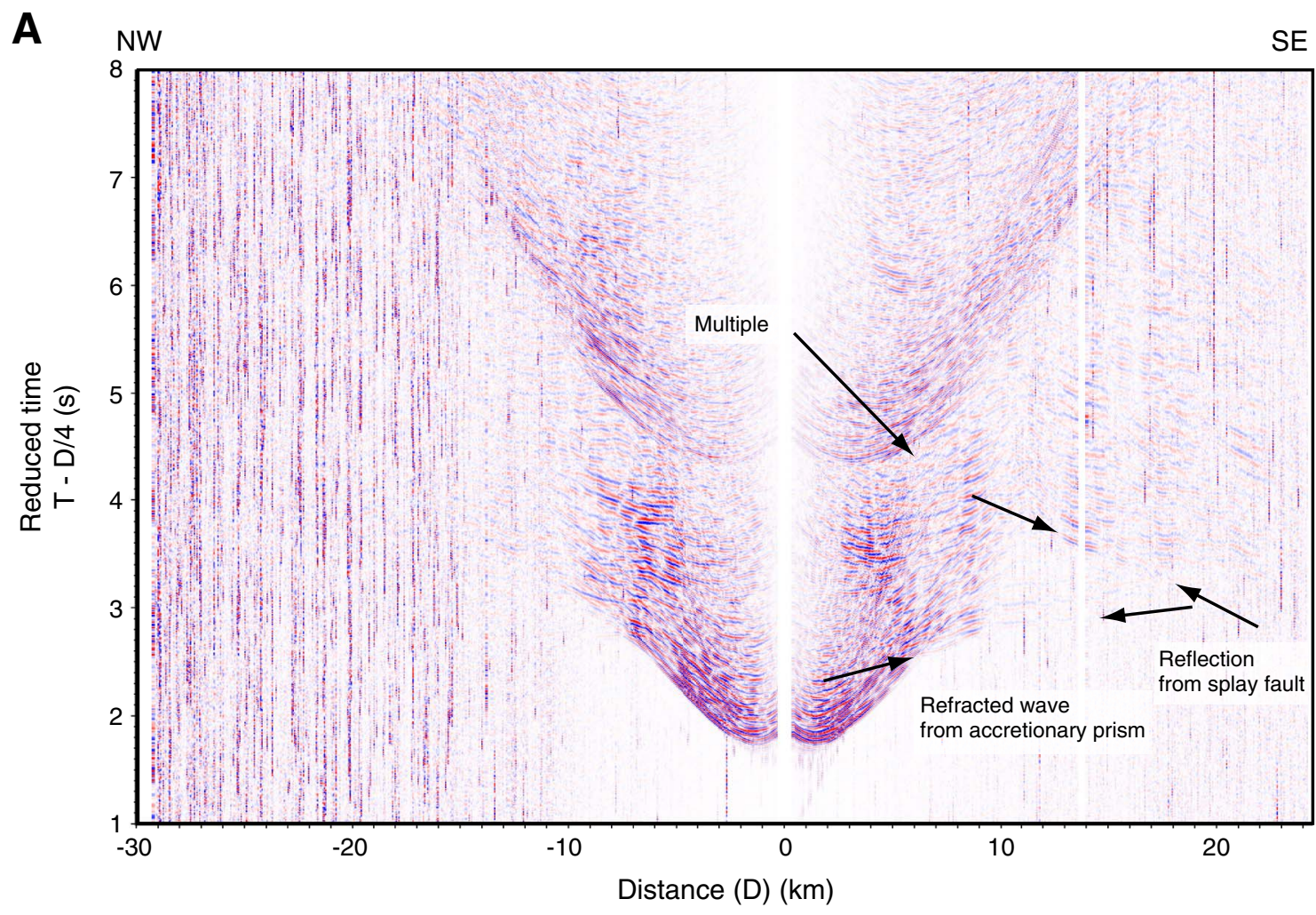

B NW $\quad$ SE

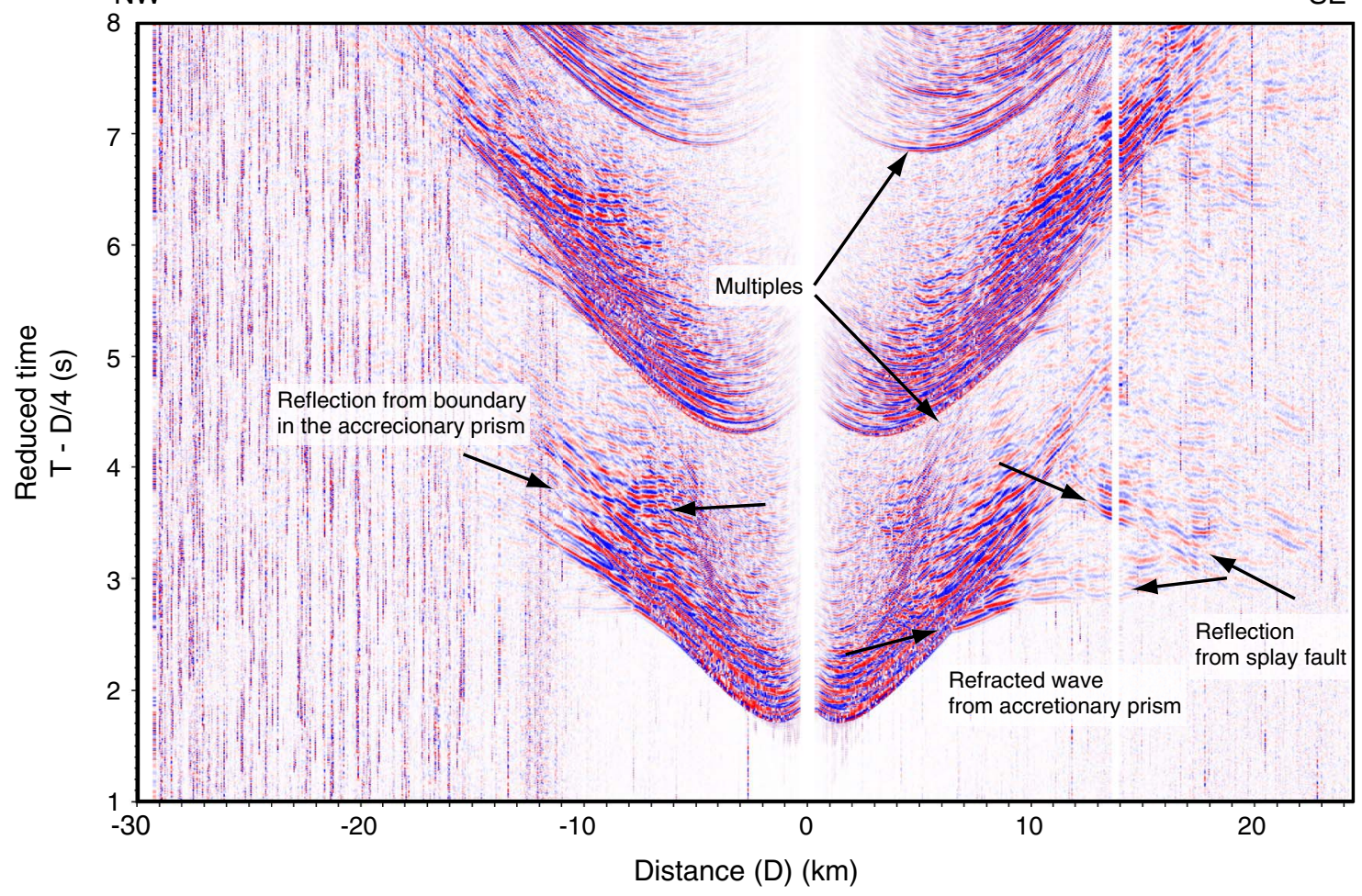


Figure F104. Frequency dependence of the vertical seismic record of all seismometers in the array shown for three walkaway VSP shots of offset $\sim 10 \mathrm{~km}$ south of borehole. Receiver gathers of three consecutive shots are plotted for different frequency bands. Scale of vertical apparent velocity shown to illustrate upgoing and downgoing wave velocities. See text for description of shaded areas.

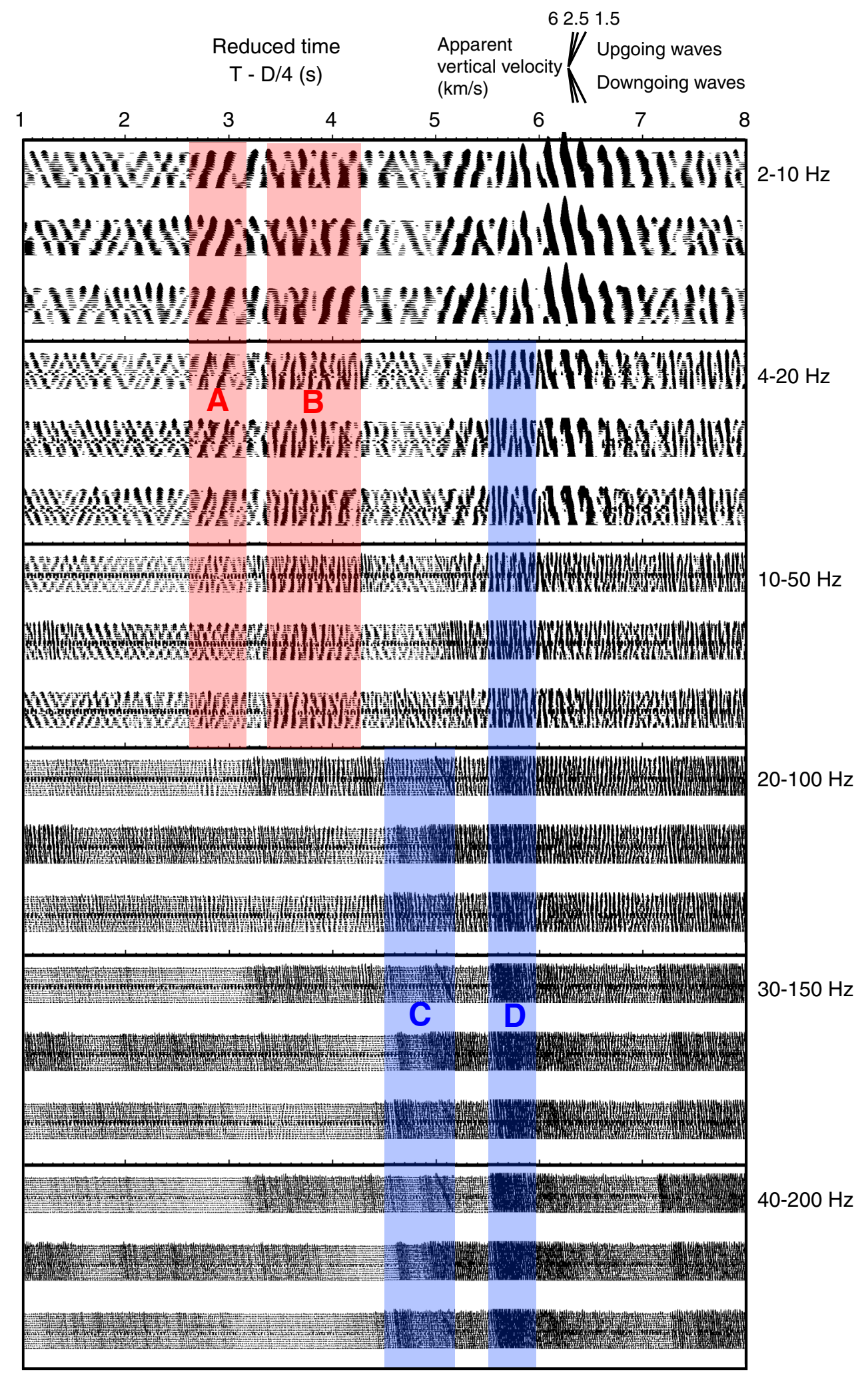


Figure F105. Frequency dependence of the radial horizontal seismic records for all seismometers in the array shown for three walkaway VSP shots of offset $\sim 10 \mathrm{~km}$ south of borehole. Scale of vertical apparent velocity shown to illustrate upgoing and downgoing wave velocities. A = upgoing refracted waves, $\mathrm{B}=$ mixed upgoing reflected and downgoing direct waves. See text for further description of shaded areas.

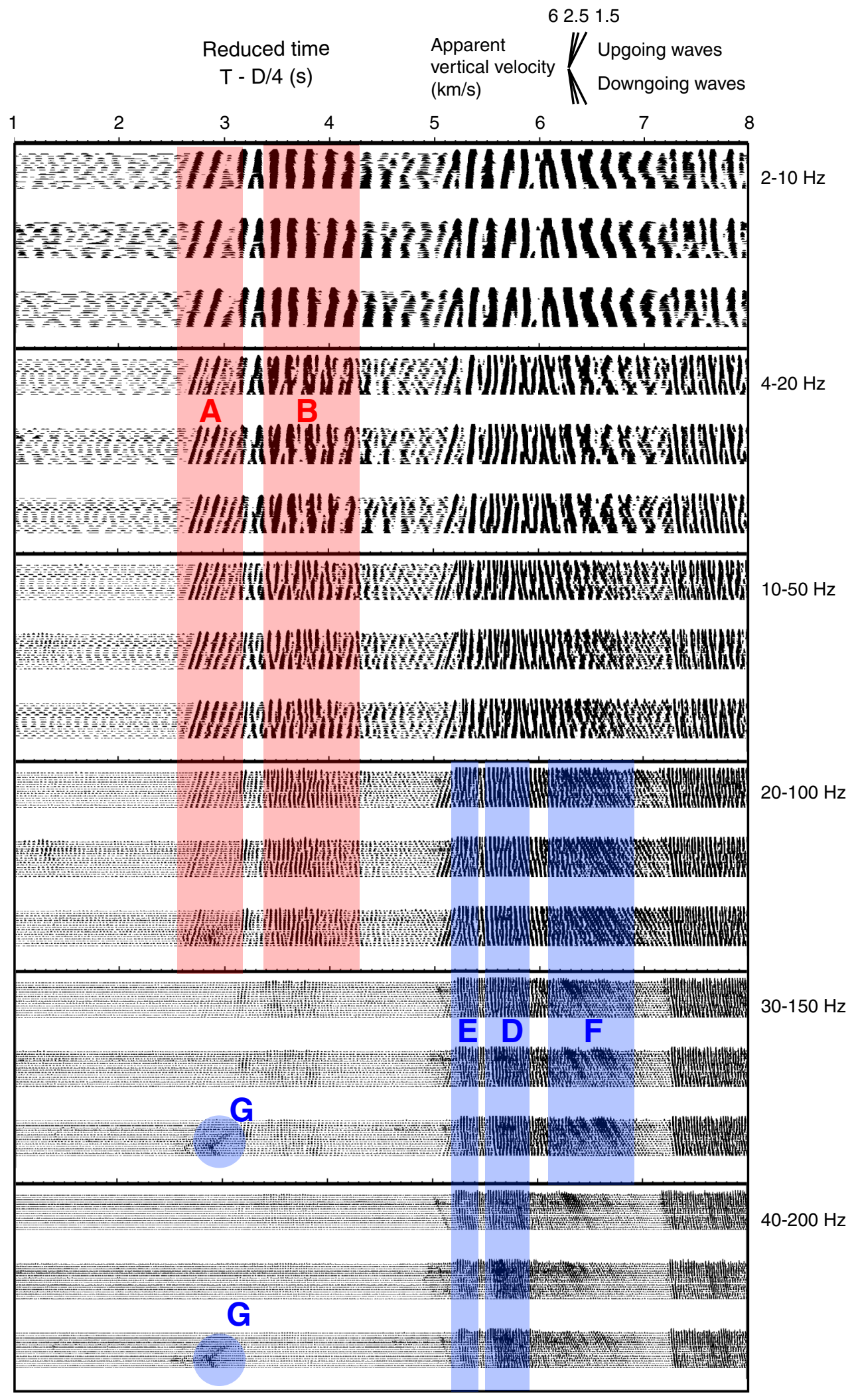


Figure F106. Stacked seismic records from zero-offset seismic experiment in Hole C0009A. 10 shot records were stacked for each depth and bandpass filtered at 10-90 Hz. The filter has zero phase response to preserve the correct arrival time of the phase. Gain proportional to the depth from the rig floor is applied to the records to compensate for geometrical spreading of components. See text for description of lines. TD = total depth. A. Vertical $z$-component. (Continued on next two pages.)

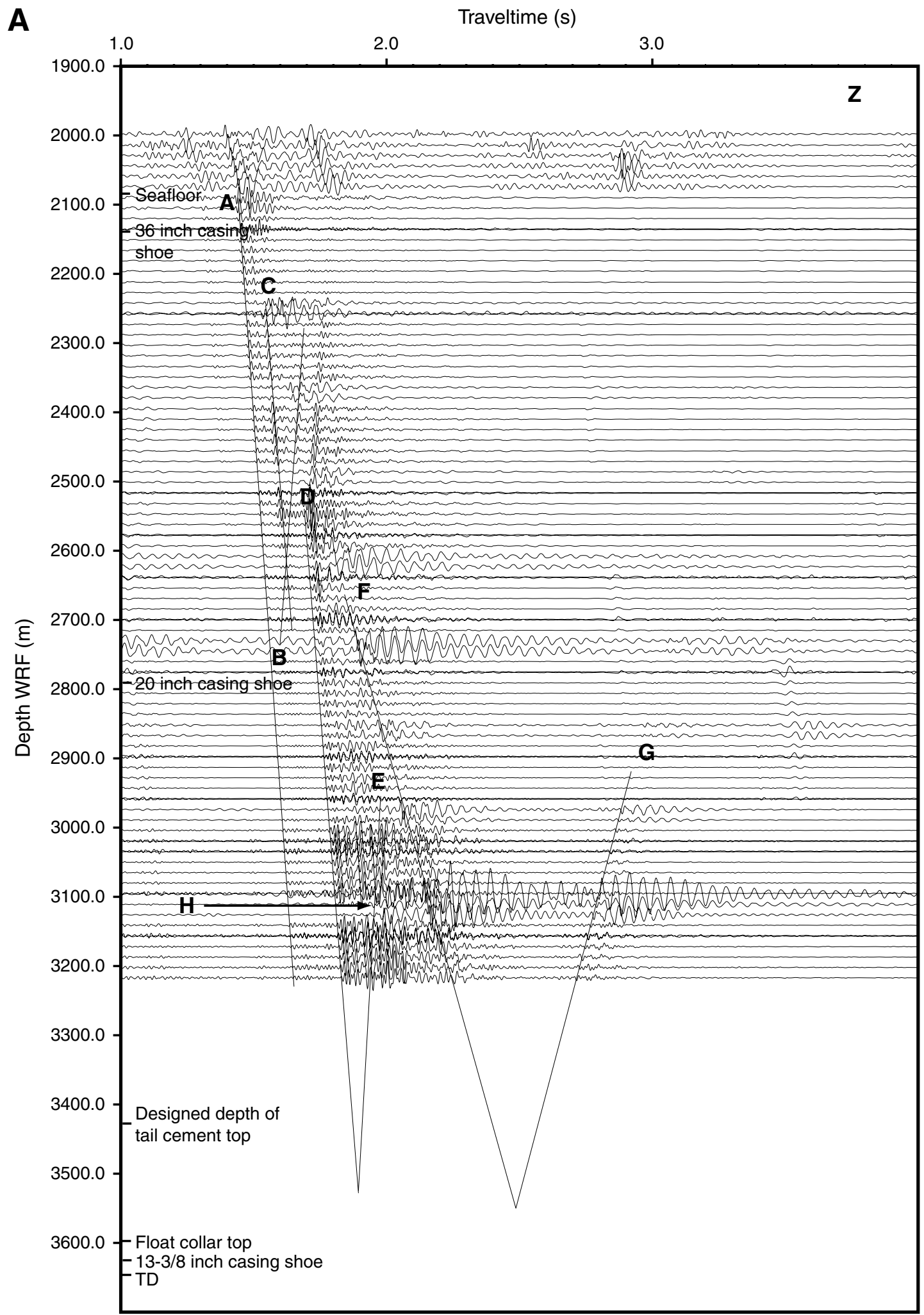


Figure F106 (continued). B. Horizontal $x$-component. (Continued on next page.)

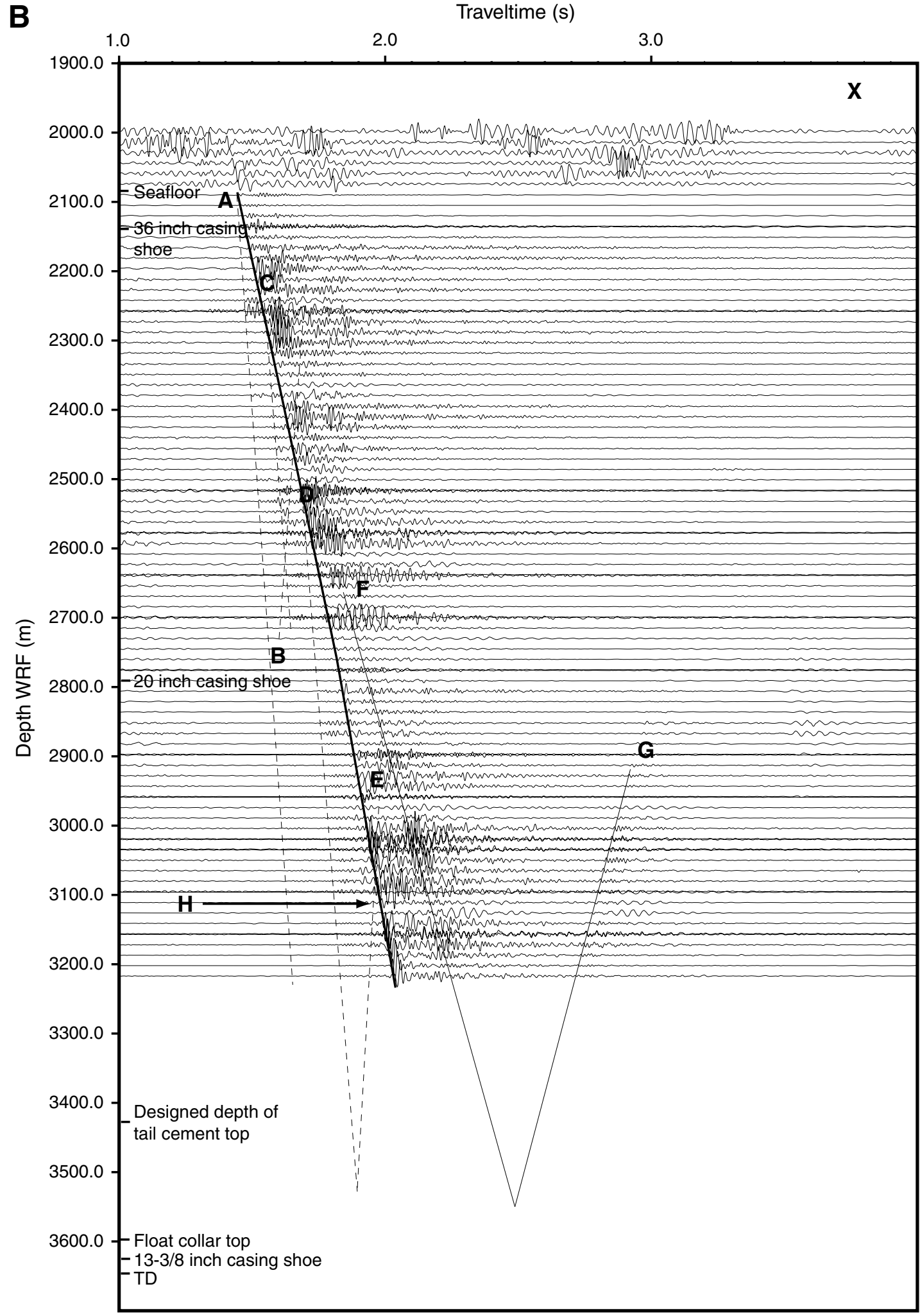


Figure F106 (continued). C. Horizontal $y$-component.

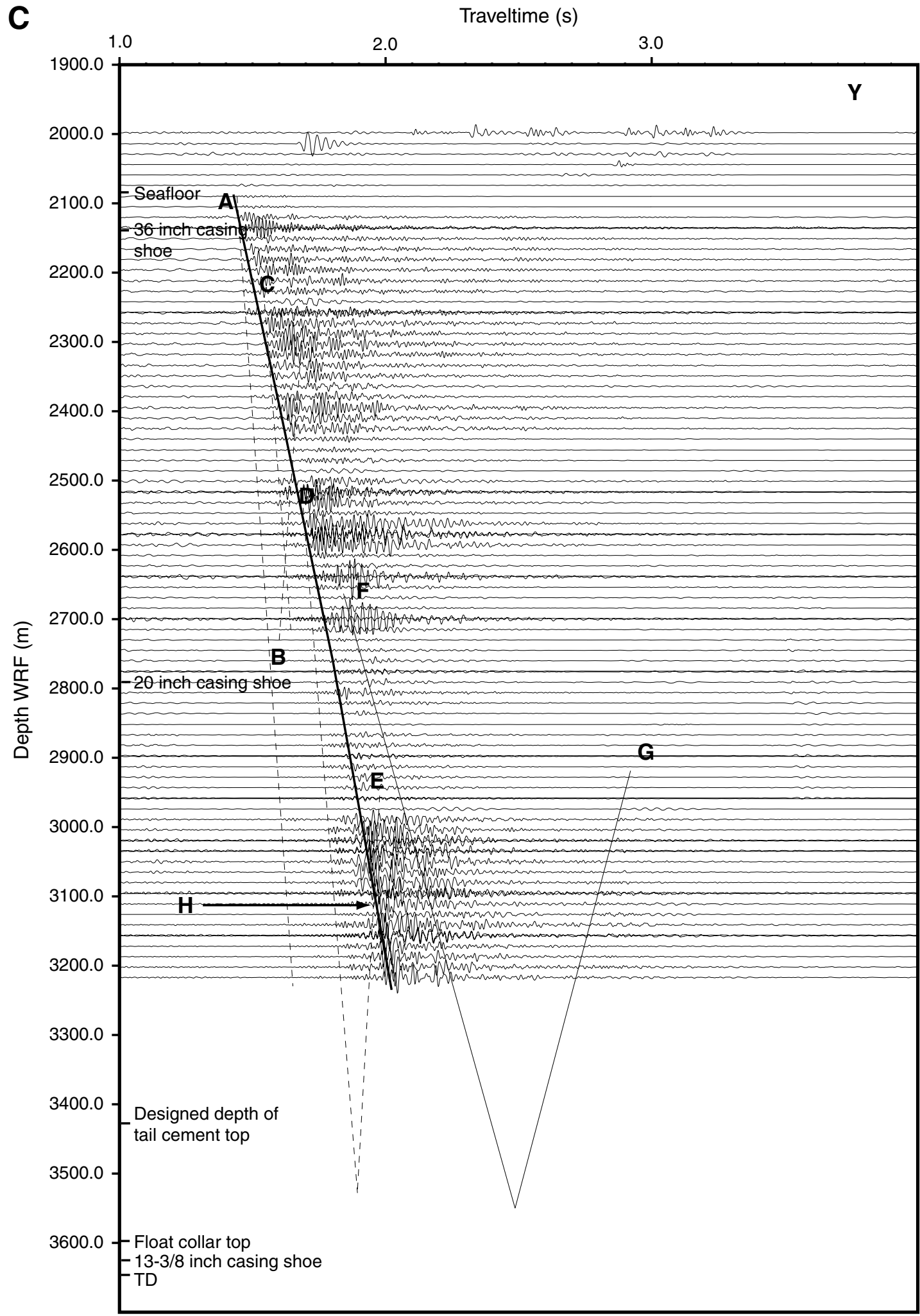


Figure F107. Velocity versus depth, Hole C0009A. Zero-offset VSP interval velocities (red squares), wireline sonic velocity (solid line), and interval velocity derived from precruise seismic processing (dashed line) are shown.

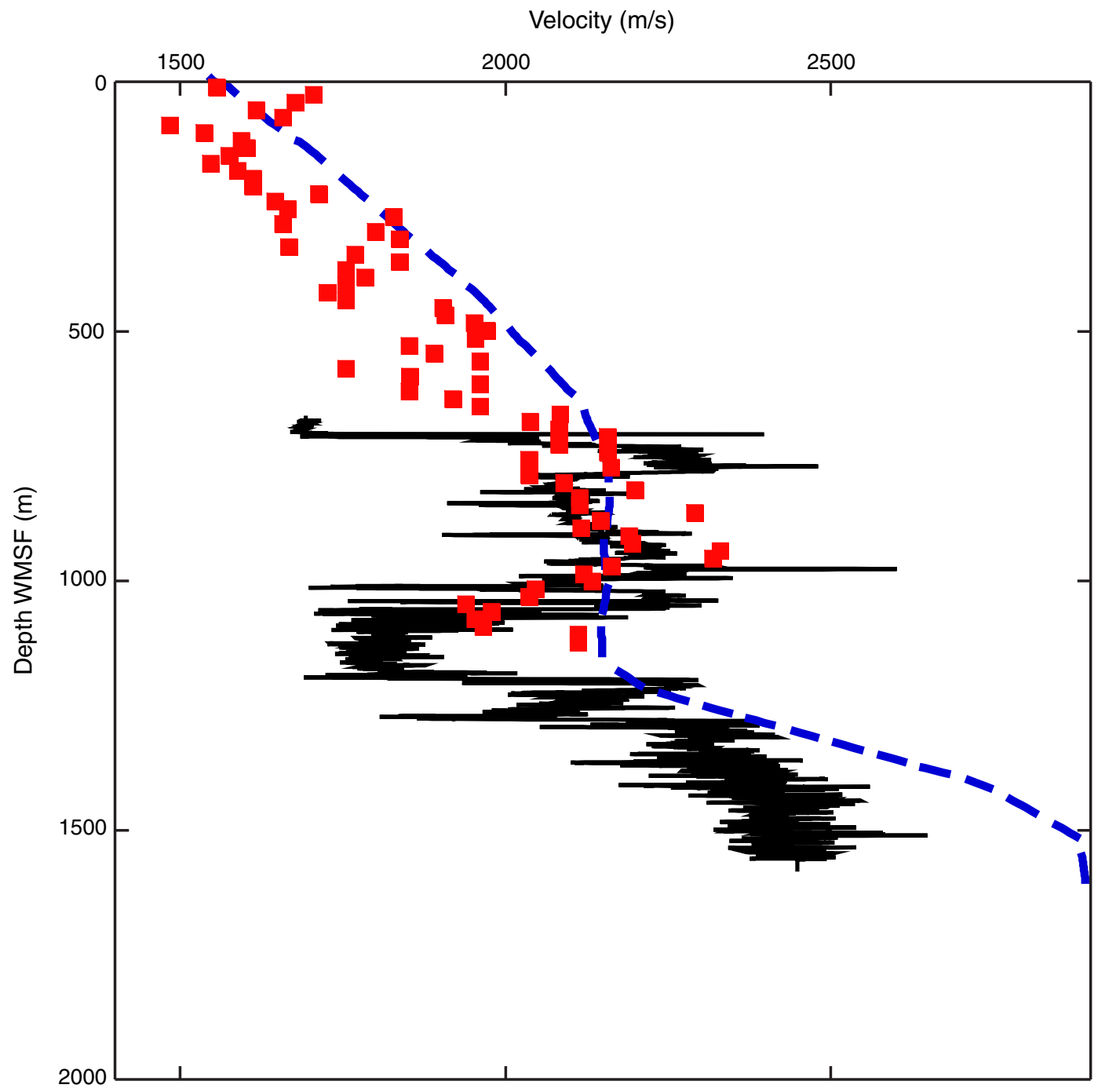


Figure F108. One-way transit time versus depth with check shot data (red squares) and traveltimes derived from precruise seismic processing (dashed line).

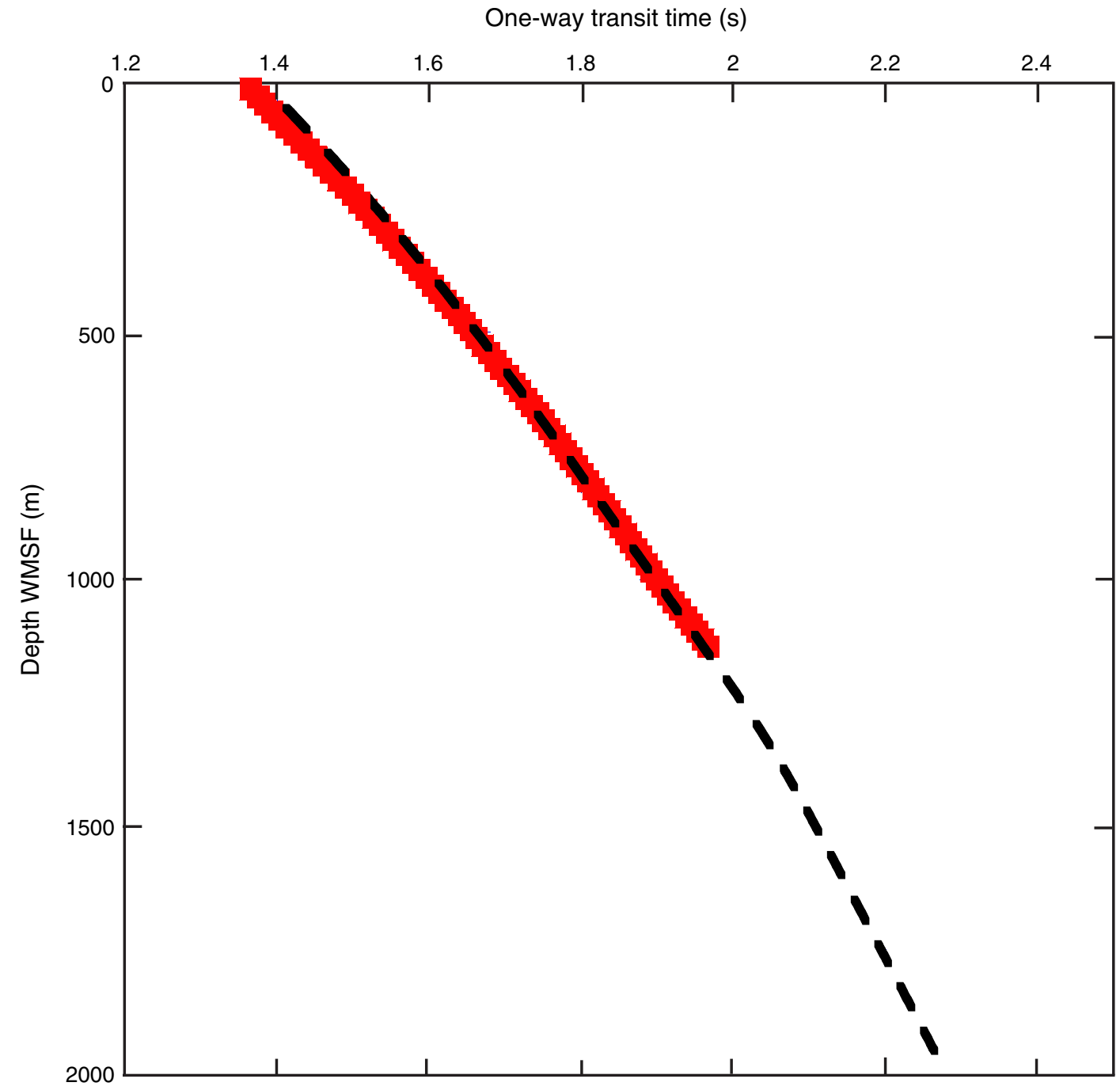


Figure F109. Velocity versus depth, Site C0009. Logging, core, and cuttings data tied to seismic data using a velocity model that combined check shot data with wireline sonic velocity. Our model velocity structure has lower velocity below $1000 \mathrm{~m}$ WMSF than interval velocity derived from precruise seismic processing. Timedepth data available in C0009_T1.XLS in CCLS in "Supplementary material."

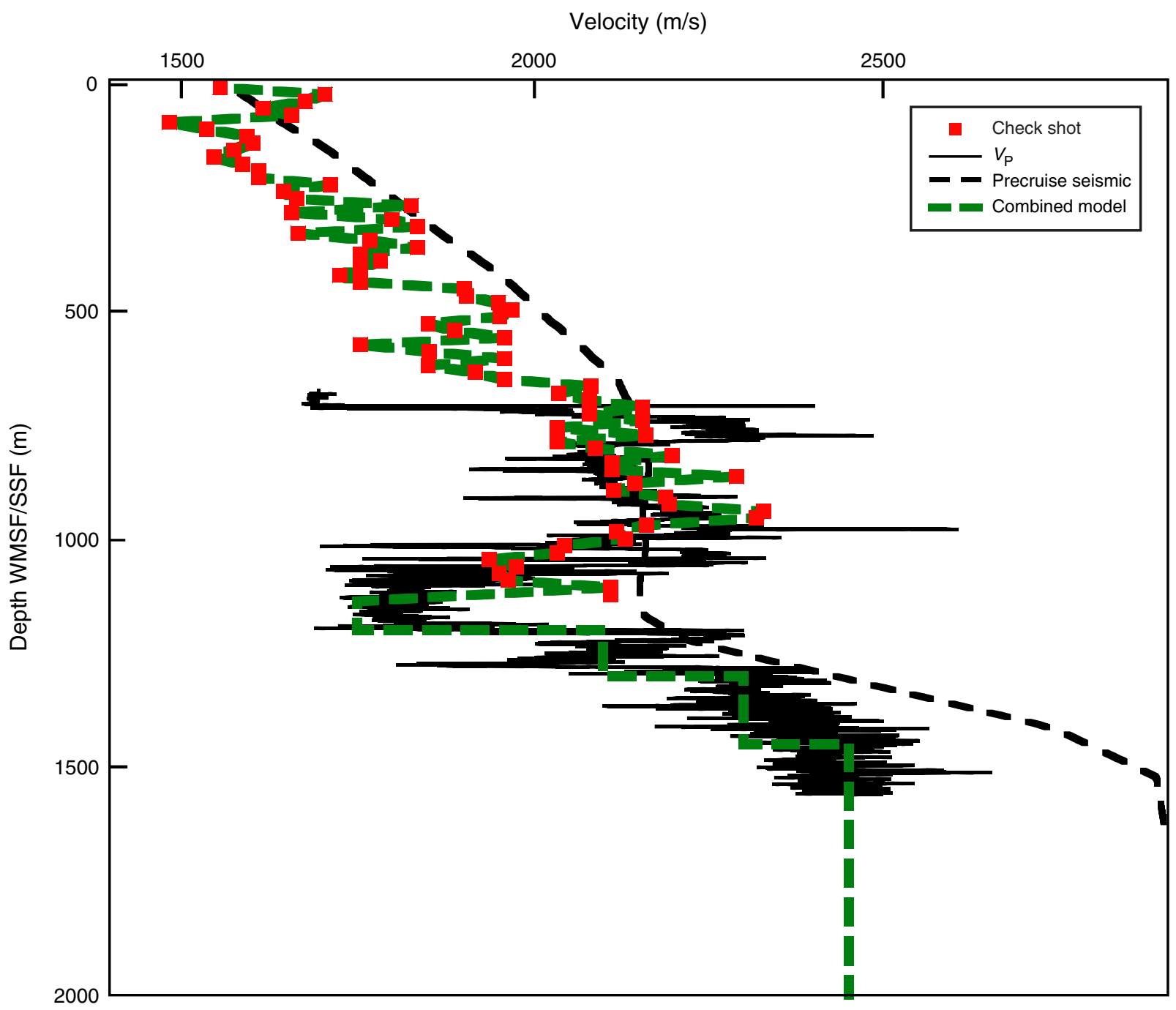


Figure F110. Logging, core, and cuttings data correlated to seismic data with a one-way traveltime versus depth model that combines check shot data with wireline sonic traveltimes. Final time-depth model (green line) derived from velocity model has larger traveltimes below $1000 \mathrm{~m}$ WMSF than traveltimes derived from precruise seismic processing (black line). Time-depth data available in C0009_T1.XLS in CCLS in "Supplementary material."

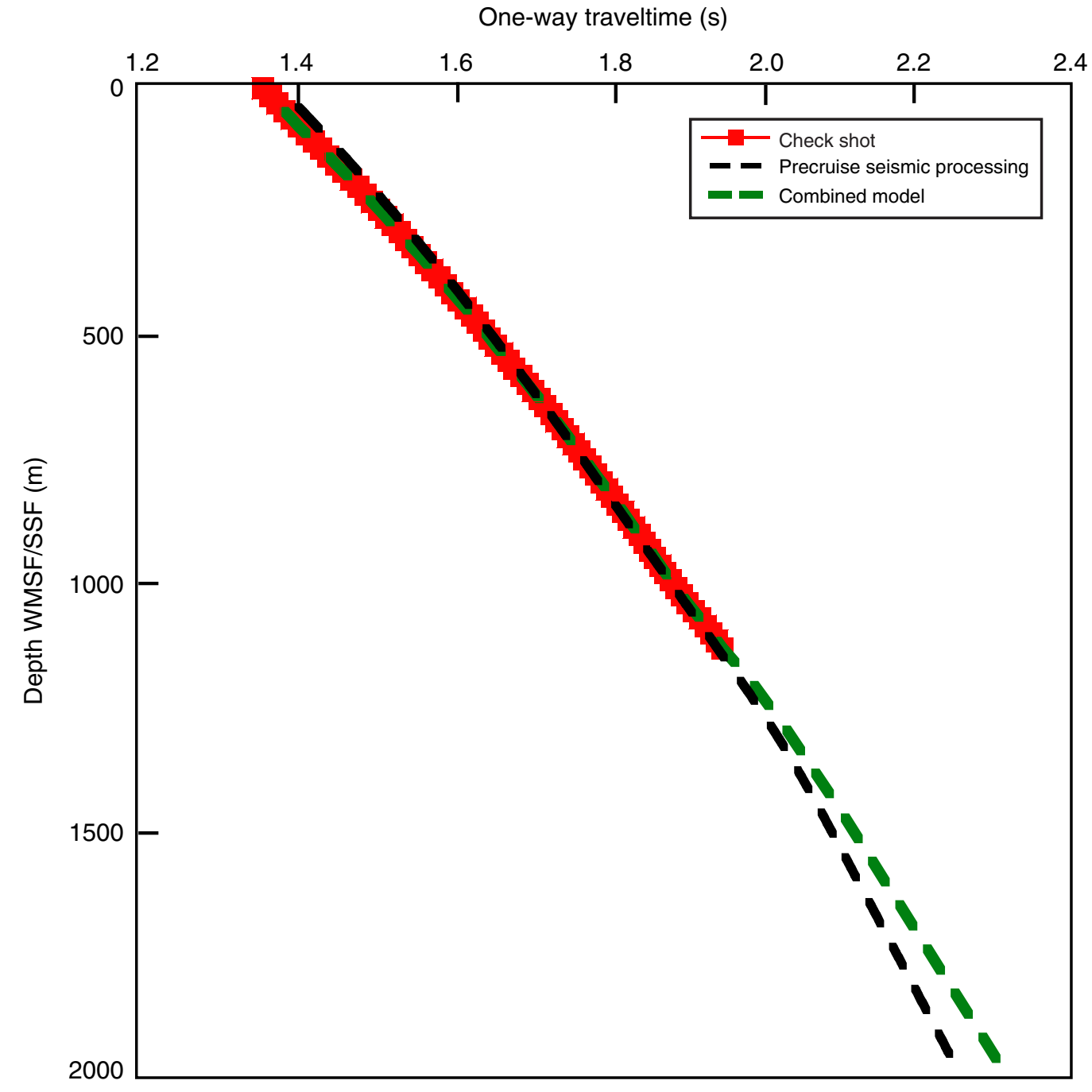


Figure F111. Seismic data correlated to well data over entire depth of Site C0009. Seismic data displayed are time-based. Vertical arrow $=$ Site C0009 location on seismic data. Two velocities are plotted to the right of the seismic. Check shot velocity was used for time-depth correlation; this combines interval velocity taken from the check shot with average velocity taken from wireline sonic velocity $\left(V_{\mathrm{P}}\right)$. Impedance is the product of compressional velocity $\left(V_{\mathrm{p}}\right)$ and bulk density $\left(\rho_{\mathrm{b}}\right)$. Far right column shows original check shot time data (red line) and one-way traveltime used in time-depth correlation (black dots) (see C0009_T1.XLS in CCLS in "Supplementary material").

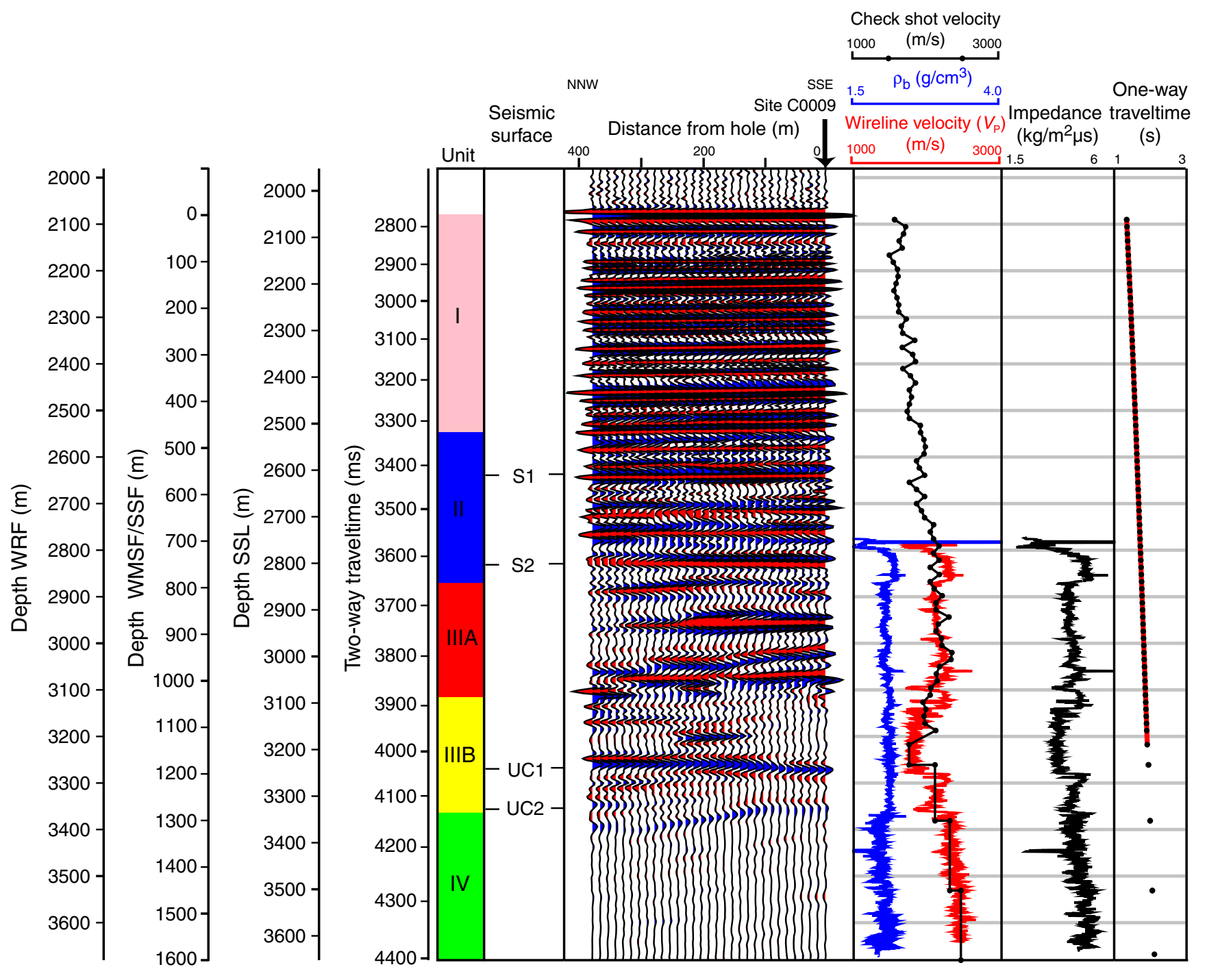


Figure F112. Seismic data correlated to well data from $700 \mathrm{~m}$ WMSF to TD, Hole C0009A. Vertical arrow = Site C0009 location on seismic data. Two velocities are plotted to the right of the seismic data. Check shot velocity was used for time-depth correlation; this combines interval velocity taken from check shot with average velocity taken from wireline sonic velocity $\left(V_{\mathrm{P}}\right)$. Impedance is the product of compressional velocity $\left(V_{\mathrm{P}}\right)$ and bulk density $\left(\rho_{\mathrm{b}}\right)$. Far right column shows original check shot time data (red line) and one-way traveltime used in time-depth correlation (black dots) (see C0009_T1.XLS in CCLS in "Supplementary material").

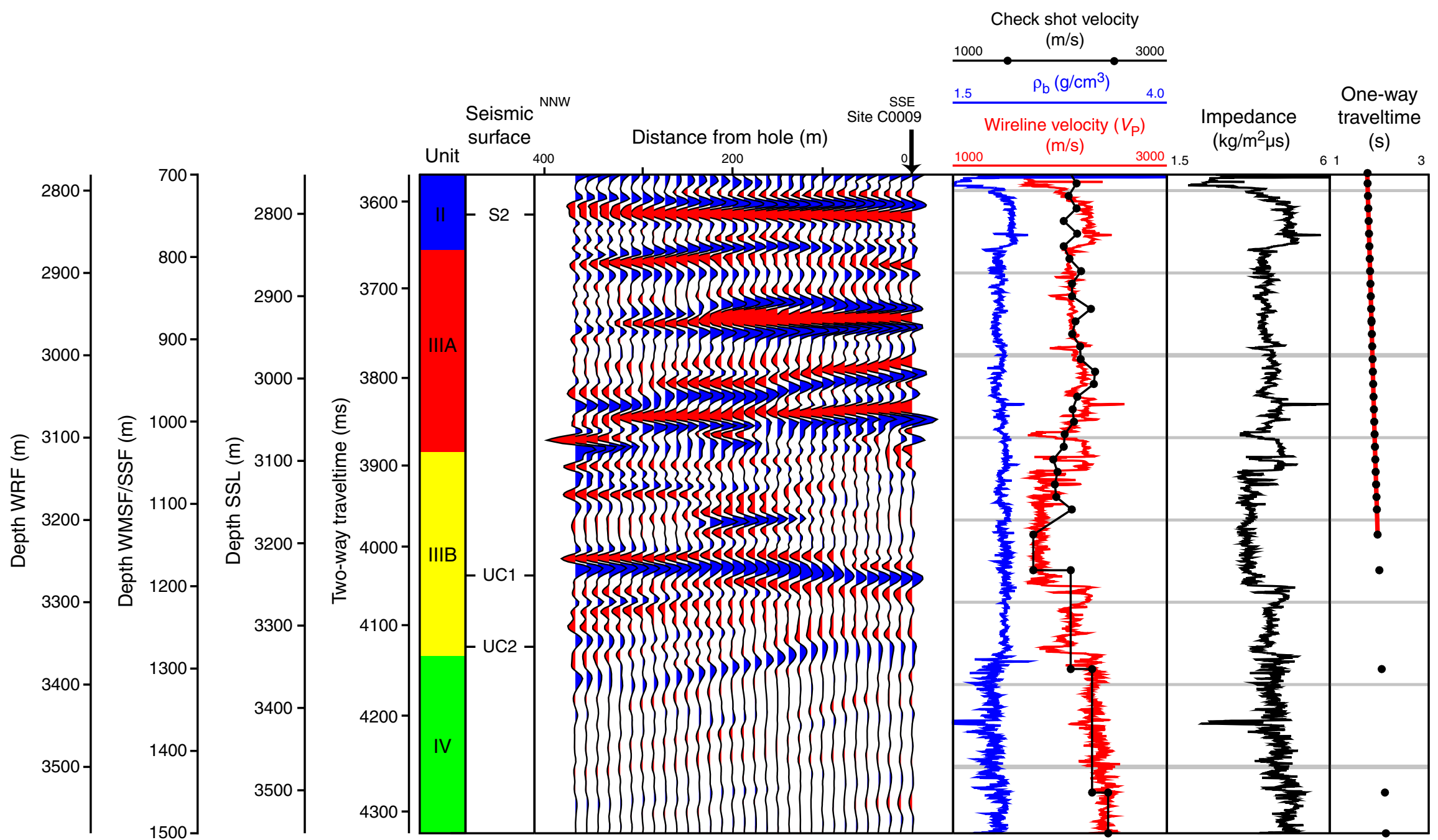


Figure F113. Seismic data correlated to well data from 690 to 840 m WMSF, Site C0009. Vertical arrow = Site C0009 location on seismic data. Two velocities are plotted to the right of the seismic data. Check shot velocity was used for time-depth correlation; this combines interval velocity taken from the check shot with average velocity taken from wireline sonic velocity $\left(V_{\mathrm{P}}\right)$. Impedance is the product of compressional velocity $\left(V_{\mathrm{P}}\right)$ and bulk density $\left(\rho_{\mathrm{b}}\right)$. Seismic Surface S2 lies $\sim 40 \mathrm{~m}$ above the Unit II/III boundary. SP $=$ spontaneous potential, PEF $=$ photoelectric effect.

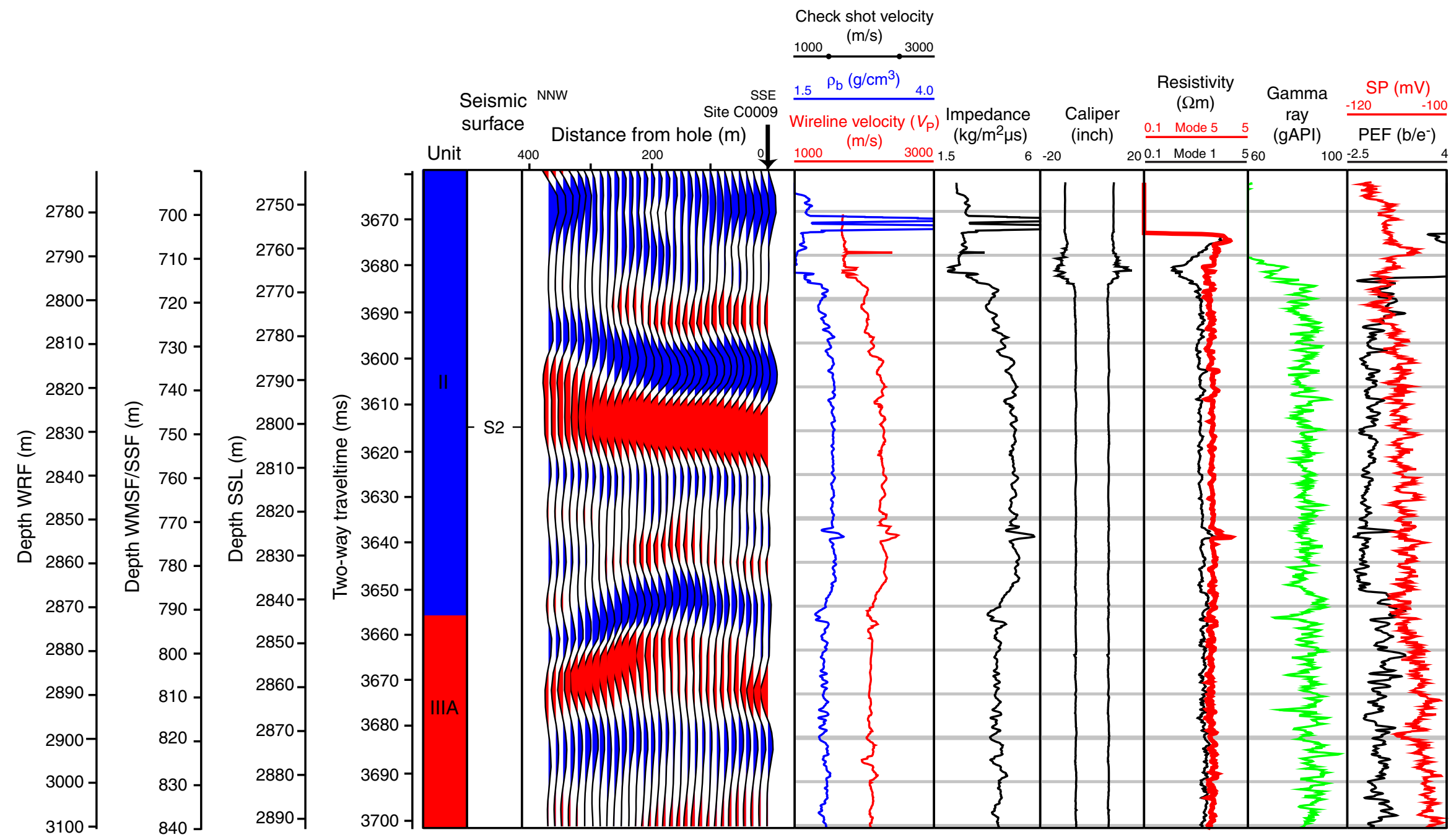


Figure F114. Seismic data correlated to well data from 700 to $1500 \mathrm{~m}$ WMSF, Site C0009. Vertical arrow = Site C0009 location on seismic data. Low wireline sonic velocity $\left(V_{\mathrm{p}}\right)$ is correlated to zones where cuttings had abundant wood fragments and elevated methane concentration from mud gas. Unit III/IV boundary is marked by an increase in clay fraction observed in cuttings from XRD and a decrease in spontaneous potential (SP). $\mathrm{R}=$ rare, $\mathrm{F}=$ few, $\mathrm{C}=$ common, $\mathrm{A}=$ abundant.

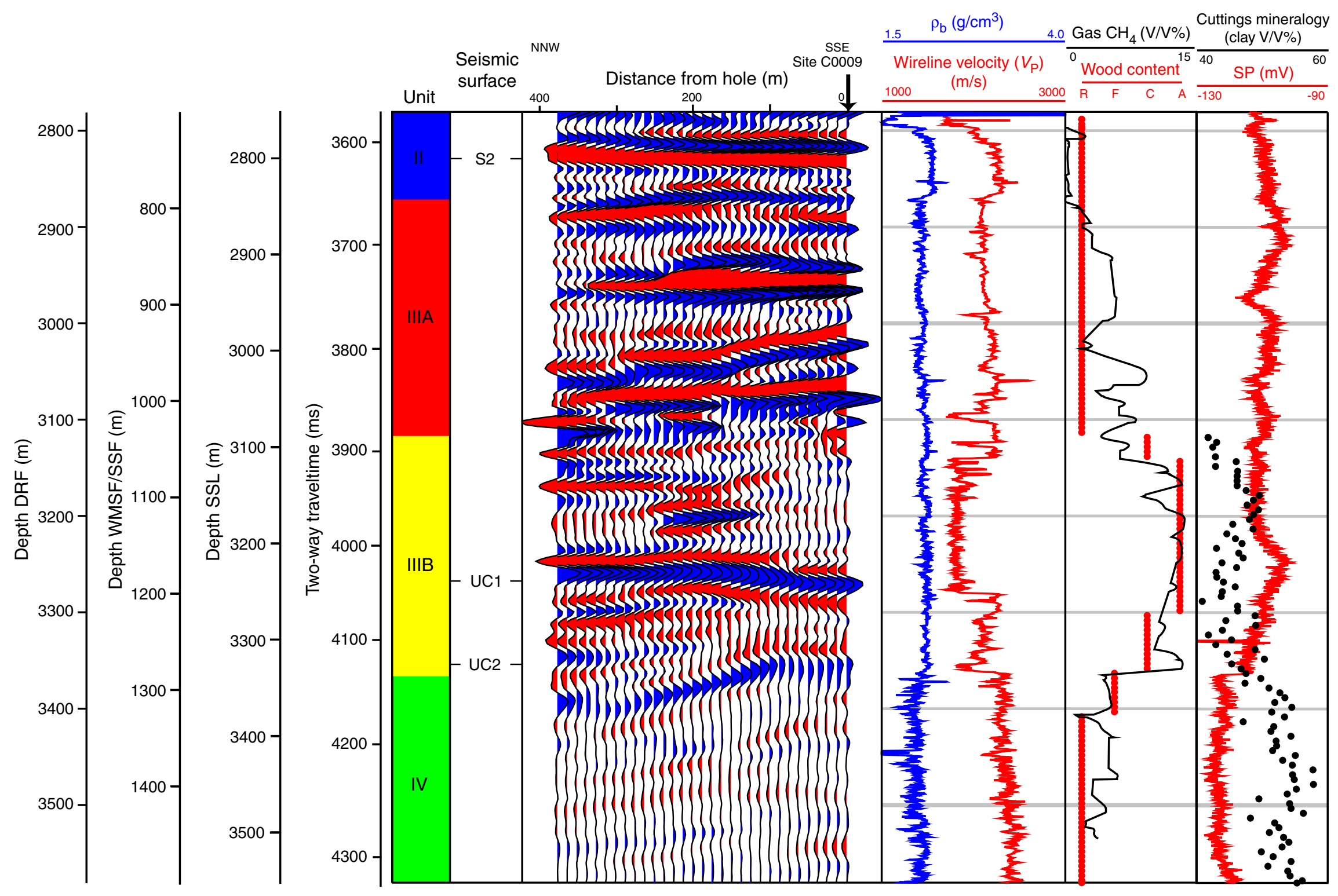


Figure F115. Seismic reflection profile in vicinity of Site C0009. Borehole position, unit boundaries, unconformities, and seismic surfaces are shown. $\mathrm{VE}=$ vertical exaggeration.

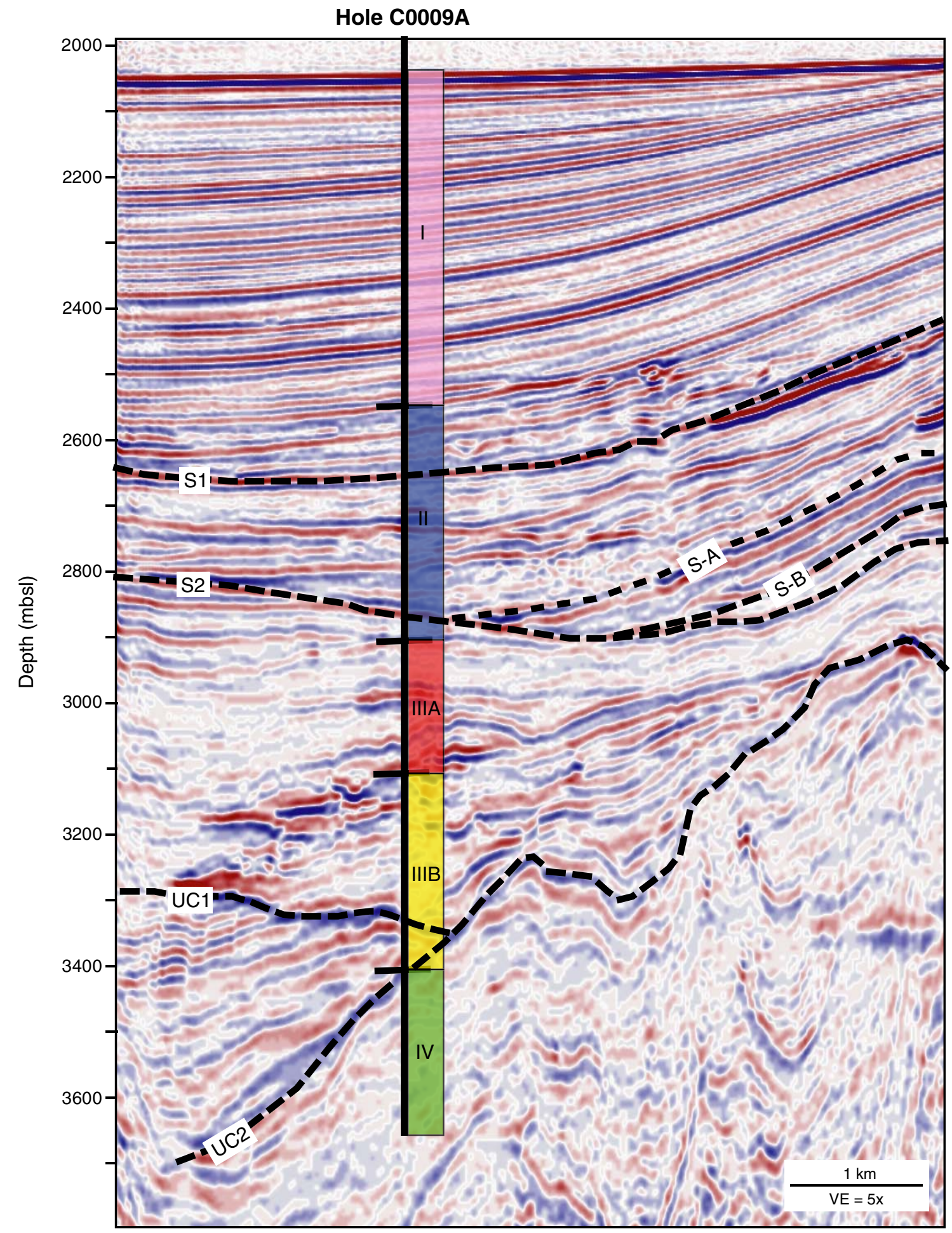


A

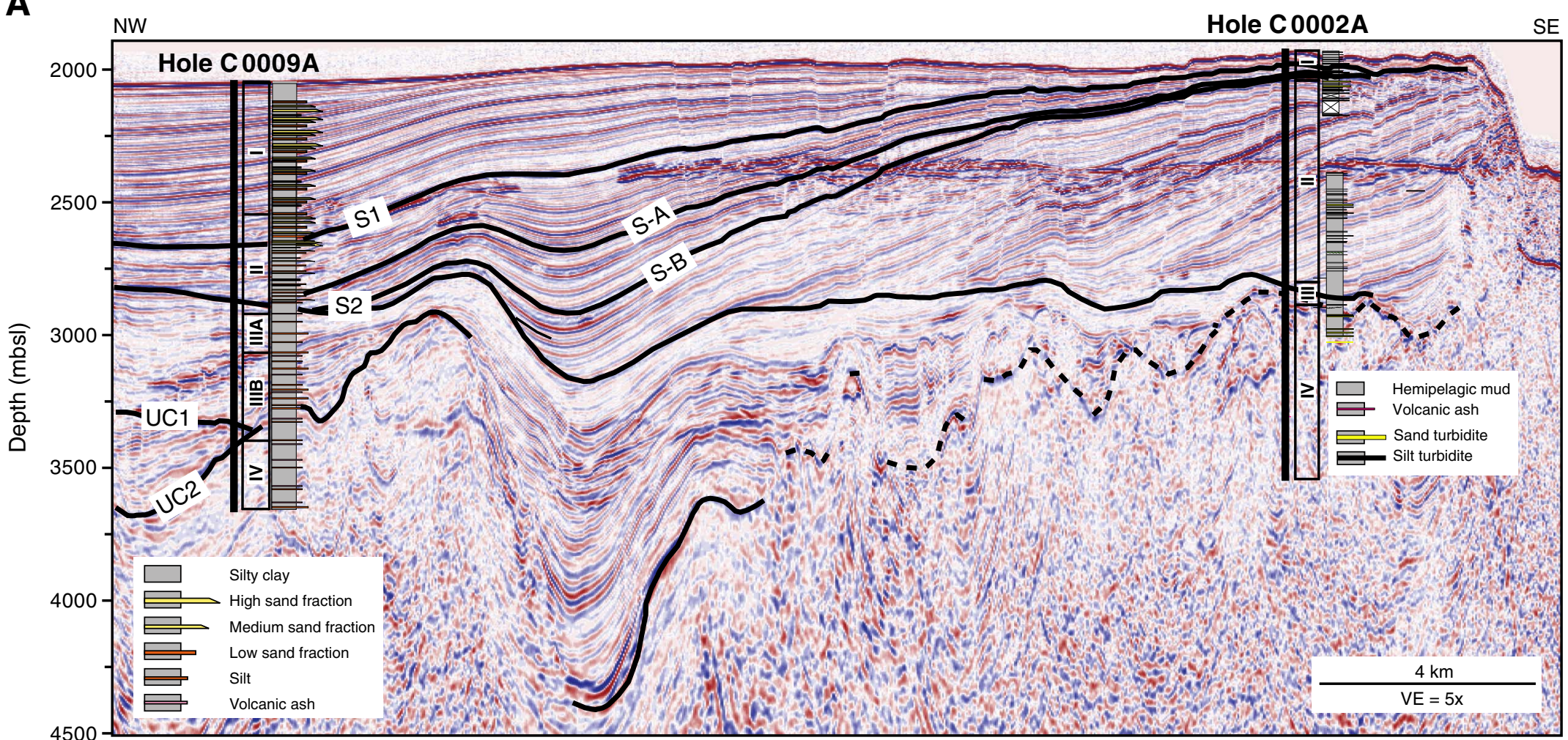


Figure F116 (continued). B. Line drawing of A. Geologic ages above and below seismic Surface S2 and Unconformity UC2 at both Sites C0009 and $\mathrm{C0002}$ are estimated. Inset at Site C0002 illustrates position of Unit III relative to Surface S2 and Unconformity UC2. We have overlain interpretation of age data acquired during Expedition 315 (Expedition 315 Scientists, 2009) to estimate age of material above and below Surface S2 and Unconformity UC2.

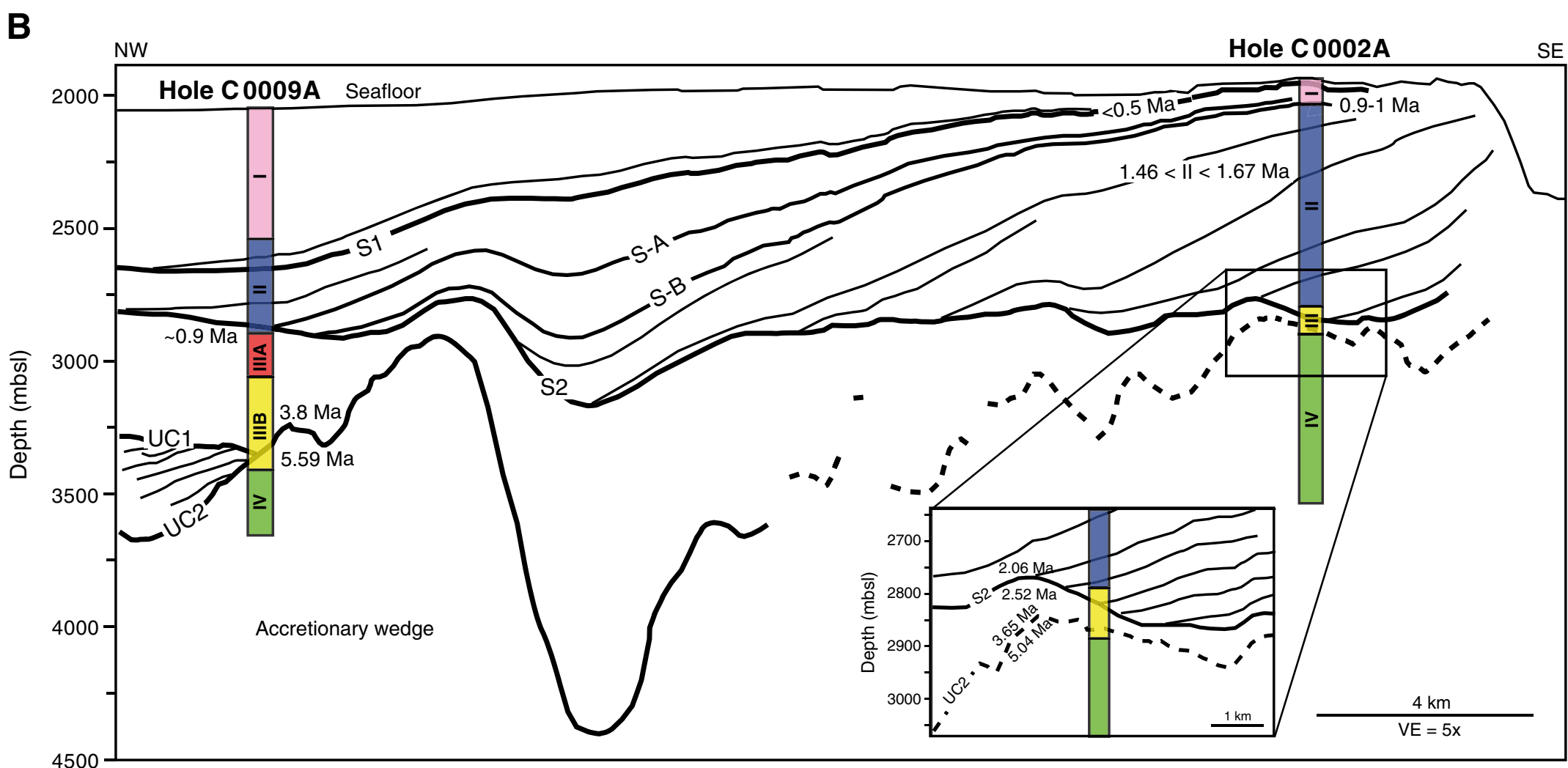


Figure F117. (A) Inclination and (B) intensity of magnetization for NRM (broken lines) and after AF demagnetization at $20 \mathrm{mT}$ (solid circles).

A

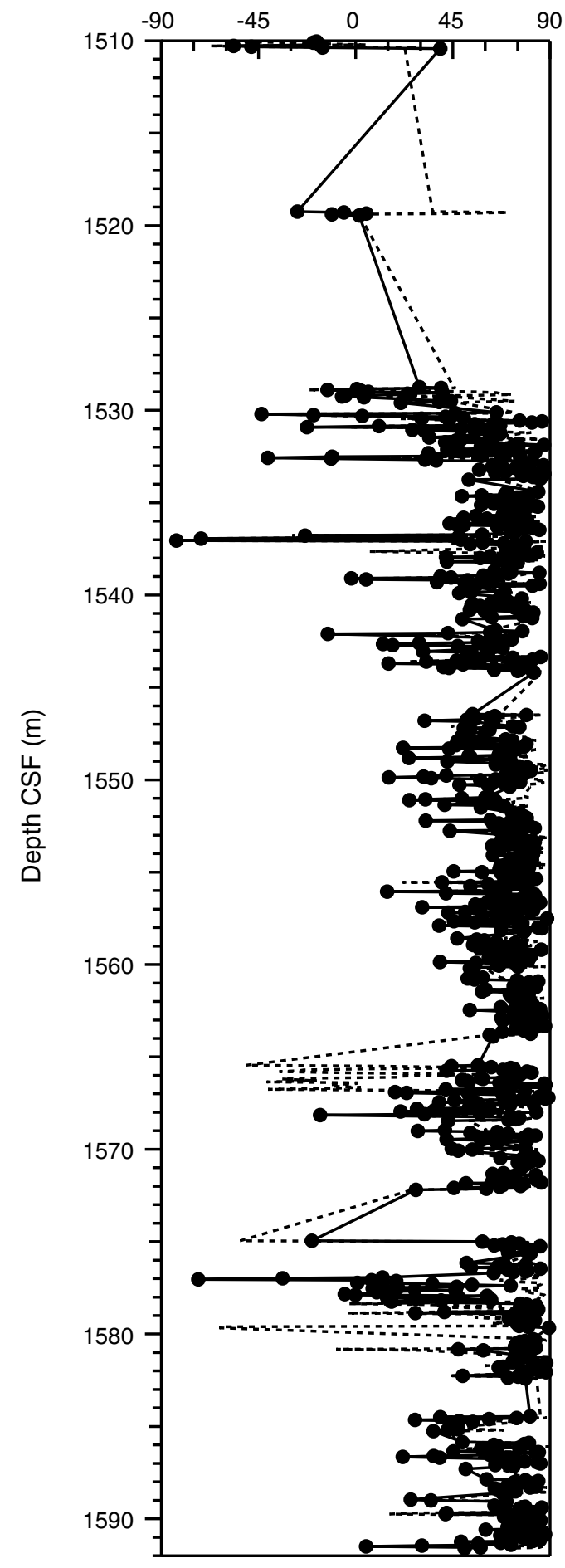

B

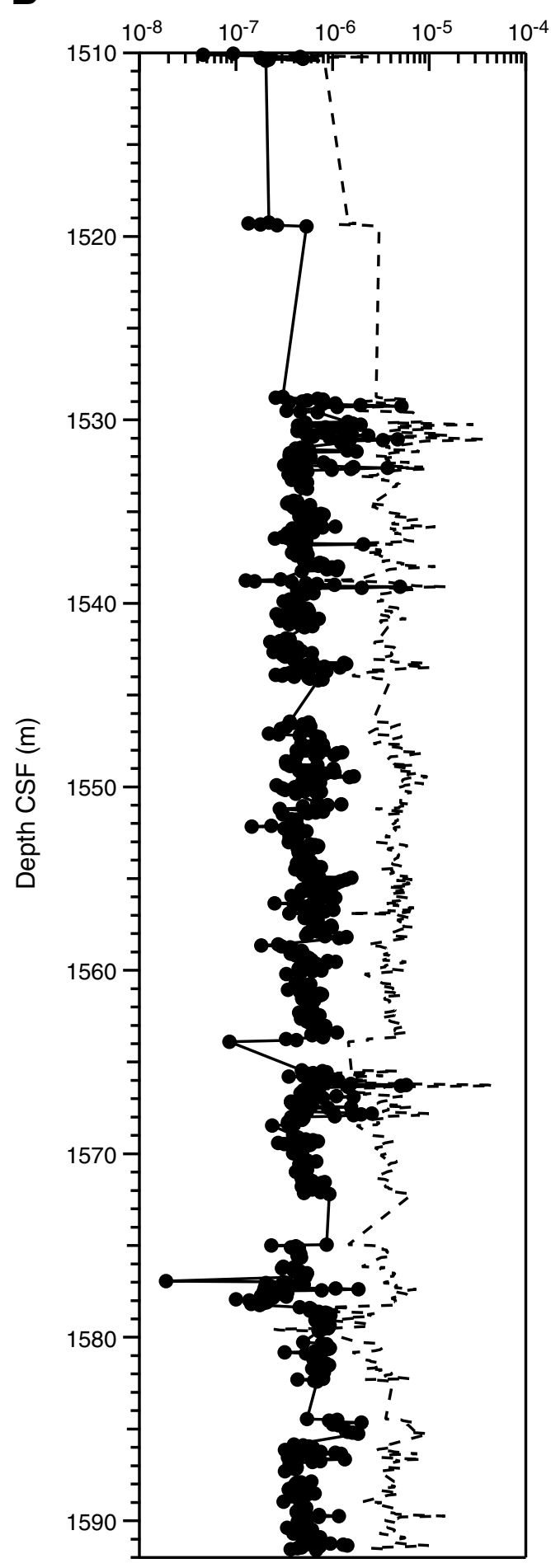


Figure F118. Histogram of inclination for (A) NRM and (B) $20 \mathrm{mT}$.

A

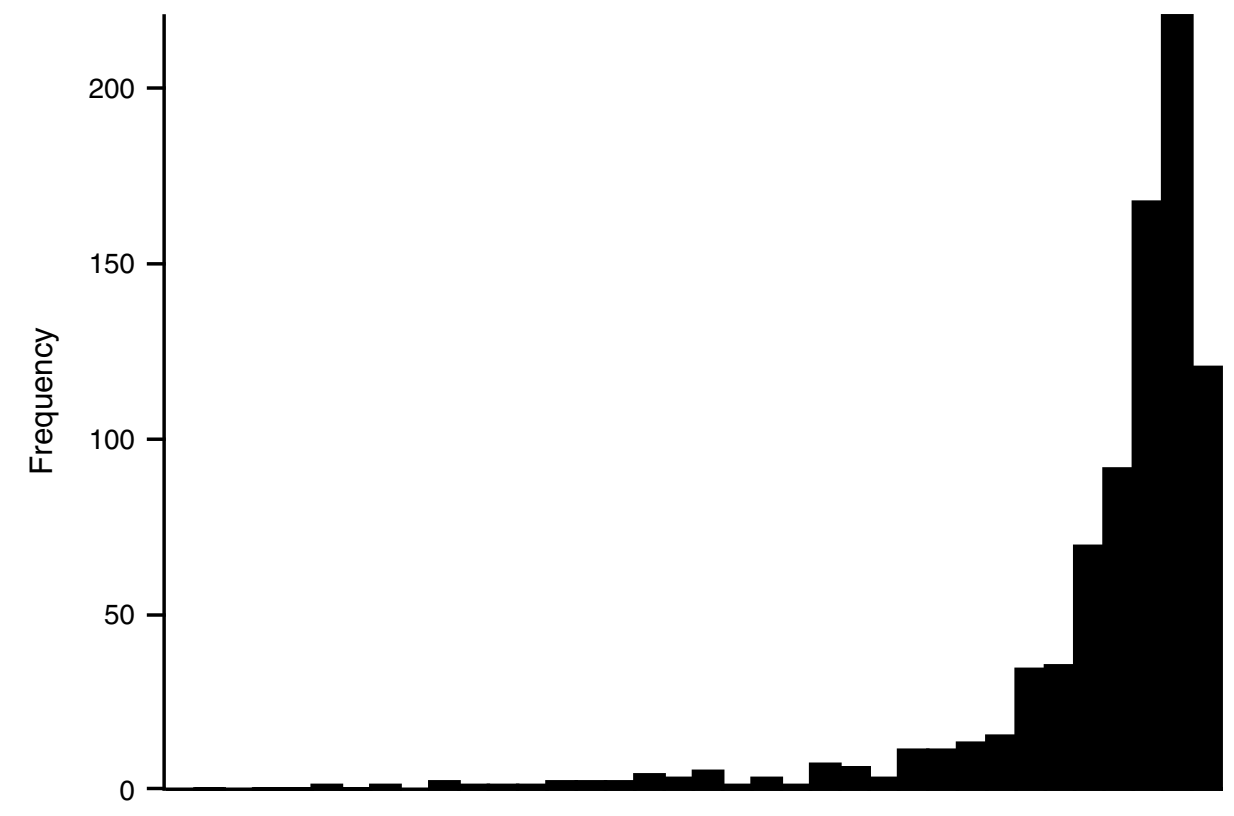

B

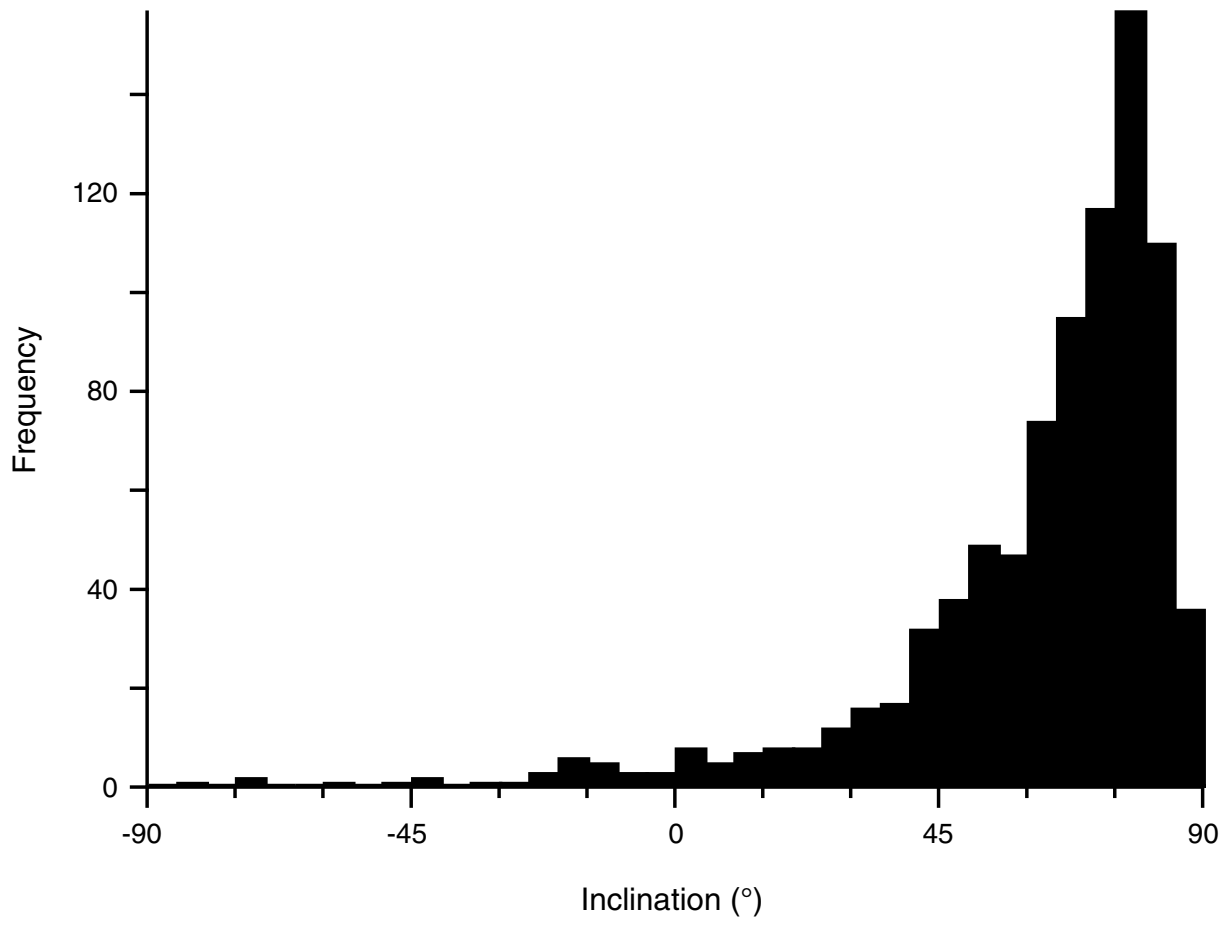


Table T1. Hole C0009A drilling operations. (See table notes.)

\begin{tabular}{|c|c|c|c|}
\hline $\begin{array}{l}\text { Hole C0009A } \\
\text { Latitude: } 33^{\circ} 27.4704^{\prime} \mathrm{N} \\
\text { Longitude: } 136^{\circ} 32.1489^{\prime} \mathrm{E} \\
\text { Water depth }(\mathrm{m}): 2054 \\
\text { Seafloor (m): } 2082.3 \mathrm{DRF} / 205 \\
20 \text { inch conductor pipe shoe ( } \\
\text { TD (m): } 3686 \text { DRF ( } 1603.7 \text { DS }\end{array}$ & $\begin{array}{l} \\
54 \mathrm{MSL} \\
(\mathrm{m}): 2786.2 \mathrm{DR} \\
\text { FF) }\end{array}$ & (703.9 DSF) & \\
\hline Operation & Drilling phase & Samples/data & Depth (mbrf) \\
\hline Riserless drilling & 1 & MWD & $2137-2795$ \\
\hline Riser drilling to $1510 \mathrm{~m}$ & 2 & $\begin{array}{l}\text { Cuttings: } 319-C 0009 A-1-S M W \text { to } 173-S M W \\
\text { Mud gas, MWD }\end{array}$ & $2798-3592$ \\
\hline Riser drilling and coring & 3 & $\begin{array}{l}\text { Core: } 319-\mathrm{C} 0009 \mathrm{~A}-1 \mathrm{R} \text { to } 9 \mathrm{R} \\
\text { Cuttings: } 319-\mathrm{C} 0009 \mathrm{~A}-176-\mathrm{SMW} \text { to } 193-\mathrm{SMW} \\
\text { Mud gas, MWD }\end{array}$ & $3592-3676.2$ \\
\hline Hole opening to $12-1 / 4$ inch & 4 & $\begin{array}{l}\text { Cuttings: } 319-C 0009 A-196-S M W \text { to } 215-S M W \\
\text { MWD }\end{array}$ & $3676-3686$ \\
\hline Wireline logging & 5 & EMS-HRLA-PEX-GR & $2773.4-3670.2$ \\
\hline Wireline logging & 6 & FMI-HNGC-Sonic Scanner-EMS-PPC & $2755.8-3662.2$ \\
\hline Wireline logging & 7 & MDT-GR & NA \\
\hline Hole opening to 17 inch & 8 & Mud gas, MWD & $2799-3650$ \\
\hline $\begin{array}{l}\text { Walkaway VSP and zero-offset } \\
\text { VSP }\end{array}$ & 9 & VSP & NA \\
\hline
\end{tabular}

Notes: $M W D=$ measurement while drilling, EMS = Environmental Measurement Sonde, HRLA = High Resolution Laterolog Array, GR $=$ gamma ray, PEX = Platform Express, FMI = Formation Microlmager, HNGC $=$ Hostile Natural Gamma Ray Spectrometry Cartridge, PPC $=$ Power Positioning Device and Caliper Tool, MDT = Modular Formation Dynamics Tester, VSP = vertical seismic profile. NA = not applicable. Depths are reported as uncorrected values, as either drillers depth or logging depth relative to the rig floor. For reference, water depth $=2054 \mathrm{~m}$ and datum at rotary table is $28.3 \mathrm{~m}$ above sea level. 
Table T2. Bottom-hole assembly, Hole C0009A riser drilling. (See table note.)

\begin{tabular}{|c|c|c|}
\hline BHA component & $\begin{array}{l}\text { Length } \\
\text { (m) }\end{array}$ & $\begin{array}{l}\text { Cumulative } \\
\text { length } \\
\text { (m) }\end{array}$ \\
\hline \multicolumn{3}{|l|}{ BHA component - 26 inch: } \\
\hline 26 inch bit & 0.55 & 0.55 \\
\hline A962M5640 XP & 9.17 & 9.72 \\
\hline Float sub (ported) & 0.88 & 10.60 \\
\hline ARC-8 & 7.43 & 18.03 \\
\hline PowerPulse HF w/I weight on bit & 8.50 & 26.53 \\
\hline $25-7 / 8$ inch stabilizer & 1.26 & 27.79 \\
\hline 8 inch nonmagnetic drilling collar & 9.35 & 37.14 \\
\hline 26 inch stabilizer & 1.57 & 38.71 \\
\hline $8-1 / 2$ inch drilling collar & 9.31 & 48.02 \\
\hline $8-1 / 2$ inch drilling collar & 9.31 & 57.33 \\
\hline $8-1 / 2$ inch drilling collar & 9.30 & 66.63 \\
\hline $8-1 / 2$ inch drilling collar & 9.30 & 75.93 \\
\hline $8-1 / 2$ inch drilling collar & 9.30 & 85.23 \\
\hline $8-1 / 2$ inch drilling collar & 9.30 & 94.53 \\
\hline $8-1 / 2$ inch drilling collar & 9.30 & 103.83 \\
\hline $8-1 / 2$ inch drilling collar & 9.30 & 113.13 \\
\hline Mechanical jar & 10.73 & 123.86 \\
\hline $8-1 / 2$ inch drilling collar & 9.31 & 133.17 \\
\hline $8-1 / 2$ inch drilling collar & 9.31 & 142.48 \\
\hline $8-1 / 2$ inch drilling collar & 9.31 & 151.79 \\
\hline $8-1 / 2$ inch drilling collar & 9.31 & 161.10 \\
\hline $8-1 / 2$ inch drilling collar & 9.31 & 170.41 \\
\hline Crossover sub & 0.79 & 171.20 \\
\hline $5-1 / 2$ inch drill pipe, premium & 10.00 & 181.20 \\
\hline \multicolumn{3}{|l|}{ BHA component - 12-1/4 inch: } \\
\hline $12-1 / 4$ inch bit & 0.28 & 0.28 \\
\hline PD 900 AA 12-1/4 inch & 4.20 & 4.47 \\
\hline 8 inch float sub & 0.80 & 5.27 \\
\hline 12 inch stabilizer & 1.99 & 7.25 \\
\hline 8 inch collar pony, nonmagnetic & 3.01 & 10.26 \\
\hline TeleScope 825 HF & 8.97 & 19.23 \\
\hline 8 inch collar NM & 9.35 & 28.58 \\
\hline $8-1 / 2$ inch drilling collar & 9.30 & 37.88 \\
\hline $8-1 / 2$ inch drilling collar & 9.30 & 47.18 \\
\hline $8-1 / 2$ inch drilling collar & 9.30 & 56.48 \\
\hline $8-1 / 2$ inch drilling collar & 9.30 & 65.78 \\
\hline $8-1 / 2$ inch drilling collar & 9.30 & 75.08 \\
\hline 7-3/4 inch drilling jar & 10.70 & 85.78 \\
\hline $8-1 / 2$ inch drilling collar & 9.30 & 95.08 \\
\hline $8-1 / 2$ inch drilling collar & 9.30 & 104.38 \\
\hline $8-1 / 2$ inch drilling collar & 9.30 & 113.68 \\
\hline $8-1 / 2$ inch drilling collar & 9.30 & 122.98 \\
\hline $8-1 / 2$ inch drilling collar & 9.30 & 132.28 \\
\hline Crossover sub & 0.79 & 133.07 \\
\hline $5-1 / 2$ inch drill pipe & 10.00 & 143.07 \\
\hline
\end{tabular}

Note: $\mathrm{BHA}=$ bottom-hole assembly. 
Table T3. Summary of mud weights used during drilling of Site C0009. (See table notes.)

\begin{tabular}{llcc}
\hline \multicolumn{1}{c}{ Operation } & \multicolumn{1}{c}{$\begin{array}{c}\text { Dates } \\
(2009)\end{array}$} & $\begin{array}{c}\text { Mud weight } \\
\left(\mathrm{g} / \mathrm{cm}^{3}\right)\end{array}$ & $\begin{array}{c}\text { Measured mud weight } \\
\text { or ECD }\left(\mathrm{g} / \mathrm{cm}^{3}\right)\end{array}$ \\
\hline Drilling 26 inch hole (riserless) & 19-29 May & 1.04 & $1.13-1.16^{*}$ \\
Drilling 12-1/4 inch hole (riser) & 27 June-2 July & 1.08 & NA \\
Drilling and coring 10-5/8 inch hole, opening hole to 12-1/4 inch (riser) $)$ & 3-6 July & 1.08 & NA \\
& 6-7 July & 1.09 & NA \\
& 8-11 July & 1.10 & NA \\
Wireline logging (Runs 1-2) & 12 July & 1.10 & NA \\
Wireline logging (Run 3 MDT) & $13-14$ July & 1.10 & 1.13 \\
Opening hole to 17 inches & $16-19$ July & 1.10 & NA \\
\hline
\end{tabular}

Notes: ${ }^{*}=$ equivalent circulating density (ECD) measured by APWD for 26 inch hole drilling. MDT = Modular Formation Dynamics Tester. NA = not available.

Table T4. Site C0009 coring intervals, times, depths, and recovered core amount and percentage.

\begin{tabular}{|c|c|c|c|c|c|c|c|c|}
\hline \multirow[b]{2}{*}{ Core } & \multicolumn{2}{|c|}{ Start coring } & \multicolumn{3}{|c|}{ Depth } & \multicolumn{2}{|c|}{ Length $(\mathrm{m})$} & \multirow[b]{2}{*}{$\begin{array}{l}\text { Recovery } \\
\text { (\%) }\end{array}$} \\
\hline & $\begin{array}{c}\text { Date } \\
\text { (June 2009) }\end{array}$ & $\begin{array}{l}\text { Local time } \\
\text { (h) }\end{array}$ & $\begin{array}{c}\text { Top } \\
\operatorname{CSF}(\mathrm{m})\end{array}$ & $\begin{array}{l}\text { Bottom } \\
\text { CSF (m) }\end{array}$ & $\begin{array}{l}\text { DSF } \\
(\mathrm{m})\end{array}$ & Cored & Recovered & \\
\hline \multicolumn{9}{|c|}{ 319-C009A- } \\
\hline $1 \mathrm{R}$ & 6 & 0425 & 1509.7 & 1519.2 & 1519.2 & 9.5 & 0.30 & 3.16 \\
\hline $2 \mathrm{R}$ & 7 & 1608 & 1519.2 & 1528.7 & 1528.7 & 9.5 & 2.10 & 22.11 \\
\hline $3 \mathrm{R}$ & 8 & 0835 & 1528.7 & 1536.9 & 1536.9 & 8.2 & 8.50 & 103.66 \\
\hline $4 \mathrm{R}$ & 8 & 2001 & 1536.9 & 1546.4 & 1546.4 & 9.5 & 7.30 & 76.84 \\
\hline $5 \mathrm{R}$ & 9 & 0005 & 1546.4 & 1555.9 & 1555.9 & 9.5 & 9.79 & 103.05 \\
\hline $6 \mathrm{R}$ & 9 & 0523 & 1555.9 & 1565.4 & 1565.4 & 9.5 & 7.70 & 81.05 \\
\hline $7 \mathrm{R}$ & 9 & 0936 & 1565.4 & 1574.9 & 1574.9 & 9.5 & 7.20 & 75.79 \\
\hline $8 \mathrm{R}$ & 9 & 1605 & 1574.9 & 1584.4 & 1584.4 & 9.5 & 7.50 & 78.95 \\
\hline $9 \mathrm{R}$ & 9 & 2000 & 1584.4 & 1593.9 & 1593.9 & 9.5 & 7.48 & 78.74 \\
\hline
\end{tabular}


Table T5. Walkaway VSP and zero-offset VSP operational details. (See table notes.)

\begin{tabular}{|c|c|c|}
\hline $\begin{array}{c}\text { Date } \\
\text { (July 2009) }\end{array}$ & $\begin{array}{l}\text { Local time } \\
\quad(h)\end{array}$ & Operation details \\
\hline 21 & 1843 & Synchronization test between Kairei and Chikyu. Kairei transmitted radio synchronization signals to Chikyu every $40 \mathrm{~s}$. \\
\hline 23 & & $\begin{array}{l}\text { Kairei deployed } 8 \text { OBSs: four at } 3.5 \mathrm{~km} \text { and four at } 0.5 \mathrm{~km} \text { distance from Hole C0009A. OBS recording started at } 1800 \mathrm{~h} \text { on } 23 \text { July } \\
\text { and stopped at } 0900 \mathrm{~h} \text { JST on } 1 \text { August. }\end{array}$ \\
\hline 24 & 1330 & Kairei deployed air gun array. Kairei tested signature of air gun waveform at $180 \mathrm{mbsl}$, and stand-by for Chikyu. \\
\hline 25 & 0500 & Start connection of VSI tools. 20 seismometers. \\
\hline 25 & 0730 & Lower tools and checked caliper. \\
\hline 25 & 1025 & Short circuit occurred in the VSI tool. Released arms and start pulling back at $1030 \mathrm{~h}$. \\
\hline 25 & 1647 & Changed the number of seismometers to 16. \\
\hline 25 & 2010 & Change anchoring depth to $2975.0 \mathrm{~m}$ DRF. All 16 seismometers anchored at $2017 \mathrm{~h}$. \\
\hline 25 & 2018 & First shot recorded for Line 1. File 008, Shot 12287. \\
\hline 26 & 0311 & Kairei $1 \mathrm{nmi}$ from Chikyu. Start to deviate from survey line (Shot 11915, File 376). \\
\hline 26 & 0327 & Kairei $1 \mathrm{nmi}$ from Chikyu. Resume to line. (Shot 11864, File 427). \\
\hline 26 & 0405 & Start circle shooting at $3.5 \mathrm{~km}$ from Hole C0009A. Shot on time at $30 \mathrm{~s}$ interval. \\
\hline 26 & 0632 & Finish circle shooting. \\
\hline 26 & 0713 & Restart Line 1 shooting. Shot 11845. \\
\hline 26 & 1100 & $\begin{array}{l}\text { Kairei shooting finished at } 29.3 \mathrm{~km} \text { from Chikyu. End of walkaway VSP survey. } \\
\text { Zero-offset VSP experiment. }\end{array}$ \\
\hline 26 & 1611 & Start zero-offset VSP. \\
\hline 26 & 1620 & $\begin{array}{l}\text { Discover that Seismometers } 9 \text { and } 10 \text { do not work. } \\
\text { Run zero-offset VSP with } 8 \text { seismometers. }\end{array}$ \\
\hline 26 & 1916 & POOH VSI tools. \\
\hline 27 & 0100 & Finish rig down. \\
\hline
\end{tabular}

Notes: VSP = vertical seismic profile, VSI = Vertical Seismic Imager. OBS - ocean-bottom seismometer. JST = Japan Standard Time. $\mathrm{POOH}=$ pull out of hole.

Table T6. Summary of depth references. (See table notes.)

\begin{tabular}{lrrrrrr}
\hline & \multicolumn{7}{c}{ Depth $(\mathrm{m})$} \\
\cline { 2 - 6 } \multicolumn{1}{c}{ Reference } & & & \multicolumn{5}{c}{ WRF } \\
\cline { 5 - 7 } & DRF & DSF & Run 1 & Run 2 & Run 3 & VSP \\
\hline Rig floor & 0.0 & - & 0.0 & 0.0 & 0.0 & 0.0 \\
Sea level & 28.3 & - & - & - & - & - \\
Seafloor & 2082.3 & 0.0 & - & - & - & - \\
36 inch casing shoe & 2136.8 & 54.5 & - & - & - & - \\
20 inch casing shoe & 2786.2 & 703.9 & 2785.0 & 2785.0 & - & - \\
Base of 26 inch hole & 2795.0 & 712.7 & 2793.7 & 2793.7 & - & 2793.7 \\
Base of 17 inch hole & 2798.0 & 715.7 & 2796.5 & 2796.5 & - & 2796.5 \\
\hline
\end{tabular}

Notes: DRF = drillers depth below rig floor, DSF $=$ drillers depth below seafloor, WRF $=$ wireline depth below rig floor. VSP $=$ vertical seismic profile. $-=$ not applicable.

Table T7. Orientation of elongated axis of borehole and $S_{\mathrm{Hmax}}$ determined from largest caliper value, Site C0009.

\begin{tabular}{ccccc}
\hline $\begin{array}{c}\text { Depth } \\
\text { WSF }(\mathrm{m})\end{array}$ & $\begin{array}{c}\text { Largest } \\
\text { caliper }\end{array}$ & $\begin{array}{c}\text { Average Pad 1 azimuth } \\
\text { on Caliper 1 } \\
\left({ }^{\circ}\right)\end{array}$ & $\begin{array}{c}\text { Orientation of } \\
\text { largest caliper } \\
\left({ }^{\circ}\right)\end{array}$ & $\begin{array}{c}\text { Orientation of } S_{\text {Hmax }} \\
\left({ }^{\circ}\right)\end{array}$ \\
\hline Interval A (1300-1455) & 2 & 313 & $43-223$ & $133-313$ \\
Interval B (1465-1530) & 1 & 230 & $50-230$ & $140-320$ \\
Interval C (1545-1578) & 2 & $\begin{array}{c}140 \\
\text { Weighted mean: }\end{array}$ & $\begin{array}{c}50-230 \\
46-226\end{array}$ \\
\hline
\end{tabular}

Table T8. Calcareous nannofossil range chart, Site C0009. This table is available in an oversized format. 
Table T9. Recognized nannofossil events and their depths, Site C0009. (See table notes.)

\begin{tabular}{|c|c|c|c|c|c|c|c|c|}
\hline \multirow[b]{2}{*}{$\begin{array}{l}\text { Zone } \\
\text { (base) }\end{array}$} & \multirow[b]{2}{*}{ Nannofossil event } & \multirow[b]{2}{*}{$\begin{array}{l}\text { Age } \\
(\mathrm{Ma})\end{array}$} & \multirow[b]{2}{*}{$\begin{array}{l}\text { Degree of } \\
\text { reliability }\end{array}$} & \multicolumn{2}{|l|}{ Event top } & \multicolumn{2}{|c|}{ Event bottom } & \multirow[b]{2}{*}{$\begin{array}{l}\text { Mean depth } \\
\text { MSF (m) }\end{array}$} \\
\hline & & & & Cuttings sample & $\begin{array}{c}\text { Bottom } \\
\text { depth } \\
\operatorname{MSF}(m)^{*}\end{array}$ & Cuttings sample & $\begin{array}{c}\text { Bottom } \\
\text { depth } \\
\operatorname{MSF}(m)^{*}\end{array}$ & \\
\hline \multirow{6}{*}{ NN20 } & & & & 319-C0009A- & & 319-C0009A- & & \\
\hline & LO Pseudoemiliania lacunosa & 0.436 & B & Above 2-SMW & $<712.7$ & Above 2-SMW & $<712.7$ & $<712.7$ \\
\hline & LCO Reticulofenestra asanoi & 0.905 & $\mathrm{~A}$ & 19-SMW & 777.7 & 21-SMW & 787.7 & 782.7 \\
\hline & LCO large Gephyrocapsa (>5.5 $\mu \mathrm{m})$ & 1.24 & B & 33-SMW & 842.7 & 35-SMW & 852.7 & 847.7 \\
\hline & LO Helicosphaera sellii & 1.34 & $\mathrm{D}$ & 44-SMW & 897.7 & 45-SMW & 902.7 & 900.2 \\
\hline & LO Calcidiscus macintyrei $(\geq 11 \mu \mathrm{m})$ & 1.60 & $\mathrm{D}$ & 45-SMW & 902.7 & 47-SMW & 912.7 & 907.7 \\
\hline NN19 & LO Discoaster brouweri & 2.06 & A & 51-SMW & 927.7 & 52-SMW & 932.7 & 930.2 \\
\hline NN18 & LO Discoaster pentaradiatus & 2.393 & A & 56-SMW & 952.7 & 57-SMW & 957.7 & 955.2 \\
\hline \multirow[t]{3}{*}{ NN17 } & LO Discoaster surculus & 2.52 & A & 61-SMW & 977.7 & 63-SMW & 987.7 & 982.7 \\
\hline & LO Discoaster tamalis & 2.87 & $A$ & 77-SMW & 1052.7 & 79-SMW & 1062.7 & 1057.7 \\
\hline & LO Sphenolithus spp. & 3.65 & $A$ & 115-SMW & 1232.7 & 117-SMW & 1242.7 & 1237.7 \\
\hline NN16 & LO Reticulofenestra pseudoumbilicus (>7 $\mu \mathrm{m})$ & 3.79 & A & 123-SMW & 1272.7 & 125-SMW & 1282.7 & 1277.7 \\
\hline \multirow[t]{3}{*}{ NN12 } & LO Discoaster quinqueramus & 5.59 & A & 125-SMW & 1282.7 & 127-SMW & 1292.7 & 1287.7 \\
\hline & PE Reticulofenestra pseudoumbilicus ( $>7 \mu \mathrm{m})$ & 7.077 & $\mathrm{C}$ & 167-SMW & 1482.7 & 169-SMW & 1492.7 & 1487.7 \\
\hline & FCO Discoaster surculus & 7.88 & $\mathrm{C}$ & Below base of section & & & & $>1603.2$ \\
\hline NN11 & FO Discoaster berggrenii & 8.52 & $\mathrm{D}$ & Below base of section & & & & $>1603.2$ \\
\hline
\end{tabular}

Notes: * $=$ Bottom depth is used for each cuttings sample representing a $5 \mathrm{~m}$ interval. $\mathrm{LO}=$ last occurrence, $\mathrm{LCO}=$ last consistent occurrence, RE $=$ reentrance, $\mathrm{PE}=$ paracme end, $\mathrm{FCO}=$ first consistent occurrence, $\mathrm{FO}=$ first occurrence. Degree of reliability: $\mathrm{A}=$ distinct, well defined, and based on LO; $\mathrm{B}=$ indistinct and less well defined but based on LO; $\mathrm{C}=$ distinct and well defined but based on FO; $\mathrm{D}=$ indistinct, poorly defined, and based on FO or incomplete range (modified from Raffi et al., 2006, to accommodate the status of stratigraphic occurrence in cuttings at Site C0009). 
Table T10. Carbon and nitrogen results from cuttings samples, Hole C0009A. (See table note.) (Continued on next page.)

\begin{tabular}{|c|c|c|c|c|c|c|}
\hline \multirow{2}{*}{$\begin{array}{l}\text { Cuttings } \\
\text { sample }\end{array}$} & \multicolumn{2}{|c|}{ Depth MSF (m) } & \multirow{2}{*}{$\begin{array}{c}\mathrm{TN} \\
(\mathrm{wt} \%)\end{array}$} & \multirow{2}{*}{$\begin{array}{c}\text { TOC } \\
\text { (wt\%) }\end{array}$} & \multirow{2}{*}{$\begin{array}{l}\mathrm{CaCO}_{3} \\
\text { (wt\%) }\end{array}$} & \multirow[b]{2}{*}{ TOC/TN } \\
\hline & Top & Bottom & & & & \\
\hline \multicolumn{7}{|l|}{ 319-C0009A- } \\
\hline 75-SMW & 1037.7 & 1042.7 & 0.062 & 1.47 & 15.13 & 23.7 \\
\hline 76-SMW & 1042.7 & 1047.7 & 0.057 & 1.53 & 14.47 & 26.7 \\
\hline 77-SMW & 1047.7 & 1052.7 & 0.062 & 1.70 & 14.59 & 27.4 \\
\hline 79-SMW & 1057.7 & 1062.7 & 0.070 & 2.58 & 14.57 & 37.0 \\
\hline 80-SMW & 1062.7 & 1067.7 & 0.077 & 2.74 & 15.05 & 35.8 \\
\hline 81-SMW & 1067.7 & 1072.7 & 0.075 & 2.46 & 14.50 & 32.7 \\
\hline 82-SMW & 1072.7 & 1077.7 & 0.075 & 2.68 & 14.53 & 35.8 \\
\hline 83-SMW & 1077.7 & 1082.7 & 0.106 & 6.04 & 13.40 & 57.2 \\
\hline 84-SMW & 1082.7 & 1087.7 & 0.095 & 3.84 & 13.90 & 40.3 \\
\hline 85-SMW & 1087.7 & 1092.7 & 0.117 & 8.69 & 12.39 & 74.5 \\
\hline 86-SMW & 1092.7 & 1097.7 & 0.114 & 6.01 & 13.51 & 52.8 \\
\hline 87-SMW & 1097.7 & 1102.7 & 0.084 & 3.43 & 12.65 & 40.8 \\
\hline 88-SMW & 1102.7 & 1107.7 & 0.075 & 3.04 & 12.22 & 40.7 \\
\hline 89-SMW & 1107.7 & 1112.7 & 0.085 & 3.03 & 14.10 & 35.4 \\
\hline 90-SMW & 1112.7 & 1117.7 & 0.094 & 3.34 & 13.67 & 35.7 \\
\hline 91-SMW & 1117.7 & 1122.7 & 0.096 & 3.84 & 13.35 & 40.0 \\
\hline 92-SMW & 1122.7 & 1127.7 & 0.086 & 2.83 & 13.78 & 32.7 \\
\hline 93-SMW & 1127.7 & 1132.7 & 0.098 & 4.01 & 13.33 & 40.8 \\
\hline 95-SMW & 1132.7 & 1137.7 & 0.091 & 3.45 & 13.47 & 38.2 \\
\hline 96-SMW & 1137.7 & 1142.7 & 0.097 & 3.86 & 14.46 & 39.7 \\
\hline 97-SMW & 1142.7 & 1147.7 & 0.108 & 4.56 & 14.80 & 42.3 \\
\hline 98-SMW & 1147.7 & 1152.7 & 0.096 & 3.60 & 15.63 & 37.3 \\
\hline 99-SMW & 1152.7 & 1157.7 & 0.101 & 4.32 & 15.03 & 43.0 \\
\hline 100-SMW & 1157.7 & 1162.7 & 0.107 & 5.24 & 14.88 & 48.9 \\
\hline 101-SMW & 1162.7 & 1167.7 & 0.112 & 5.90 & 15.92 & 52.5 \\
\hline 102-SMW & 1167.7 & 1172.7 & 0.097 & 5.51 & 15.05 & 56.7 \\
\hline 103-SMW & 1172.7 & 1177.7 & 0.113 & 6.51 & 15.66 & 57.8 \\
\hline 104-SMW & 1177.7 & 1182.7 & 0.103 & 6.19 & 14.12 & 60.3 \\
\hline 105-SMW & 1182.7 & 1187.7 & 0.128 & 8.70 & 14.97 & 67.9 \\
\hline 106-SMW & 1187.7 & 1192.7 & 0.128 & 8.36 & 14.64 & 65.4 \\
\hline 107-SMW & 1192.7 & 1197.7 & 0.092 & 4.49 & 16.31 & 48.7 \\
\hline 108-SMW & 1197.7 & 1202.7 & 0.112 & 6.79 & 14.79 & 60.4 \\
\hline 109-SMW & 1202.7 & 1207.7 & 0.108 & 6.05 & 15.95 & 56.0 \\
\hline 110-SMW & 1207.7 & 1212.7 & 0.095 & 4.10 & 15.51 & 43.1 \\
\hline 111-SMW & 1212.7 & 1217.7 & 0.097 & 4.60 & 16.09 & 47.6 \\
\hline 112-SMW & 1217.7 & 1222.7 & 0.088 & 4.01 & 16.22 & 45.7 \\
\hline 114-SMW & 1222.7 & 1227.7 & 0.094 & 3.88 & 15.69 & 41.3 \\
\hline 115-SMW & 1227.7 & 1232.7 & 0.090 & 4.25 & 15.75 & 47.2 \\
\hline 116-SMW & 1232.7 & 1237.7 & 0.091 & 4.16 & 14.38 & 45.6 \\
\hline 117-SMW & 1237.7 & 1242.7 & 0.090 & 3.07 & 14.17 & 34.0 \\
\hline 118-SMW & 1242.7 & 1247.7 & 0.090 & 3.89 & 14.59 & 43.2 \\
\hline 119-SMW & 1247.7 & 1252.7 & 0.079 & 2.65 & 14.91 & 33.6 \\
\hline 120-SMW & 1252.7 & 1257.7 & 0.079 & 2.34 & 14.19 & 29.7 \\
\hline 121-SMW & 1257.7 & 1262.7 & 0.076 & 1.89 & 13.53 & 24.9 \\
\hline 122-SMW & 1262.7 & 1267.7 & 0.080 & 1.95 & 13.31 & 24.4 \\
\hline 123-SMW & 1267.7 & 1272.7 & 0.079 & 1.88 & 13.11 & 23.6 \\
\hline 124-SMW & 1272.7 & 1277.7 & 0.078 & 1.95 & 12.85 & 25.0 \\
\hline 125-SMW & 1277.7 & 1282.7 & 0.083 & 1.82 & 13.12 & 22.0 \\
\hline 126-SMW & 1282.7 & 1287.7 & 0.080 & 1.67 & 12.28 & 20.9 \\
\hline 127-SMW & 1287.7 & 1292.7 & 0.069 & 1.44 & 12.29 & 20.8 \\
\hline 128-SMW & 1292.7 & 1297.7 & 0.076 & 1.43 & 12.16 & 18.9 \\
\hline 129-SMW & 1297.7 & 1302.7 & 0.075 & 1.48 & 12.54 & 19.8 \\
\hline 130-SMW & 1302.7 & 1307.7 & 0.071 & 1.45 & 12.69 & 20.4 \\
\hline 131-SMW & 1307.7 & 1312.7 & 0.073 & 1.43 & 12.39 & 19.5 \\
\hline 132-SMW & 1312.7 & 1317.7 & 0.065 & 1.24 & 13.56 & 19.1 \\
\hline 134-SMW & 1317.7 & 1322.7 & 0.071 & 1.40 & 13.96 & 19.6 \\
\hline 135-SMW & 1322.7 & 1327.7 & 0.070 & 1.19 & 14.90 & 17.1 \\
\hline 136-SMW & 1327.7 & 1332.7 & 0.066 & 1.49 & 13.17 & 22.5 \\
\hline 137-SMW & 1332.7 & 1337.7 & 0.051 & 1.36 & 11.26 & 26.5 \\
\hline 138-SMW & 1337.7 & 1342.7 & 0.068 & 1.11 & 12.25 & 16.3 \\
\hline 139-SMW & 1342.7 & 1347.7 & 0.069 & 1.31 & 13.72 & 19.1 \\
\hline 140-SMW & 1347.7 & 1352.7 & 0.069 & 1.25 & 12.99 & 18.1 \\
\hline 141-SMW & 1352.7 & 1357.7 & 0.069 & 1.10 & 13.58 & 16.1 \\
\hline 142-SMW & 1357.7 & 1362.7 & 0.070 & 1.16 & 13.30 & 16.6 \\
\hline 143-SMW & 1362.7 & 1367.7 & 0.071 & 1.18 & 12.28 & 16.6 \\
\hline 144-SMW & 1367.7 & 1372.7 & 0.071 & 1.12 & 11.54 & 15.7 \\
\hline
\end{tabular}


Table T10 (continued).

\begin{tabular}{|c|c|c|c|c|c|c|}
\hline \multirow{2}{*}{$\begin{array}{l}\text { Cuttings } \\
\text { sample }\end{array}$} & \multicolumn{2}{|c|}{ Depth MSF (m) } & \multirow{2}{*}{$\begin{array}{c}\mathrm{TN} \\
\text { (wt\%) }\end{array}$} & \multirow{2}{*}{$\begin{array}{c}\text { TOC } \\
\text { (wt\%) }\end{array}$} & \multirow{2}{*}{$\begin{array}{c}\mathrm{CaCO}_{3} \\
\text { (wt\%) }\end{array}$} & \multirow[b]{2}{*}{$\mathrm{TOC} / \mathrm{TN}$} \\
\hline & Top & Bottom & & & & \\
\hline 145-SMW & 1372.7 & 1377.7 & 0.072 & 1.17 & 11.60 & 16.2 \\
\hline 146-SMW & 1377.7 & 1382.7 & 0.066 & 1.07 & 11.37 & 16.3 \\
\hline 147-SMW & 1382.7 & 1387.7 & 0.065 & 1.05 & 11.28 & 16.2 \\
\hline 148-SMW & 1387.7 & 1392.7 & 0.064 & 1.00 & 11.45 & 15.7 \\
\hline 149-SMW & 1392.7 & 1397.7 & 0.066 & 1.02 & 11.52 & 15.4 \\
\hline 150-SMW & 1397.7 & 1402.7 & 0.060 & 1.06 & 11.88 & 17.6 \\
\hline 151-SMW & 1402.7 & 1407.7 & 0.061 & 0.97 & 12.77 & 15.8 \\
\hline 152-SMW & 1407.7 & 1412.7 & 0.064 & 0.98 & 13.46 & 15.4 \\
\hline 153-SMW & 1412.7 & 1417.7 & 0.064 & 1.02 & 13.70 & 15.9 \\
\hline 155-SMW & 1417.7 & 1422.7 & 0.063 & 1.01 & 13.77 & 16.0 \\
\hline 156-SMW & 1422.7 & 1427.7 & 0.065 & 1.01 & 14.09 & 15.5 \\
\hline 157-SMW & 1427.7 & 1432.7 & 0.064 & 1.03 & 14.16 & 16.0 \\
\hline 158-SMW & 1432.7 & 1437.7 & 0.063 & 1.04 & 14.09 & 16.5 \\
\hline 159-SMW & 1437.7 & 1442.7 & 0.073 & 1.06 & 14.36 & 14.4 \\
\hline 160-SMW & 1442.7 & 1447.7 & 0.071 & 0.98 & 14.85 & 13.8 \\
\hline 161-SMW & 1447.7 & 1452.7 & 0.057 & 0.99 & 14.91 & 17.4 \\
\hline 162-SMW & 1452.7 & 1457.7 & 0.059 & 0.98 & 15.12 & 16.6 \\
\hline 163-SMW & 1457.7 & 1462.7 & 0.059 & 0.93 & 15.17 & 15.7 \\
\hline 164-SMW & 1462.7 & 1467.7 & 0.059 & 0.94 & 15.15 & 16.0 \\
\hline 165-SMW & 1467.7 & 1472.7 & 0.058 & 0.95 & 15.02 & 16.6 \\
\hline 166-SMW & 1472.7 & 1477.7 & 0.058 & 0.96 & 14.56 & 16.6 \\
\hline 167-SMW & 1477.7 & 1482.7 & 0.057 & 1.00 & 13.56 & 17.5 \\
\hline 168-SMW & 1482.7 & 1487.7 & 0.058 & 1.04 & 12.62 & 18.0 \\
\hline 169-SMW & 1487.7 & 1492.7 & 0.061 & 1.08 & 13.10 & 17.6 \\
\hline 170-SMW & 1492.7 & 1497.7 & 0.065 & 1.20 & 12.56 & 18.6 \\
\hline 171-SMW & 1497.7 & 1502.7 & 0.065 & 1.15 & 12.23 & 17.7 \\
\hline 172-SMW & 1502.7 & 1507.7 & 0.067 & 1.33 & 11.60 & 19.9 \\
\hline 173-SMW & 1507.7 & 1509.7 & 0.067 & 1.22 & 11.58 & 18.0 \\
\hline 176-SMW & 1509.7 & 1512.7 & 0.068 & 2.19 & 11.86 & 32.3 \\
\hline 177-SMW & 1512.7 & 1517.7 & 0.068 & 1.80 & 12.49 & 26.3 \\
\hline 179-SMW & 1517.7 & 1522.7 & 0.072 & 1.87 & 12.25 & 26.2 \\
\hline 180-SMW & 1522.7 & 1527.7 & 0.069 & 1.86 & 12.24 & 26.8 \\
\hline 181-SMW & 1527.7 & 1532.7 & 0.069 & 2.06 & 11.47 & 29.9 \\
\hline 182-SMW & 1532.7 & 1537.7 & 0.068 & 1.87 & 11.50 & 27.6 \\
\hline 183-SMW & 1537.7 & 1542.7 & 0.067 & 2.02 & 11.29 & 30.1 \\
\hline 184-SMW & 1542.7 & 1547.7 & 0.068 & 2.00 & 10.88 & 29.4 \\
\hline 185-SMW & 1547.7 & 1552.7 & 0.068 & 1.88 & 10.77 & 27.8 \\
\hline 186-SMW & 1552.7 & 1557.7 & 0.066 & 1.90 & 10.88 & 28.7 \\
\hline 187-SMW & 1557.7 & 1562.7 & 0.066 & 1.86 & 10.68 & 28.1 \\
\hline 188-SMW & 1562.7 & 1567.7 & 0.069 & 2.01 & 9.91 & 29.0 \\
\hline 189-SMW & 1567.7 & 1572.7 & 0.067 & 1.75 & 9.97 & 26.0 \\
\hline 190-SMW & 1572.7 & 1577.7 & 0.068 & 1.86 & 8.80 & 27.3 \\
\hline 191-SMW & 1577.7 & 1582.7 & 0.065 & 1.93 & 8.88 & 29.6 \\
\hline 192-SMW & 1582.7 & 1587.7 & 0.065 & 1.85 & 8.18 & 28.5 \\
\hline 193-SMW & 1587.7 & 1592.7 & 0.065 & 1.85 & 7.56 & 28.5 \\
\hline
\end{tabular}

Note: $\mathrm{TN}=$ total nitrogen, $\mathrm{TOC}=$ total organic carbon. 
Table T11. Carbon and nitrogen results from core samples, Hole C0009A. (See table notes.)

\begin{tabular}{cccccr}
\hline $\begin{array}{c}\text { Core, } \\
\text { section }\end{array}$ & $\begin{array}{c}\text { Depth } \\
\text { CSF }(\mathrm{m})\end{array}$ & $\begin{array}{c}\mathrm{TN} \\
\text { (wt\%) }\end{array}$ & $\begin{array}{c}\text { TOC } \\
(\mathrm{wt} \%)\end{array}$ & $\begin{array}{r}\mathrm{CaCO}_{3} \\
(\mathrm{wt} \%)\end{array}$ & TOC/TN \\
\hline 319-C0009A- & & & & & \\
1R-1 & 1509.80 & 0.230 & 0.669 & 5.74 & - \\
2R-1 & 1519.35 & 0.103 & 0.649 & 9.01 & 6.3 \\
3R-1 & 1529.93 & 0.074 & 0.584 & 4.96 & 7.9 \\
3R-3 & 1531.89 & 0.096 & 0.818 & 7.84 & 8.5 \\
3R-5 & 1534.28 & 0.073 & 0.736 & 6.92 & 10.1 \\
3R-7 & 1536.65 & 0.101 & 0.564 & 7.67 & 5.6 \\
4R-2 & 1539.19 & 0.035 & 0.334 & 2.70 & 9.6 \\
4R-4 & 1540.25 & 0.050 & 0.394 & 3.36 & 7.9 \\
4R-6 & 1541.79 & 0.097 & 0.581 & 5.44 & 6.0 \\
4R-8 & 1543.90 & 0.044 & 0.604 & 4.40 & 13.7 \\
4R-CC & 1544.30 & 0.094 & 0.657 & 5.80 & 7.0 \\
5R-2 & 1548.68 & 0.069 & 0.478 & 7.57 & 7.0 \\
5R-3 & 1549.59 & 0.062 & 0.423 & 4.14 & 6.8 \\
5R-4 & 1550.78 & 0.089 & 0.576 & 6.38 & 6.5 \\
5R-6 & 1552.15 & 0.058 & 0.558 & 4.49 & 9.6 \\
5R-8 & 1554.90 & 0.082 & 0.476 & 6.44 & 5.8 \\
6R-1 & 1556.28 & 0.053 & 0.556 & 8.64 & 10.5 \\
6R-3 & 1558.20 & 0.082 & 0.553 & 4.98 & 6.7 \\
6R-5 & 1560.64 & 0.101 & 0.661 & 5.30 & 6.6 \\
6R-5 & 1561.08 & 0.090 & 0.898 & 6.32 & 9.9 \\
6R-6 & 1561.66 & 0.067 & 0.592 & 4.11 & 8.9 \\
6R-7 & 1563.68 & 0.103 & 0.860 & 6.29 & 8.3 \\
7R-2 & 1567.11 & 0.083 & 0.553 & 8.27 & 6.7 \\
7R-3 & 1568.88 & 0.068 & 0.518 & 4.93 & 7.6 \\
7R-4 & 1570.73 & 0.070 & 0.523 & 5.64 & 7.5 \\
7R-5 & 1571.35 & 0.059 & 0.606 & 5.38 & 10.3 \\
8R-1 & 1575.41 & 0.086 & 0.625 & 8.38 & 7.3 \\
8R-1 & 1576.08 & 0.086 & 0.637 & 8.99 & 7.4 \\
8R-4 & 1578.28 & 0.062 & 0.462 & 4.87 & 7.5 \\
8R-6 & 1580.78 & 0.078 & 0.254 & 1.03 & 3.3 \\
9R-1 & 1584.74 & 0.060 & 0.599 & 5.04 & 10.0 \\
9R-2 & 1587.20 & 0.077 & 0.693 & 5.51 & 9.0 \\
9R-4 & 1588.43 & 0.055 & 0.572 & 4.23 & 17.9 \\
9R-7 & 1591.48 & 0.045 & 0.807 & 4.94 & \\
\hline & & & & & \\
\hline
\end{tabular}

Notes: $\mathrm{TN}=$ total nitrogen, $\mathrm{TOC}=$ total inorganic carbon. Bold $=$ exceeds maximum standard concentration. $-=$ not applicable. 
Table T12. Interstitial water data from squeezing of whole-round core samples, Hole C0009A. (See table note.)

\begin{tabular}{lccccccccccc}
\hline $\begin{array}{c}\text { Core, section, } \\
\text { interval (cm) }\end{array}$ & $\begin{array}{c}\text { Depth CSF } \\
(\mathrm{m})\end{array}$ & $\begin{array}{c}\text { Squeezing } \\
\text { time }(\mathrm{h})\end{array}$ & $\begin{array}{c}\text { Refractive } \\
\text { index }\end{array}$ & $\begin{array}{c}\mathrm{Chlorinity} \\
(\mathrm{mM})\end{array}$ & $\begin{array}{c}\mathrm{Br} \\
(\mathrm{mM})\end{array}$ & $\begin{array}{c}\mathrm{SO}_{4}^{2-} \\
(\mathrm{mM})\end{array}$ & $\begin{array}{c}\mathrm{Na}^{+} \\
(\mathrm{mM})\end{array}$ & $\begin{array}{c}\mathrm{K}^{+} \\
(\mathrm{mM})\end{array}$ & $\begin{array}{c}\mathrm{Mg}^{2+} \\
(\mathrm{mM})\end{array}$ & $\begin{array}{c}\mathrm{Ca}^{2+} \\
(\mathrm{mM})\end{array}$ & $\begin{array}{c}\mathrm{Li}^{+} \\
(\mu \mathrm{M})\end{array}$ \\
\hline Seawater & & BDL & 1.33946 & 560 & 0.86 & 28.9 & 480 & 10.4 & 54.0 & 10.6 & 26 \\
319-C0009A- & & & & & & & & & & & \\
4R-6, 0-40 & 1536.9 & 23 & 1.34200 & 870 & 1.61 & 0.39 & 722 & 50.1 & 12.5 & 38.9 & $\mathbf{2 4 1 9}$ \\
5R-4, 0-40 & 1546.4 & 12 & 1.34272 & 953 & 1.52 & 0.33 & 790 & 51.6 & 11.7 & 46.2 & $\mathbf{2 5 7 4}$ \\
6R-5, 53-93 & 1559.9 & 17 & 1.34391 & 1052 & 1.61 & 0.38 & 870 & 88.2 & 13.3 & 50.7 & $\mathbf{2 5 6 0}$ \\
7R-3, 26-66 & 1565.4 & 12 & 1.34358 & 1032 & 1.56 & 0.32 & 825 & 83.7 & 13.0 & 49.3 & $\mathbf{2 6 7 3}$ \\
8R-1, 84-117.5 & 1574.9 & 54 & 1.34104 & 776 & 1.45 & 0.28 & 675 & 26.3 & 9.9 & 39.4 & $\mathbf{2 5 6 6}$ \\
9R-3, 0-40 & 1584.4 & 9 & 1.34382 & 1053 & 1.66 & 0.37 & 847 & 99.4 & 14.2 & 53.7 & $\mathbf{2 7 2 7}$ \\
\hline
\end{tabular}

Note: $\mathrm{BDL}=$ below detection limit, bold = exceeds maximum standard concentration, $\mathrm{NA}=$ not analyzed.

\begin{tabular}{|c|c|c|c|c|c|c|c|c|c|c|c|c|c|c|}
\hline $\begin{array}{l}\text { Core, section, } \\
\text { interval }(\mathrm{cm})\end{array}$ & $\begin{array}{c}\text { B } \\
(\mu \mathrm{M})\end{array}$ & $\begin{array}{c}\mathrm{Mn} \\
(\mu \mathrm{M})\end{array}$ & $\begin{array}{c}\mathrm{Fe} \\
(\mu \mathrm{M})\end{array}$ & $\begin{array}{c}\mathrm{Si} \\
(\mu \mathrm{M})\end{array}$ & $\begin{array}{c}\mathrm{Sr} \\
(\mu \mathrm{M})\end{array}$ & $\begin{array}{c}\mathrm{Ba} \\
(\mu \mathrm{M})\end{array}$ & $\begin{array}{c}V \\
(n M)\end{array}$ & $\begin{array}{c}\mathrm{Cu} \\
(\mathrm{nM})\end{array}$ & $\begin{array}{c}\mathrm{Zn} \\
(\mathrm{nM})\end{array}$ & $\begin{array}{c}\mathrm{Rb} \\
(\mathrm{nM})\end{array}$ & $\begin{array}{l}\text { Mo } \\
(n M)\end{array}$ & $\begin{array}{c}\mathrm{Cs} \\
(\mathrm{nM})\end{array}$ & $\begin{array}{c}\mathrm{Pb} \\
(\mathrm{nM})\end{array}$ & $\underset{(n M)}{U}$ \\
\hline Seawater & 480 & 0 & 0 & 150 & 87 & 0 & 33 & & 90 & 1160 & 98 & 1.8 & 0 & 13.0 \\
\hline \multicolumn{15}{|l|}{ 319-C0009A- } \\
\hline $4 \mathrm{R}-6,0-40$ & 55 & 2.9 & BDL & 335 & 404 & 653 & 48 & NA & 2199 & 3589 & 1606 & 14 & BDL & 4.3 \\
\hline $5 R-4,0-40$ & 27 & 2.3 & BDL & 181 & 463 & 793 & 53 & NA & 2240 & 3674 & 1371 & 15 & BDL & 8.5 \\
\hline $6 \mathrm{R}-5,53-93$ & 45 & 3.4 & BDL & 255 & 450 & 710 & 58 & NA & 3143 & 5144 & 1899 & 24 & BDL & 8.2 \\
\hline 7R-3, 26-66 & 36 & 1.9 & BDL & 151 & 460 & 789 & 58 & NA & 1698 & 4866 & 1356 & 21 & BDL & 3.4 \\
\hline 8R-1, 84-117.5 & 36 & 2.2 & BDL & 213 & 350 & 560 & 47 & NA & 2472 & 2697 & 3001 & 12 & BDL & 1.4 \\
\hline 9R-3, 0-40 & 58 & 2.3 & BDL & 170 & 423 & 622 & 63 & NA & 1476 & 4992 & 1487 & 23 & BDL & 3.9 \\
\hline
\end{tabular}


Table T13. Parameters used for the computation of gas saturation from $P$-wave and $S$-wave velocities.

\begin{tabular}{llc}
\hline Quantity & \multicolumn{1}{c}{ Description } & Value \\
\hline $1 / V_{\mathrm{p}}$ & $P$-wave slowness for matrix $(\mu$ s/ft) & 60 \\
$V_{\mathrm{p}} / V_{\mathrm{S}}$ & Ratio of $P$-wave velocity to $S$-wave velocity of matrix & 1.8 \\
$\mathrm{C}$ & Coefficient of Brie equation (Equation 3) & 8 \\
$K_{\mathrm{w}}$ & Water bulk modulus $(\mathrm{GPa})$ & 2.2 \\
$K_{\mathrm{g}}$ & Gas bulk modulus $(\mathrm{MPa})$ & 30 \\
\hline
\end{tabular}

Table T14. Summary of MDT deployments performed, Site C0009. (See table notes.)

\begin{tabular}{lcrrlll}
\hline & & \multicolumn{2}{c}{ Depth $(\mathrm{m})$} & & \\
\cline { 3 - 4 } Event \# & File name & WRF & WMSF & & Measurement & \multicolumn{1}{c}{ Description } \\
\hline 1 & MDT_059 & 2811.0 & 729.9 & & Single probe pressure test & Good seal, high mobility \\
2 & MDT_060 & 2958.0 & 876.9 & & Single probe pressure test & Bad seal \\
3 & MDT_061 & 2959.0 & 877.9 & & Single probe pressure test & Good seal, low mobility \\
4 & MDT_065 & 3256.1 & 1174.9 & & Single probe pressure test & Good seal, high mobility \\
5 & MDT_067 & 3417.0 & 1335.9 & & Single probe pressure test & Bad seal \\
7 & MDT_073 & 3622.0 & 1540.9 & & Drawdown mobility test & Dual packer drawdown \\
8 & MDT_074 & 3615.0 & 1533.9 & & Hydraulic fracture test & Dual packer hydraulic fracture \\
9 & MDT_074 & 3613.0 & 1531.9 & & Single probe pressure test & Bad seal \\
10 & MDT_075 & 3546.0 & 1464.9 & & Single probe pressure test & Good seal, low mobility \\
11 & MDT_078 & 3300.0 & 1218.9 & & Single probe pressure test & Good seal, low mobility \\
12 & MDT_080 & 2956.0 & 874.9 & & Single probe pressure test & Good seal, low mobility \\
13 & MDT_080 & 2958.0 & 876.9 & & Hydraulic fracture test & Dual packer hydraulic fracture \\
\hline
\end{tabular}

Notes: Data for each of these deployments is in C0009_T1.XLS in DOWNHOLE in "Supplementary material." WRF = wireline depth below rig floor, WMSF = wireline log matched depth below seafloor.

Table T15. Summary of MDT single probe test measurements, Site C0009. (See table notes.)

\begin{tabular}{|c|c|c|c|c|c|c|c|c|}
\hline \multirow[b]{2}{*}{ File name } & \multicolumn{2}{|c|}{ Depth $(m)$} & \multicolumn{2}{|c|}{ Mud pressure (MPa) } & \multirow{2}{*}{$\begin{array}{l}\text { Last build-up } \\
\text { pressure } \\
(\mathrm{MPa})\end{array}$} & \multirow{2}{*}{$\begin{array}{l}\text { Hydrostatic } \\
\text { pressure } \\
\text { (MPa) }\end{array}$} & \multirow{2}{*}{$\begin{array}{c}\text { Drawdown } \\
\text { mobility } \\
\left(\mathrm{m}^{2} / \mathrm{cp}\right)\end{array}$} & \multirow[b]{2}{*}{ Description } \\
\hline & WRF & WMSF & Before test & After test & & & & \\
\hline MDT_059LTP & 2811.0 & 729.9 & 31.2 & 31.2 & 28.3 & 27.9 & $4.2 \times 10^{-14}$ & Good seal, high mobility \\
\hline MDT_060LTP & 2958.0 & 876.9 & 32.8 & 32.8 & 30.1 & 29.4 & $1.4 \times 10^{-16}$ & Bad seal \\
\hline MDT_061LTP & 2959.0 & 877.9 & 32.8 & 32.8 & 31.0 & 29.4 & $3.0 \times 10^{-16}$ & Good seal, low mobility \\
\hline MDT_065LTP & 3256.1 & 1175.0 & 36.1 & 36.1 & 32.8 & 32.4 & $2.4 \times 10^{-14}$ & Good seal, high mobility \\
\hline MDT_067LTP & 3417.0 & 1335.9 & 37.9 & 37.9 & 34.4 & 34.0 & $3.0 \times 10^{-16}$ & Bad seal \\
\hline MDT_074LTP & 3613.0 & 1531.9 & 40.0 & 40.0 & 32.4 & 35.9 & $7.8 \times 10^{-16}$ & Bad seal \\
\hline MDT_075LTP & 3546.0 & 1464.9 & 39.3 & 39.3 & 35.7 & 35.3 & $9.9 \times 10^{-17}$ & Good seal, low mobility \\
\hline MDT_078LTP & 3300.0 & 1218.9 & 36.6 & 36.6 & 33.3 & 32.8 & $6.9 \times 10^{-16}$ & Good seal, low mobility \\
\hline MDT_080LTP & 2956.0 & 874.9 & 32.8 & 32.8 & 30.8 & 29.4 & $1.2 \times 10^{-15}$ & Good seal, low mobility \\
\hline
\end{tabular}

Notes: Hydrostatic pressure was calculated by assuming both seawater density and pore fluid density of $1023 \mathrm{~kg} / \mathrm{m}^{3}$. WRF $=$ wireline depth below rig floor, WMSF = wireline log matched depth below seafloor. $10^{-15} \mathrm{~m}^{2} / \mathrm{cp}=1 \mathrm{md} / \mathrm{cp}$. 
Table T16. Event summary for all MDT deployments.(See table notes.) (Continued on next page.)

\begin{tabular}{|c|c|c|}
\hline Test & $\begin{array}{l}\text { Elapsed } \\
\text { time (s) }\end{array}$ & Event \\
\hline \multirow[t]{5}{*}{ MDT_059 } & 45.0 & Probe set @ 2,811.0 m single probe module (MRPS) 1 \\
\hline & 114.3 & Vert pretest $5.0 \mathrm{~cm}^{3} @ 60 \mathrm{~cm}^{3} / \mathrm{m}$ single probe module (MRPS) 1 \\
\hline & 198.0 & Vert pretest $4.8 \mathrm{~cm}^{3} @ 60 \mathrm{~cm}^{3} / \mathrm{m}$ single probe module (MRPS) 1 \\
\hline & 290.7 & Vert pretest $9.9 \mathrm{~cm}^{3} @ 60 \mathrm{~cm}^{3} / \mathrm{m}$ single probe module (MRPS) 1 \\
\hline & 496.5 & Retract single probe module (MRPS) 1 \\
\hline \multirow[t]{4}{*}{ MDT_061 } & 93.0 & Probe set @ 2,959.0 m single probe module (MRPS) 1 \\
\hline & 189.3 & Vert pretest $5.0 \mathrm{~cm}^{3} @ 40 \mathrm{~cm}^{3} / \mathrm{m}$ single probe module (MRPS) 1 \\
\hline & 234.6 & Vert pretest $4.8 \mathrm{~cm}^{3} @ 30 \mathrm{~cm}^{3} / \mathrm{m}$ single probe module (MRPS) 1 \\
\hline & 442.5 & Retract single probe module (MRPS) 1 \\
\hline \multirow[t]{5}{*}{ MDT_065 } & 49.2 & Probe set @ 3,256.1 m single probe module (MRPS) 1 \\
\hline & 113.7 & Vert pretest $4.9 \mathrm{~cm}^{3} @ 40 \mathrm{~cm}^{3} / \mathrm{m}$ single probe module (MRPS) 1 \\
\hline & 186.0 & Vert pretest $9.8 \mathrm{~cm}^{3} @ 60 \mathrm{~cm}^{3} / \mathrm{m}$ single probe module (MRPS) 1 \\
\hline & 357.3 & Vert pretest $5.0 \mathrm{~cm}^{3} @ 80 \mathrm{~cm}^{3} / \mathrm{m}$ single probe module (MRPS) 1 \\
\hline & 511.8 & Retracted single probe module (MRPS) 1 \\
\hline \multirow[t]{6}{*}{ MDT_067 } & 40.5 & Probe set @ 3,417.0 m single probe module (MRPS) 1 \\
\hline & 102.0 & Auto reset single probe module (MRPS) 1 \\
\hline & 121.2 & Vert pretest $4.9 \mathrm{~cm}^{3} @ 40 \mathrm{~cm}^{3} / \mathrm{m}$ single probe module (MRPS) 1 \\
\hline & 189.9 & Auto reset single probe module (MRPS) 1 \\
\hline & 274.2 & Vert pretest $4.8 \mathrm{~cm}^{3} @ 30 \mathrm{~cm}^{3} / \mathrm{m}$ single probe module (MRPS) 1 \\
\hline & 407.4 & Retract single probe module (MRPS) 1 \\
\hline \multirow[t]{5}{*}{ MDT_075 } & 45.6 & Probe set @ 3,546.0 m single probe module (MRPS) 1 \\
\hline & 122.1 & Vert pretest $4.9 \mathrm{~cm}^{3} @ 50 \mathrm{~cm}^{3} / \mathrm{m}$ single probe module (MRPS) 1 \\
\hline & 338.7 & Auto reset single probe module (MRPS) 1 \\
\hline & 472.5 & Vert pretest $4.9 \mathrm{~cm}^{3} @ 30 \mathrm{~cm}^{3} / \mathrm{m}$ single probe module (MRPS) 1 \\
\hline & 784.8 & Retract single probe module (MRPS) 1 \\
\hline \multirow[t]{4}{*}{ MDT_078 } & 39.0 & Probe set @ 3,300.0 m single probe module (MRPS) 1 \\
\hline & 120.6 & Vert pretest $4.9 \mathrm{~cm}^{3} @ 40 \mathrm{~cm}^{3} / \mathrm{m}$ single probe module (MRPS) 1 \\
\hline & 239.7 & Vert pretest $2.9 \mathrm{~cm}^{3} @ 30 \mathrm{~cm}^{3} / \mathrm{m}$ single probe module (MRPS) 1 \\
\hline & 544.5 & Retract single probe module (MRPS) 1 \\
\hline \multirow[t]{21}{*}{ MDT_073 } & 34.5 & Pump in started dual pumpout module (MRPO) \\
\hline & 665.4 & Pumping stopped $8,784.0 \mathrm{~cm}^{3}$ dual pumpout module (MRPO) \\
\hline & 680.4 & Pump in started dual pumpout module (MRP) \\
\hline & 2020.8 & Pumping stopped $21,228.0 \mathrm{~cm}^{3}$ dual pumpout module (MRPO) \\
\hline & 2173.8 & Probe set @ 3,620 m single probe module (MRPS) 1 \\
\hline & 2272.5 & Vert pretest $4.9 \mathrm{~cm}^{3} @ 50 \mathrm{~cm}^{3} / \mathrm{m}$ single probe module (MRPS) 1 \\
\hline & 2371.8 & Pump out started dual pumpout module (MRPO) \\
\hline & 2625.0 & Auto reset single probe module (MRPS) 1 \\
\hline & 2824.2 & Auto reset single probe module (MRPS) 1 \\
\hline & 2874.0 & Pumping stopped $1,464.0 \mathrm{~cm}^{3}$ dual pumpout module (MPRPO) \\
\hline & 2913.6 & Retract single probe module (MRPS) 1 \\
\hline & 3041.1 & Pump in started dual pumpout module (MRPO) \\
\hline & 3111.0 & Pumping stopped $732.0 \mathrm{~cm}^{3}$ dual pumpout module (MRPO) \\
\hline & 3222.6 & Probe set @ 3,620.0 m single probe module (MRPS) 1 \\
\hline & 3319.8 & Auto reset single probe module (MRPS) 1 \\
\hline & 3329.7 & Pump out started dual pumpout module (MRPO) \\
\hline & 3351.3 & Auto reset single probe module (MRPS) 1 \\
\hline & 3419.0 & Auto reset single probe module (MRPS) 1 \\
\hline & 3462.0 & Auto reset single probe module (MRPS) 1 \\
\hline & 3470.4 & Pumping stopped $1,098.0 \mathrm{~cm}^{3}$ dual pumpout module (MRPO) \\
\hline & 3548.1 & Retract single probe module (MRPS) 1 \\
\hline \multirow[t]{16}{*}{ MDT_074 } & 42.3 & Pump in started dual pumpout module (MRPO) \\
\hline & 47.7 & Pumping stopped $0.0 \mathrm{~cm}^{3}$ dual pumpout module (MRPO) \\
\hline & 72.9 & Pump in started dual pumpout module (MRPO) \\
\hline & 1779.0 & Probe set @ 3,613.0 m single probe module (MRPS) 1 \\
\hline & 1730.7 & Pumping stopped $3,012.0 \mathrm{~cm}^{3}$ dual pumpout module (MRPO) \\
\hline & 1950.0 & Auto reset single probe module (MRPS) 1 \\
\hline & 2003.4 & Pump in started dual pumpout module (MRPO) \\
\hline & 2012.1 & Pumping stopped $0.0 \mathrm{~cm}^{3}$ dual pumpout module (MRPO) \\
\hline & 2040.3 & Pump in started dual pumpout module (MRPO) \\
\hline & 2177.4 & Pumping stopped $2,196.0 \mathrm{~cm}^{3}$ dual pumpout module (MRPO) \\
\hline & 2201.7 & Vert pretest $4.9 \mathrm{~cm}^{3} @ 50 \mathrm{~cm}^{3} / \mathrm{m}$ single probe module (MRPS) 1 \\
\hline & 2298.9 & Pump in started dual pumpout module (MRPO) \\
\hline & 2323.8 & Pumping stopped $0.0 \mathrm{~cm}^{3}$ dual pumpout module (MRPO) \\
\hline & 2363.4 & Pump in started dual pumpout module (MRPO) \\
\hline & 2389.5 & Pumping stopped $0.0 \mathrm{~cm}^{3}$ dual pumpout module (MRPO) \\
\hline & 2404.2 & Pump in started dual pumpout module (MRPO) \\
\hline
\end{tabular}


Table T16 (continued).

\begin{tabular}{|c|c|c|}
\hline Test & $\begin{array}{l}\text { Elapsed } \\
\text { time (s) }\end{array}$ & Event \\
\hline & 2466.6 & Pumping stopped $732.0 \mathrm{~cm}^{3}$ dual pumpout module (MRPO) \\
\hline & 2553.6 & Pump in started dual pumpout module (MRPO) \\
\hline & 2578.2 & Pumping stopped $0.0 \mathrm{~cm}^{3}$ dual pumpout module (MRPO) \\
\hline & 2602.8 & Pump in started dual pumpout module (MRPO) \\
\hline & 3187.8 & Pumping stopped $10,980.0 \mathrm{~cm}^{3}$ dual pumpout module (MRPO) \\
\hline & 3380.4 & Vert pretest $4.8 \mathrm{~cm}^{3} @ 50 \mathrm{~cm}^{3} / \mathrm{m}$ single probe module (MRPS) 1 \\
\hline & 3468.9 & Open sample chamber module 12 ( 1 gallon), sample number $=1$ \\
\hline & 3604.5 & Retract single probe module (MRPS) 1 \\
\hline & 3707.0 & Probe set @ 3,613.0 m single probe module (MRPS) 1 \\
\hline & 3768.0 & Vert pretest $5.0 \mathrm{~cm}^{3} @ 50 \mathrm{~cm}^{3} / \mathrm{m}$ single probe module (MRPS) 1 \\
\hline & 3824.4 & Pump up started dual up-down pumpout module (MRPOUD) \\
\hline & 3876.3 & Pump in started dual pumpout module (MRP) \\
\hline & 3962.1 & $\begin{array}{l}\text { Pumping stopped } 2,910.0 \mathrm{~cm}^{3} \text { dual up-down pumpout module } \\
\text { (MRPOUD) }\end{array}$ \\
\hline & 3963.0 & Pumping stopped $732.0 \mathrm{~cm}^{3}$ dual pumpout module (MRPO) \\
\hline & 4231.5 & Auto reset single probe module (MRPS) 1 \\
\hline & 4206.9 & $\begin{array}{l}\text { Pumping stopped } 3,880.0 \mathrm{~cm}^{3} \text { dual up-down pumpout module } \\
\text { (MRPOUD) }\end{array}$ \\
\hline & 4017.6 & Pump up started dual up-down pumpout module (MRPOUD) \\
\hline & 4776.0 & Vert pretest $5.0 \mathrm{~cm}^{3} @ 50 \mathrm{~cm}^{3} / \mathrm{m}$ single probe module (MRPS) 1 \\
\hline & 4867.2 & Retract single probe module (MRPS) 1 \\
\hline & 4953.3 & Seal sample chamber module 12 ( 1 gallon) \\
\hline \multirow[t]{21}{*}{ MDT_080 } & 64.8 & Open sample chamber module 12 ( 1 gallon), sample number $=2$ \\
\hline & 109.2 & Pump up started dual up-down pumpout module (MRPOUD) \\
\hline & 1162.5 & Pumping stopped $2,0370 \mathrm{~cm}^{3}$ dual up-down pumpout module (MRPOUD) \\
\hline & 1169.4 & Seal sample chamber module 12 ( 1 gallon) \\
\hline & 1485.9 & Pumping stopped $5,124.0 \mathrm{~cm}^{3}$ dual pumpout module (MRPO) \\
\hline & 1574.1 & Probe set @ 2,956.0 m single probe module (MRPS) 1 \\
\hline & 1676.4 & Vert pretest $4.7 \mathrm{~cm}^{3} @ 50 \mathrm{~cm}^{3} / \mathrm{m}$ single probe module (MRPS) 1 \\
\hline & 1770.9 & Auto reset single probe module (MRPS) 1 \\
\hline & 1772.1 & Pump in started dual pumpout module (MRPO) \\
\hline & 2068.5 & Pumping stopped $6,222.0 \mathrm{~cm}^{3}$ dual pumpout module (MRPO) \\
\hline & 2420.7 & Pump in started dual pumpout module (MRPO) \\
\hline & 2577.3 & Pumping stopped $29,280 \mathrm{~cm}^{3}$ dual pumpout module (MRPO) \\
\hline & 2894.7 & Pump in started dual pumpout module (MRPO) \\
\hline & 2986.2 & Pumping stopped $1,464.0 \mathrm{~cm}^{3}$ dual pumpout module (MRPO) \\
\hline & 3282.3 & Retract single probe module (MRPS) 1 \\
\hline & 3396.3 & Pump out started dual pumpout module (MRPO) \\
\hline & 3573.6 & Pumping stopped $1,830.0 \mathrm{~cm}^{3}$ dual pumpout module (MRPO) \\
\hline & 3719.1 & Pump in started dual pumpout module (MRPO) \\
\hline & 3730.5 & Pumping stopped $0.0 \mathrm{~cm}^{3}$ dual pumpout module (MRPO) \\
\hline & 3752.1 & Pump in started dual pumpout module (MRPO) \\
\hline & 3992.4 & Pumping stopped $4,758.0 \mathrm{~cm}^{3}$ dual pumpout module (MRPO) \\
\hline
\end{tabular}

Notes: These are the notes recorded during MDT deployments, transcribed from the field copy of the Schlumberger log provided. All depths are in WRF. Deployment notes for MDT_060 are not included in Schlumberger log.

Table T17. Parameters used to derive hydraulic parameters. (See table note.)

\begin{tabular}{lll}
\hline \multicolumn{1}{c}{ Parameter } & Symbol & \multicolumn{1}{c}{ Value } \\
\hline Well compliance $\left(\mathrm{m}^{3} / \mathrm{Pa}\right)$ & $\mathrm{C}$ & $4.0 \times 10^{-11}$ \\
Fluid viscosity $(\mathrm{cp})$ & $\mu$ & 0.72 \\
Wellbore radius & $r_{\mathrm{w}}$ & $12-1 / 4$ inch $/ 2=156 \mathrm{~mm}$ \\
Length of open section $(\mathrm{m})$ & $L$ & 1
\end{tabular}

Note: Parameters used to estimate storage and permeability from the dual packer drawdown test. 
Table T18. Instantaneous shut in pressures for MDT_080 hydraulic fracture. (See table notes.)

\begin{tabular}{lcc}
\hline Cycle & $\begin{array}{c}\text { ISIP time } \\
(\mathrm{s})\end{array}$ & $\begin{array}{c}\text { ISIP pressure } \\
(\mathrm{MPa})\end{array}$ \\
\hline 1 & 2075 & 34.82 \\
2 & 2584 & 35.05 \\
3 & 2994 & 35.13 \\
4 & 3997 & 35.17 \\
\hline
\end{tabular}

Notes: These values were chosen by plotting pressure versus linear time and determining the first break in slope after the cessation (shut in) of pumping. See "Dual packer hydraulic fracture test" for discussion. ISIP = instantaneous shut in pressure.

Table T19. Event summary for leak-off tests. (See table notes.)

\begin{tabular}{ll}
\hline Time (h) & \\
\hline 2325 & Flush line, replace seawater by mud, pressure test line. \\
0148 & End of test of kill line at 1000 psi. The test is $\sim 0.4$ bbl. Bleed off at $0155 \mathrm{~h}$. Data being recorded. \\
0158 & Reset cumulative volume and zero of pumping rate. \\
0200 & Pressure test of the line. Pressure set at 1300 psi and kept $5 \mathrm{~min}$. Stop and bleed off. \\
0215 & Pump tank at Level $2(20 \mathrm{~cm}$ below brim of the tank). \\
0201 & Reset the cumulative volume and zero of pumping rate. \\
0220 & Start LOT 1. Initial pressure $=44$ psi (attributed to hydrostatic load: pipe manifold is above pump). Flow rate $=0.25$ bbl/min. LOP $=\sim 105$ psi. \\
0230 & Shut in (after sudden drop of pressure?). \\
0245 & Bleed-off after only 15 min because pressure is stable. \\
0204 & Pump tank level at 1.5. \\
0306 & Flow-back in the BOP. Mud seen in moonpool. Perhaps due to BOP leak at seafloor. $2 \mathrm{nd}$ leak-off test is planned. \\
0309 & Pressure test of line. Pressure stays at 272 psi. \\
0322 & Start LOT 2. Initial pressure $=42$ psi. Rate 0.25 bbl/min. Leak pressure $=100$ psi. \\
0337 & Shut in. \\
0352 & Bleed off. 3.5 bbl did not return.
\end{tabular}

Notes: Summary compiled by scientists on location and from daily drilling report. LOT $=$ leak-off test, LOP $=$ leak-off pressure. $B O P=$ blowout preventer.

Table T20. Estimated azimuth of seismometers in walkaway VSP experiment, Hole C0009A. (See table notes.)

\begin{tabular}{|c|c|c|c|c|c|}
\hline \multirow[b]{2}{*}{$\begin{array}{l}\text { Depth } \\
\text { DRF (m) }\end{array}$} & \multicolumn{2}{|c|}{$x$} & \multicolumn{2}{|c|}{$y$} & \multirow[b]{2}{*}{$\begin{array}{l}\text { Difference in estimated } \\
\text { azimuth }(x-y)\left({ }^{\circ}\right)\end{array}$} \\
\hline & $\begin{array}{l}\text { First motion } \\
\text { amplitude }\end{array}$ & $\begin{array}{l}\text { Estimated } \\
\text { azimuth }\left({ }^{\circ}\right)\end{array}$ & $\begin{array}{l}\text { First motion } \\
\text { amplitude }\end{array}$ & $\begin{array}{l}\text { Estimated } \\
\text { azimuth }\left({ }^{\circ}\right)\end{array}$ & \\
\hline 2989 & 0.041 & 75.0 & 0.04 & 341.7 & 93.3 \\
\hline 3004 & 0.036 & 96.4 & 0.038 & 5.0 & 91.4 \\
\hline 3019 & 0.037 & 139.9 & 0.032 & 49.2 & 90.7 \\
\hline 3034 & 0.035 & 184.1 & 0.032 & 89.0 & 95.1 \\
\hline 3050 & 0.032 & 216.6 & 0.035 & 135.5 & 81.1 \\
\hline 3065 & 0.031 & 291.2 & 0.03 & 195.9 & 95.3 \\
\hline 3080 & 0.034 & 324.1 & 0.031 & 230.0 & 94.1 \\
\hline 3095 & 0.039 & 343.2 & 0.033 & 253.2 & 90.0 \\
\hline 3111 & 0.029 & 26.3 & 0.031 & 308.6 & 77.6 \\
\hline 3126 & 0.008 & 56.2 & 0.012 & 333.1 & 83.1 \\
\hline 3141 & 0.031 & 125.9 & 0.031 & 23.9 & 102.0 \\
\hline 3156 & 0.027 & 185.2 & 0.022 & 95.1 & 90.1 \\
\hline 3172 & 0.024 & 204.2 & 0.02 & 125.5 & 78.7 \\
\hline 3187 & 0.023 & 168.2 & 0.023 & 85.8 & 82.4 \\
\hline 3202 & 0.028 & 149.7 & 0.022 & 57.0 & 92.6 \\
\hline 3217 & 0.031 & 151.6 & 0.026 & 76.9 & 74.8 \\
\hline
\end{tabular}

Notes: Azimuth estimated using amplitude of first motion of shots in circle shooting. Differences of estimated azimuth between $x$-and $y$-components are indicated on the right. 
Table T21. Summary of zero-offset VSP deployments performed, Site C0009 (See table notes.) (Continued on next page.)

\begin{tabular}{|c|c|c|c|c|c|c|c|}
\hline \multirow[b]{2}{*}{$\begin{array}{l}\text { Measured } \\
\text { depth }(m)\end{array}$} & \multirow{2}{*}{\multicolumn{2}{|c|}{ True vertical depth $(\mathrm{m})$}} & \multicolumn{2}{|c|}{ Transit time (s) } & \multirow[b]{2}{*}{$\begin{array}{c}\text { Interval } \\
\text { distance }(\mathrm{m})\end{array}$} & \multirow[b]{2}{*}{$\begin{array}{l}\text { Interval time } \\
(s)\end{array}$} & \multirow[b]{2}{*}{$\begin{array}{c}\text { Interval } \\
\text { velocity }(\mathrm{m} / \mathrm{s})\end{array}$} \\
\hline & & & $\begin{array}{l}\text { Observed } \\
\text { (hyd-geo) }\end{array}$ & $\begin{array}{c}\text { Vertical } \\
\text { (MSL-geo) }\end{array}$ & & & \\
\hline 2090.22 & 2061.92 & 9.22 & 1.3587 & 1.3653 & 15.2400 & 0.0098 & 1555 \\
\hline 2105.46 & 2077.16 & 24.46 & 1.3685 & 1.3751 & 15.3135 & 0.0090 & 1704 \\
\hline 2120.78 & 2092.48 & 39.78 & 1.3775 & 1.3841 & 15.1665 & 0.0091 & 1676 \\
\hline 2135.94 & 2107.64 & 54.94 & 1.3865 & 1.3932 & 15.2400 & 0.0094 & 1616 \\
\hline 2151.18 & 2122.88 & 70.18 & 1.3959 & 1.4026 & 15.2400 & 0.0092 & 1657 \\
\hline 2166.42 & 2138.12 & 85.42 & 1.4051 & 1.4118 & 15.2400 & 0.0103 & 1483 \\
\hline 2181.66 & 2153.36 & 100.66 & 1.4154 & 1.4221 & 15.2400 & 0.0099 & 1536 \\
\hline 2196.90 & 2168.60 & 115.90 & 1.4253 & 1.4320 & 15.2400 & 0.0096 & 1593 \\
\hline 2212.14 & 2183.84 & 131.14 & 1.4349 & 1.4416 & 15.3137 & 0.0096 & 1601 \\
\hline 2227.46 & 2199.16 & 146.46 & 1.4445 & 1.4511 & 15.3286 & 0.0097 & 1574 \\
\hline 2242.79 & 2214.49 & 161.79 & 1.4542 & 1.4609 & 15.2400 & 0.0099 & 1546 \\
\hline 2258.03 & 2229.73 & 177.03 & 1.4641 & 1.4707 & 15.2402 & 0.0096 & 1587 \\
\hline 2273.27 & 2244.97 & 192.27 & 1.4737 & 1.4804 & 15.1511 & 0.0094 & 1610 \\
\hline 2288.42 & 2260.12 & 207.42 & 1.4831 & 1.4898 & 15.2400 & 0.0095 & 1610 \\
\hline 2303.66 & 2275.36 & 222.66 & 1.4925 & 1.4992 & 15.3289 & 0.0090 & 1712 \\
\hline 2318.99 & 2290.69 & 237.99 & 1.5015 & 1.5082 & 15.1511 & 0.0092 & 1645 \\
\hline 2334.14 & 2305.84 & 253.14 & 1.5107 & 1.5174 & 15.3289 & 0.0092 & 1664 \\
\hline 2349.47 & 2321.17 & 268.47 & 1.5199 & 1.5266 & 15.1155 & 0.0083 & 1827 \\
\hline 2364.58 & 2336.28 & 283.58 & 1.5282 & 1.5349 & 15.2400 & 0.0092 & 1657 \\
\hline 2379.82 & 2351.52 & 298.82 & 1.5374 & 1.5441 & 15.3645 & 0.0085 & 1799 \\
\hline 2395.19 & 2366.89 & 314.19 & 1.5459 & 1.5526 & 15.1157 & 0.0082 & 1836 \\
\hline 2410.30 & 2382.00 & 329.30 & 1.5542 & 1.5609 & 15.2400 & 0.0091 & 1666 \\
\hline 2425.54 & 2397.24 & 344.54 & 1.5633 & 1.5700 & 15.3643 & 0.0087 & 1768 \\
\hline 2440.91 & 2412.61 & 359.91 & 1.5720 & 1.5787 & 15.1157 & 0.0082 & 1836 \\
\hline 2456.02 & 2427.72 & 375.02 & 1.5802 & 1.5870 & 15.2400 & 0.0087 & 1754 \\
\hline 2471.26 & 2442.96 & 390.26 & 1.5889 & 1.5957 & 15.4915 & 0.0087 & 1783 \\
\hline 2486.75 & 2458.45 & 405.75 & 1.5976 & 1.6043 & 15.2400 & 0.0087 & 1754 \\
\hline 2501.99 & 2473.69 & 420.99 & 1.6063 & 1.6130 & 14.9885 & 0.0087 & 1725 \\
\hline 2516.98 & 2488.68 & 435.98 & 1.6150 & 1.6217 & 15.2400 & 0.0087 & 1754 \\
\hline 2532.22 & 2503.92 & 451.22 & 1.6237 & 1.6304 & 15.2400 & 0.0080 & 1903 \\
\hline 2547.46 & 2519.16 & 466.46 & 1.6317 & 1.6384 & 15.2400 & 0.0080 & 1906 \\
\hline 2562.70 & 2534.40 & 481.70 & 1.6397 & 1.6464 & 15.2400 & 0.0078 & 1951 \\
\hline 2577.94 & 2549.64 & 496.94 & 1.6475 & 1.6542 & 15.2400 & 0.0077 & 1970 \\
\hline 2593.18 & 2564.88 & 512.18 & 1.6552 & 1.6620 & 15.1838 & 0.0078 & 1953 \\
\hline 2608.37 & 2580.07 & 527.37 & 1.6630 & 1.6698 & 15.2400 & 0.0082 & 1851 \\
\hline 2623.61 & 2595.31 & 542.61 & 1.6712 & 1.6780 & 15.5476 & 0.0082 & 1889 \\
\hline 2639.15 & 2610.85 & 558.15 & 1.6795 & 1.6862 & 15.2400 & 0.0078 & 1960 \\
\hline 2654.39 & 2626.09 & 573.39 & 1.6872 & 1.6940 & 15.2400 & 0.0087 & 1754 \\
\hline 2669.63 & 2641.33 & 588.63 & 1.6959 & 1.7027 & 15.2402 & 0.0082 & 1852 \\
\hline 2684.87 & 2656.57 & 603.87 & 1.7042 & 1.7109 & 15.2400 & 0.0078 & 1960 \\
\hline 2700.11 & 2671.81 & 619.11 & 1.7119 & 1.7187 & 15.2400 & 0.0082 & 1851 \\
\hline 2715.35 & 2687.05 & 634.35 & 1.7202 & 1.7270 & 14.9092 & 0.0078 & 1918 \\
\hline 2730.26 & 2701.96 & 649.26 & 1.7279 & 1.7347 & 15.2400 & 0.0078 & 1960 \\
\hline 2745.50 & 2717.20 & 664.50 & 1.7357 & 1.7425 & 15.2402 & 0.0073 & 2083 \\
\hline 2760.74 & 2732.44 & 679.74 & 1.7430 & 1.7498 & 15.2400 & 0.0075 & 2037 \\
\hline 2775.98 & 2747.68 & 694.98 & 1.7505 & 1.7573 & 15.2400 & 0.0073 & 2081 \\
\hline 2791.22 & 2762.92 & 710.22 & 1.7578 & 1.7646 & 15.2402 & 0.0071 & 2156 \\
\hline 2806.46 & 2778.16 & 725.46 & 1.7649 & 1.7717 & 15.2400 & 0.0073 & 2081 \\
\hline 2821.70 & 2793.40 & 740.70 & 1.7722 & 1.7790 & 15.2400 & 0.0071 & 2156 \\
\hline 2836.94 & 2808.64 & 755.94 & 1.7793 & 1.7861 & 15.4150 & 0.0076 & 2035 \\
\hline 2852.36 & 2824.06 & 771.36 & 1.7869 & 1.7937 & 15.2400 & 0.0071 & 2161 \\
\hline 2867.60 & 2839.30 & 786.60 & 1.7939 & 1.8007 & 15.2402 & 0.0075 & 2035 \\
\hline 2882.84 & 2854.54 & 801.84 & 1.8014 & 1.8082 & 15.0647 & 0.0072 & 2089 \\
\hline 2897.90 & 2869.60 & 816.90 & 1.8086 & 1.8154 & 15.2400 & 0.0069 & 2198 \\
\hline 2913.14 & 2884.84 & 832.14 & 1.8156 & 1.8224 & 15.2400 & 0.0072 & 2113 \\
\hline 2928.38 & 2900.08 & 847.38 & 1.8228 & 1.8296 & 15.2400 & 0.0072 & 2113 \\
\hline 2943.62 & 2915.32 & 862.62 & 1.8300 & 1.8368 & 15.2400 & 0.0067 & 2290 \\
\hline 2958.86 & 2930.56 & 877.86 & 1.8366 & 1.8435 & 15.3953 & 0.0072 & 2145 \\
\hline 2974.26 & 2945.96 & 893.26 & 1.8438 & 1.8506 & 14.9783 & 0.0071 & 2115 \\
\hline 2989.24 & 2960.94 & 908.24 & 1.8509 & 1.8577 & 15.5017 & 0.0071 & 2189 \\
\hline 3004.74 & 2976.44 & 923.74 & 1.8580 & 1.8648 & 15.2402 & 0.0069 & 2194 \\
\hline 3019.98 & 2991.68 & 938.98 & 1.8649 & 1.8718 & 14.9780 & 0.0064 & 2329 \\
\hline 3034.96 & 3006.66 & 953.96 & 1.8714 & 1.8782 & 15.5020 & 0.0067 & 2318 \\
\hline 3050.46 & 3022.16 & 969.46 & 1.8780 & 1.8849 & 15.2395 & 0.0071 & 2162 \\
\hline 3065.70 & 3037.40 & 984.70 & 1.8851 & 1.8919 & 14.9785 & 0.0071 & 2119 \\
\hline 3080.68 & 3052.38 & 999.68 & 1.8922 & 1.8990 & 15.2400 & 0.0071 & 2132 \\
\hline
\end{tabular}


Table T21 (continued).

\begin{tabular}{|c|c|c|c|c|c|c|c|}
\hline \multirow{3}{*}{$\begin{array}{l}\text { Measured } \\
\text { depth }(m)\end{array}$} & & & \multicolumn{2}{|c|}{ Transit time (s) } & \multirow{3}{*}{$\begin{array}{c}\text { Interval } \\
\text { distance }(\mathrm{m})\end{array}$} & \multirow{3}{*}{$\begin{array}{l}\text { Interval time } \\
(\mathrm{s})\end{array}$} & \multirow{3}{*}{$\begin{array}{c}\text { Interval } \\
\text { velocity }(\mathrm{m} / \mathrm{s})\end{array}$} \\
\hline & True vert & lepth (m) & \multirow{2}{*}{$\begin{array}{l}\text { Observed } \\
\text { (hyd-geo) }\end{array}$} & \multirow{2}{*}{$\begin{array}{c}\text { Vertical } \\
\text { (MSL-geo) }\end{array}$} & & & \\
\hline & MSL & WMSF & & & & & \\
\hline 3095.92 & 3067.62 & 1014.92 & 1.8993 & 1.9062 & 15.2400 & 0.0075 & 2045 \\
\hline 3111.16 & 3082.86 & 1030.16 & 1.9068 & 1.9136 & 15.5017 & 0.0076 & 2035 \\
\hline 3126.66 & 3098.36 & 1045.66 & 1.9144 & 1.9212 & 14.9783 & 0.0077 & 1938 \\
\hline 3141.64 & 3113.34 & 1060.64 & 1.9221 & 1.9290 & 15.2400 & 0.0077 & 1977 \\
\hline 3156.88 & 3128.58 & 1075.88 & 1.9298 & 1.9367 & 15.2400 & 0.0078 & 1952 \\
\hline 3172.12 & 3143.82 & 1091.12 & 1.9376 & 1.9445 & 15.2400 & 0.0078 & 1965 \\
\hline 3187.36 & 3159.06 & 1106.36 & 1.9454 & 1.9522 & 15.2400 & 0.0072 & 2111 \\
\hline 3202.60 & 3174.30 & 1121.60 & 1.9526 & 1.9595 & 15.2400 & 0.0072 & 2111 \\
\hline 3217.84 & 3189.54 & 1136.84 & 1.9598 & 1.9667 & & & \\
\hline
\end{tabular}

Notes: Data extracted from check shot table provided by Schlumberger/CDEX on 6 August 2009.

Table T22. Two-way traveltime of seismic surfaces. (See table note.)

\begin{tabular}{lcccc}
\hline $\begin{array}{c}\text { Seismic } \\
\text { surface/ } \\
\text { unconformity }\end{array}$ & $\begin{array}{c}\text { Depth } \\
\text { SSF }(\mathrm{m})^{*}\end{array}$ & $\begin{array}{c}\text { Two-way } \\
\text { traveltime } \\
(\mathrm{ms})\end{array}$ & $\begin{array}{c}\text { Velocity } \\
\text { corrected } \\
\text { depth SSF } \\
(\mathrm{m})\end{array}$ & $\begin{array}{c}\text { Depth } \\
\text { SSF }(\mathrm{m})\end{array}$ \\
\hline & C0009- & & & C0002- \\
S1 & 607 & 3420 & 556 & 20 \\
S-A & 820 & & & 85 \\
S-B & 860 & & & 105 \\
S2 & 815 & 3615 & 748 & 885 \\
UC1 & 1281 & 4040 & 1187 & - \\
UC2 & 1370 & 4125 & 1271 & 925 \\
\hline
\end{tabular}

Note: ${ }^{*}=$ derived from depth-converted seismic data provided prior to Expedition 319. $~-=$ not applicable. 